\title{
Daniel Schümann
}

\section{Die Suche \\ nach dem "neuen" Menschen in der deutschen und russischen Literatur der Jahrhundertwende}

\author{
Frank Wedekinds Mine-Haha \\ und Michail Petrovič Arcybaševs Sanin
}

Verlag Otto Sagner München · Berlin · Washington D.C.

Digitalisiert im Rahmen der Kooperation mit dem DFG-Projekt „Digi20“

der Bayerischen Staatsbibliothek, München. OCR-Bearbeitung und Erstellung des eBooks durch den Verlag Otto Sagner:

http://verlag.kubon-sagner.de

() bei Verlag Otto Sagner. Eine Verwertung oder Weitergabe der Texte und Abbildungen, insbesondere durch Vervielfältigung, ist ohne vorherige schriftliche Genehmigung des Verlages unzulässig. 


\title{
Daniel Schümann
}

\author{
Die Suche nach dem 'neuen Menschen' \\ in der deutschen und russischen Literatur \\ der Jahrhundertwende
}

\author{
Frank Wedekinds Mine-Haha \\ und Michail Petrovič Arcybaševs Sanin
}

Mit einer Zusammenfassung in russischer Sprache/

С аннотацией на русском языке 
PVA

2001.

3646 


\section{Vorwort}

Wie andere vergleichbare Projekte hätte auch die vorliegende Studie, eine überarbeitete Version meiner im August 1999 an der Universität Bamberg eingereichten Magisterarbeit, kaum ohne die freundliche Unterstützung durch eine Reihe von Personen und Institutionen realisiert werden können. Zunächst möchte ich mich bei den beiden Gutachtern, Herm Prof. Dr. Peter Thiergen von slavistischer sowie Herm Prof. Dr. Wulf Segebrecht von germanistischer Seite, für die kompetente Betreuung und Beratung während der Entstehung meiner Arbeit bedanken. Was die Kapitel über Mine-Haha anbelangt, so brachten weiterhin meine Besuche bei der Editions- und Forschungsstelle Frank Wedekind in Darmstadt sowie im Archiv der Münchner Stadtbibliothek Monacensia zahlreiche neue Erkenntnisse. Mein besonderer Dank gilt in diesem Zusammenhang Herm Prof. Dr. Hartmut Vinçon und Frau Dr. Elke Austermühl aus Darmstadt sowie Frau Ursula Hummel aus München. Herr Dr. Sebastian Köppl von der Universitătsbibliothek Bamberg half mir freundlicherweise rasch und unbürokratisch bei der Beschaffung benötigter Forschungsliteratur. Der Studienstiftung des deutschen Volkes habe ich fur ein großzügiges Stipendium zu danken und ebenso auch meinen Eltern für ihre finanzielle Unterstützung. Bedanken möchte ich mich selbstverständlich auch bei den Korrekturlesern des Manuskripts - Silke Fromm und Ingo Michalak, meinen Geschwistern Nicola und Michael sowie meiner Lebensgefahrtin Susanne, mit der ich inzwischen verheiratet bin. Herr Dr. Aschot Isaakjan sowie Herr Semen Kaganovskyy haben sich dankenswerterweise bereit erklärt, die russische Zusammenfassung nochmals durchzusehen. Ich freue mich, daß mir Herr Prof. Dr. Peter Thiergen vom Lehrstuhl für Slavische Philologie in Bamberg die Möglichkeit gibt, die vorliegende Arbeit in der von ihm herausgegebenen Reihe Vorträge und Abhandlungen zur Slavistik zu veröffentlichen.

Bamberg, im März 2001

Daniel Schümann 



\section{INHALTSVERZEICHNIS}

Vorwort

1. EINFÜHRUNG INS THEMA ...................................................11

2. DER ‘NEUE MENSCH’ ALS SKANDALON ....................................19

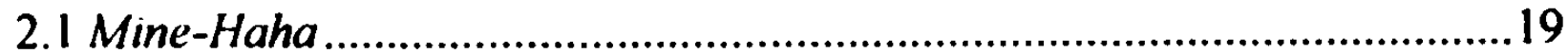

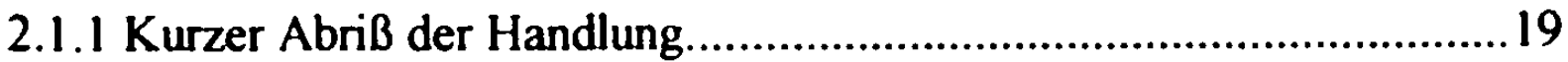

2.1.2 Zur Entstehungs- und Publikationsgeschichte................................20

2.1.3 Rezeptionsgeschichte und Forschungslage ...................................24

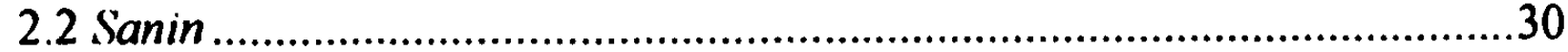

2.2.1 Kurzer Abriß der Handlung.......................................................30

2.2.2 Zur Entstehungs- und Publikationsgeschichte................................31

2.2.3 Rezeptionsgeschichte und Forschungslage ......................................34

3. DER 'NEUE MENSCH' ALS GEGENENTWURF ZUM MENSCHEN DER GEGENWART …...................................................................

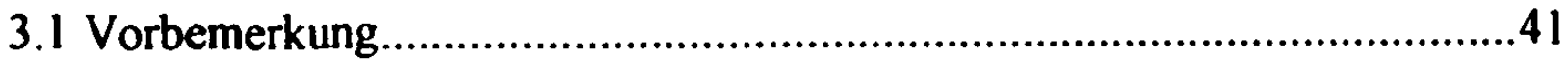

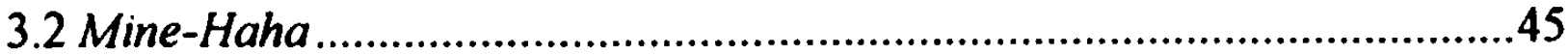

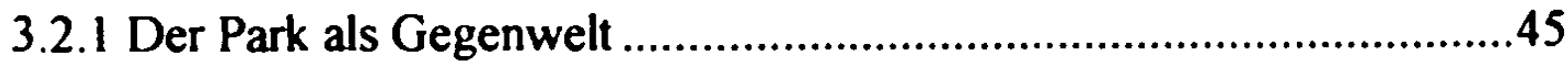

3.2.2 Die Ästhetik der inszenierten Natur - zum Enigma des Titels ............47

3.2.3 Zwischen Gesellschaftskritik und Bürgerlichkeit.............................50

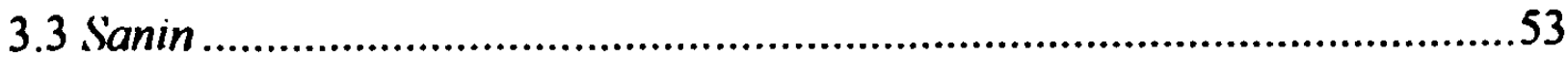

3.3.1 Natur anstelle von Zivilisation .................................................53

3.3.2 Abrechnung mit den alten Eliten ...............................................59

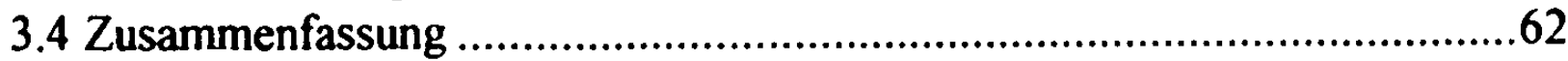

4. DER ‘NEUE MENSCH’ ZWISCHEN KÖRPER UND GEIST................65

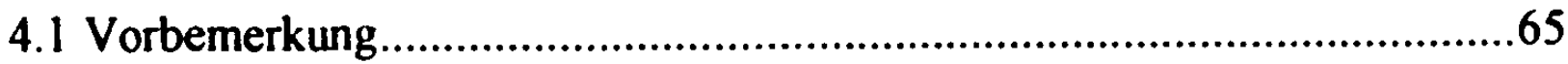

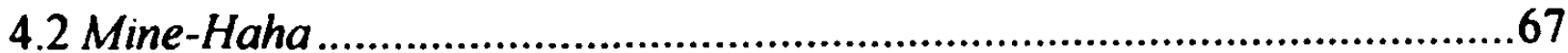

4.2.1 Primat des Körpers gegenüber dem Geist....................................67

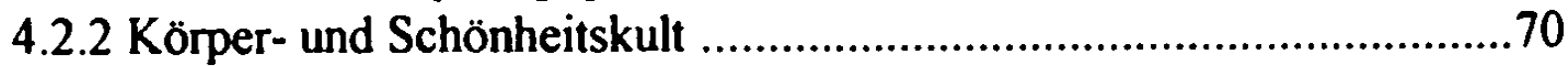

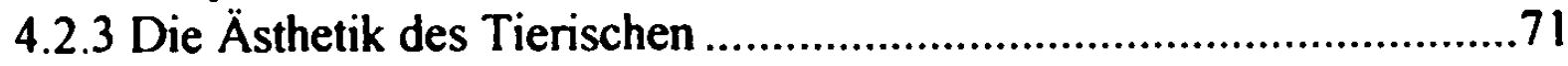

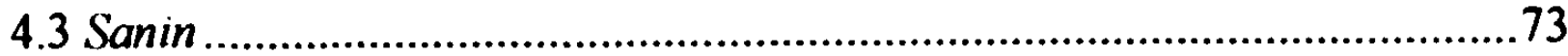

4.3.1 Verkultung des schönen Körpers ..............................................73

4.3.2 Jurij Svarožič - Sterilităt des Geistes...........................................75

4.3.3 Sanin - gesunder Geist im schönen Körper......................................77

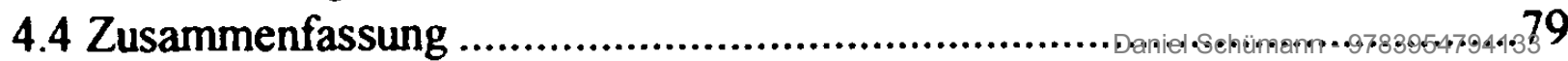


5. DIE GENESE DES ‘NEUEN MENSCHEN’ ........................................81

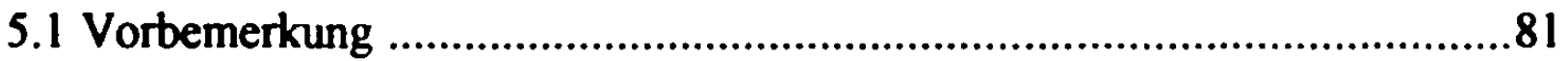

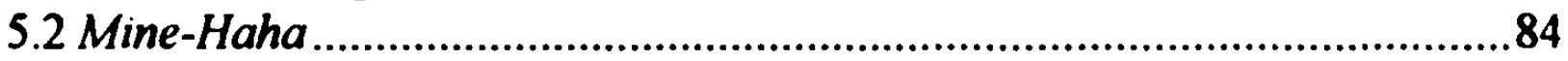

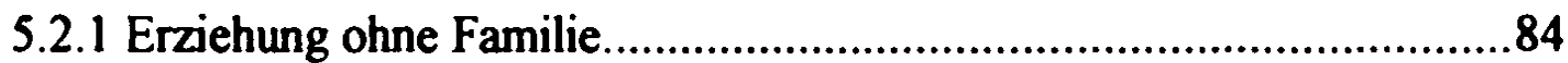

5.2.2 Unwissenheit als Erziehungsgrundsatz ........................................86

5.2.3 Entwicklung als gelenkter Reifeprozeß ......................................88

5.2.4 Bezwingung der Natur als Ziel der menschlichen Entwicklung..........91

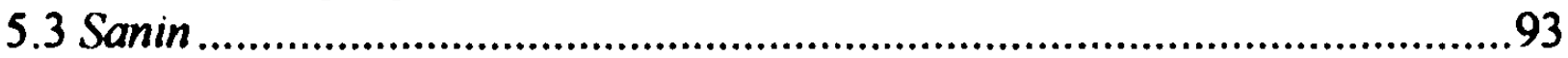

5.3.1 Sanins Entwicklung ............................................................93

5.3.2 Aufgeklärte Natürlichkeit als Ziel der menschlichen Entwicklung .....97

5.3.3 Sanin - ein Roman ohne Entwicklung ......................................... 100

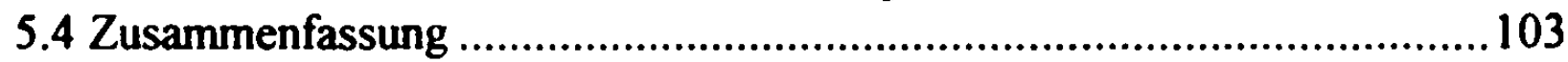

6. DER ‘NEUE MENSCH’ UND DIE GESELLSCHAFT ........................ 105

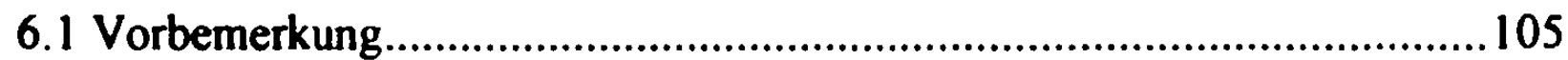

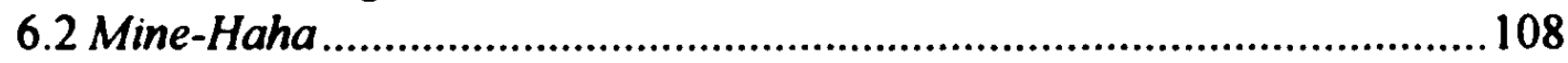

6.2.1 Der 'neue Mensch' als kollektives Massenwesen .......................... 108

6.2.2 Unvollständige Gesellschaft................................................110

6.2.3 Hierarchisch gegliederte Gesellschaft......................................111

6.2.4 Glück durch Unterordnung................................................112

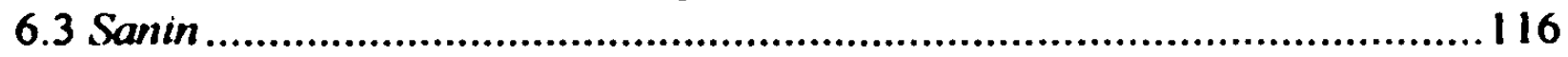

6.3.1 Der 'neue Mensch' als Einzelwesen ..........................................116

6.3.2 Triebe als Grundlage des menschlichen Zusammenlebens ...............118

6.3.3 Kein Lebensrecht für Schwache ................................................. 120

6.3.4 Glück durch Überordnung...................................................... 125

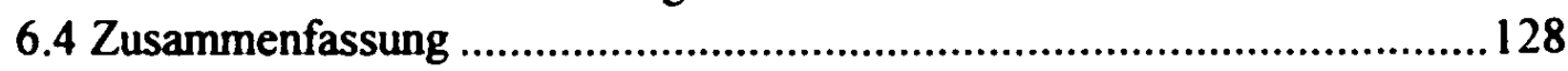

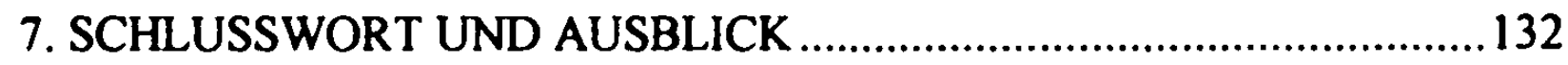

АННОТАЦИЯ (Zusammenfassung in russischer Sprache)...................... 136

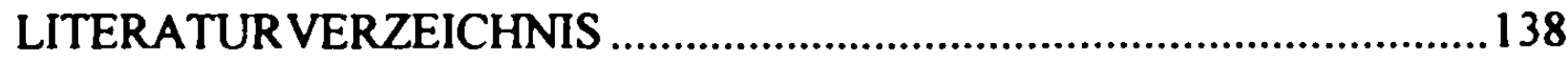

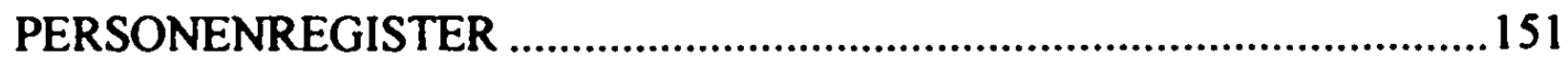




\section{EINFÜHRUNG INS THEMA}

Der Vergleich zweier oder mehrerer Gegenstände ist seit jeher ein wichtiges Mittel des Erkenntnisgewinns in allen Bereichen des menschlichen Lebens, denn er bietet die Möglichkeit, Gemeinsamkeiten, Unterschiede sowie Relationen zwischen den verglichenen Entitäten zu ermitteln. Darüber hinaus regt er dazu an, in einem weiteren Schritt Gedanken über die Gründe von Übereinstimmungen, Abweichungen und Beziehungen zwischen den einzelnen comparata anzustellen. Bereits seit geraumer Zeit wird deshalb auch innerhalb der Literaturwissenschaft die Auffassung vertreten, daß man durch die Gegenüberstellung zweier oder mehrerer literarischer Werke zu einem besseren Verständnis der Einzeltexte gelangen könne. Als besonders reizvoll hat sich dabei auch der Vergleich von Werken unterschiedlicher Literaturen erwiesen, da dieser die Möglichkeit bietet, bei den untersuchten Texten „differenzanalytisch spezifisch ästhetische Individualitäten und deren jeweiligen historischen Bedingungszusammenhang herauszuarbeiten. "I

Zwei Dinge zu vergleichen ist bekanntermaßen nur dann sinnvoll, wenn sie weder gleich noch völlig verschieden sind. Vielmehr bezieht der Vergleich seinen heuristischen Wert aus dem Spannungsverhältnis zwischen Ähnlichkeit und Verschiedenheit der zueinander in Beziehung gesetzten Gegenstănde. ${ }^{2}$ Aus deren gemeinsamen Eigenschaften ergibt sich die Grundlage des Vergleichs, das tertium comparationis, während vor allem die Vergegenwärtigung der Unterschiede für den Betrachter einen Zugewinn an Erkenntnis bringen kann. Für die folgende literaturwissenschaftliche Gegenüberstellung ist also eine gute Grundlage gegeben, denn die hier verglichenen Werke - das Prosafragment MineHaha von Frank Wedekind (1864-1918) sowie der Roman Sanin von Michail Petrovið Arcybasev (1878-1927) - gehören nicht nur zwei unterschiedlichen Literaturen an, sondern sie sind auch in bezug auf technische und inhaltliche Aspekte ăußerst verschieden.

Das tertium comparationis des in dieser Arbeit durchgefühten Vergleichs bilden die Vorstellungen vom 'neuen Menschen' an der Wende zum zwanzigsten Jahrhundert. Diese Formulienung enthält zwei Begriffe, hinsichtlich derer Klärungsbedarf besteht. Zunächst: Was genau verbirgt sich hinter dem Ausdruck Wende zum zwanzigsten Jahrhundert bzw. dem oft synonym dazu gebrauchten Kompositum Jahrhundertwende? Die Entstehung und Publikation der beiden hier

' G. R. Kaiser, Einführung in die vergleichende Literaturwissenschaft. Forschungsstand Kritik - Aufgaben (1980), 137.

${ }^{2} \mathrm{Vgl}$. hierzu G. Schenk in H. J. Sandkühler, Europäische Enzyklopadie zu Philosophie und Wissenschafien (1990), 699 
untersuchten literarischen Werke umfaßt, wie im folgenden Kapitel noch näher ausgefuhrt werden soll, in etwa die Zeitspanne zwischen 1889 und 1907. Damit liegen Mine-Haha und Sanin durchaus im zeitlichen Rahmen des kulturhistorisch und geistesgeschichtlich verstandenen Jahrhundertwende-Begriffs, unter dem in einschlăgigen Untersuchungen üblicherweise der Zeitraum von etwa 1890 bis 1914 zusammengefaßt wird. ${ }^{3}$

Ungleich komplizierter als die Definition des (gleichwohl nach vorne wie nach hinten eine gewisse Dehnbarkeit aufweisenden) Terminus Jahrhundertwende ist jedoch die Beantwortung der Frage, was ein 'neuer Mensch' sei. Das Schlagwort vom 'neuen Menschen' im Gegensatz zum 'alten Menschen' hat eine lange Tradition in der abendländischen Geistesgeschichte, und sein Auftreten ist besonders in Zeiten der Krise zu beobachten. Bei einer Untersuchung der Begriffsgeschichte lăßt sich als Konstante erkennen, daß man im 'neuen Menschen' zu allen Zeiten mehr sah als nur einen 'anderen', einen ungewőhnlichen Menschen. Vielmehr ist für die Vorstellung von einem 'neuen Menschen', wie M. Amdt und U. Dirse richtig feststellten, „das Bewußtsein einer definitiven, erlősten gegenüber einer bloß vorläufigen Wirklichkeit ${ }^{\star 4}$ ausschlaggebend.

Ausgehend von einigen Aussagen im Neuen Testament ${ }^{5}$ verstand man den 'neuen Menschen' lange Zeit unter christlichem Vorzeichen als den durch seinen Glauben an Gott erlösten Menschen. Mit der Aufklärung trat jedoch eine allmăhliche Săkularisierung dieser Vorstellung ein. So ist der 'neue Mensch' beispielsweise für Immanuel Kant (1724-1804) „ein moralisch guter Mensch“6 Dieser Prozeß gipfelte schlieBlich in der Philosophie Friedrich Nietzsches (18441900), der, ausgehend von seiner bekannten These vom Tod Gottes, den 'Übermenschen' als Vision eines 'neuen Menschen' verkündigte. Nietzsches

\footnotetext{
${ }^{3} \mathrm{Vgl}$. beispielsweise R. Hamann/ J. Hermand, Stilkunst um 1900 (2. Aufl. 1975), 7ff. Viktor Żmegax zufolge wird mit den Jahren zwischen 1890 und 1910 ,ungefähr der Spielraum des Begriffes Jahrhunderrwencte abgesteckt"; V. Zmegač, Deutsche Literatur der Jahrhundertwende (1981), X.

'M. Arndt sowie U. Dirse in: J. Ritter/ K. Gründer (Hrsg.), Historisches Wörterbuch der Philosophie. Vollig neubearbeitete Ausgabe des Worterbuches der philosophischen Begriffe von Rucblf Eisler, Bd. 5 (1980), 1112. Hier findet sich auch ein Überblick über die Geschichte des Begriffs neuer Mensch.

${ }^{5}$ Hier ist vor allem auf die Briefe des Paulus zu verweisen, und zwar neben Kolosser 3, 9ff in erster Linie auf folgende Stelle: Emeuert euch aber in eurem Geist und Sinne und zieht den neuen Menschen an, der nach dem Bild Gottes geschaffen ist in wahrer Gerechtigkeit und Heiligkeit" (Epheser 4, 22). Zu nennen ist in diesem Zusammenhang auch 2. Korinther 5,17, wo es heißt: "Ist jemand in Christus, so ist er eine neue Schöpfung; das Alte ist vergangen, siehe, ein Neues ist geworden".

${ }^{6}$ Ritter/ Gründer, Bd. 5 (1980), 1114.
} 
Vorstellungen werden gerade in bezug auf Arcybaševs Roman im weiteren Verlauf dieser Untersuchung noch von Bedeutung sein.

Unter dem Einfluß der Nietzscheschen Vorstellung vom 'Übermenschen' spielte der Topos des 'neuen Menschen' in der deutschen Literatur vor allem während der Zeit des Expressionismus eine wichtige Rolle. Die Suche nach einem 'neuen Menschen' war hier Ausdruck der tiefempfundenen Sehnsucht nach grundlegender Emeuerung. Dabei nahm dieses Streben in vielen literarischen Werken des Expressionismus quasi-religiöse Züge an, und nicht umsonst ist der Begriff Erlösung eine häufig gebrauchte expressionistische Vokabel. ${ }^{7}$

Bereits bevor Nietzsche im Zarathustra sein Konzept des 'Übermenschen' darlegte, fand der Topos des 'neuen Menschen' in den 1860er Jahren Eingang in die russische Literatur und Geistesgeschichte. $\mathrm{Zu}$ erwähnen ist in diesem Zusammenhang vor allem der 1862 erschienene Roman (Otcy $i$ deti [deutscher Titel: Väter und Söhne] von Ivan Sergeevic Turgenev (1818-1883), in dem der Gegensatz von 'altem' und 'neuem Menschen' als Generationenkonflikt dargestellt wird. $\mathrm{Zu}$ diesem Text wurde Arcybaševs Sanin gelegentlich in Beziehung gesetzt. ${ }^{8}$

Ein Jahr spăter als Turgenevs ()tcy $i$ deti erschien 1863 ein Werk, das das Programm eines 'neuen Menschen' bereits im Titel enthält - der Roman Čto delat"? Iz rasskazov o novych ljudjach [deutscher Titel: Was tun? Erzählungen von neuen Menschen] des Literaturkritikers Nikolaj Gavrilovið Černyševskij (1828-1889). In ihm hat die weibliche Protagonistin Vera Pavlovna die Vision einer zukünttigen Gesellschaft von gemeinsam in einem Palast aus Eisen und Glas lebenden Menschen, in der die Hierarchien und Besitzverhältnisse der zeitgenössischen Gesellschaft aufgehoben sind. ${ }^{9}$ Auch Prosawerke des heftig gegen Černyševskij polemisierenden Fedor Michajlovič Dostoevskij (18211881), vor allem sein 1871/72 erschienener Roman Besy [deutscher Titel: Die

\footnotetext{
$7 \mathrm{Vgl}$. dazu D. Kellner, Fxpressionist Literature and the Dream of the "New' Man" (1983), 169. Auf die Verbreitung des Topos des 'neuen Menschen' in der Literatur des Expressionismus weist auch Walter Riedel hin, wobei er sich bei seiner Untersuchung bewußt auch auf Werke der nachexpressionistischen Zeit stützt. Vgl. dazu W. Riedel, Der neue Mensch. Mythos und Wirklichkeit (1970), Iff.

${ }^{8}$ Vgl dazu V. V. Vorovskij, Bazarov i Samin. Dva migilizma (1923); N. Malyక̌eva, (Obraz Bazarova v obsčestuemmo-političeskoj polemike 1908-1910gg. (1986), 119ff.

${ }^{9} \mathrm{Da}$ in Cernyševskijs Roman eine weibliche Figur Trägerin der neuen Ideen ist, spricht Bianka Pietrow-Ennker in ihrer kürzlich erschienenen Habilitationsschrift von einer 'neuen Frau' und bezieht dieses Schlagwort auch auf andere literarische Heldenentwürfe der 1860er Jahre. Vgl. dazu B. Pietrow-Ennker, RuBlands 'newe Menschen'. Die Entwicklung der Frawenhewegung von den Anfängen bis zur Oktoberrevolution (1999), 38.
} 
Dämonen], wurden mit dem Topos des 'neuen Menschen' in Verbindung gebracht. $^{10}$

Vladimir Il'ič Lenin [eigentlich: Ul'janov] (1870-1924) schätzte Čemyð̌evskij sehr," was sich nicht zuletzt auch in der Tatsache zeigt, daß er seinerseits mit der 1902 in Stuttgart veröffentlichten Schrift Cıo delat"? Nabolevšie voprosy našego dviženija [deutscher Titel: Was tun? Brennende Fragen unserer Bewegung] Bezug auf Černyševskijs Prosawerk nimmt. Insofern füren unmittelbare Verbindungslinien von den in den $1860 \mathrm{er}$ Jahren von Čemy̌̌evskij entworfenen Visionen zu den Vorstellungen, die man sich vom 'neuen Menschen' in der jungen Sowjetunion machte. An der Suche nach einer Emeuerung der Menschheit war die Literatur jener Jahre maßgeblich beteiligt.

Dabei sahen durchaus nicht alle Schriftsteller in der Idee des 'neuen Menschen' etwas Positives, wie etwa der 1920 entstandene und erst 1988 in der Sowjetunion erschienene antiutopische Roman $M y$ [deutscher Titel: Wir] von Evgenij Ivanovič Zamjatin (1881-1937) zeigt. Ein kritisches Portrait des 'neuen Menschen' zeichnet auch Michail Afanas'evic Bulgakov (1891-1940) in seiner 1925 entstandenen grotesk-satirischen Erzählung Sobac' $e$ serdce [deutscher Titel: Hundeherz]. Bulgakovs Text schildert die - am Ende allerdings wieder rückgängig gemachte - Metamorphose eines streunenden Hundes zu einem ungebildeten Proletarier nach der Einpflanzung menschlicher Organe.

Mit dem ersten sowjetischen Schriftstellerkongreß im August 1934 wurde der sozialistische Realismus zur alleinigen staatlich sanktionierten Stilrichtung in der Literatur. Da für die übrigen Künste ăhnliches galt, ist oft von einer „Verstaatlichung der Kultur"12 die Rede. Die Idee des 'neuen Menschen' nahm eine zentrale Stellung im Programm der einzigen bei Partei und Staat erwünschten Kunstrichtung ein, hing man doch vielerorts dem Glauben an, durch den planmäßigen Umbau von Staat und Gesellschaft einen neuen Menschentypus, jene später spöttisch als homo sovieticus bezeichnete 'Spezies', hervorbringen zu können. Die konkrete Ausgestaltung dieser Idee in Form von 'positiven Helden' sowie - davon ausgehend - die erzieherische Beeinflussung der breiten Volksmassen wurden fortan als wesentliche Aufgabe von Künstlem und Schriftstellern angesehen. Die Folge dieser Degradienung der Literatur zum bloßen Erfüllungsgehilfen von Politik und marxistischer Ideologie waren zahlreiche literarische Werke voller schablonenhaft entworfener Figuren, denen

${ }^{10} \mathrm{Vgl}$. dazu G. Küenzlen, Der Neue Mensch. Zur säkularen Religionsgeschichte (1994), 147. Derek Müller weist darauf hin, daß die Idee des 'neuen Menschen' in Dostoevskijs Besy eindeutig negativ konnotient ist. Vgl. dazu D. Müller, Der Topos des Neuen Menschen in der russischen und sowjetrussischen Geistesgeschichte (1998), 61.

"Zur Rezeption der Ideen Cernyకevskijs durch Lenin und andere führende Köpfe der sowjetischen Ideologie vgl. ebd., $40 \mathrm{f}$.

12 Müller (1998), 238. 
das ursprünglich innovative Moment der Idee vom 'neuen Menschen' weitgehend abhanden gekommen war.

Die Bedeutung der Idee des 'neuen Menschen' für die sowjetische Ideologie - besonders während der Zeit des Stalinismus - steht außer Frage. Infolgedessen liegen eine Reihe von geistesgeschichtlichen Untersuchungen zur Geschichte dieses Topos vor, die auch die Literatur in ihr Blickfeld einbeziehen. Zum Teil wurden dabei auch vor der Oktoberrevolution entstandene Texte mit der sowjetischen Tradition des 'neuen Menschen' in Verbindung gebracht, wie etwa der 1906/07 zuerst in englischer Sprache erschienene und später zum Mustertext des sozialistischen Realismus auserkorene Roman Mother [russisch: Mat'; deutsch: Die Mutter] des Schriftstellers Maksim Gor'kij [tatsächlicher Name: Aleksej Maksimovic Peskov] (1868-1936). ${ }^{13}$

Was jedoch überrascht, ist die Tatsache, daß bisher offensichtlich keine detailliertere Untersuchung zum Thema des 'neuen Menschen' in der russischen Literatur und Geistesgeschichte speziell an der Wende zum zwanzigsten Jahrhundert vorliegt. Auch in wissenschaftlichen Arbeiten zur deutschen Literatur und Kultur ist das Schlagwort des 'neuen Menschen' bisher kaum mit der Zeit der Jahrhundertwende in Verbindung gebracht worden. ${ }^{14}$ Allerdings zeigte kürzlich die vom Deutschen Hygiene-Museum Dresden mit Blick auf die bevorstehende Jahrtausendwende organisierte Ausstellung, da $B$ man den Traum vom 'neuen Menschen' außerhalb der Literaturwissenschaft durchaus als prägend für die Zeit um 1900 ansieht. $^{15}$

Ziel der vorliegenden Arbeit ist es, Frank Wedekinds Mine-Haha und Michail Petrovic Arcybaševs Sanin als literarische Manifestationen der Suche nach dem 'neuen Menschen' miteinander zu vergleichen. Als Vorbereitung dazu soll auch der geistesgeschichtliche Kontext der beiden Werke - die diversen Emeuerungsbewegungen in den Jahren um 1900 - aufgezeigt werden. Da die Suche nach Erneuerung und Erlösung des Menschen das tertium comparationis des Vergleichs bildet, konzentriert sich die vorliegende Studie nicht primär auf

\footnotetext{
${ }^{13} \mathrm{Vgl}$. ebd., 94. Neben Müller stellt auch Andrej Sinjawskij Verbindungen zwischen der Idee des 'neuen Menschen' und der Literatur her. Vgl dazu A. Sinjawskij [Sinjavskij]. Der Traum vom neuen Menschen oder Die Sowjetzivilisation (1989), 196ff.

It Als Beispiel für die Verwendung des Begriffs in bezug auf die Literatur der Jahrhundertwende sei auf einen von Dieter Kafitz herausgegebenen Sammelband verwiesen Die Formulierung 'neuer Mensch' wird hier im Titel zweier Beiträge aufgegriffen In seiner Einfuhrung spricht Kafitz selbst von einer, gegenbildlichen Sehnsucht nach einem

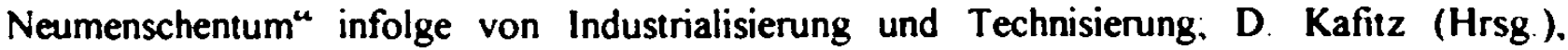
Dekadenz in Deutschland. Beiträge zur Eirforschung der Romanliteratur um die Jahrhumulertwende (1987), 38.

is Vgl. dazu N. Lepp/ M. Roth/ K. Vogel (Hrsg.), Der Neue Mensch. Obsessionen des 20. Jahrhunderts. Katalog zur Ausstellung im Deutschen Hygiene-Museum Dresden vom 22. April bis 8. August 1999 (1999), 142ff.
} 
biographische Aspekte bzw. das Thema der Erotik, die in der bisherigen literaturwissenschaftlichen Diskussion der beiden Texte zumeist Gegenstand des Interesses waren. Gleichwohl spielt das Erotische sowohl in Mine-Haha als auch im Sanin selbstverständlich eine wichtige Rolle, so daß es in einer Untersuchung der Vorstellungen vom 'neuen Menschen' natürlich nicht unbeachtet bleiben kann.

Angesichts der in literaturhistorischen Arbeiten zur Jahrhundertwende immer wieder betonten ungeheuren Vielseitigkeit der Literatur um 1900 - Viktor Žmegą̌ spricht von einem ,Stil- und Gesinnungspluralismus des Zeitalters" ${ }^{\text {"16 }}$ soll keinesfalls behauptet werden, bei den verglichenen Texten handle es sich um repräsentative Werke ihrer Zeit. Grundlage des Vergleichs der beiden Prosatexte ist auch nicht die Annahme einer direkten, auf der Beeinflussung des späteren Textes durch den früheren beruhenden Beziehung. Infolge der unzureichenden philologischen Aufarbeitung von Arcybaševs Werk sind Aussagen über die Beeinflussung des Autors durch ausländische Schriftsteller und Denker ohne aufwendige Archivstudien ohnehin nur beschränkt möglich.

Entscheidend für die Themenstellung ist vielmehr die Tatsache, daß sich Wedekind und Arcybašev mehr oder weniger zeitgleich bemühten, dem Menschen der zeitgenössischen Gegenwart in ihren Texten eine Alternative gegenüberzustellen. Der Begriff neuer Mensch wird insofern in der vorliegenden Arbeit vor allem als Vision verstanden, der der Wunsch nach Erlösung der Menschheit von den Problemen der Gegenwart zugrunde liegt. Trotz der grundsätzlichen Gemeinsamkeit, die in der Ablehnung des gegenwärtigen Menschen besteht, sind die beiden Entwürfe eines 'neuen Menschen' jedoch unterschiedlich genug, um einen Vergleich reizvoll zu machen und durch den Kontrast die künstlerischen und weltanschaulichen Eigenheiten beider Werke zu verdeutlichen.

Unter Verwendung der Terminologie des slowakischen Komparatisten Dionýz Durišin ist also festzuhalten, daß im Mittelpunkt des Interesses in der vorliegenden Arbeit nicht genetische, d. h. auf Kontakt beruhende, sondern typologische, auf Analogien basierende literarische Zusammenhänge stehen. ${ }^{17}$ Gleichwohl sollen auch literarische, kulturelle und soziale Einflüsse aufgezeigt werden, denen die beiden Schriftsteller ausgesetzt waren. Wie Zoran Konstantinović betont hat, bietet gerade eine Kombination der beiden grundlegenden komparatistischen Betrachtungsweisen - genetisch und

${ }_{10}^{16} Z$ ŹmegaX (1981), VII.

17 Zur grundsätzlichen Unterscheidung zwischen genetischen und typologischen Zusammenhängen vgl. D. Duurisin, Die wichtigsten Typen literarischer Beziehungen und Zusammenhänge (1980), 91ff.; Übersichtsschema siehe 101. Durisin hat seine Gedanken zu den verschiedenen Arten von literarischen Beziehungen an folgender Stelle nochmals ausfuhrlicher dargelegt: D. Durisin, Theory of Literary Comparatistics (1984), 107ff. 
typologisch - die besten Möglichkeiten, interliterarische Zusammenhänge zu erkennen. ${ }^{18}$ Aus diesem Grund wird den einzelnen Abschnitten dieser Arbeit jeweils eine Vorbemerkung vorangestellt, die der Darlegung des Diskussionszusammenhangs dienen soll, in dem sich die beiden literarischen Versuche der Schaffung eines 'neuen Menschen' bewegen.

Die Themenstellung der vorliegenden Arbeit bringt es mit sich, daß besonders in den Vorbemerkungen der Bereich der reinen Literaturwissenschaft wiederholt verlassen wird und auch Fragestellungen der Philosophie, Theologie, Geschichte, Soziologie, Pädagogik, Kunstgeschichte sowie sogar der Geographie miteinbezogen werden. Um einem Auseinanderfallen der Untersuchung in zwei Teile entgegenzuwirken, entschied sich der Verfasser für eine integrative Vorgehensweise beim Vergleich der beiden Texte. Insofern werden die beiden literarischen Entwürfe eines 'neuen Menschen' jeweils unter übergeordneten Gesichtspunkten miteinander verglichen. Ein Kapitel zur Entstehungs- und Wirkungsgeschichte von Wedekinds Mine-Haha und Arcybaševs Sanin wird der Untersuchung vorangestellt. Da beide Werke nicht zum Kanon der bekanntesten Texte der deutschen bzw. russischen Literatur zählen, finden sich hier auch zwei kurze Handlungsparaphrasen. Um diese in deutscher Sprache verfaßte Arbeit möglichst vielen russischen Lesern zugänglich zu machen, findet sich im Anschluß an das Schlußwort eine kurze russische Zusammenfassung der wichtigsten Untersuchungsergebnisse.

Nötig sind an dieser Stelle noch einige weitere Bemerkungen zum technischen Procedere: Leider fehlt bisher eine verläßliche historisch-kritische Ausgabe der Wedekindschen Werke, die die Mängel der in den Jahren 1912 bis 1921 von Arthur Kutscher herausgegebenen Gesammelten Werke korrigiert. In der vorliegenden Arbeit werden Wedekinds literarische und publizistische Schriften nach der 1969 in Berlin und Weimar erschienenen Ausgabe von Manfred Hahn zitiert, da dies die vollständigste unter den neueren WedekindEditionen ist. Die 1990 erschienene, von Erhard Weidl besorgte zweibändige Ausgabe von Werken Wedekinds konnte nicht als Zitiergrundlage herangezogen werden, da Mine-Haha nicht aufgenommen wurde.

Als Textgrundlage für die Kapitel zu Arcybaševs Sanin wurde der 1990 von S. S. Nikonenko herausgegebene Band mit ausgewählter Prosa des Autors herangezogen. In dieser Ausgabe wurde die Orthographie den seit 1917 geltenden Regeln angepaßt, und außerdem wurden einige typographische Ungereimtheiten des 1969 bei Bradda Books in Letchworth erschienenen Nachdrucks, besonders

$18 \mathrm{Vgl} \mathrm{Z}$. Konstantinovic, l'ergleichende Literatumissenschaft. Bestandsunfinahme unkd Ausblicke (1988), 91. „Dem heutigen Forschungsstand der Komparatistik, die aus einer Vielzahl von Einzelarbeiten zu synthetischen Überblicken über interliterarische Zusammenhange zu gelangen versucht, werden jene Zusammenfassungen am ehesten gerecht. die Genetisches nicht vom Typologischen trennen " 
die fehlerhafte Kapitelzăhlung ab Kapitel XL, beseitigt. Quellen, die vor der Reform der russischen Orthographie im Jahre 1917 erschienen sind, werden in dieser Arbeit aus drucktechnischen Gründen nach den für das heutige Russisch gültigen Regeln für Schreibung und Morphologie zitiert.

Russische Zitate werden stets in kyrillischer Schrift angeführt. Für Namen von Personen sowie von literarischen bzw. publizistischen Texten hingegen wird um der besseren syntaktischen Integrierbarkeit willen die lateinische Schrift benutzt, wobei die in der deutschen Slavistik verbreiteten Regeln der wissenschaftlichen Transkription herangezogen werden. Da die vorliegende Arbeit auf Grund ihrer Themenstellung eine Synthese aus germanistischer und russistischer Untersuchung darstellt, werden Zitate aus Sanin sowie aus der russischsprachigen Sekundärliteratur im Fußnotenapparat übersetzt. Die letzte verfügbare deutsche Übersetzung des Romans von Stefania Goldenring aus dem Jahre 1921 weist eine Reihe von Mängeln auf - der wohl schwerwiegendste ist das Fehlen des Epigraphs -, so daß sie nicht immer für die Fußnoten herangezogen werden konnte. Sofern Zitate aus russischen Quellen vom Verfasser selbst übersetzt wurden, wurde dies kenntlich gemacht. Zitate aus englischen und französischen Quellen werden grundsätzlich nicht übersetzt. 


\section{DER ‘NEUE MENSCH’ ALS SKANDALON}

\subsection{Mine-Haha}

\subsubsection{Kurzer Abriß der Handlung}

In der erweiterten Version von 1903 beginnt Frank Wedekinds Mine-Haha oder Üher die körperliche Erziehung der jungen Mädchen mit einer kurzen Rahmenhandlung. In dieser tritt ein Ich-Erzähler auf, der sich als Autor von Frühlings Erwachen bezeichnet. Weiterhin erklärt er, bei den nachfolgenden Seiten handle es sich um ein Manuskript, das er von seiner Zimmernachbarin, einer 84jährigen pensionierten Lehrerin namens Helene Engel erhalten habe. Die Verfasserin der Aufzeichnungen habe sich inzwischen aus dem Fenster gestürzt.

Das Manuskript enthält die aus vier Kapiteln bestehende und in der Ichform gehaltene Beschreibung der Jahre, die ein Mädchen mit dem Namen Hidalla in einem hermetisch von der Außenwelt abgeschlossenen Park verbracht hat. Im Park befindet sich eine Erziehungskolonie, in der Hidalla in einem Kollektiv gemeinsam mit Hunderten von Kindern ohne jegliche Beziehung zu Eltern oder Familie aufwächst. Die Ausbildung im Park verläuft nach einem fest vorgegebenen, invariablen Plan und gleicht der Dressur von Tieren, da sie sich ausschließlich auf die Entwicklung körperlicher Fertigkeiten beschränkt.

In den ersten Lebensjahren lebt die Erzählerin in einer Gruppe gleichaltriger Jungen und Mädchen unter der Obhut zweier junger Erzieherinnen, die die Kinder im ästhetischen Gehen und in der Kunst der Körperbeherrschung unterweisen. Daneben verbringen die Zöglinge viel Zeit im Freien, zumeist ohne Kleider. Mit ungefähr sieben Jahren spürt Hidalla instinktiv eine bevorstehende Veränderung, woraufhin sie von einer der Erzieherinnen in eine Kiste eingeschlossen wird.

Als die Kiste geöffnet wird, findet sich Hidalla in einer neuen Umgebung wieder, und für sie beginnt der zweite Abschnitt ihrer Ausbildung. Die Erzählerin lebt nun in einer reinen Mädchengruppe, in der das älteste der insgesamt sieben Mädchen die Funktion einer Erzieherin ausübt. $\mathrm{Zu}$ festen Zeiten muß Hidalla ihre Wohngruppe verlassen, um im 'Weißen Haus' zusammen mit Mädchen aus anderen Gruppen Tanz- und Musikunterricht zu erhalten. Viele Aspekte des Lebens im Park bleiben für Hidalla unklar - zum Beispiel das weitere Schicksal der Jungen oder welchem Zweck die geheimnisvolle Auswahlprozedur im 'Weißen Haus' dient, die ein großes Ereignis im Leben jedes Mädchens darstellt. Von einem anderen Mädchen erfährt die Erzählerin jedoch, was mit den 
Zöglingen geschieht, die sich den strengen Regeln der Erziehungsanstalt widersetzten: Ohne jede Aussicht auf Entlassung müssen sie bis an ihr Lebensende als Dienerinnen im Park verbleiben.

Das jeweils älteste Mảdchen der Gruppe tritt abends in einem Theater auf, in dem ein allabendlich aus der Stadt anreisendes Publikum mit Stücken erotischen Inhalts zu rasenden Beifallsstürmen aufgestachelt wird. Mit Eintritt der Menarche muß die Gruppenälteste ihre Kameradinnen verlassen, und nach kurzer Zeit wird in einer Kiste ein neues Mädchen angeliefert. Nachdem sich schließlich auch bei Hidalla die körperliche Reife eingestellt hat, wird sie zusammen mit gleichaltrigen Mädchen aus den anderen Wohngruppen in einer unterirdischen Bahn in die Stadt gebracht. Inmitten dieser vollkommen ungewohnten Umgebung werden die Mädchen mit einer Gruppe von Knaben zusammengeführt, und wie ihre Altersgenossinnen erhält auch Hidalla einen männlichen Begleiter. Das Manuskript endet damit, daß die Erzählerin zusammen mit ihrem Begleiter in die bedrohlichen Menschenmassen eines gigantischen Volksfestes eintaucht.

\subsubsection{Zur Entstehungs- und Publikationsgeschichte}

Die Veröffentlichung von Wedekinds Fragment Mine-Haha, das ursprünglich als Teil eines größeren Prosawerks konzipiert war, verlief in zwei Schritten: Zunăchst erschien im Jahre 1901 eine lediglich die Kapitel I bis III enthaltende, durch drei Illustrationen von Felix Vallotton ergänzte Version im Band 2 der von Otto Julius Bierbaum, Alfred Walter Heymel und Rudolf Alexander Schröder herausgegebenen Zeitschrift Die Insel. ${ }^{19}$ Wedekind fügte diesem Text ein viertes Kapitel, den Untertitel Über die körperliche Erziehung der jungen Mädchen. Aus Helene Engels schriftlichem Nachlaß herausgegeben von Frank Wedekind, eine Vorrede sowie eine Nachschrift eines fiktiven Herausgebers hinzu. Das so entstandene Werk wurde 1903 als Band 55 der Reihe Kleine Langensche Bibliothek im Verlag von Albert Langen in München veröffentlicht. ${ }^{20}$ Die enweiterte Version von 1903, die von Wedekind noch einmal für die Publikation in den Gesammelten Werken im Jahre 1912 autorisiert wurde, bildet die Textgrundlage für diese Arbeit.

\footnotetext{
${ }^{19} \mathrm{Vgl}$. Die Insel 2/3 (1901), 27ff.; 93ff.; 234ff.

${ }^{20} \mathrm{Vgl}$. zur Publikationsgeschichte von Mine-Haha A. Kutscher, Frank Wedekind. Sein Leben und seine Werke, Bd. 2 (1927), 126; M. Hahns Anmerkungen in F. Wedekind, Werke in drei Bänden, Bd. 3 (1969), 652f.; W. Schmitz/ U. Schneider, Editorische Nachbemerkung (1994), 92f. 31
} 
Aussagen zur Entstehungsgeschichte des Wedekindschen Textes werden dadurch erschwert, daß das Werk des Autors bisher noch nicht vollständig philologisch aufgearbeitet ist. Bis zum Erscheinen des Romanfragments MineHaha in einer philologischen Ansprüchen genügenden Ausgabe werden wohl noch einige Jahre vergehen. ${ }^{21}$ Ein großer Teil der nachgelassenen Schriften Wedekinds, insbesondere auch die in Zusammenhang mit Mine-Haha sehr aufschlußreichen Entwürfe zum Projekt Die große liebe, ist nach wie vor nicht philologisch zuverlässig ediert und insofern nur schwer zugänglich, Teile unterliegen gar noch einer Sperrung durch die Erben. Weitere Schwierigkeiten ergeben sich aus der Tatsache, daß die Wedekind-Forschung in Ermangelung anderer zuverlässiger Quellen in vielen Bereichen auf die Aussagen von Wedekinds Herausgeber und Biographen Arthur Kutscher angewiesen ist, der bisweilen „eine Art Zensurphilologie ${ }^{\text {c.22 }}$ betrieb und auch eine Reihe von inzwischen widerlegten Angaben machte. ${ }^{23}$

Wedekind selbst gibt die Entstehungszeit des später unter dem Titel MineHaha veröffentlichten Fragments mit Juli bis Oktober 1895 an. ${ }^{24}$ Aus dem Anhang zu einem Brief des Autors an den dänischen Literaturkritiker Georg Brandes (1842-1927) vom 10.1.1909 geht hervor, daß der publizierte Text lediglich den Anfang einer ursprünglich auf 18 Kapitel angelegten Utopie darstellt. ${ }^{25}$ Wie Kutscher berichtet, sollte deren Titel zunächst Hidalla oder Das Lehen einer Schneiderin lauten. ${ }^{26}$ Bereits vor 1895 setzte sich Wedekind mit der in Mine-Haha behandelten Idee einer körperlichen Mädchenerziehung auseinander - zu nennen sind etwa das Dramenfragment Schloß Wildenstein von 1890 sowie das bisher der Sperrung durch die Wedekind-Erben unterliegende Manuskript Eden von 1889/90. ${ }^{27}$ Eine thematische Verbindung besteht auch zu dem erst posthum als Fragment veröffentlichten Drama Das Sonnenspektrum, mit dessen Ausarbeitung sich Wedekind im Jahre 1894 befaßte. $^{28}$

${ }^{21}$ So lautet eine mündliche Mitteilung, die der Verfasser dieser Arbeit von Herm Prof. Dr Hartmut Vinçon, dem Leiter der Editions- und Forschungsstelle Frank Wedekind, erhielt. Eine Inhaltsangabe für die einzelnen Bände der bereits begonnenen Kritischen Studienausgahe findet sich in H. Vinçon, Prolegomenon zur Kritischen Studienausgabe der Werke Frank Wedekinds (1996), 170.

$22 \mathrm{H}$. Vinçon, Anmerkungen zu einer newen leseausgabe von Frank Wedekinds Werken (1991), 317.

${ }^{23} \mathrm{Vgl}$. hierzu ebd. $318 \mathrm{f}$.

${ }^{24} \mathrm{Vgl}$. Wedekind, Bd. 3 (1969), 335.

${ }^{25} \mathrm{Vgl}$. hierzu K. Bohnen, Frank Wedekind und (jeorg Brandes. IImeröffemlichte Briefe (1978), 114

${ }^{26} \mathrm{Vgl}$. hierzu Kutscher, Bd. 2 (1927), 131.

${ }^{27} \mathrm{Vgl}$. hierzu H. Vincon, Frank Wedekind (1987), $55 f$.

$28 \mathrm{Vgl}$. hierzu A. Höger, Das Parkleben. Darstellung und Analyse von Frank Wedekinds Fragmem Das Sonnenspektrum (1983), 36. 
Ein Teil von Kapitel III des Wedekindschen Textes, der die Beschreibung der erotischen Tanzpantomime Der Mückenprinz enthält, erschien in nahezu gleicher Textgestalt bereits 1897 im Sammelband Die Fürstin Russalka. ${ }^{29}$ In dem 1901 entstandenen Aufsatz Autobiographisches gibt Wedekind an, Mine-Haha wăhrend der Zeit der Haftstrafe, die er von September 1899 bis März 1900 wegen angeblicher Majestătsbeleidigung in seinem Simplicissimus-Gedicht Palästinafahrt auf der Festung Königstein verbüßen mußte, noch einmal überarbeitet $\mathrm{zu}$ haben. ${ }^{30}$ Inzwischen sind jedoch starke Zweifel an dieser Selbstaussage, die von Kutscher und in dessen Gefolge von großen Teilen der Mine-Haha-Forschung übernommen wurde, aufgekommen. ${ }^{31}$

Eine Besonderheit des Wedekindschen Werks besteht darin, da $B$ die Namen von Figuren bisweilen in mehreren Texten erscheinen. Alan Best beschreibt diese Eigenart des Autors mit den folgenden Worten: "Wedekind constantly collected events and personalities and stored them away for further use". 32 So taucht der Name der Ich-Erzăhlerin in Mine-Haha ${ }^{33}$ in Wedekinds 1904 in München zunächst in Buchform publiziertem Drama Hidalla oder Sein und Haben (ab 1911 verwendeter Titel: Karl Hetmann, der Zwerg-Riese) wieder auf. Allerdings erscheint er hier nur als Titel eines von dem zentralen Helden, Karl Hetmann, verfaßten Traktats. ${ }^{34}$ Den Namen einer weiblichen Figur aus diesem Drama, Fanny Kettler, erwog Wedekind 1903 als Titel eines Romans „von 200 bis 300 Seiten ${ }^{\star 35}$ zu verwenden.

Obwohl Wedekind in den Jahren ab der Jahrhundertwende in zunehmendem Maße der Durchbruch als Theaterautor gelang und insofern die Dramatik allmählich den größten Teil seiner Zeit und Energie zu absorbieren begann, schickte er sich 1906 noch einmal an, sein Projekt eines utopischen Romans zu

${ }^{29} \mathrm{Vgl}$. F. Wedekind, Die Fürstin Russalka (1897), 232ff.; vgl. dazu auch F. Wedekind, Werke. Bd. III/l (1996), 39ff. sowie Bd. III/2 (1996), 769ff.

${ }^{30} \mathrm{Vgl}$. hierzu Wedekind, Bd. 3 (1969), 334.

${ }^{31}$ Dies wurde dem Verfasser dieser Arbeit von Herm Vinçon mündlich mitgeteilt. Bereits 1981 hatte Hoger Zweifel an Kutschers Behauptung angemeldet, Wedekind habe sein Romanfragment auf der Festung Königstein nochmals überarbeitet. Vgl. dazu A. Höger, Hetärismus und bürgerliche Gesellschaft im Frühwerk Frank Wedekinds (1981), 17.

${ }^{32}$ A. Best, Frank Wedekind (1975), 23.

33 Wedekind entlehnte ihn zusammen mit den Namen einiger Nebenfiguren aus den Ossianischen Epen des schottischen Schriftstellers James Macpherson (1736-1796). Vgl. dazu Schmitz/ Schneider (1994), 94. Der einzige inhaltliche Konnex zwischen Wedekinds und Macphersons Hidalla - einem jungen irischen Krieger und Stammeshäuptling - scheint in dem schonen Haar zu bestehen, das beide haben; vgl. dazu: J. Macpherson, The Poems of Ossian and related works (1996), 257: "Calm and stately, to the beam of the oak, arose the form of young Hidalla. His hair falls round his blushing cheek, in wreaths of waving light."

${ }^{34}$ Der volle Titel lautet Hidalla oder Die Moral der Schönheit. Vgl. dazu Wedekind, Bd. 1 (1969), 663.

${ }^{35}$ F. Wedekind, (jesammelle Briefe (1924), Bd. 2, 107. 
vollenden. Von diesen Bemühungen zeugen die Fortsetzungspläne in den Notizbüchem 38 bis 42, die im Archiv der Monacensia in München aufbewahrt werden. $^{36}$ Das Konvolut von Skizzen und Entwürfen enthält auch die von Kutscher zur Bezeichnung des gesamten Projekts herangezogene Bezeichnung Die große Liehe [,Die grosse Liebe“] (vgl. z. B. NB 40/1 zur Bezeichnung eines geplanten Gedichts). In den enthaltenen Notizen wird ein utopischer Staat entworfen, dessen soziale Ordnung sich auf körperliche Schönheit, Ästhetik der Bewegungen und sexuelle Leistungsfähigkeit gründet.

Dem einzelnen werden im System des Staates keinerlei individuelle Entscheidungsmöglichkeiten zugebilligt. Gerade auch der Koitus wird als Pflichtübung im Rahmen sogenannter Frühlings- und Herbstfeiem - ritueller Opferungen von Mädchen und Knaben „auf dem Altar der Liebe“ (NB 39/7) dargestellt. Zum Teil enthalten die Notizbücher auch bereits nahezu druckreife Prosa, so z. B. den in der Ich-Form gehaltenen Bericht eines „Götterknaben“ vom Moment seiner Auswahl im Weißen Haus an (vgl. NB 42/3ff.) sowie die analoge Erzählung eines „Göttermädchens“ mit dem Namen Lora (vgl. 42/12ff.).

Die Tatsache, daß der Autor sein Romanprojekt unausgeführt ließ, hat natürlich Auswirkungen auf die Deutung von Mine-Haha und war insofern wiederholt Gegenstand des Interesses der Wedekind-Forschung. Kutscher macht hierfür einen Wandel in Wedekinds Menschenbild verantwortlich, den er für die Zeit der Arbeit an der Fortsetzung von Mine-Haha konstatiert. ${ }^{37}$ Medicus hingegen vertritt in seiner Arbeit die Auffassung, daß die von Wedekind in seinen Notizbuchaufzeichnungen zum Große-Liebe-Projekt skizzierten sexuellen Initiationsrituale von vornherein in dem publizierten Fragment angedeutet sind, $\mathrm{da} B$ also beim Autor kein Gesinnungswandel stattfand. ${ }^{38}$ Nach dem heutigen Stand der Mine-Haha-Forschung erscheint es wahrscheinlich, daß es eine Kombination verschiedener Faktoren war, die Wedekind zum Abbruch seines Romanprojekts bewog. Zu nennen sind hier einerseits sein Durchbruch als Dramenautor während seiner Beschäftigung mit dem erzählerischen Stoff, daneben Wedekinds notorische Probleme mit der Zensur und nicht zuletzt auch

\footnotetext{
${ }^{36}$ Eine Zusammenfassung des Inhalts der betreffenden Notizbücher findet sich in Kutscher, Bd 2 (1927), 133ff. Für Verweise auf die Notizbücher, die in den laufenden Text eingefügt werden, wird in dieser Arbeit folgendes Verfahren verwandt: NB Nummer des Notizbuchs' handschriflich eingetragene Seitenzahl auf der von der Mainzer Akademie der Wissenschaften erstellten maschinengeschriebenen Transkription.

${ }^{37}$ A. Kutscher, Frank Wedekind. Lehen und Werk (1964), 208. Auch Friedrich Rothe geht von einem Wandel in Wedekinds Menschenbild aus, auf Grund dessen in der erweiterten Fassung von 1903 der distanzierende Rahmen eingefügt worden sei. Vgl. dazu F. Rothe. Frank Wedekinds Dramen. Jugenutstil und Lebensphilosophie (1968), 76

${ }^{38} \mathrm{Vgl}$ Th. Medicus, ,Die große Liebe “. Okonomie und Konstruktion der Körper im Werk von Frank Wedekind. (1982), 128ff.
} 
„die Frage, wie der gewaltige historische Stoff zu bewältigen sei“c39, den sich der Autor mit dem Entwurf eines umfassenden utopischen Gesellschaftssystems vorgenommen hatte.

\subsubsection{Rezeptionsgeschichte und Forschungslage}

Kurz nach dem Erscheinen der erweiterten Textfassung von 1903 wurde MineHaha in einer Simplicissimus-Rezension eine weitreichende Wirkung vorhergesagt:

Man braucht erst nicht ausdrücklich zu sagen, daß es sich hier um ein äußerst originelles Werk handelt. Das versteht sich bei Wedekind von selbst, und sicherlich wird dies Buch großes Aufsehen erregen. ${ }^{40}$

Nahezu ein Jahrhundert nach der Veröffentlichung der ersten Version läßt sich heute feststellen, daß sich diese Prophezeiung bisher kaum bewahrheitet hat. Vielmehr wurde Wedekind in erster Linie als Dramatiker bekannt, und insofern beklagte Vinçon 1987 zu Recht, daß die Prosa „von der Wedekind-Forschung lange Zeit stiefmütterlich behandelt ${ }^{\text {“41 }}$ wurde. Dies triff auch für das in dieser Arbeit behandelte Romanfragment zu, das unter den Wedekindschen Prosatexten den umfangreichsten und für eine literaturwissenschaftliche Untersuchung sicherlich ergiebigsten darstellt, wenngleich sein fragmentarischer Charakter häufig kritisiert wurde. ${ }^{42}$

Obgleich Mine-Haha in der literaturwissenschaftlichen Diskussion über das Wedekindsche Werk lediglich eine marginale Rolle spielt, hat der Text die Aufmerksamkeit einer Reihe von prominenten Lesern erregt. Bereits wenige Jahre nach der Erstveröffentlichung publizierte der prominente russische Revolutionär Lev Davidovix Trockij [eigentlicher Familienname: Bronštejn] (1879-1940) 1908 in der deutschen Zeitschrift Die neue Zeit einen Artikel über Wedekind. In diesem geht er neben anderen Werken des Schriftstellers auch auf Mine-Haha ein, wobei er dem Schriftsteller die „Verkündung sozialistischer

\footnotetext{
${ }^{39}$ Vinçon (1987), 165. Vgl. dazu auch Vinçon (1991), 317.

${ }^{40}$ Simplicissimus 8 (1903), Nr. 3, 2. Beiblatt.

${ }^{41}$ Vinçon (1987), 164.
}

${ }^{42}$ So bereits in einer frühen Rezension von Willy Rath; vgl. Das literarische Echo 5 (1902/03), 1291. Ein hartes Verdikt fallt auch Kutscher in seiner die spätere Mine-Haha-Rezeption stark beeinflussenden Werkbetrachtung; vgl. Kutscher, Bd. 2 (1927), 130: „Wie das Werk dasteht, macht es einen höchst schrullenhaften und ziemlich nichtigen Eindruck. Das KünstlerischFormale ist unbeträchtlich, wenn man nicht die Sprache als solche hervorheben will.“ 
Erziehungsynundsätze" ${ }^{43}$ bescheinigt. Kurz darauf meldete sich im Jahr 1909 auch der spätere Bundespräsident Theodor Heuss (1884-1963) in der Zeitschrift Der Kunstwart mit einem eher kritischen Artikel über Frank Wedekind zu Wort, in dem er Mine-Haha als Zeugnis von „Wedekinds positiver Geschlechtsmoral ${ }^{\text {“44 }}$ auslegt.

Was die innerliterarische Auseinandersètzung mit dem Wedekindschen Romanfragment anbelangt, so kann hier zunächst auf eine Parodie auf Wedekinds Gedicht Erdgeist ${ }^{45}$ verwiesen werden, die Hanns Freiherr von Gumppenberg (1866-1928), Mitbegründer des Münchner Kabaretts Die elf Scharfrichter, unter dem Titel Mine Haha Succuba. Zur Erziehung der jungen Mädchen verfaßte:

\author{
Kind, wie bist du ungeschickt! \\ Muß man alles dir noch zeigen? \\ Wenn dich nicht der Teufel spickt, \\ Wirst du immer Trübsal geigen. \\ Glaubst du, daß er dich betrügt, \\ Weil die Welt so schwarz ihn malte? \\ Jede, die sich inm gefügt, \\ Rühmt, wie vornehm er bezahlte! \\ Hebe dein Pilasterbein, \\ Tritt den Grabstein der Gesetze - \\ Doch in Höschen hüll' es ein, \\ Daß die Hölle ganz dich schätze! \\ Schöner lockt der Rosenstrauß \\ In durchbrochenen Manschetten. \\ Und das gleiche zeichnet aus \\ Allerzarteste Koteletten!
}

\footnotetext{
${ }^{43}$ Hier zitiert nach: L. Trotzkij [Trockij], Literatur und Revolution (1968), 375. Der Artikel wurde 1923 in etwas veränderter Form im Band Literatura i rewoljucija erneut veröffentlicht. In dieser Arbeit wird der russische Text nach der Werkausgabe von 1926 zitiert. In dieser steht die angefuihrte Textpassage an folgender Stelle: L. Trockij, Sox́inenija, Bd. 20 (1926), 413 ${ }^{4}$ Th. Heuß [Heuss], Frank Wedekind (1909), 267. Auch aus dem Jahre 1914 liegt ein ebenfalls recht kritisch gehaltener - Aufsatz von Heuss über Frank Wedekind vor, und auch in diesem wird Mine-Haha kurz erwähnt; hier zitiert nach Th. Heuss, Frank Wedekind (1961), 257

${ }^{45}$ In: Wedekind, Bd. 2 (1969), 526.
} 
Glaube, so wie ich gesinnt,

Sind die besten Erdengeister -

Und nun gute Nacht, mein Kind,

Mache Freude deinem Meister! to $^{\text {to }}$

In Buchform wurde die Parodie zum ersten Mal in der posthum erschienenen 14. Auflage von Gumppenbergs Das teutsche Dichterroß, in allen Gangarten vorgeritten aus dem Jahre 1929 veröffentlicht. Bereits davor soll sie jedoch in Zeitschriften abgedruckt worden sein. ${ }^{47}$

Von einer Kenntnis des Wedekindschen Textes zeugt auch ein Kapitel in dem autobiographischen Band Geschichte einer Jugend von Hans Carossa (1878-1956), in dem der Schriftsteller bekennt, daß ihm Mine-Haha ,ein höchst lebensvolles Bruchstuck blieb, so daß die unerfahrene Phantasie noch jahrelang daran weiterspinnen konnte. “48 Weniger anerkennend äußerte sich der schweizerische Autor Adolf Muschg (Jahrgang 1934) in einer Werkbesprechung aus dem Jahre 1969 über Mine-Haha:

So sieht der Zuchterfolg von Wedekinds Phantasie aus - und wenn man ihre Linien nachzeichnet, die keineswegs schummrig, sondern zart und ornamental gezogen sind wie diejenigen eines Bildes von Beardsley, so wird einem bewusst, was ein obszönes Buch ist. [...] Obszön ist das - wenn auch pervertierte - sittliche Prinzip, das in Gestalt einer drakonischen Disziplin über dieser Kolonie hängt.

Erwăhnt sei an dieser Stelle weiterhin Otto F. Bests vorsichtig formulierte Vermutung, zwischen Mine-Haha und dem 1909 erschienenen Roman Jakob von Gunten. Ein Tagebuch des schweizerischen Schriftstellers Robert Walser (18781956) bestehe ein gewisser genetischer Zusammenhang. ${ }^{50}$

Weitgehend spekulativ sind bisher auch Annahmen über die außerliterarische Wirkung von Mine-Haha geblieben: Fritz Strich, der Herausgeber von Wedekinds Briefen, sowie Kutscher behaupten, der aus der Schweiz stammende Musikpädagoge Émile Jaques-Dalcroze [eigentlich: Jakob Dalkes] (1865-1950) habe für die von ihm entwickelte rhythmische Ausdrucksgymnastik Anregungen aus Mine-Haha bezogen. ${ }^{51}$ Besonders

\footnotetext{
${ }^{46}$ Zitiert nach: E. Rotermund, Gegengesänge. Lyrische Parodien vom Mittelalter bis zur Gegenwart (1964), $216 f$.

${ }^{47} \mathrm{Vgl}$. dazu K.-W. F. v. Wintzigerode-Knorr, Hanns v. Gumppenbergs künstlerisches Werk. Ein Beitrag zur Geschichte der deutschen Literatur der Wende vom 19. zum 20. Jahrhundert (1958), $157 \mathrm{ff}$.

${ }^{48}$ H. Carossa, Mine-Haha (1957), 465.

49 A. Muschg, Frank Wedekind: 'Mine-Haha' (1980), 44.

${ }^{50} \mathrm{Vgl}$. O. F. Best, Zwei mal Schule der Körperbeherrschung und drei Schrifisteller (1970), 729.

${ }^{31} \mathrm{Vgl}$. dazu: Wedekind, Bd. 2 (1924), 370; Kutscher, Bd. 2 (1927), 130 f.
} 
Kutschers Annahme einer Beeinflussung Jaques-Dalcrozes durch Wedekind wurde in der nachfolgenden Forschung immer wieder kritiklos wiederholt. ${ }^{52}$ Elfriede Feudel gibt einen anschaulichen Bericht von Jaques-Dalcrozes Wirken in Hellerau, wobei in der Tat zahlreiche Elemente an die pädagogische Kolonie in Mine-Haha erinnem. ${ }^{53}$ Wedekind besuchte die Bildungsanstalt der Gartenstadt Hellerau (seit 1950 zu Dresden gehörig), wo Jaques-Dalcroze von 1910 bis 1914 seine neue Lehrmethode erprobte, im Juni 1912. Von diesem Besuch zeugen zwei Briefe Wedekinds an seine Frau Tilly vom 25. bzw. 28. Juni 1912, in denen jedoch kein Bezug zu der fiktiven Erziehungsanstalt in Mine-Haha hergestellt wird. ${ }^{54}$ Auch in den Schriften des Musikpädagogen läßt sich, wie Marc Muylaert festgestellt hat, kein Hinweis auf eine Bekanntschaf mit dem Wedekindschen Text nachweisen. ${ }^{55}$

Was die Auseinandersetzung mit dem Wedekindschen Romanfragment in literaturwissenschaftlichen Forschungsarbeiten betriff, so lassen sich - stark vergröbernd - zwei Phasen unterscheiden: Bis zum Beginn des 3. Reiches beschäftigen sich neben den bereits erwähnten Publikationen von Trockij und Kutscher eine 1909 erschienene Veröffentlichung von Julius Kapp sowie die biographisch ausgerichteten Arbeiten des Schriftstellers und Literaturhistorikers Paul Fechter (1880-1958) und des niederländischen Literaturwissenschaftlers Karel F. Proost aus den Jahren 1920 bzw. 1928 eingehender mit Mine-Haha. ${ }^{56}$ Aus der nationalsozialistischen Zeit, in der Wedekinds Werk nahezu keine Beachtung fand, liegt eine Dissertation zur Stellung der Frau in Wedekinds Werken vor, in der auch auf Mine-Haha eingegangen wird. In dieser formal mangelhaften und wenig überzeugend argumentierenden Arbeit von Adolf $R$. Vieth von 1939 werden jedoch keine für die literaturwissenschaftliche Diskussion über Wedekinds Romanfragment relevanten Positionen vertreten. ${ }^{57}$

Nach einer längeren Unterbrechung ist Ende der 1960er Jahre wieder ein gewisses literaturwissenschaftliches Interesse an Wedekinds Utopie der körperlichen Erziehung zu erkennen - man vergleiche etwa die Arbeiten von Sol Gittleman (1969), Otto F. Best (1970), Audrone Barunas Willeke (1972), Hans Wagener (1979), Vivetta Vivarelli (1981), Thomas Medicus (1982), Libuse Moniková (1985), Marc Muylaert (1985) und Elisabeth Boa (1987). Mit Hartmut Vinçons Übersichtsband zu Frank Wedekind aus dem Jahre 1987 liegt erstmals

\footnotetext{
$\$ 2$ Vgl. dazu z. B. Willeke (1972), 217

${ }^{53} \mathrm{Vgl}$. dazu E. Feudel, Die Geschichte der Bilctungsantstalt Hellerau (19/0-19/4) (1956).

s4 $\mathrm{Vgl}$. Wedekind Bd. 2 (1924), $270 \mathrm{f}$.

ss Vgl. dazu M. Muylaert, L.'image de la femme clans l'seuvre [!] de Frank Wedekind (1985), 180.

s6 J. Kapp, Frank Wedekind. Seine Eigenart und seine Werke (1909); zu Mine-Haha vgl. 36ff P. Fechter, Frank Wedekind. Der Men.sch und das Werk (1920); zu Mine-Haha vgl. I5Iff. K. F. Proost, Frank Wedekind. Zijn leven en werken (1928); zu Mine-Haha vgl. $105 f$ f.

${ }^{57} \mathrm{Vgl}$. A R Vieth, Die Stellung der Fraw in den Werken von Frank Wedekind (1939)
} 
auch ein Bericht über die Forschungslage zu Mine-Haha vor. Ergänzt werden kann dieser noch durch den Hinweis auf Uwe Schneiders Magisterarbeit zu MıneHaha und nachgelassenen Schriften Wedekinds von 1992, auf Elke Austermühls Überblicksartikel zu Frank Wedekind aus dem Jahre 1994 sowie auf zwei Aufsătze Ortrud Gutjahrs, deren Publikation 2001 erfolgte bzw. erfolgen wird.

Auch einige Nachworte in verschiedenen Ausgaben des Wedekindschen Textes enthalten wertvolle Informationen sowie reizvolle Interpretationsansätze. Zu nennen sind an dieser Stelle vor allem das Nachwort von Jürg Mathes im Reclam-Band Prosa des Jugendstils aus dem Jahre 1982 sowie die Editorische Nachbemerkung zu der von Walter Schmitz und Uwe Schneider 1994 herausgegebenen Neuauflage von Mine-Haha im Insel-Verlag. Nicht unerwähnt bleiben soll in diesem Zusammenhang auch Jones und Shaws WedekindBibliographie von 1996, die weitere, bei Vinçon (1987) noch nicht erfaßte Literaturhinweise zu Mine-Haha enthält. ${ }^{58}$

Von besonderem Interesse ist fur die vorliegende Arbeit natürlich die Frage, inwieweit Wedekinds Prosafragment auch in RuBland rezipiert wurde. Leider sind diesbezügliche Aussagen ohne aufwendige eigene Recherchen in russischen Archiven nur beschränkt möglich. Ein direkter genetischer Zusammenhang zwischen Mine-Haha und Michail Petrovix Arcybasevs Sanin ist jedoch wenig wahrscheinlich. Gleichwohl war Wedekind in der Zeit um das Erscheinungsjahr des Arcybaševschen Romans in Kreisen der russischen Intelligenz ein erstaunlich viel rezeptierter Autor, so daß Trockij 1908 in seinem Aufsatz schreiben konnte: „Die russischen Intelligenzler haben im Verlaufe von etwa einem Jahr Wedekind eine Popularităt verschaff, die er in seiner Heimat nicht hat. “\$59

Allerdings dürfe die breite Wedekind-Rezeption in den russischen Metropolen Moskau und Sankt Petersburg erst nach dem Erscheinen des Sanın

${ }^{58}$ Hier die Titel der erwähnten Forschungsarbeiten, sofern sie noch nicht zitiert wurden: $\mathbf{S}$. Gittleman, Frank Wedekind (1969); zu Mine-Haha vgl. besonders 130ff. H. Wagener, Frank Wedekind (1979); zu Mine-Haha vgl. 53ff. V. Vivarelli, Mine-Haha e l'utopia autoritaria di Frank Wedekind (1981). J. Mathes, Nachwort (1982); zu Mine-Haha vgl. 366ff. L. Moniková, Das totalitüre Glück. Frank Wedekind (1985). Muylaert (1985); zu Mine-Haha vgl. 96; 177ff E. Boa, The Sexual Circus. Wedekind's Theatre of Subversion (1987); zu Mine-Haha vgl. 189-196. U. Schneider, Das Projekt sinnlicher Erziehung im Frühwerk Frank Wedekinds. Untersuchungen zu Mine-Haha und den zugeordmeten Nachlaßieilen (1992). E. Austermühl, Frank Wedekind (1994); zu Mine-Haha vgl. 49f. R. A. Jones/ L. R. Shaw (Hrsg.), Frank Wedekind. A Bibliographic Handbook (1996). O. Gutjahr, Erziehung zur Schamlosigkeit. Frank Wedekinds Mine-Haha oder Über die körperliche Erziehung der jungen Mädchen und der intertextuelle Bezug zu Frühlings Erwachen (2001). O. Gutjahr, Mit den Hüften denken lernen? Körperrituale und Kulturordmung in Frank Wedekinds Mine-Haha oder Über die körpertiche Erziehung der jungen Mädchen (Typoskript).

39 Trockij (1968), 382. Russischer Text nach Trockij (1926), 420: „Русская интеллигенция в теченне хахого-нибудь года создала Ведехинду популярность, вахой он не имеет у себя на родине.“ 
eingesetzt haben. Es ist zu vermuten, daß hieran die Eröffnung der Theatersaison im Herbst 1907 mit einer Aufführung von Frühlings Erwachen [russischer Titel: Probuždenie vesny] im Theater der Schauspielerin und Theaterreformerin Vera Fedorovna Komissarževskaja (1864-1910) in Sankt Petersburg entscheidenden Anteil hatte. Der symbolistische Schriftsteller Aleksandr Aleksandrovic Blok (1880-1921) berichtet wenig begeistert von der Premiere des Wedekindschen Stücks am 15.9.1907. ${ }^{60}$

Immerhin scheint Wedekinds Bekanntheit in Rußland innerhalb weniger Monate so groß geworden zu sein, daß E. A. Koltonovskaja bereits in einem zuerst 1908 publizierten Aufsatz verkünden konnte:

У Арцыбашева есть нечто общее с Ведекиндом, если не по натуре и темпераменту, то по литературным задачам и, наконец, в данный момент по литературной судь $6 \mathrm{e}^{6 !}$

Koltonovskaja erläutert ihre Annahme einer typologischen Beziehung zwischen Wedekind und Arcybašev durch Verweise auf die Wedekindschen Dramen Totentanz [ab 1909: Tod und Teufel], Hidalla [ab 1911: Karl Hetmann, der Zwergriese], Musik sowie das Doppeldrama Lulu.

Wie in Deutschland gründete sich das Interesse an dem deutschen Dichter auch in Rußland allem Anschein nach in erster Linie auf dessen dramatische Werke, wohingegen die Prosa augenscheinlich keine Beachtung erfuhr. Was die literaturwissenschaftliche Wedekind-Rezeption in Rußland bzw. der Sowjetunion betrifft, so ist dem Verfasser dieser Arbeit lediglich ein Übersichtsband zur deutschen Literatur bekannt, in dem in Zusammenhang mit einer weitgehend negativen Bewertung der Wedekindschen Prosa auch auf Mine-Haha verwiesen wird. ${ }^{62}$

${ }^{60} \mathrm{Vgl}$. A. A. Blok, Sobranie sočinenij v vos' 'mi tomach, Bd. 5 (1962), 194ff.

${ }^{61}$ Hier zitiert nach: E. A. Koltonovskaja, Problema pola v molodoj literature. (Wedekind i Arcybašv) (1910), 104f. Übersetzung: „Arcybašev weist gewisse Gemeinsamkeiten mit Wedekind auf, wenn nicht der Natur und dem Temperament nach, so doch hinsichtlich der literarischen Problemstellungen und schließlich, zum gegenwärtigen Zeitpunkt, hinsichtlich seines literarischen Schicksals" [Übers. d. Verf.].

${ }^{62}$ I. V. Volevix, Vedekind (1968), 533. 


\subsection{Sanin}

\subsubsection{Kurzer Abriß der Handlung}

Im Zentrum der Handlung von Arcybaševs skandalumwittertem Roman steht der Titelheld Vladimir Petrovic Sanin, ein etwa 25jähriger junger Mann von athletischer Statur. Man darf annehmen, daß er aus einer verarmten Adelsfamilie stammt, wobei der Leser nur recht wenige Details aus dem Vorleben des Helden erfăhrt. Die Handlung spielt sich zu Beginn des 20. Jahrhunderts ab. Sie erstreckt sich über die Sommermonate und endet im frühen Herbst.

Der Roman beginnt mit Sanins Rückkehr in seinen Geburtsort, eine russische Provinzstadt an einem träge dahinfließenden Fluß. In der mehrjährigen Zeit seiner Abwesenheit hat sich die Titelfigur derart verändert, daß die in der Heimatstadt verbliebene Mutter Sanins sowie seine 19jăhrige Schwester Lida ihn kaum wiedererkennen. Sanins Charakter, so der Erzähler, ist inzwischen gefestigt, und er schätzt seine Freiheit über alles. So verbleibt er auch nach seiner Rückkehr in deutlicher Distanz zu der aus Angehörigen des Militärs, verbannten Revolutionăren sowie der lokalen Intelligenz bestehenden Oberschicht des Provinzstädtchens.

Sanin beobachtet amüsiert, wie sich zwischen seiner attraktiven Schwester Lida und dem Rittmeister Zarudin, einem Frauenheld, eine Affäre anbahnt, wăhrend der ebenfalls an Lida interessierte, allerdings wenig selbstbewußte Arzt Novikov das Nachsehen hat. Auch Sanins Verhältnis zu seiner Schwester ist nicht frei von erotischer Spannung. Zarudin verfuhrt schließlich Lida, lehnt aber, als diese schwanger wird, jede Verantwortung für sie ab. Lida unternimmt daraufhin einen Selbstmordversuch, wird jedoch rechtzeitig von ihrem Bruder an der Ausfuihrung ihres Plans gehindert.

Als Sanin den stutzerhaften Rittmeister kurz darauf vergleichsweise unfein des Hauses verweist, erhălt er von diesem eine Duellforderung. Sanin lehnt ab, da ihm der adelig-militărische Ehrenkodex nichts bedeutet. Wenig spăter kommt es im Stadtpark zu einer zufalligen Begegnung Sanins mit Zarudin, während derer der Offizier plötzlich mit seiner Reitgerte nach Sanin ausholt. Der Titelheld kommt ihm jedoch zuvor und streckt den Angreifer mit einem einzigen mächtigen Faustschlag zu Boden. Nach dieser Demütigung vor den Augen der kleinstădtischen Öffentlichkeit nimmt sich der Rittmeister kurze Zeit später selbst das Leben.

Parallel zu den Episoden mit Sanin und seiner Schwester entwickelt sich ein zusătzlicher Handlungsstrang um den 26jährigen Technologiestudenten Jurij Nikolaevič Svarožič, der wegen staatsfeindlicher revolutionärer Aktivităten aus Moskau in die Provinzstadt verbannt wurde. Svarožic fühlt sich von der jungen 
und attraktiven Zinaida Karsavina angezogen, und auch diese scheint einer Beziehung zu dem verbannten Studenten nicht abgeneigt zu sein. Bei einer nächtlichen Verabredung mit Karsavina versagt Svarožič jedoch im entscheidenden Moment als Liebhaber.

Nach dieser Szene, die sich in der Nähe eines Klosters auf der anderen Seite des kleinen Flusses abspielt, trifft die junge Frau zufällig Sanin, der ihr anbietet, sie über den Fluß zurück zur Stadt zu rudern. Bereits seit langem hat Karsavina unbewußt die geheimnisvolle Anziehungskraft Sanins verspürt. Während der Bootsfahrt fallen alle gesellschaftlichen und moralischen Schranken zwischen den beiden, und es kommt in der Mitte des Flusses zu einer intensiven intimen Begegnung. Obgleich Sanin nicht ernsthaft eine feste Bindung mit Karsavina erwägt, bringt die Titelfigur, anders als Zarudin, seiner Partnerin aber auch am Tag nach dem Liebesabenteuer noch Achtung entgegen.

Zur gleichen Zeit wird der Student Jurij Svarožič von tiefen Selbstzweifeln gequält, die sich noch verstärken, als er einige selbstverfaßte religiösphilosophische Aphorismen liest. Seine Unzufriedenheit mit der eigenen Person und sein Lebensüberdruß werden schließlich so groß, daß er sich unbemerkt von seinen Familienangehörigen und alles andere als entschlossen eine Kugel in die Brust schießt.

Als Svarožiz unter großer Anteilnahme der kleinstädtischen Öffentlichkeit beigesetzt wird, bittet man Sanin, am Grab einige Worte über den Verstorbenen zu sagen. Die Reaktion des Titelhelden ist voll des Spotts für den Selbstmörder. Da man ihm dies seitens der übrigen Anwesenden übelnimmt, beschließt Sanin kurzerhand, die in seinen Augen engstimige Kleinstadt baldmöglichst zu verlassen. Noch am selben Abend besteigt er einen Zug und springt unterwegs in der Steppe ab. Im Gefühl grenzenloser Freiheit schreitet er der aufgehenden Sonne entgegen.

\subsubsection{Zur Entstehungs- und Publikationsgeschichte}

Die Entstehungsgeschichte des bekanntesten unter den Arcybaševschen Romanen ist bisher nur unzureichend philologisch dokumentiert. Dies läßt sich auf zwei Faktoren zurückfuihren: Zum einen wurde das Werk des Schriftstellers aus ideologischen Gründen von der sowjetischen Literaturwissenschaft und -kritik kaum beachtet. In der westlichen Slavistik hingegen ist bis heute die Auffassung weit verbreitet, bei Arcybašev handle es sich um einen Trivialautor. So liegt bisher keine umfassende Darstellung von Leben und Werk des Autors vor ${ }^{63}$ - ein

${ }^{63}$ Ein knapper Abriß zu Leben und literarischem Werdegang Arcybałevs findet sich bei $\mathrm{N}$. Luker/ S. M. O'Dell: Mikhail Artsybashev. A ('omprehensive Bibliography (1983), $20 \mathrm{ff}$. Überarbeitet und erweitert auch in N. Luker, In Defence of a Reputation. Eascays on the Farly' 
Desiderat, dem die russische Literaturwissenschaft trotz ihrer starken biographischen Ausrichtung nach dem Kenntnisstand des Verfassers bisher nicht begegnet ist. Insofern sind Angaben zur Entstehungsgeschichte des Sanin im Rahmen dieser Arbeit nur beschränkt möglich.

Arcybašev, so berichtet Nicholas Luker, begann die Arbeit an seinem ersten großen Prosawerk bereits im Alter von 16 Jahren. Zumindest ab 1901 scheint er sich ernsthaft der Ausführung seines Romanprojekts gewidmet zu haben, wobei sein ursprünglicher Plan einen Roman mit dem Titelhelden Jurij Svorožiz vorsah. $^{64} \mathrm{DaB}$ der Autor später anstelle des unglücklichen Technologiestudenten Sanin zur Hauptfigur seines Werkes macht, hat natürlich weitreichende Auswirkungen auf die Deutung des Romans, was in einem späteren Kapitel dieser Arbeit noch thematisiert werden soll.

Bereits im Jahre 1902 bemüht sich Arcybašev mit Unterstützung des Kritikers Angel Bogdanovic sowie des Schriftstellers Aleksandr Ivanovic Kuprin (1870-1938) um eine Publikation des Textes, diesmal bereits unter dem Namen Sanin, in der von den beiden geleiteten Zeitschrift Mir božij. Allerdings kam es aus Angst vor der in Rußland zu dieser Zeit allgegenwärtigen Zensur nicht zu der geplanten Veroffentlichung. ${ }^{65}$ Arcybašev selbst nannte später 1903 als Jahr des Abschlusses der Arbeiten am Sanin und wandte sich damit gegen Deutungen, die den Roman als Reaktion auf die revolutionären Ereignisse von 1905 auslegten. ${ }^{66}$ Gleichwohl hat Baloueff darauf hingewiesen, daß im Erstdruck einige politische Verweise enthalten sind, die erst nach 1905 in den Text eingefugt worden sein können. ${ }^{67}$

Erst rund vier Jahre nach dem gescheiterten Publikationsversuch begann ab Januar 1907 die Veroffentlichung des Sanin in den Nummern 1-5 sowie 9 der Zeitschrift Sovremennyj mir. Ein Jahr später, 1908, kam die erste Buchausgabe des Romans auf den Markt, und im Jahre 1917 erschien der Sanin zum ersten Mal im Rahmen einer Werkausgabe des Autors. ${ }^{68}$ Die Veroffentlichung seines ersten großen Prosawerkes brachte Arcybašev schlagartige Bekanntheit als

Prose of Mikhail Artsybashev (1990), Iff. Weitere Details zu Arcybasevs Biographie enthält das äußerst subjektiv gehaltene Vorwor Timofej Prokopovs zur Werkausgabe von 1994. Vgl. dazu T. Prokopov, Żizni i smerti Michaila Arcybaševa (1994), 5ff.

${ }^{6}$ Zur Entstehungsgeschichte des Sanin vgl. Luker (1990), 3ff. Vgl außerdem S. Nikonenko, Michail Arcybasev (1990), 9.

${ }^{65}$ Hiervon berichtet John J. Baloueff in seiner Dissertation, in der er sich auf die Memoiren der ersten Frau Kuprins, M. K. Kuprina-Jordanskaja, stützt. Vgl. dazu J. J. Baloueff, Reflection of the Young Intelligentsia in Russian Fiction 1905-1914 (1976), $166 \mathrm{f}$.

${ }^{66} \mathrm{Vgl}$. M. P. Artzibashef [M. P. Arcybasev], Introduction (1969), 7.

${ }^{67} \mathrm{Vgl}$. dazu Baloueff (1976), 175f. Auch L'vov-Rogačevskij hat darauf hingewiesen, daß Arcybasev nach der Fertigstellung des Manuskripts 1902 noch einige Ergänzungen vorgenommen haben muß. Vgl. dazu V. L'vov-Rogacevskij, M. Arcybašev (1909), $36 \mathrm{f}$.

${ }^{68} \mathrm{Vgl}$. Luker (1990), 130. 
Prophet des Amoralismus und löste eine Reihe von öffentlichkeitswirksamen Gerichtsverfahren gegen Autor und Roman aus. Der hierdurch in der russischen Intelligenz ausgelöste Streit um den Sanin scheint sogar derartig hohe Wellen geschlagen zu haben, daß sich Maksim Gor'kij im September 1908 von der Insel Capri aus in einem Brief an den Sankt Petersburger Rechtsanwalt Oskar Osipovic Gruzenberg (1866-1940) für die Verteidigung des angeklagten Schriftstellers einsetzte. ${ }^{69}$ Obgleich ein Verbot des Sanin nicht erwirkt werden konnte, verlor Arcybašev kurz nach der Veröffentlichung des Sanin durch die von den Behörden angeordnete Schließung seinen Posten als literarischer Herausgeber der Zeitschrift Žurnal alja vsech, den er von 1904 an innegehabt hatte. ${ }^{70}$

Als Folge seiner offen antisowjetischen Haltung konnten Arcybaševs Werke nach seiner Emigration nach Warschau im Jahre 1923 jahrzehntelang nur in russischen Exilverlagen erscheinen, so da $B$ sie nur noch einer kleinen Minderheit von russischen Lesern zugänglich waren. Der Roman Sanin wurde 1969 von einem im englischen Letchworth ansässigen Verlag für Slavica in der alten russischen Orthographie und mit zahlreichen Druckfehlern nochmals aufgelegt. Dies ist die Ausgabe, in der Arcybaševs Text bis zur Gorbačev-Zeit von westlichen Slavisten rezipiert wurde. Erst im Zuge der Perestrojka wurde es im Jahre 1990 wieder möglich, eine Ausgabe des Sanin sowie ausgewählter Erzählungen in der Sowjetunion zu publizieren. Damit wurde fast sieben Jahrzehnte nach der Emigration des Schriftstellers die Literatur Arcybaševs zum ersten Mal wieder einem größeren Lesepublikum zugänglich. Im Zuge des Wegfalls der Zensur und der Aufhebung alter Tabus nach dem Zusammenbruch der Sowjetunion wurde 1994 eine dreibändige, die wichtigsten literarischen und publizistischen Texte des Autors enthaltende Ausgabe auf den Markt gebracht. ${ }^{71}$ Auf diese Edition stützt sich die vorliegende Arbeit bei Zitaten aus Arcybaševs publizistischen Schriften.

Der Ruhm des Sanin blieb nicht auf Rußland beschränkt. Innerhalb kurzer Zeit wurde der Roman in verschiedene Fremdsprachen übersetzt und erschien in Frankreich, Deutschland, Italien, Böhmen, Dänemark, Bulgarien, Ungarn und Japan. ${ }^{72}$ In Deutschland wurde der Roman in der Übersetzung von André Villard und S. Bugow bekannt, die im September 1908 in dem in München und Leipzig ansässigen Verlag Georg Müller erschien - jenem Verlag, der ab Mai 1910 auch Wedekinds Werke publizierte. Ähnlich umstritten wie in seinem Heimatland war

\footnotetext{
${ }^{69}$ Vgl. dazu 1. S. Zil'berštejn N. I. Dikušina (Hrsg.), Gor'kij i russkaja žurnalistika načala XX veka Neizdannaja perepiska (1988), 1000ff.

${ }^{70}$ Vgl. hierzu Luker (1990), 6; L. G. Vjazmitinova, Samin (1997), 362

"Vgl. M. P Arcybašev, Sanin (1969); M. P. Arcybałev, Roman. povesti, rasskazy' (1990); M

P. Arcybašev, Sobranie socinenij v trech tomach (1994).

$n$ Vgl. N. Luker, Artsybashev's Sanin A Reappraisal (1980), 58; Luker (1983), 21; Nikonenko (1990), 3.
} 
Arcybał̌evs Text auch hierzulande, wie ein Blick auf die Publikationsgeschichte des Sanin in Deutschland zeigt. ${ }^{73}$

Neben dem zeitweise gleichen Verlag verbindet den russischen Schriftsteller auch ein weiterer Umstand mit Wedekind - der erbitterte Widerstand, dem die beiden gerade seitens der Münchner Zensurbehörden ausgesetzt waren. ${ }^{74}$ So erwirkte die Münchner Staatsanwaltschaft Ende November 1908 ein Verbot des Sanin sowie die Beschlagnahmung der bereits gedruckten Exemplare „wegen Verstoß[es] gegen die Sittlichkeit". Weiter heißt es in der Urteilsbegründung: „Der Roman 'Sanin' ist geeignet, das Scham- und Sittlichkeitsgefühl eines normal empfindenden Lesers in geschlechtlicher Beziehung gröblich zu verletzen. “75 Was folgte, war ein vier Monate dauernder Rechtsstreit zwischen dem Verleger Georg Müller und dem Landgericht München, in dem als Gutachter unter anderen der bayerische Heimatschriftsteller Ludwig Ganghofer (1855-1920) auftrat. Dieser schrieb in seiner Stellungnahme:

Der mir zur Beurteilung vorgelegte Roman ist als eine dichterisch hochstehende, aus künstlerischem Geist entsprungene Schöpfung zu bezeichnen, die in der Geschichte der russischen Literatur neben den Meisterwerken von Gogol, Turgenjew, Dostojewski und Gontscharow ihren verdienten Ehrenplatz finden wird. $^{76}$

Am 26. März 1909 schließlich erhielt der Verlag Georg Müller Recht, und es erfolgte die gerichtliche Freigabe des Romans. Einige Jahre später, 1913, publizierte der Münchner und Leipziger Verlag auch einen Sammelband von Arcybaševs Erzählungen mit dem Titel Mstitel'. Sbornik rasskazov in russischer Sprache. $^{n}$

\subsubsection{Rezeptionsgeschichte und Forschungslage}

Der Name Arcybašev ist heute nur einer Minderheit von Lesern ein Begriff. Daß der Autor, dessen Roman Sanin zu Beginn des zwanzigsten Jahrhunderts einen

\footnotetext{
${ }^{73}$ Vgl. G. Müller, Der Sanin und seine Schicksale in Deutschland (1909), VII-LXX.

$74 \mathrm{Zu}$ Wedekinds literarischem Schicksal in München vgl. M. Meyer. Theaterzensur in München 1900 - 1918. Geschichte und Entwicklung der polizeilichen Zensur und des Zensurbeirates unter besonderer Berücksichtigung Frank Wedekinds (1982), 300: „Kein anderer Autor wird zwischen 1908 und 1918 so häufig mit einem Aufführungsverbot belegt und muß mit so vielen Zensurschwierigkeiten rechnen wie Frank Wedekind."

${ }^{75}$ Hier zitiert nach: Müller (1909), XVI.

${ }^{76}$ Hier zitiert nach ebd., XXXXVf.

${ }^{n}$ Vgl. Luker (1990), 131.
} 
der größten Skandale in der russischen Literatur auslöste, ${ }^{78}$ derartig in Vergessenheit geriet, kann im wesentlichen auf zwei Faktoren zurückgeführt werden: Zum einen nahm Arcybašev nach seiner Emigration nach Warschau im Jahre 1923 eine antisowjetische Haltung ein - er war einer der Herausgeber der in Warschau erscheinenden antibolschewistischen Zeitschrift $\mathrm{Za}$ svobodu. ${ }^{79}$ Dieser Schritt brachte für Arcybašev - wie für viele andere nach 1917 im Exil lebende russische Autoren auch - den Verlust des Massenpublikums im Heimatland mit sich. Zum anderen haftete dem Autor seit der Veröffentlichung seines Sanin der Vorwurf an, „Pornographie in Prosa“"80 zu schreiben sowie ein in erster Linie epigonaler Schriftsteller zu sein. ${ }^{81}$ Diese Einschätzung, die von der Forschung erst vor einigen Jahren korrigiert wurde, behinderte die Rezeption des Sanin im Westen.

Arcybašev selbst, so berichtet sein Zeitgenosse Petr Pil'skij in einem Zeitungsartikel aus dem Jahre 1927, hielt seinen Roman Sanin für ein philosophisches Werk. ${ }^{82}$ In der 1915 publizierten Einleitung zur englischen Ausgabe der Erzählung Milliony [englischer Titel: The Millionaire] beklagt sich der Autor über die seiner Meinung nach inadäquate Rezeption des Sanin und gibt gleichzeitig Auskunft uber seine Wirkungsabsicht:

Some praised the novel far more than it deserves, others complained bitterly that it was a defamation of youth. I may, however, without exaggeration assert that no one in Russia took the trouble really to fathom the ideas of the novel. [...] In case it might interest you to know what I myself think of Sanine. I will tell you that I consider it neither a novel of ethics nor a libel on the younger generation. Sanine is the apology for individualism; the hero of the novel is a type. In its pure form this type is still new and rare, but its spirit is in every frank, bold, and strong representative of the new Russia. ${ }^{83}$

\footnotetext{
78 Vgl. Luker (1980), 58

79 Arcybašev beteiligte sich aktiv am propagandistischen Kampf dieser Zeitschrift gegen die neugegründete Sowjetunion, unter anderem mit einer Kampagne für die Freisprechung des Attentäters, der 1923 den sowjetischen Unterhändler bei der Konferenz von Lausanne. den marxistischen Literatur- und Kunstkritiker Vaclav Vaclavovic Vorovskij (1871-1923), ermordete. Vgl. dazu A. A. Revjakina, Arcybał̌sev Michail Petrovic (1997), 44f Wegen Arcybaßevs antisowjetischem Engagement soll es am 3.4.1925 sogar zur Überreichung einer Protestnote an den polnischen Botschafter in Moskau durch einen Vertreter des Kommissariats für Auswärtige Angelegenheiten der UdSSR gekommen sein. Vgl dazu F Sielicki. Michal Arcybaszew w Polsce (1974), 134.

${ }^{20}$ U. Steltner, Symbolismus und Symbolik in M. P. Arcybaševs Roman Sanin (1988), 229.

${ }^{81}$ Aleksandar Flaker beispielsweise bezeichnet ArcybaŠev als "èpigone du réalisme“; A. Flaker, Avant-garde et érotisme (1988), 93.

${ }^{82} \mathrm{Vgl}$. P. Pil'skij, M. Arcybał̌ev (1994), 768.

83 Artzibashef (1969), 9.
} 
Wie kein späteres Werk des Autors löste die Veröffentlichung des Sanin eine Welle von Publikationen in der russischen Literaturkritik und Publizistik aus, wobei der Roman die russische Intelligenz bis zum Beginn des Ersten Weltkriegs in zwei Lager spaltete. Auf der einen Seite meldeten sich Leser zu Wort, die Arcybaševs Werk als Plădoyer für die freie Liebe und als Verunglimpfung der Familie ablehnten, auf der anderen Seite hingegen fand der Roman begeisterte Anhänger. ${ }^{84}$ Wie man aus André Villards Vorwort zur deutschen Ausgabe des Sanin von 1909 entnehmen kann, führte die Veröffentlichung von Arcybaševs Roman sogar zur Bildung einer Bewegung innerhalb der russischen Jugend, die unter dem Namen 'Saninisten' versuchte, die Lebensphilosophie des Titelhelden in die Tat umzusetzen. ${ }^{85}$

Als eine der ersten namhaften Figuren der russischen Literaturszene hat sich 1907 der bereits in Zusammenhang mit Wedekind erwähnte symbolistische Schriftsteller Aleksandr Blok zum Sanin geäußert. Blok bezeichnete den Roman als "geschmacklos und grob", während er Arcybasev jedoch Talent als Schriftsteller bescheinigte. ${ }^{86}$ Von der großen Wirkung, die Arcybašev mit seinem Sanin in den Kreisen der russischen Intelligenz in den Jahren vor dem Ersten Weltkrieg hatte, zeugt auch ein fiktives Kaffeehausgespräch, das Lev Trockij 1908 in den Odesskie Novosti veroffentlichte. In diesem tritt ein Journalist auf, der wortgewandt semer Ablehnung der als ариыбашевщина und санинщина bezeichneten gesellschaftlichen Phänomene - nur unzureichend als 'ArcybaKeverei' und 'Saninerei' zu übersetzen - Ausdruck verleiht und damit möglicherweise Trockijs eigene Position vertritt. ${ }^{87}$

Besonders scharfe Kritik aus dem Lager der Gegner des Sanin kam von dem Schriftsteller und Literaturwissenschaftler Kornej Ivanovič Čukovskij [eigentlich: Nikolaj Vasil'evič Kornejčukov] (1882-1969). Dieser ăußerte seine Ablehnung der weltanschaulichen Tendenzen sowie der stilistischen Machart des Romans in einem persönlichen Angriff auf Arcybasev, den er mit dem kraftlosen Romanhelden Jurij Svarožic verglich:

84 Als Beispiele für im wesentlichen ablehnende Kritiken sei hier auf folgende Arbeiten verwiesen: K. I. Cukovskij, M. Arcybał̌̌ev (3. Aufl. 1912); A. P. Omel'Čenko, Geroj nezdorovogo tworčestva. Sanin. Roman Arcybaševa (1908). Eher anerkennende Urteile über Arcybasevs Samin, vor allem wegen der Behandlung neuer, kontroverser Themien, finden sich in folgenden Publikationen: Koltonovskaja (1910); A. N. Ostrogorskij, Pedagogičeskie ikskursii v oblast' literatury. Sanin Arcybaseva. K voprosu o besedach o polovomu voprosu (1908). Eine umfangreiche Bibliographie zur Wirkung des Sanin findet sich bei Luker (1990), $135 \mathrm{ff}$.

${ }^{85} \mathrm{Vgl}$. dazu A. Villard, Vorwort (1909), LXXII. Auch Arthur Rundt spricht 1932 in seinem 'Rußlandbuch' vom Phänomen des „Ssaninismus“ [!]; vgl. dazu A. Rundt, Der Mensch wird umgebaut. Ein RuBlandbuch (1932), 146.

${ }^{86}$ Blok, Bd. 5 (1962), 120. Vgl. auch 115.

${ }^{87}$ Hier zitiert nach: L. Trockij, O smerti i ob èrose (1926), 285. 
Бедный Юрий Сварожич, симулянт сладострастия, после бессильных поползновений на девичью честь, пошел и застрелился. но разве не мог он остаться в живых, пойти в литераторы, написать роман, назвать его „Санин“" и поместить в „Современном мире “ж88

Der solchermaßen verunglimpfte Schriftsteller, so berichtet A. A. Revjakina, sandte dem Verfasser dieser Zeilen eine Forderung zum Duell, das allerdings nicht zustande kam. ${ }^{89}$

Nach seinem Erscheinen in Deutschland beschäftigte Arcybaševs Roman nicht nur die Gerichte, sondern auch die hiesige Literaturkritik und Publizistik. Als Zeugnisse dieses Interesses am Sanin sind hier die Veröffentlichungen von Paul Barchan und J. E. Poritzky zu erwähnen. ${ }^{90}$ Insgesamt gesehen zeigte sich jedoch das deutsche Publikum weniger empfänglich für den Saninschen Gestus der Rebellion gegen gesellschaftliche Normen und Wertvorstellungen als das russische, so daß an Arcybaševs Prosawerk vor allem die anschaulichen Landschafts- und Naturschilderungen gelobt wurden. ${ }^{91}$

Neben der Rezeption des Sanin in Deutschland sei an dieser Stelle auch auf eine gewisse Wirkung des Romans in Arcybaševs Exilheimat, dem nach dem Ersten Weltkrieg als Staat wiedererstandenen Polen, hingewiesen. Immerhin scheint das Interesse an Arcybasevs Text dort groß genug gewesen zu sein, um eine Verfilmung des Romans im Jahre 1925 zu ermöglichen. ${ }^{92}$ In Rußland selbst war es vor der Oktoberrevolution lediglich im Jahre 1910 zu einer Bearbeitung des Romans für die Bühne durch S. Trefilov unter dem Titel Kak žit'?! [Wie soll man leben?!; Übers. d. Verf.] gekommen. ${ }^{93}$

In den Anfangsjahren der Sowjetunion scheint sich noch keine einheitliche Haltung gegenüber Arcybašev und seinem Sanin durchgesetzt zu haben, so daß sich sowohl anerkennende Würdigungen als auch harsche Kritik finden lassen. Noch 1928 lobt beispielsweise L. Voitolovskij den bereits emigrierten

${ }^{88}$ Cukovskij (3. Aufl. 1912), 119. Übersetzung: „Armer Jurij Svarožið, Simulant der Wollust, nach den kraftlosen Angriffen auf die Ehre einer jungen Frau ging er hin und erschoß sich, aber hätte er denn nicht am Leben bleiben, unter die Schriftsteller gehen, einen Roman schreiben, ihn 'Sanin' nennen und in der Zeitschrift 'Sovremennyj mir' veröffentlichen können?' [Übers. d. Verf.].

${ }^{20} \mathrm{Vgl}$. dazu A. Rudnev, .,Ja čelovek žizmi, i tol 'ko žizmi, zemnoj, čelovečeskoj... “ (1991), 352. $\mathrm{Vgl}$ außerdem A. A. Revjakina, Arcyhašev Michail Petrovič (1993), 58.

90 Vgl. P. Barchan, Sanin und die erotische Bewegung (1909); J. E. Poritzky, Itamonische Dichter. Probleme und Porträts (1921); vgl. zu Arcybašev 465-478.

${ }^{91} \mathrm{Vgl}$. ebd. 470

${ }^{92}$ Sielicki erwähnt eine polnisch-russische Koproduktion unter der Regie von Ferdynand Feher und Boleslaw Newolin. Vgl. dazu Sielicki (1974), 133.

${ }^{93} \mathrm{Vgl}$. L. Engelstein, The Keys to Happine.ss. Sex and the Search for Modernity in Fin-deSiecle Russia (1992), 418. 
Schriftsteller in einer für die sowjetischen Schulbibliotheken vorgesehenen Literaturgeschichte wegen seines schriftstellerischen Talents und wegen seiner Angriffe gegen die 'bourgeoisen Sittenapostel'. 94 So wichtig die Ablehnung der alten Gesellschaft auch im Zuge der Suche nach einer gesellschaftichen Erneuerung in der frühsowjetischen Geistesgeschichte war, so wenig konnte sich die offizielle Ideologie auf lange Sicht mit Arcybaševs Vorschlägen anfreunden, wie ein 'neuer Mensch' auszusehen habe. So wurde Arcybasevs Sanin bereits 1923 von Kritikem wie Vaclav Vaclavovix Vorovskij als Ausdruck reaktionärer Tendenzen innerhalb der russischen Intelligenz angesehen. ${ }^{95}$ Sehr aufschlußreich für die spätere sowjetische Haltung gegenüber Arcybaševs Vorstellungen vom 'neuen Menschen' sind auch die folgenden Worte A. V. Bagrijs:

Санин оказался не новым человеком, а представителем умираюшего дворянства, нравственно-тупым человеком с ненормально развитой половой распущенностью. 96

Wegen des sowohl in der Sowjetunion als auch im Westen gefällten Verdikts der Pornographie wurde es ab den 1930er Jahren still um das skandalumwitterte Prosawerk der Jahrhundertwende. Mit Ausnahme von einer in der Sowjetunion sowie zwei im Ausland erschienenen Publikationen von 1976 sowie 1966 bzw. $1974^{97}$, die den literarischen Wert des Romans allesamt nicht besonders hoch veranschlagen, beginnt sich erst in der zweiten Hälfte der siebziger Jahre wieder Interesse für den Sanin zu regen.

Eine Vorreiterrolle übernahm hierbei die Slavistik des angelsăchsischen Sprachraums. So versuchten Sally Margaret O'Dell mit der bisher offenbar einzigen Dissertation zu Arcybaక̌evs Werk aus dem Jahre 1980 sowie der

94 Hiet zitient nach L. Voitolovskij, Oxerki istorii russkoj literatury XIX $i X X$ vekov, Bd. 2 (1969), 236ff.

${ }_{95} \mathrm{Vgl}$. V. V. Vorovskij, Bazarov $i$ Samin. Dva nigilizma (1923), 89.

96 A. V. Bagrij, Russkaja literatura XIX-go - pervoj Cetverti XX-go w. Posobie k lekcijam (1926), 292. Übersetzung: „Sanin erwies sich nicht als neuer Mensch, sondern als Vertreter des absterbenden Adels, als moralisch abgestumpfter Mensch mit einer abnormal entwickelten sexuellen Zügellosigkeit" [Übers. d. Verf.].

${ }^{97} \mathrm{Vgl}$. N. M. Zorkaja, Na rubeže stoletij. U istokov massovogo iskusstua v Rossii 1900-1910 godov (1976); T. Pachmus, Michail Artsybashev in the Criticism of Zinaida Gippius (1966); Sielicki (1974). Während Pachmus in ihrer Arbeit konstatiert, Arcybasevs Sanin sei "devoid of all literary merit" (80), bezeichnet Sielicki Arcybasev in seinem in der Volksrepublik Polen erschienenen Artikel als "czolowy literat rosyjskiego dekadentyzmu“ (131) [,führender Schriftsteller der russischen Dekadenz"; Übers. d. Verf.]. Auch Zorkaja, die ihre Kritik besonders gegen Arcybasevs Sanin richtet, außert sich in ihrer Abeit sehr abfällig über den Schriftsteller: "...Aрцыбашев есть четвое выражение 'второго' и 'третьего' сорта в литературе..." (142). Übersetzung: „....Arcybasev ist der deutliche Ausdruck 'zweiter' und 'dritter' Wahl in der Literatur... " [Übers. d. Verf.]. 
neuseeländisch-britische Slavist Nicholas Luker mit einem im selben Jahr veröffentlichten Artikel, die bisherige Einschătzung Arcybaševs als Trivialautor zu korrigieren. ${ }^{98}$ Bereits einige Jahre zuvor erschien 1976 die bereits zitierte, an der Universităt Nashville im Bundesstaat Tennessee entstandene Dissertation John J. Baloueffs mit dem Titel Reflection of the Young Intelligentsia in Russian Fiction 1905-1914. In dieser in russischer Sprache verfaßten Arbeit wird auch Arcybaševs Sanin zur Untersuchung herangezogen, wobei Baloueffs Urteile über den Roman in vielem lediglich die Meinung des bereits erwähnten Kornej Cukovskij widerzuspiegeln scheinen.

Offensichtlich ohne Kenntnis der Publikationen der angloamerikanischen Forschung bemühte sich wenig später auch Sigrid Nolda um eine Neubewertung des Textes. In ihrem Aufsatz von 1983 stellt sie fest, daß mit Arcybaß̌evs vergessenem Roman „ein hinter Klischee-Vorstellungen verborgenes Werk ans Licht gebracht werden könnte, das durch die Aktualität mancher der in ihm behandelten Fragen eine Auseinandersetzung lohnt." ${ }^{\text {"99 }}$ Als weiterer Beitrag der deutschen Slavistik zur Sanin-Forschung kann hier Ulrich Steltners Aufsatz von 1988 erwähnt werden, in dem vor allem die technische Machart des Romans untersucht wird. $^{100}$

In erster Linie mit dem philosophischen Gehalt des Sanin beschäftigen sich zwei Arbeiten von Edith W. Clowes von 1986 und 1988, in denen die Verbindung des Romans zur Philosophie Nietzsches untersucht wird. Dabei wirft Clowes dem russischen Schriftsteller, den sie zu den 'lowbrow writers' zăhlt, vor, mit Romanhelden wie Sanin zur Diskreditierung und Vulgarisierung Nietzsches bei der russischen Leserschaft beigetragen $z u$ haben. ${ }^{101}$ Nicht unerwähnt bleiben darf an dieser Stelle auch Laura Engelsteins Veröffentlichung von 1992, in der Arcybaševs Sanin in den Kontext der literarischen Massenkultur am Beginn der russischen Moderne gestellt wird. Engelstein weist auf den großen

\footnotetext{
${ }^{98} \mathrm{Vgl}$. S. M. O'Dell, Mikhail Petrovich Artsybashev (1878-1927). A ('emtemmial Presemation and Assessmem (1980); Luker (1980).

99 Nolda (1983), 386.

${ }^{100} \mathrm{Vgl}$. U. Steltner, Symbolismus und Symbolik in M. P. Arcybałevs Roman Sanin (1988).

$101 \mathrm{Vgl}$. dazu E. Clowes, The Revolution of Moral Consciousness. Nietzsche in Russian Literature, 1890-1914 (1988), 9; E. Clowes, Literany Reception as Vulgarization. Nietzsche 's Idea of the Superman in Neo-Realist Fiction (1986), 326.
} 
Einfluß hin, den Arcybaševs Sanin auf andere populäre Autoren der Zeit hatte. Vor allem gilt dies für die Journalistin und Schriftstellerin Anastasija Alekseevna Verbickaja (1861-1928), in deren sagenhafte Auflagenstärken erreichendem Roman Kljuci sčast 'ja [Die Schlüssel des Glücks; Übers. d. Verf.] (1906-1913) Bezug auf Arcybaševs Text genommen wird. ${ }^{102}$

${ }^{102} \mathrm{Vgl}$. Engelstein (1992), 405. 


\section{DER 'NEUE MENSCH' ALS GEGENENTWURF ZUM MENSCHEN DER GEGENWART}

\subsection{Vorbemerkung}

Die kulturelle und soziale Wirklichkeit des ausgehenden neunzehnten Jahrhunderts war bekanntermaßen besonders in Deutschland durch die zunehmende Verstädterung der Gesellschaft und durch das starke Anwachsen des im Zuge der Industrialisierung aufgekommenen Industrieproletariats geprägt. Vor dem Hintergrund der gestiegenen gesellschaftichen und kulturellen Bedeutung der Stadt erhielt die Suche nach dem 'neuen Menschen' und der 'neuen Gesellschaft' um die Wende zum zwanzigsten Jahrhundert auch eine geographische Dimension. Es war dies die Zeit, in der sich eine „verwirrende Vielfalt von Reformbewegungen " ${ }^{\text {"103 }}$ herausbildete, deren Gemeinsamkeit darin bestand, daß sie eine bewußte Abkehr von der Stadt als Lebensraum der Zukunft und die Hinwendung zur Natur propagierten.

Nicht zufallig liegen also gerade in jenen Jahren die Anfänge der sogenannten Natur- und Heimatschutzbewegung. Wie Rolf Peter Sieferle in seiner Arbeit gezeigt hat, handelte es sich dabei um eine Reaktion auf das starke Anwachsen der Großstädte mit ihrer Nivellierung regionaler kultureller Unterschiede sowie auf die bereits spürbaren negativen Folgen der Industrialisierung. ${ }^{104}$ Ebenso liegen die Anfänge der Jugendwanderbewegung, die ebenfalls aus einem zivilisationskritischen Impetus heraus entstand, in den 1890er Jahren. Die Ideen dieser Bewegung fanden in dem 1901 in Steglitz gegründeten Verein Wandervogel, Ausschuß für Schülerfahrten ihren organisatorischen Niederschlag. ${ }^{105}$

Zivilisationskritisches Gedankengut und besonders auch das tiefe Unbehagen gegenüber den sich planlos ausbreitenden wilhelminischen Großstädten spiegeln sich auch in der Suche nach neuen künstlerischen Lebensformen in den Jahren um die Jahrhundertwende wider. So wurden - dem Beispiel der französischen Impressionisten folgend - im ausgehenden neunzehnten Jahrhundert in verschiedenen ländlichen Gegenden Deutschlands

103 R. P. Sieferle, Fortschrittsfeinde? Opposition gegen Technik und Industrie von der Romantik bis zur Gegernwart (1984), 156.

${ }^{104} \mathrm{Vgl}$. ebd. $161 \mathrm{ff}$.

${ }^{105}$ Zur Geschichte des Wandervogels vgl. Chr. Völpel, Hermann Hesse und die deutsche Jugendbewegung. Fine IIntersuchung über die Beziehungen zwischen dem Wandervogel und Hermann Hesses Irühwerk (1977), 16ff. 
Kolonien von bildenden Künstlem gegründet. Berühmtestes Beispiel ist sicherlich die 1889 in der Nähe von Bremen inmitten ländlicher Umgebung gegründete Künstlerkolonie Worpswede. ${ }^{106}$ Besonders dem vielseitigen Maler Heinrich Vogeler (1842-1942) ist es zu verdanken, daß sich der Einfluß Worpswedes nicht nur auf die bildende Kunst beschränkte. Vielmehr trug Vogeler über Buch- und Zeitschriftenillustrationen sowie durch seine Freundschaft mit dem Schriftsteller Rainer Maria Rilke (1875-1926) dazu bei, daß die norddeutsche Künstlerkolonie auch auf die zeitgenössische Literatur ausstrahlte. Gleichwohl gab es eine ăhnliche Fluchtbewegung aus der großstädtischen Zivilisation auch in Kreisen der Literaturschaffenden: Erinnert sei in diesem Zusammenhang an den seit Ende der 1880er Jahre in Friedrichshagen bei Berlin bestehenden Dichterkreis, zu dem neben einigen anderen prominenten Literaten auch Frank Wedekind Verbindungen hatte. ${ }^{107}$

$\mathrm{Ab}$ Ende der 1890er Jahre hielt der Gedanke der Rückkehr des Menschen zur Natur auch Einzug in Architektur und Stadtplanung: Unabhängig voneinander entwarfen 1896 der deutsche antisemitische Publizist Theodor Fritsch (18521933) sowie 1898 der britische Parlamentsstenograph Ebenezer Howard (18501928) das Konzept der Gartenstadt. ${ }^{108}$ Howards unter der Bezeichnung Garden City bekanntgewordenem Versuch, als "praktisch-sozialreformerische Reaktion auf Folgen der Industrialisierung " 109 Urbanität und Natur miteinander zu kombinieren, war allerdings eine ungleich größere Wirkung beschieden als Fritschs Theorien. ${ }^{110}$

${ }^{106}$ Wietek weist auf den Einfluß von Rousseaus Philosophie und Pädagogik auf die Gründung der verschiedenen Künstlerkolonien hin. Vgl. dazu G. Wietek (Hrsg.), Deutsche Künstlerkolonien und Künstlerorte (1976), 7. Zur Künstlerkolonie Worpswede vgl. ebd. 100ff. 107 Zur Geschichte des Friedrichshagener Kreises vgl. K. Günther, Literarische Gruppenbildung im Berliner Naturalismus (1972), 123ff. Wedekind hatte in den Jahren 1889 und 1895 Kontakte zu den in Friedrichshagen lebenden Schriftstellem. Vgl. dazu G. Seehaus, Frank Wedekind mit Selbstzeugnissen und Bilddokumenten (6. Aufl. 1993), 144f. Vgl. außerdem Vinçon (1987), 40; 51

$108 \mathrm{Vgl}$. hierzu W. R. Krabbe, Gesellschafisveränderung durch lebensreform. Strukturmerkmale einer sozialreformerischen Bewegung im Deutschland der Industrialisierungsperiode (1974), 28ff.

109 Chr. De Rentiis, Zum historischen Konzept Helleraus Werkstätten. Gartenstadt und Bildungsanstalt) und den Möglichkeiten seiner ökologisch-industriell orientierten Entwicklung (1995), 28

${ }^{110}$ Der Grundgedanke von Howards Gartenstadt-Konzept, das 1903 durch die Gründung von Letchworth in Hertfortshire seine erste konkrete Realisation fand, war die Schaffung einer planmäßigen, in ihrer maximalen Ausdehnung durch einen Grüngürtel beschränkten Kleinstadt. In dieser auf Genossenschaftsbasis funktionierenden Stadt sollte die Einheit von Wohnen und Arbeiten sowie von Kultur und Natur verwirklicht sein. $\mathrm{Vgl}$. hierzu besonders das erste Kapitel in E. Howard, Garden Cities of To-Morrow (1965), 50ff. 
Mit dem Streben nach einer Rückkehr zur Natur verband sich in der Gartenstadtbewegung stets auch die Hoffnung auf eine erzieherische Wirkung. "II Obgleich nicht anzunehmen ist, daß Wedekind bereits um die Jahrhundertwende Kenntnis von Howards Ideen hatte, so zeigt der Entwurf des Parks in Mine-Haha doch deutlich, daß der Glaube an die erzieherische Wirkung der Natur zu dieser Zeit auch in den Kreisen der Literaturschaffenden verbreitet war. Nicht umsonst fand der aus England kommende Gartenstadtgedanke in Deutschland einen günstigen Nährboden: Bereits im ersten Jahrzehnt des zwanzigsten Jahrhunderts entstand vor den Toren der Stadt Dresden die erste deutsche Gartenstadt Hellerau. ${ }^{112}$ Mag Hellerau auch ,aus heutiger Sicht eine kulturhistorische Arabeske $^{\text {"113 }}$ sein, so darf dennoch der von dem gesellschaftsreformerischen Projekt ausgehende geistesgeschichtliche Impuls nicht unterschätzt werden. Durch die Bildungsanstalt des Musikpädagogen Jaques-Dalcroze und deren jährlich stattfindende Festspiele sowie einige berühmte Theaterinszenierungen im Festspielhaus zog Hellerau bis zum Beginn des Ersten Weltkriegs zahlreiche prominente Besucher an, darunter auch Frank Wedekind.

In diesem Zusammenhang kann auch auf einen weiteren Versuch hingewiesen werden, abseits vom Chaos der zeitgenössischen Großstadt einen geordneten und ästhetisch einheitlich gestalteten Lebensraum für einen 'neuen Menschen' zu schaffen - die Künstlerkolonie auf der Darmstädter Mathildenhöhe. „Eine Stadt müssen wir erbauen, eine ganze Stadt! Alles andere ist nichts! Die Regierung soll uns [...] ein Feld geben, und da wollen wir dann eine Welt schaffen", 114 hatte der Wiener Architekt Joseph Maria Olbrich (18671908) im Jahre 1897 gefordert. Gehör fand Olbrich mit seinen Ideen bei dem weltmännischen und kunstinteressierten Großherzog von Hessen und bei Rhein Emst Ludwig (1868-1937). Dieser stellte ihm einen Park am damaligen Stadtrand von Darmstadt zur Verfügung, in dem er ab 1899 seine architektonischen Vorstellungen im Geiste des Jugendstils verwirklichen konnte. Vieles von dem, was Olbrich und andere in den Jahren bis zum Ausbruch des Ersten Weltkriegs auf der Mathildenhöhe schufen, erscheint wie die architektonische Umsetzung der Beschreibung des Parks in Wedekinds Mine-Haha. Nicht umsonst nennt Dominik Jost als wesentliches Merkmal des literarischen Jugendstils die "Tatsache, daß die gesellschaftliche Wirklichkeit in ihm völlig ausgespart ist". ${ }^{\prime 15}$ "Wenn auch die

i1) Vgl. hierzu das Kapitel (jartenstadt als Erzieher in K. Hartmann, Deutsche Gartenstadtbewegung. Kulturpolitik und (jesellschaftsreform (1976), 40f.

112 Zur Geschichte Helleraus vgl. ebd., 46ff; vgl. auch De Rentiis (1995), 25ff.

${ }^{113}$ H.-J. Sarfert, Hellercu. Die (jartenstadt unul Künstlerkolonie (3. Aufl. 1995), 105.

114 Zitien nach: Magistrat der Stadt Darmstadt. Denkmalschutz - Kulturamt (Hrsg.), Die Darmstàdter Mathildenhöhe. Architektur im Aufbruch zur Moderne (1998), 9. Hier finden sich auch weiterführende Informationen zur Geschichte der Künstlerkolonie.

${ }^{113}$ D. Jost, Literarischer Jugendstil (1969), 15 
Übertragung des Begriffs Jugendstil von Kunstgewerbe und bildender Kunst auf die Literatur nicht unumstritten ist, so verweist gerade auch das Motiv der Flucht aus der Zivilisation in eine stilisierte Natur in Wedekinds Text auf parallele Phănomene in der Kunst.

In der nussischen Gesellschaft mit ihrer übermächtigen Dominanz des primären Sektors war zur selben Zeit der für Deutschland so prägende Prozeß der Verstädterung und Vermassung erst in den Anfängen begriffen. ${ }^{116}$ Gleichwohl durchlief auch das Zarenreich gegen Ende des neunzehnten Jahrhunderts eine Phase der forcierten Industrialisierung mit allen sozialen und kulturellen Begleiterscheinungen. Zudem bestanden unter dem Einfluß des in Rußland in der zweiten Hälfte des neunzehnten Jahrhunderts stark rezipierten deutschen Kulturhistorikers und Novellisten Wilhelm Heinrich Riehl (1823-1897) auch innerhalb der russischen Intelligenz zivilisationskritische Strömungen, ${ }^{117}$ deren Anliegen die Zurückdrängung des als verderblich empfundenen kulturellen Einflusses der Stadt war.

Der in den Jahren 1875-1877 erschienene Roman Anna Karenina von Lev Nikolaevic Tolstoj (1828-1910) bezeugt, daß der Gedanke der Stadt- und Zivilisationskritik auch Eingang in die Literatur des russischen Realismus gefunden hat. ${ }^{118}$ Daneben war der Gedanke der Abkehr von der Stadt und der Hinwendung zum Land auch bei der Entstehung des russischen Pendants zum deutschen Jugendstil, der unter dem Namen Modern bekanntgewordenen Kunstrichtung, von Bedeutung. Das Aufkommen jener Stilrichtung nämlich war eng mit der Gründung zweier Künstlerkolonien außerhalb der beiden Metropolen Moskau und Sankt Petersburg verbunden, wobei der Gang der Künstler aufs Land in Rußland viel stärker als in Deutschland als Ausdruck der Suche nach einer nationalen Kunst zu verstehen ist. ${ }^{119}$

${ }^{116}$ Im Jahre 1897 gehörten von der Bevölkerung des Zarenreiches 77,1 \% dem Bauernstand an, wohingegen die städtischen Stände zusammengenommen lediglich 11,1\% ausmachten. Zur selben Zeit lebten im europäischen Rußland nur 12,2\% der Bevölkerung in Städten. Zahlen nach H. Altrichter, Rußland 1917. Ein Iand auf der Suche nach sich selbst (1997), 557f.

117 Besonders sei an dieser Stelle auch auf den Einfluß der Riehlschen Großstadtkritik in der russischen Publizistik der zweiten Hälfte des neunzehnten Jahrhunderts hingewiesen. $\mathrm{Vgl}$. hierzu P. Thiergen, Wilhelm Heinrich Riehl in RuBland (1856-1886). Studien zur russischen Publizistik und Geistesgeschichte der zweiten Halfie des 19. Jahrhunderts (1978), $261 \mathrm{ff}$.

118 Indem Tolstoj in Anna Karenina die Schicksale der beiden Hauptfiguren - den Landbewohner Konstantin Levin und die in städtischen Kreisen verkehrende Titelheldin miteinander kontrastiert, läßt er allein das Landleben als Basis einer sinnerfüllten menschlichen Existenz erscheinen.

${ }^{119}$ Es sind dies die bereits 1870 von dem russischen Kunstmäzen Savva Ivanovic Mamontov (1841-1918) auf seinem Landgut in Abramcevo bei Sergiev Posad ins Leben gerufene Künstlergemeinschaft sowie der in den Anfangsjahren des zwanzigsten Jahrhunderts in Talaškino bei Smolensk begründete Künstlerkreis um die Prinzessin Marja Klavdievna Tenił̌eva (1867-1928). Vgl. dazu E. A. Borisova/ G. Ju. Sternin, Russshj Modern (1994), $16 \mathrm{ff}$. 
Dieser knappe Abriß über gesellschafts- und zivilisationskritische Strömungen in Deutschland und Rußland, die um die Jahrhundertwende eine besondere Dynamik entwickelten, soll den sich nun anschließenden Vergleich von Frank Wedekinds Mine-Haha und Michail Petrovic Arcybaševs Sanin einleiten. Im folgenden Kapitel dieser Arbeit wird die Frage im Vordergrund stehen, unter welchen Vorzeichen die zeitgenössische Gegenwart in den beiden in dieser Arbeit behandelten literarischen Werken erscheint. Von besonderem Interesse wird in diesem Zusammenhang der Gegensatz von Natur und Zivilisation sein, dem in beiden Texten eine prominente Stellung zukommt. Ziel des Vergleichs ist es, zu klären, welche Position der 'neue Mensch' im Spannungsfeld von Natur und Kultur einnimmt.

\subsection{Mine-Haha}

\subsubsection{Der Park als Gegenwelt}

In der Forschungsliteratur $\mathrm{zu}$ Mine-Haha wurde Wedekinds Text wiederholt mit dem Begriff der Utopie in Verbindung gebracht. So bezeichnen Fritz Dehnow und Manfred Hahn das Fragment als „eine utopisch-phantastische Darstellung natürlicher Menschenerziehung“ bzw. als "Gesellschaftsutopie“. ${ }^{120}$ Vivetta Vivarelli und Libuše Moniková hingegen weisen auf die Kehrseite der Utopie in Mine-Haha hin - für Vivarelli stellt Wedekinds Text eine "utopia autoritaria" dar, für Moniková eine "negative Utopie“. ${ }^{121}$ Thomas Medicus deutet das Romanfragment weniger negativ, indem er es unter der Überschrift „Uiopie der glücklichen Körper ${ }^{\text {(122 }}$ abhandelt. Tatsächlich ist ein utopisches Element in Mine-Haha unübersehbar, denn im Gegensatz zu der Außenwelt der Theaterbesucher und der Erwachsenen ist die Erziehungsanstalt im Park ganz im Sinne der Bedeutung des Begriffs Utopie ein nicht real existenter, imaginativer Ort als "Gegenentwurf zur als mangelhaft empfundenen Wirklichkeit“. ${ }^{23}$

Durch Mauern, Gitter und eiserne Tore mit vergoldeten Spitzen von der übrigen Welt hermetisch abgeschirmt, verleben hier junge Mädchen ihre streng geordnete Kindheit und Jugend. Die Erziehung zum 'neuen Menschen' verläuft bis zum Alter von ungefähr sieben Jahren gemischtgeschlechtlich, danach werden

${ }^{120}$ F. Dehnow, Frank Wedekind (1922), 102. M. Hahn, Frank Wedekind. Leben und Werk (1969), 87.

121 Vivarelli (1981), 57; Moniková (1985), 125.

122 Medicus (1982), 124 [Hervorhebung im Original].

${ }^{123}$ H. Gnüg (Hrsg.), Literarische Utopie-Entwürfe (1982), 9. 
Jungen und Mädchen bis zum Einsetzen der Pubertät getrennt. Vergleicht man das Parkleben mit den wenigen Schilderungen der Außenwelt, wie sie im Text bei der Beschreibung des Theaters sowie in Kapitel IV erscheinen, so lassen sich einige auffâllige Gegensatzpaare konstatieren: Das Leben im Park ist gekennzeichnet durch eine klare Struktur auf Grund einer rigiden Führung des Individuums, (zugegebenermaßen eingeschränkte) persönliche Kontakte zwischen den Heranwachsenden sowie die Nähe zur Natur. Demgegenüber scheinen in der Außenwelt Chaos, anonyme Massengesellschaft und naturfernes Großstadtleben vorzuherrschen.

Wie genau das Leben nach der Entlassung aus dem Park aussehen soll, läßt der Text infolge seines fragmentarischen Charakters offen. In der 1903 um Vorwort, Kapitel IV sowie Nachschrift ergänzten Version des Romanfragments jedenfalls erscheint das Verlassen des Parks am Ende des Kapitels III als Eintritt in das 'normale' Leben, ${ }^{124}$ denn die Schilderung der Großstadtkulisse in Kapitel IV trägt durchaus realistische Züge. Das Ungewöhnliche an Hidallas Leben bleibt auf die Jahre ihrer Erziehung im Park beschränkt, so daß durch die Rahmung Utopie und Realităt in Wedekinds Text ineinander übergehen. Hierzu trägt in besonderer Weise das Vorwort des fiktiven Herausgebers bei, das die Utopie des Parklebens wieder in die Realităt einbindet. Dies geschieht durch Verweise auf bekannte Orte und Ereignisse - Brasilien, Deutschland, die Schlacht nahe dem lothringischen Gravelotte im Jahre 1870 sowie eine Revolution (wohl die von 1848).

Sosehr Helene Engels Biographie auch von der anderer zeitgenössischer

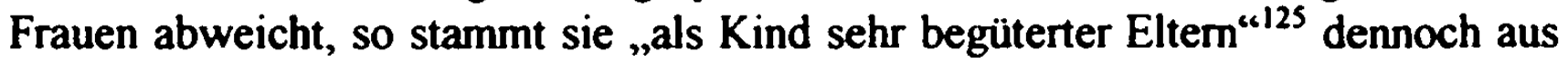
geregelten Familienverhältnissen, hat mit siebzehn Jahren gegen den Willen ihrer Familie geheiratet und war nach ihrer Rückkehr aus Amerika Lehrerin ,an einer höheren Töchterschule“ (vgl. 87). Auf ebendiese Zeit, so vermutet der Herausgeber, sei die Entstehung des Manuskripts zu datieren, das die IchErzahlerin nach eigenen Angaben in ihrem „dreiundsechzigsten Jahr“ (101), also rund zwei Jahrzehnte vor ihrem Selbstmord, niederschreibt.

Die Einbindung der pensionierten Lehrerin in die zeitgenössische bürgerliche Gesellschaft durch den fiktiven Herausgeber läßt Hidallas Lebensbericht als bloße Fiktion Helene Engels erscheinen. Wie sonst wären deren begüterte Eltern mit der Schilderung der elternlosen Erziehung in MineHaha in Einklang zu bringen? Im Spannungsverhältnis zwischen der

\footnotetext{
124 In diese Richtung geht auch die Interpretation des Schlusses in Kapps Arbeit: „Der Schluß ist wohl symbolisch zu verstehen. Der Zug durch die festlich geschmückte Volksmenge ist der Einzug ins Leben überhaupt, das dann mit der körperlichen Vereinigung der beiden jetzt $z \mathbf{z u}$ fertigen Menschen herangereiften jungen Wesen zu beginnen hätte“; Kapp (1909), 39.

${ }^{125}$ Wedekind, Bd. 3 (1969), 86. Der Einfachheit halber werden Zitate aus dieser Ausgabe von Mine-Haha fortan im laufenden Text in runden Klammern ausgewiesen.
} 
Innenperspektive Hidallas und der Außenperspektive des fiktiven Herausgebers liegt jedoch ein wesentlicher Faktor, der den Reiz des Textes ausmacht. Ortrud Gutjahr spricht in bezug auf die Rahmenhandlung in Mine-Haha von einem „erzähltechnische[n] Spiel um die hybride Autorschaft“. 126

Durch die Gestaltung der Erzăhlsituation bleibt letztendlich offen, inwieweit Wedekind die Loyalität der Ich-Erzählerin gegenüber dem in der Parkanstalt verwirklichten Erziehungsideal teilt. Helene Engels Selbstmord sowie die vorangegangenen Anfalle geistiger Verwirrung jedenfalls wurden in der Forschung teilweise als Anzeichen von Zweifeln an der Richtigkeit des hinter der Erziehungsanstalt stehenden Bildungsgedankens gedeutet. ${ }^{127}$ Diese Lesart erscheint wesentlich überzeugender als die von Elizabeth Boa in ihrer feministisch orientierten Wedekind-Studie vertretene These, Helene Engel begehe Selbstmord, da sie durch eine Einweisung in eine Irrenanstalt an der Publikation ihrer Erinnerungen gehindert werden sollte. ${ }^{128}$

\subsubsection{Die Ästhetik der inszenierten Natur - zum Enigma des Titels}

Ohne Zweifel verfügt der enigmatische Titel von Wedekinds Romanfragment über eine hohe Signalwirkung. Daß Hidallas Lebenserzählung den exotisch klingenden Namen Mine-Haha trägt, unterstreicht zunăchst die bizarre Wirkung des gesamten Textes. Auch die erst in der Ausgabe von 1903 hinzugefügte Erklärung des fiktiven Herausgebers, der Titel sei indianisch und bedeute „Lachendes Wasser" (134; Hervorhebung im Original), trägt auf den ersten Blick wenig zum besseren Verständnis des Textes bei. Was sollte mit diesem Titel gemeint sein, der offensichtlich von Hidalla selbst stammt und den auch der fiktive Herausgeber nach eigenen Angaben nur dank der Hilfe eines jungen Amerikaners entschlüsseln konnte? Ruft man sich die Tatsache in Erinnerung, daB die Verfasserin des Manuskripts in Brasilien gelebt haben und dort Indianerkinder unterrichtet haben soll (vgl. 87), so erscheinen die vier exotischen Silben als Verweis auf den ungewöhnlichen Lebensweg der verstorbenen Lehrerin, der so gar nicht dem der durchschnittlichen bürgerlichen Frau des neunzehnten Jahrhunderts entspricht.

Möglicherweise besaß der Titel für den zeitgenössischen Leser eine größere Aussagekraft als für den heutigen, denn wie man aus der Forschungsliteratur erfahren kann, entnahm ihn Wedekind aus dem Versepos The Song of Hiawatha

${ }^{126}$ Gutjahr, Mit den Hüften denken lernen? (Typoskript), 3.

${ }^{127} \mathrm{Vgl}$. Medicus (1982), 128f. Vgl. dazu auch Vieth (1939), $23 \mathrm{f}$.

$128 \mathrm{Vgl}$. dazu Boa (1987), 192. 
des amerikanischen Schriftstellers Henry Wadsworth Longfellow (1807-1882) aus dem Jahre $1855 .{ }^{129}$ Dieses Werk war bereits ein Jahr später in einer deutschen Übersetzung erschienen, ${ }^{130}$ und die Existenz zahlreicher bis zur Jahrhundertwende erschienener deutscher Ausgaben läßt auf die große Beliebtheit schließen, der sich Longfellows Epos allem Anschein nach bei deutschen Lesern erfreute. Offensichtlich war in gewissen Kreisen der bürgerlichen Gesellschaft die Bekanntschaft mit den Figuren aus dem Longfellowschen Text so groß, daß sogar eine Züricher Jugendfreundin Wedekinds den Namen Minehaha tragen konnte. Auf Wedekind scheint der Name eine große Faszination ausgeübt zu haben, denn er griff ihn in Form des Pseudonyms Cornelius Minehaha auf, unter dem er 1895/96 als Rezitator auftrat. ${ }^{131}$ Zudem ist unter dem Titel Bethel eine erst posthum veröffentlichte Pantomime Wedekinds überliefert, in der der Name ein weiteres Mal auftaucht. ${ }^{132}$

In Longfellows The Song of Hiawatha erscheint der Name, geschrieben als Minnehaha, in Zusammenhang mit der Tochter eines Pfeilmachers vom Stamm der Dakota-Indianer. In diese verliebt sich Hiawatha, der dem Stamm der Ojibwa angehörende Held des Epos, und schließlich wird sie seine Frau. Minnehaha ist bei Longfellow der Inbegriff der wilden Naturschönheit:

In the land of the Dacotahs

Lives the Arrow-maker's daughter,

Minnehaha, Laughing Water,

Handsomest of all the women. ${ }^{133}$

Indem die Geliebte und spătere Frau Hiawathas nach einem - im übrigen realen Wasserfall ${ }^{134}$ benannt wird, wird sie in The Song of Hiawatha zum Sinnbild der unbezwingbaren Natur stilisiert.

$129 \mathrm{Vgl}$. hierzu Fechter (1920), 55. Vgl. dazu auch Kapp (1909), 36 sowie, als aktuellere Forschungsarbeit, R. Kieser, Amerikanische Motive im Werk Benjamin Franklin Wedekinds (1992), 375.

${ }^{130}$ Es erschien 1856 in Leipzig in der Übersetzung von A. Böttger unter dem Titel Das Lied won Hiawarha.

131 Vgl. dazu Manfred Hahns Kommentar in Wedekind, Bd. 3 (1969), 653

$132 \mathrm{Vgl}$. Kieser (1992), 375. Die Pantomime Bethel ist abgedruckt in: Wedekind, Werke, Bd. IIV/1 (1996), 91ff. Mine-Haha ist hier der Name eines Indianerhăuptlings. Was die Entstehungszeit der Pantomime anbelangt, so nennt Hartmut Vinçon das Frühjahr 1897. Vgl. dazu Wedekind, Werke, Bd. IIL/2 (1996), 803.

${ }^{133}$ H. W. Longfellow, The Poems of Longfellow (1944), 180.

134 Die Minnehaha Falls befinden sich am Rand der Stadt Minneapolis im US-Bundesstaat Minnesota. Ihr Name wird übrigens bereits in der Quelle, die Longfellow für sein Epos heranzog, fälschlicherweise als Laughing Water übersetzt. Tatsächlich handelt es sich bei dem Ausdruck um ein allem Anschein nach erst von den weißen Siedlem geschaffenes Kompositum, dessen Bestandteile in der Sprache der Sioux-Indianer 'Wasser' (minne) sowie 
Durch den aus Longfellows Epos entliehenen Titel Mine-Haha wird also eine Beziehung hergestellt zwischen Hiawathas Geliebter bzw. Frau und der weiblichen Hauptfigur in Wedekinds Romanfragment, Hidalla bzw. - in der erweiterten Ausgabe von 1903 - Helene Engel. Für diejenigen Leser Wedekinds, die Longfellows Epos kannten, mußte der Titel wie die Formulierung eines neuen Erziehungs- und Entwicklungsideals klingen - das der wilden Naturschönheit, die fernab der bürgerlichen Zivilisation des neunzehnten Jahrhunderts aufgewachsen ist. Die Tatsache, daß Hiawathas Geliebte und Frau in Longfellows The Song of Hiawatha nach einem Wasserfall, einem Naturphänomen also, benannt ist, läßt die Natur selbst in Wedekinds Text als Ziel der menschlichen Entwicklung erscheinen.

Auf den ersten Blick erweckt der Park in der Tat den Eindruck einer grenzenlosen Natürlichkeit. Neben den Kindern beherbergt er auch Tiere wie Rehe, Hasen und Fische, und mit seinen Wäldern, Sümpfen, Wiesen „so weit das Auge reichte“ (98) sowie dem sich scheinbar endlos erstreckenden breiten Bach scheint er von ungeheuren Ausmaßen zu sein. Im Laufe von Hidallas Erzählung wird dieser Eindruck jedoch korrigiert. So hat der Fluß eine Schleuse - der Beschreibung nach ist wohl eher ein Wehr gemeint (vgl. ebd.) -, und außerdem erkennt Hidalla, daß der Park von Mauern umgeben ist. Verschiedene Beobachtungen zeigen der Erzählerin, daß es offensichtlich auch eine Realität außerhalb der Parkmauern gibt: Bei einem Spaziergang mit Pamela entdeckt Hidalla einen Vogelbeerbaum, der von außen über die Parkmauer reicht (vgl. 114), und später sieht sie einen Raben, der auf der Mauer sitzt (vgl. 115).

Es wird also deutlich, daß es sich um eine eingefangene, vom Menschen gestaltete Natur, um eine "inszenierte Parklandschaft“, 135 handelt. Die Gestaltung der Natur als Prinzip des Parks findet ihre Entsprechung in der Erziehung der Zöglinge. So ist das im I. Kapitel von Mine-Haha beschriebene früheste Stadium der Erziehung durch die größte Nähe zur Natur gekennzeichnet. In diesem Erziehungsabschnitt spielt das Baden und Spielen im Wasser eine große Rolle, und den Mädchen und Knaben ist es erlaubt, die meiste Zeit barfuß zu gehen. Die Schnürschuhe, Symbol der Bezwingung der Natur, müssen bis zum Alter von vier Jahren gar nicht und danach nur zu den körperlichen Übungen getragen werden (vgl. 90). Ebenso werden auch Kleider nur zum Essen und zu den Übungen angezogen.

Auch die Gebäude, in denen die Edukanden bis zur Geschlechtertrennung untergebracht sind, zeichnen sich durch eine relativ große Nähe zur Natur aus: Das erste Haus, in dem insgesamt dreißig Kinder wohnen, ist nur einstöckig, hat Blumen vor den Fenstern sowie ein hohes, teilweise mit Moos bewachsenes

'Wasserfall' (haha) bedeuten. Vgl. dazu W. Upham, Minnesota (jeographic Names. Their Origin and Historic Significance (1969), 230.

135 Medicus (1982), 170. 
Schieferdach, „das sich in den Wipfeln der Bäume verlor" (89). Das Wohnhaus im zweiten Erziehungsabschnitt hat bereits zwei Stockwerke, und beim Theater schließlich handelt es sich um ein dreistöckiges, fensterloses Gebäude aus gelbem Backstein (vgl. 108), das nur über unterirdische Verbindungswege - einen Gang vom Weißen Haus aus und eine Untergrundbahn von der Stadt aus - zugänglich ist.

Die Zöglinge der Erziehungsanstalt werden also im Laufe ihres Aufenthalts im Park allmählich immer stärkeren Einflüssen der Zivilisation ausgesetzt offensichtlich mit dem Ziel, sie auf ihr Leben außerhalb der Parkmauem vorzubereiten. Das Verhältnis zwischen Text und Titel ist in Mine-Haha insofern keinesfalls so eindeutig, wie es auf den ersten Blick erscheinen mag. Wie noch in einem späteren Kapitel darzustellen sein wird, bestehen auffällige Widersprüche zwischen der scheinbar im Titel erhobenen Forderung nach natürlicher Schönheit und dem pädagogischen Programm der von Hidalla beschriebenen Erziehungsanstalt.

\subsubsection{Zwischen Gesellschaftskritik und Bürgerlichkeit}

Bei einer Untersuchung der Haltung, die in Frank Wedekinds Text zur zeitgenössischen bürgerlichen Gesellschaft eingenommen wird, ergeben sich im wesentlichen zwei Probleme. Z.um einen ist nochmals daran zu erinnern, daß in Mine-Haha nur ein Teil von Wedekinds ursprünglichem Romanplan verwirklicht ist. Eine Behandlung auch der Jahre nach dem Einsetzen der Pubertät hätte natürlich ein anderes Porträt der Gesellschaft, als es sich in dem fragmentarischen Text gestaltet, sowie offensichtlich einen noch stärkeren Konflikt mit den wilhelminischen Moralvorstellungen und damit mit den Zensurbehörden zur Folge gehabt. $^{136}$

Zum anderen hindert die Erzählhaltung in Mine-Haha den Leser daran, aus Wedekinds Text eine eindeutige Botschaft herauszulesen, was den Reiz der Beschäftigung mit dem Romanfragment allerdings eher steigert, als daß es ihn mindert. Seit der Ergänzung des Textes im Jahre 1903 erscheint Mine-Haha als ein von einem fiktiven Herausgeber, der sich selbst als Autor von Frühlings Erwachen bezeichnet, veröffentlichtes Manuskript. Bei diesem erzähltechnischen Kunstgriff handelt es sich, wie Wagener zu Recht festgestellt hat, um ein besonders in der Epik des 19. Jahrhunderts beliebtes Authentisierungs- und Distanzierungsverfahren. ${ }^{137}$

\footnotetext{
${ }^{136} \mathrm{Vgl}$. hierzu Medicus (1982), 174ff.

137 Vgl. Wagener (1979), 54
} 
Schwierigkeiten bei der Gleichsetzung des in Mine-Haha entworfenen Erziehungsprogramms mit Wedekinds eigenem Standpunkt ergeben sich außerdem aus einem weiteren Umstand: Auf der Grundlage des veröffentlichten Textes ist letztlich nicht eindeutig zu klären, inwieweit die Ich-Erzählerin mit der vierundachtzigjährigen Zimmernachbarin des fiktiven Herausgebers, die im Vorwort als Verfasserin des Manuskripts bezeichnet wird, identisch ist. Auffällig ist zunächst die Verschiedenheit der Namen - der Herausgeber bezieht sich auf eine pensionierte Lehrerin mit dem Namen Helene Engel, die Ich-Erzählerin des Manuskripts wird jedoch von ihren Gefährtinnen Hidalla genannt. Letztere erwăhnt in ihren Aufzeichnungen mit keinem Wort eine Tätigkeit als Lehrerin. Statt dessen spricht sie davon, im Alter von etwa 28 Jahren - offensichtlich zum Zwecke des Broterwerbs - Kleider entworfen zu haben (vgl. 108). ${ }^{138}$ Tatsächlich gibt der fiktive Herausgeber in seiner Nachschrift zu, im Nachlaß der verstorbenen Helene Engel keinen Hinweis auf den Inhalt des Manuskripts gefunden zu haben (vgl. 135). Es bleibt also unklar, welche Beziehung genau zwischen Wedekind und Helene Engel bzw. Hidalla besteht.

Bereits zu Beginn ihrer Aufzeichnungen distanziert sich die Ich-Erzählerin deutlich von der Idee der Emanzipation der Frau, indem sie den Gedanken, eine Schriftstellerin zu sein, weit von sich weist. Selbst eine Prostituierte stehe in ihren Augen höher als eine Frau, die ihren Lebensunterhalt durch Journalistik oder Schriftstellerei verdiene ( $\mathrm{vgl}$. 88). Vielmehr sei es die völlige Verschiedenheit ihres eigenen Werdegangs von dem der sie umgebenden Frauen, die sie zur Niederschrift ihrer Erfahrungen veranlaßt habe. Aus dem Bewußtsein der eigenen Inkongruenz heraus ergibt sich für die Ich-Erzählerin eine kritische Haltung der zeitgenőssischen Gesellschaft und Zivilisation gegenüber:

Indessen bin ich vielleicht gerade durch jene unglaublichen Lebenslagen $\mathrm{zu}$ der überlegenen Weltanschauung gelangt, von der aus mir heute unsere gesamte menschliche Kultur als eine ziemlich fragwürdige Errungenschaft erscheint (133).

Trotz ihrer kritischen Distanz zur zeitgenössischen Kultur und trotz ihres unbürgerlichen Lebenslaufes ist allerdings darauf hinzuweisen, daß die IchErzählerin selbst durchaus ein Teil der bürgerlichen Gesellschaft ist. So erwähnt sie Rücksichten ihrem in „kleinlichen Verhältnissen“ (88) lebenden Sohn Edgar gegenüber, auf Grund derer ihre Aufzeichnungen möglicherweise nicht veröffentlicht werden könnten.

Auch einige Details in der Vorrede zeigen, daß die Erzählerfigur selbst in der bürgerlichen Gesellschaft verwurzelt ist: Vom Tod ihres ersten Mannes

138 Auch der Titel eines unvollendeten Romanprojekts vom Ende der 1890er Jahre - Hidalla oder Das leben einer Schneiderin - suggeriert, daß Hidalla eine Schneiderin sei. Vgl. dazu Kutscher (1964), 205. 
erfährt sie aus der Wochenzeitschrift Gartenlaube - jenem Inbegriff kleinbürgerlicher Kultur in der zweiten Hälfte des 19. Jahrhunderts. Des weiteren läßt sich der Name der pensionierten Lehrerin, Helene Engel, als ironischer Verweis auf Helene Lange (1848-1930) deuten. ${ }^{139}$ Bei letzterer handelte es sich um einen der führenden Köpfe der Frauenbewegung und um die Mitautorin des Handbuchs der Frauenbewegung (1901ff.) - um eine schreibende Frau also, über die Wedekind bereits am 1. Juni 1889 in seinem Berliner Tagebuch notiert hatte: „Eine Broschüre von Helene Lange über Frauenstudium droht, mich den Humor verlieren zu lassen."140 Wie der fiktive Herausgeber in Mine-Haha dem Leser mitteilt, habe er bei dem Treffen mit der Vierundachtzigjährigen von „irgendwelcher Parteinahme für die Ziele der heutigen Frauenbestrebungen [...] aus ihren Worten nichts entnehmen“ (87) können. Wedekind, der selbst der zeitgenossischen Frauenbewegung bekanntermaßen eher ablehnend gegenüberstand, ${ }^{141}$ spielt hier offensichtlich mit widersprüchlichen Signalen.

Sehr aufschlußreich für die uneindeutige Position der Ich-Erzählerin zwischen Bürgerlichkeit und Anti-Bürgertum ist auch ein genauerer Blick auf die Theaterszenen des III. Teils. Das Theater bildet gewissermaßen die Schnittstelle zwischen Außenwelt und der hermetisch von ihr abgeriegelten 'pädagogischen Provinz'. Zweifelsohne macht das Publikum der abendlichen Vorstellungen, das sich aus der Gesellschaft von außerhalb des Parks rekrutiert, in Hidallas Erzăhlung einen brutalen und primitiven Eindruck. Mathes ist daher der Meinung, daß Wedekind im Theaterpublikum „die Gesellschaft demaskiert, die sich durch gedankenlose Manipulation dieser Mädchen Genüsse an der Grenze zur Obszönităt verschafft. " ${ }^{142}$ So einfach verlaufen jedoch die Fronten zwischen Park und Außenwelt nicht, denn schließlich ist an die Tatsache zu erinnem, daß die Erzăhlerin mit ihrem Eintritt ins Erwachsenenleben selbst ein Teil dieser "besinnungslosen, wollusttrunkenen, rohen Menschenwelt" (132) wird und als Zuschauerin auf der anderen Seite des Gitters sitzt. Gerade die Offenlegung der ökonomischen Verflechtungen zwischen Park und Außenwelt - aus den Einnahmen des Theaters werden die Unterhaltskosten der Erziehungsanstalt bestritten (vgl. 122) - zeigt deutlich, daß die Grenzen zwischen realer Gesellschaft und der Utopie einer besseren Gesellschaft in Mine-Haha nicht klar gezogen werden.

\footnotetext{
$139 \mathrm{Vgl}$. hierzu Höger (1981), 181.

${ }^{140}$ F. Wedekind, Die Tagebücher (1986), 47.

141 Kapp hat in seiner Arbeit von 1909 bereits auf Wedekinds kritische Haltung au den Anliegen der Frauenbewegung aufmerksam gemacht. Vgl. dazu Kapp, 106ff. Als neuere Veröffentlichung vgl. auch Muylaert (1985), $49 \mathrm{ff}$.

${ }^{142}$ Mathes (1982), 370.
} 
Es bleibt also festzuhalten, daß die Figur der fiktiven Verfasserin des Manuskripts Helene Engel durch die erwähnten ironischen Verweise und die Widersprüche in ihrer Biographie offensichtlich zwischen Bürgerlichkeit und Rebellion angesiedelt wird. In dieser Uneindeutigkeit scheint sich die Position Wedekinds selbst widerzuspiegeln, der einerseits das bürgerliche Publikum mit seinen Stücken und Balladen schockierte, andererseits jedoch aus dessen Lust am Skandal geschickt Kapital zu schlagen verstand. Damit verliert der Gestus der Ablehnung der bürgerlichen Gesellschaft viel von seiner Emsthaftigkeit und wird im wesentlichen zu einer spielerisch gestalteten Denkfigur. Insofern seien Zweifel angemeldet an der von Hans Wagener vertretenen Behauptung, die in Mine-Haha literarisch verarbeitete Idee der Schaffung eines 'neuen Menschen' durch eine radikale Umgestaltung des Erziehungsprozesses sei Wedekind „bitterer Emst ${ }^{\text {“143 }}$ gewesen.

\subsection{Sanin}

\subsubsection{Natur anstelle von Zivilisation}

Naturbeschreibungen nehmen in Arcybaševs Text einen auffällig breiten Raum ein. Offensichtlich wurde Arcybašev durch seine Studienzeit an der Char'kover Schule für Zeichnung und Malerei [russische Bezeichnung: Харьковская Школа Рисования и Живописи] nachhaltig beeinflußt, denn die Naturbeschreibungen im Sanin weisen einen ausgesprochen bildhaften Charakter auf. ${ }^{144}$ Ein Großteil der Romanhandlung findet unter freiem Himmel statt, und immer wieder werden entscheidende Ereignisse in der Handlung durch ausführliche Schildenungen der umgebenden Natur begleitet bzw. eingerahmt - man denke etwa an die Bootspartie (V-VI), Lidas Selbstmordversuch (XIX), die Verfürung Karsavinas durch Sanin (XXXVIII) sowie Sanins Weggang am Ende des Romans (XLVI). Eine besondere Rolle spielen bei den Naturbeschreibungen auch Schilderungen der von der Natur ausgehenden Geräusche und Gerüche, so daß sich oft eine synästhetische Mischung der verschiedenen Sinneseindrücke ergibt.

143 Wagener (1979), 54.

it $\mathrm{Vgl}$. hierzu Luker (1980), 74f. L'vov-Rogað̌evskij geht sogar so weit, Arcybałev als 'Monet der russischen Literatur' zu bezeichnen. Vgl. dazu L'vov-Rogačevskij (1909), 28. Bei den Naturbeschreibungen handelt es sich um denjenigen Aspekt an Arcybasevs Werk, der sogar von Kritikem der Saninschen Lebensphilosophie in der Regel als gelungen bezeichnet wird. Vgl. dazu z. B. Poritzky (1921), 470. 
Bei der Lektüre des Sanin fallen eine Reihe von Naturphänomenen auf, die sich leitmotivisch durch den gesamten Text ziehen. Das sicherlich auffäligste unter ihnen ist der Fluß, mit dem mehrere entscheidende Stationen im Handlungsplan des Romans in Zusammenhang stehen. Daneben ist das Motiv des Waldes sowie auch das des Gartens der Familie Sanin zu nennen. Die Beschreibung des letzteren, der in zahlreichen Kapiteln des Romans als Kulisse für die Handlung fungiert, zeigt deutlich, daß es sich um einen Naturraum handelt, der nur zu einem geringen Grad von Menschenhand gestaltet ist. Über den Garten heißt es zu Anfang des Romans, daß er einer dunkelgrünen Wolke gleiche, die sich auf der Erde niedergelassen habe, und es ist von dem in ihm zu beobachtenden natürlichen Verfall und unvermeidlichen Absterben die Rede (I, $22 ; 9)^{145}$.

Nicht ohne Bedeutung ist sicherlich auch der Umstand, daß der Garten eine direkte Verbindung zum Fluß hat, der an zahlreichen Stellen der Handlung als Sinnbild der Natürlichkeit und elementaren Urkraft der Natur erscheint. So findet die skandalträchtige Verfürung Karsavinas durch Sanin in Kapitel XXXVIII nicht ohne Grund - gewissermaßen im Einklang mit der kosmischen Natur - in einem Ruderboot auf dem Fluß statt. Verstärkt wird die Symbolik der Entgrenzung noch durch die Kulisse des geheimnisvollen nächtlichen Waldes sowie Karsavinas Wunsch, ihren Hut ins Wasser zu werfen und ihr Haar zu öffnen (XXXVIII, 282; 348).

Weitere leitmotivisch auftretende Naturphänomene sind neben dem Fluß auch die Himmelskörper Sonne, Mond und Sterne. Bereits zu Anfang des Romans wird hier das Naturphänomen der Sonne mit Freiheit assoziiert, so daß das Motiv der Sonne den Roman gewissermaßen einrahmt, wenn Sanin im letzten Kapitel der aufgehenden Sonne entgegengeht (XLVI). Die Sonne wird damit zum Inbegriff der Freiheit, der Kraft und des Lebens stilisiert, und durch die symbolische Vereinigung Sanins mit ihr erscheint sie in Arcybasevs Text als Vorbild, nach dem der 'neue Mensch' streben soll. Insofern kann man im Sanin durchaus, wie Steltner es getan hat, von einem „Kult der 'Sonne' ${ }^{\text {‘c/46 }}$ sprechen.

Die quasi-religiöse Verklärung des Himmelskörpers Sonne war um die Jahrhundertwende ein beliebtes Motiv in Literatur und bildender Kunst - man denke etwa an die lyrische Erzăhlung Sonnenopfer des deutsch-polnischen Schriftstellers Stanislaw Przybyszewski (1868-1927) bzw. an die Illustrationen

145 Zitate aus Arcybasevs Samin erfolgen in dieser Arbeit in Klammern im laufenden Text, wobei die römische Ziffer auf das Kapitel verweist, die arabische jedoch auf die Seitenzahl in folgender Ausgabe: M. P. Arcybašev, Teni utra. Roman, povesti, rasskazy (1990); die kursiven arabischen Ziffern verweisen auf die entsprechende Seite in Stefania Goldenrings deutscher Übersetzung: M. Artzibaschew [Michail Petrovið ArcybaSev], Ssanin. Aus dem Russischen übersetat von Stefania Goldenring (o. J.).

${ }^{146}$ Steltner (1988), 233. 
des der deutschen Freikörperkultur nahestehenden Zeichners Fidus [eigentlich: Hugo Höppener] (1868-1948). ${ }^{147}$ Mit Blick auf die slavophile Tradition in der russischen Geistesgeschichte läßt sich Sanins Verschmelzen mit der aufgehenden Sonne am Ende des Romans auch als programmatische Abwendung von den okzidentalen Wertehierarchien und religiös-philosophischen Denkmustern und als Rückbesinnung auf die eigene slavische Tradition deuten.

Interessant ist in diesem Zusammenhang, mit welchen Eigenschaften Natur und Naturphänomene im Sanin in Verbindung gebracht werden. Sehr gut läßt sich das am Beispiel des Kapitels untersuchen, in dem beschrieben wird, wie Ivanovs Onkel Petr Il'ic die verlassene Datschenkolonie besucht (XLII). Hier lassen sich verschiedene Topoi der romantischen Literatur erkennen, wie etwa die Natur als Verkörperung des Geheimnisvollen und Erhabenen - beispielsweise ist die Rede von 'unbegreiflichen, geheimnisvollen Schriftzeichen' („непонятные таинственные письмена“) (XLII, 376; vgl. 302 [Übers. d. Verf.]). Daneben werden der Natur auch fast naiv anmutende anthropomorphe Eigenschaften zugeschrieben, wenn es heißt, der Fluß schreibe geheimnisvolle Schriftzeichen bzw. er erhebe sich lachend über den Berg. ${ }^{148}$ Es kommt also zu einer Aufhebung der Grenzen zwischen Mensch und Natur.

Der Gedanke, daß der Mensch ein Teil der Natur ist, wird in den Äußerungen des Titelhelden immer wieder aufgegriffen - so etwa in Sanins Unterhaltung mit Jurij Svarožič, Petr Il'iž und Ivanov nach dem Tod des Studenten Semenov: Im Gespräch zieht Sanin eine deutliche Parallele zwischen Mensch und Natur, wobei er sich gegen die Annahme ausspricht, im Gegensatz zum Menschen sei die Natur gut:

- Что ж природа, - слабо улыбаясь, махнул рукой Санин. - Ведь это так только принято говорить, что прнрода совершенна... А по правде говоря, она так же плоха, как и человек: кахдый из вас, без особого напряхеняя фантазия, может представить себе мир во сто раз лучше того, что есть... $(\mathrm{XII}, 100)^{149}$

${ }^{147}$ Przybyszewskis Sonnenopfer wurde zuerst veröffentlicht in Pan 3 (1897/98), 219ff. In einer kürzeren Fassung nochmals abgedruckt in S. Przybyszewski, Studienansgabe. Werke, Aufzeichmungen und ausgewählte Briefe in acht Bänden und einem Kommentarband, Bd. 1 (1990), 77ff. Der Zeichner Fidus war einer der berühmtesten deutschen Buch- und Zeitschriftenillustratoren der Jahrhundertwende. Das Motiv der kultischen Verehrung der Sonne findet sich in zahlreichen seiner Zeichnungen, u. a. in seinen Sonnenambetern von 1901; abgebildet in: J. Hermand, Der Schein des schönen Lebens. Studien zur Jahrhundertwende (1972), 73. Hier findet sich auch ein mit vielen weiteren lllustrationen versehener Abriß über die ebenso interessante wie skurrile Biographie des Malers und Zeichners ( $55 \mathrm{ff}$ ).

${ }^{148}$ XLII, 302: „Река смеялась над горой, вся дрожа голубым и серебристым смехом, а гора хмурилась, и деревья шумели."

149 Übersetzung: „'Was ist mit der Natur?' wehrte Ssanin mit der Hand ab und lächelte müde.' Es ist doch nur eine Gewohnheit zu sagen, daß die Natur vollkommen ist. ... In Wirklichkeit ist 
Wie noch zu einem späteren Zeitpunkt in dieser Arbeit näher ausgefuihrt werden soll, ist aus dieser Aussage jedoch nicht die Schlußfolgerung abzuleiten, die Natur sei per se grausam und somit liege Grausamkeit in der Natur des Menschen. Vielmehr propagiert der Roman über die Beschreibung des Verhaltens des Titelhelden eine Annäherung des Menschen an die Natur durch die Rückbesinnung auf die eigenen Wurzeln.

Ein Blick auf das Figurenensemble des Romans zeigt, daß die beiden männlichen Hauptfiguren des Romans auch in bezug auf ihre Haltung der sie umgebenden Natur gegenüber sehr unterschiedlich charakterisiert werden. So befreit Sanin während einer Unterhaltung mit Ivanov und Svarožič einen Schmetterling, der hilflos an der Fensterscheibe auf- und niederflattert (XII, 102; 112). Kurz darauf empfindet er Mitleid für die von Jurij Svarožič und dessen zukünftigem Schwager Rjazancev auf der Jagd erlegten Enten (XIII, 109; 121). Sanin wird also unverkennbar als eine Figur gezeichnet, die in einer Art „organic bond with nature“lso steht. Demgegenüber wird betont, daß sich Svarožič im Gegensatz zum Titelhelden nicht im Einklang mit der Natur befindet: Hin- und hergerissen von inneren Zweifeln, ob er seine Schwester über die heimlichen Bordellbesuche ihres Verlobten aufklären soll, zertritt er im Garten einen Frosch (XIV, 118; 132). Die Bestürzung, die dieses Ereignis bei dem Technologiestudenten auslöst, offenbart ein Grundproblem Jurij Svarožičs - die Unfähigkeit, auch den Tod als Teil der Natur zu begreifen.

Trotz der erkennbaren Faszination für die Natur und alles Natürliche muß angemerkt werden, daß in Arcybaševs Roman nicht alle Tiere mit positiven Konnotationen behaftet sind. Bereits zu Anfang des Romans vergleicht der Erzăhler in einem seiner vielen auktorialen Einschübe Sanins Mutter Mar'ja Ivanovna mit einer Ameise sowie ihr Leben mit einer Kaserne (II, 24; 1I). Bezeichnenderweise erscheint die Ameise, bekanntermaßen ein in einer festen sozialen Ordnung mit ausgeprägter Arbeitsteilung lebendes Insekt, nicht als Vorbild für den im Sanin propagierten Typus des 'neuen Menschen'. Später bezeichnet Sanin seine Mutter in Gedanken als "Tier" („животное“; XXVIII, 202; 242), als er bemerkt, daß sie immer noch den traditionellen Moralvorstellungen anhängt. Neben der Ameise erscheint auch das Rind als domestiziertes (und damit nach der Logik des Sanin pervertiertes) Tier nicht in einem positiven Licht. So bezeichnet Lida den Rittmeister Zarudin, der jede Verantwortung für ihre Schwangerschaft von sich weist, als 'Mistvieh' (скотина, vgl. XVII, 142 [Übers. d. Verf.]; vgl. 164). Dieses Wort wird im

sie ebenso schlecht, wie der Mensch; jeder von uns ist, selbst ohne besondere Anstrengung der Phantasie, imstande, sich eine Welt vorzustellen, die hundertmal besser wäre, als die jetzige" (XII, 110).

${ }^{\text {iso }}$ Luker (1980), 67. 
letzten Kapitel des Romans noch einmal aufgegriffen, als Sanin im Zugabteil beobachtet, wie ein anderer Fahrgast seine Frau mißhandelt (vgl. XLVI, 316; 396). ${ }^{151}$

Nicht ohne Grund spielt sich die Handlung des Romans in einer (relativ naturnahen) Provinzstadt ab, für deren Beschreibung sich Arcybašev, wie Luker vermutet hat, ${ }^{152}$ das Städtchen Achtyrka zum Vorbild genommen haben könnte, und nicht in einer der beiden Metropolen Moskau bzw. Sankt Petersburg. Städte erscheinen in Arcybaševs Text eindeutig in einem schlechten Licht, da sie mit all dem in Verbindung gebracht werden, was im Kontext des Romans als negativ bewertet wird - mit zivilisationsgeschädigten und lebensunfähigen Studenten, die sich politisch engagieren, sozialen Spannungen sowie mit den als moralisch verdorben charakterisierten Vertretern des Militärs.

Bezeichnenderweise erfăhrt der Leser über den Titelhelden zu Anfang des Sanin, daß dieser eine Abneigung gegen große Städte habe und deshalb die Freiheit des Landlebens vorziehe:

Большгие города, с их торопливым шумом и суетливой цепкой жизнью, опротивели ему. Вокруг были солнце и свобода, а будущее не заботило его, потому что он готов был принять от жизни все, что она могла дать ему (II, 23). ${ }^{153}$

Nicht die von der Zivilisation überformte Stadt also, sondern das naturnahe Land mit seiner traditionellen Lebensweise wird als der Lebensraum angesehen, in dem sich der 'neue Mensch' entwickeln kann. Damit weist Arcybaševs Roman von seiner ideologischen Ausrichtung her eine deutliche Parallele zu den in Deutschland und anderen westeuropäischen Lăndern um die Jahrhundertwende verbreiteten zivilisationskritischen Bewegungen auf.

151 Die von Stefania Goldenring gewählte Übersetzung des russischen Worts сxоmина als „Bestie“ (XVII, 164) und „Biest“ (XLVI, 396) zerstört den im Original erkennbaren Sinnzusammenhang zwischen domestizjertem Tier und 'perversem' Verhalten dem anderen Geschlecht gegenüber.

$152 \mathrm{Vgl}$. Luker (1980), 60. Auch wenn biographische Details für die vorliegende Untersuchung des Sanin wenig relevant sind, sei an dieser Stelle dennoch darauf verwiesen, daß in Evgenij Agafonovs Beschreibung der ukrainischen Heimat Arcybasevs - der Kleinstadt Achtyrka und ihrer Umgebung - zahlreiche reale Orte erwähnt werden, die der Leser unschwer im Samin wiederfinden kann - der Fluß Vorskla, die zahlreichen Gärten, ein Stadtpark, ein Boulevard, ein Kloster mit Herberge usw. Vgl. hierzu E. Agafonov, Vospominamija o M. P. Arcybaševe (1994), $761 \mathrm{ff}$.

153 Übersetzung: „Die großen Städte mit ihrem hastigen Lärm und dem unruhigen [zu ergänzen: „zähen“; Anm. d. Verf.] Leben waren ihm widerwärtig geworden. Um ihn war Sonne und Freiheit, um die Zukunft machte er sich keine Sorge, denn er war bereit, vom Leben alles zu empfangen, was es ihm geben konnte" (II, $I I)$. 
Im Gegensatz zu den übrigen handelnden Personen des Romans wird Sanin als eine Figur gezeichnet, die in der Lage ist, sich weitestgehend von den Beschränkungen der menschlichen Zivilisation zu befreien. Wohin diese Haltung letztlich führen muß, wird noch zu einem spăteren Zeitpunkt eingehender zu untersuchen sein. Jedenfalls scheinen Sanin Zweifel in der Art derer, die seinen Gegenspieler Jurij Svarožič quälen, völlig fremd zu sein. In der Eindimensionalität seiner Psyche gleicht Sanin eher einem Kind als einem erwachsenen Menschen. So heißt es über den Titelhelden denn auch zu Beginn des Kapitels XXIII, als dieser die Geschichte vom einsamen Tod eines alten Geistlichen liest: „Санин читал, думал, шевелил губами и был похож на большого маленького мальчика, углубившегося в книгу“ (XXIII, 169). ${ }^{154}$

Es ist dies eine der wenigen Szenen der Romanhandlung, in denen der Leser Sanin in einem geschlossenen Raum sieht. Allerdings wird bei der Beschreibung der gesamten Szene betont, daß zwischen Sanins Zimmer und der umgebenden Natur lediglich ein sehr geringer Unterschied besteht. Die Năhe des Titelhelden zur Natur ist ein Thema, das sich durch Arcybaševs gesamten Text zieht. So wird Sanin zu Beginn des Romans mit einem Baum verglichen, der sich in freier Natur ohne Einfluß von außen entfalten konnte $(1,19 ; 5)$ - eine Textpassage, die in Zusammenhang mit der Analyse des pădagogischen Programms des Sanin noch von zentraler Bedeutung sein wird. Kurz darauf heißt es, daß das Schilf am Flußufer Sanin 'wie seinesgleichen' begrüße (vgl. I, 23; 10).

Besonders deutlich wird die enge Verbindung des Titelhelden zur Natur auch in der Szene, als Sanin und Ivanov am Fluß heimlich Karsavina mit einer Gruppe von jungen Frauen beim Baden beobachten und schließlich von einem Gewitter überrascht werden. Bereits hier wird Sanin gewissermaßen eins mit der mächtigen Natur, indem er versucht, das Krachen des Donners mit seiner Stimme zu übertönen:

Когда опять сверкнула молния, всем сушеством ошущая жизнь и силу, Саннн раскинул руки и во все горло долго и протяжно и счастливо захричал навстречу грому, с гулом и грохотом перехатываюшемуся по небу из конца в конец могучего простора $(\mathrm{XXXV}, 259) .{ }^{155}$

Im Gegensatz zum Titelhelden hat Ivanov, wie in der besagten Szene erwăhnt wird, Angst vor Gewittern.

154 Übersetzung: „Ssanin las, grübelte, bewegte die Lippen und sah einem großen, kleinen Jungen ähnlich, der sich in sein Buch versenkt hatte" (XXIII, 198).

13s Übersetzung: „Als wieder ein Blitz aufleuchtete, breitete Sanin, der mit seinem ganzen Wesen ein Gefühl des Lebens und der Kraft verspürte, die Arme aus und brüllte aus voller Kehle lange und anhaltend und glücklich dem Donner entgegen, der dröhnend und krachend über den Himmel vom einen Ende des mächtigen Raums zum anderen rollte “ [Übers. d. Verf.] (vgl. XXXV, 317) 


\subsubsection{Abrechnung mit den alten Eliten}

Neben den Naturbeschreibungen nehmen philosophische Diskurse einen vergleichsweise breiten Raum im Samin ein. In ihnen werden die Weltanschauungen einzelner Figuren miteinander kontrastiert, wobei alle Gespräche letzten Endes den Zweck zu verfolgen scheinen, die Lebensphilosophie des Titelhelden zu offenbaren. Es fält auf, daß mit Ausnahme der beiden differenzierter gezeichneten Hauptfiguren Sanin und Jurij Svarožič alle übrigen Figuren stark typisiert sind. Die durch das Nebeneinander von russischer und ukrainischer Kultur geprägte Kleinstadt sowie deren ländliche Umgebung bilden gewissermaßen eine Bühne, auf der die Eliten der zeitgenössischen russischen Gesellschaft um die Jahrhundertwende zusammengebracht werden. Das Zusammentreffen mit verschiedenen Vertretern von Adel, Militär, Lehrerschaft, Industriellen, Studenten und Geistlichkeit bietet für den Titelhelden die Moglichkeit, mit dem 'alten Menschen' ins Gericht zu ziehen und seine Vorstellungen von einem 'neuen Menschen' darzulegen.

Äußerst negativ werden in Arcybaševs Text die Vertreter des Militärs gezeichnet, wobei der Autor hier an eine Traditionslinie in der russischen Literatur anknüpft. ${ }^{156}$ Unter den verschiedenen im Roman auftretenden Angehörigen der Armee fält besonders der Rittmeister Viktor Sergeevic Zarudin auf, der Sanins Schwester Lida verführt und schwăngert, im nachhinein jedoch jede Verantwortung für sein Handeln ablehnt. Keinesfalls scheinen Frauenbeziehungen von dieser Art dem zu entsprechen, was im Sanin in bezug auf die neuen Beziehungen zwischen den Geschlechtem propagiert wird. Nicht nur in ihren Beziehungen zum weiblichen Geschlecht, sondern auch zu den übrigen Menschen ist das Verhalten der Vertreter des Militärs durch Unaufrichtigkeit geprägt. Besonders gut ist dies an Tanarovs Verhalten Zarudin gegenüber zu erkennen: Nachdem letzterer von Sanin in der Öffentlichkeit durch einen Faustschlag ins Gesicht gedemütigt wurde, distanziert sich Tanarov von seinem ehemaligen Kameraden, um seine eigene Reputation nicht zu gefâhrden (vgl. XXXI).

Der Rittmeister Zarudin wird trotz seiner attraktiven Erscheinung als zutiefst unfreier Mensch gezeichnet. Als er nach seinem Streit mit Sanins Schwester auf Veranlassung des aus Sankt Petersburg angereisten Vološin das Haus der Sanins aufsucht, um vor seinem Kameraden mit seiner Geliebten zu prahlen, heißt es über Zarudin: „Временами он прямо ненавидел Волошина, но шел за ним, как прикованный, не имея сил показать свою настояшую душу“

${ }^{156}$ Vgl. Luker (1980), 71. 
(XXVIII, 203). ${ }^{157}$ Als Zeichen von ausgesprochener Unfreiheit wird auch der Ehrenkodex der militärischen Elite dargestellt, der Zarudin vorschreibt, vom Titelhelden Satisfaktion zu verlangen, als dieser ihn zur persona non grata im Haus der Sanins erklärt (vgl. XXXVIII, 205; 245). Zarudin als Vertreter des Militărs verstößt also gegen die von Sanin propagierten Grundsätze der Natürlichkeit, Freiheit und Aufrichtigkeit, und Zarudins Selbstmord im Kapitel XXXII läßt sich gleichermaßen als vernichtendes Urteil über den gesamten Soldatenstand deuten. ${ }^{158}$

Als pauschales Urteil über eine Gruppe in der vorrevolutionären russischen Gesellschaft kann auch ein weiterer Selbstmord, der des jüdischen Mühlenbesitzers Solovejcik, interpretiert werden. Nicht nur das Schicksal Solovejxiks im Sanin, sondern auch Schildenungen von Zeitgenossen Arcybaševs zeigen deutlich Spuren des in Rußland an der Wende zum zwanzigsten Jahrhundert so verbreiteten Antisemitismus: Wie aus den Erinnerungen des mit dem Schriftsteller befreundeten Arztes Evsej Markovic Aspiz (1877-1968) hervorgeht, soll Arcybašev ihm gegenüber in einer Unterhaltung gesagt haben: „Знаете, [...] верно предсказал Достоевский, пророчески написал он в своем дневнике, что Россия погибнет от жидов.“"159

Weitestgehend negativ fallt auch die Zeichnung der Vertreter der Geistlichkeit aus, wie sie am Krankenbett des schwindsüchtigen Studenten Semenov in Erscheinung treten. Wiederum beginnt die negative Charakteristik des Klerus bereits bei der Beschreibung des äußeren Frscheinungsbildes: „Отворилась дверь, и застучали дробные старческие шаги. Пришел маленький и толстенький священник с псаломщиком, худым и черным человеком“ $(\mathrm{X}, 88) .{ }^{160}$ Aus der Schildenung der sich anschließenden Sterbeszene geht deutlich hervor, daß der institutionalisierte Glauben, wie er von den beiden anwesenden Vertretern der orthodoxen Kirche repräsentiert wird, dem Sterbenden keine Unterstützung bieten kann.

Der Adel wird im Sanin als eine in einem Prozeß der Auflösung und fortschreitenden Vermischung mit dem Bürgertum befindliche Schicht porträtiert. So wird das Grundstück, auf dem das Herrschaftshaus der Familie Sanin steht, allmählich von der Natur zurückerobert. Daß die frühere Elite des Staates in

157 Übersetzung: „Bisweilen haßte er Volołin geradezu, aber er lief hinter ihm her, als sei er an ihn gekettet, und hatte nicht die Kraft, seine wirkliche Seele zu zeigen" [Übers. d. Verf.] (vgl. XXVIII, 242).

${ }^{158} \mathrm{Vgl}$. dazu Ostrogorskij (1908), 11.

${ }^{159}$ E. Aspiz, Vospominamija o M. P. Arcybał̌eve (1991), 359. Übersetzung: „Wissen Sie, [...] Dostoevskij hat es richtig vorhergesagt, prophetisch schrieb er in seinem Tagebuch, daß Rußland an dem Judengesindel zugrunde gehen wird" [Übers. d. Verf.]

160 Übersetzung: „Die Tür offnete sich, und wie Staccato ertönten die Schritte eines alten Mannes. Ein kleiner, dicklicher Priester kam mit einem Psalmensänger, einem mageren, schwarzen Menschen" [Übers. d. Verf.] (vgl. X, 95). 
Arcybaševs Roman ihre ursprüngliche Bedeutung eingebüßt hat, zeigt auch das Schicksal der zweiten adeligen Familie des Romans, der des Grundbesitzers Nikolaj Egorovið Svarožic (Jurijs Vater): Ihr steht mit der geplanten Heirat zwischen Ljalja und dem Arzt Anatolij Pavlovič Rjazancev die Verbindung mit einem Vertreter der sogenannten разночинцы, jener im Laufe des 19. Jahrhunderts immer mehr an Bedeutung gewinnenden nichtadeligen Intellektuellen, bevor. Gleichwohl geht Rjazancev einem traditionellen Zeitvertreib des russischen Adels nach - der Jagd.

Demgegenüber wird das Leben der Bauem im Sanin naturnäher dargestellt als das der städtischen Bevölkerungsschichten. Besonders deutlich wird dies an den für Arcybaševs Text so wichtigen Beziehungen zwischen den Geschlechtern. So hat der alte Bauer Kuz'ma, bei dem Jurij Svarožic und sein Schwager in spe Rjazancev nach ihrem Jagdausflug verweilen, nichts gegen eine vorübergehende Affäre Sanins mit seiner Enkelin einzuwenden (vgl. XIII, 111; 123). Mit seiner positiven Bewertung des Landlebens nähert sich der Sanin weltanschaulich an die Positionen der russischen Slavophilen an, obgleich für diese das promiskuitive Verhalten des Titelhelden keinesfalls akzeptabel gewesen wäre.

Auffallend positiv im Vergleich zu den übrigen männlichen Nebenfiguren wird auch der Lehrer Ivanov gezeichnet, Sanins Freund und treuer Gefolgsmann. ${ }^{161}$ Mit langen Haaren und breiten Schultern erinnert der Lehrer an die Recken auf den Bildern des Malers Viktor Michajlovix Vasnecov (18481926). Stiche nach dessen Gemälden zieren die Wände in Ivanovs Zimmer, das, wie es im Text heißt, eher einer Rumpelkammer als einem Raum zum Wohnen gleiche (XII, 98; 107). In zahlreichen philosophischen Diskursen erweist sich Ivanov als Anhänger einer unverkennbar an Nietzsche angelehnten Weltanschauung, und er spricht sich in Anlehnung an Nietzsches Figur des Zarathustra für die Rechte des Individuums gegenüber der Masse aus. Von Jurij Svarožið wird er deshalb verăchtlich als 'Übermensch' („сверхчеловек“; XXXVIII, 272; 334) bezeichnet. Trotz der weitgehend positiven Zeichnung des Lehrers wird betont, daß Ivanov nach Sanins Weggang aus der Kleinstadt nicht in der Lage ist, sich in der gleichen Weise von allen Beschränkungen des Lebens durch die Gesellschaft zu befreien wie der Titelheld. Nach dem Abschied von Sanin ist er lediglich fähig, ins Wirtshaus zu gehen, um dort seinen Abschiedsschmerz im Alkohol zu ertränken: „ЗЗапить, что ли?’ - спросил он

161 Luker hat Ivanov als 'Jünger' (disciple) Sanins bezeichnet, während er in dem Student Safrov einen 'Jünger' Jurij Svarožixs sieht; vgl. Luker (1980), 68. Bereits davor hatte Baloueff Ivanov als 'treuen Gefolgsmann' („верный последователь“) Sanins bezeichnet. Vgl. dazu Baloueff (1976), 160. 
себя, и бледный длинный призрак долгой бесцветной жизни пошел с ним в трактир“ $(\mathrm{XLV}, 315){ }^{162}$

Anhänger einer festgefügten Weltanschauung zu sein wird in Arcybaševs Roman nicht als positive Eigenschaft bewertet. ${ }^{163}$ So wird beispielsweise Lev Nikolaevix Tolstojs christlich-pazifistische Lehre in der Figur des offensichtlich dem deutschen Adel entstammenden Offiziers Jakov Adol'fovic fon Dejc [von Deitz] parodiert. Dieser spricht sich in philosophischen Gesprächen für den Verzicht auf Gewalt aus, was ihn jedoch nicht daran hindert, Sanin gemeinsam mit Tanarov als Zarudins Sekundant eine Forderung zum Duell zu überbringen (vgl. XXIX).

In einem außerst ungünstigen Licht wird in Arcybaševs Roman auch die sozialistische Bewegung dargestellt. Diese erscheint im Text in Form des von dem Studenten Gožienko geleiteten Lese- und Debattierzirkels (vgl. XXV). Derartige, oft von Studenten und Angehörigen der Intelligenz geleitete Kreise bildeten sich in den Jahren um die Jahrhundertwende vielerorts in Rußland, als die von vielen Intelligenzlern aus dem linken und liberalen Spektrum erhofften politischen und sozialen Neuerungen auch nach der Krönung Zar Nikolajs II im Jahre 1894 ausblieben. ${ }^{164}$ Die karikaturistischen Züge bei der Zeichnung des Studenten Gožienko sowie der ergebnislose Verlauf des konspirativen Treffens machen jedoch deutlich, daß der 'neue Mensch' der Botschaft des Sanin zufolge nicht aus der organisierten Reform von Staat und Gesellschaft heraus entstehen kann.

\subsection{Zusammenfassung}

Sowohl bei Mine-Haha als auch beim Sanin handelt es sich um Versuche, dem in der europäischen Geistesgeschichte zu Beginn unseres Jahrhunderts vielfach beobachtbaren Streben nach einem Paradigmenwechsel literarisch Ausdruck zu verleihen. In beiden Fällen bildet die Opposition zum Bestehenden, d. h. zu den Werten und Lebensformen der Gesellschaft der Jahrhundertwende, die Grundlage

162 Übersetzung: „Vielleicht sollte ich erst einmal einen trinken gehen?', fragte er sich selbst, und das blasse, dünne Gespenst eines langen, farblosen Lebens ging mit ihm ins Wirtshaus“ [Übers. d. Verf.] (vgl. XIV, 395).

${ }^{163}$ Diese Feststellung triff auch Baloueff in seiner Dissertation. Vgl. dazu Baloueff (1976), 151.

${ }^{164} \mathrm{Vgl}$. aur innenpolitischen und gesellschaftichen Situation in Rußland unter Zar Nikolaj II G. Stökl, Russische Geschichte. Von den Anfängen bis zur Gegerwart (5. Aufl. 1990), 559ff. $\mathrm{Vgl}$. dazu außerdem J. N. Westwood, Encturance and Endeawour. Russian History 1812-1986 (3. Aufl. 1987), 145ff. 
für die Propagierung des Neuen. Bezeichnenderweise erstreckt sich die sowohl bei Wedekind als auch bei Arcybašev erkennbare Kritik an der bestehenden Gesellschaft auch auf zeitgenössische Reformbestrebungen - auf die Frauenbewegung in Mine-Haha bzw. auf die studentischen Revolutionsbewegungen in Rußland im Sanin.

Aus dem Gestus der Ablehnung des Gegenwärtigen heraus ist es zu erklären, daß sich in beiden Texten zahlreiche Gegensatzpaare finden lassen. Einige von ihnen wurden in den vorangegangenen Abschnitten dieser Arbeit bereits angesprochen - so etwa der auffallige Gegensatz von Zivilisation und Natur in beiden Texten, der Gegensatz von Parkleben und Außenwelt sowie von Ordnung und Chaos in Mine-Haha bzw. der Gegensatz von Freiheit und Unfreiheit sowie von Leben und Tod im Samin.

Trotz dieser grundsätzlichen typologischen Verwandtschaft der beiden literarischen Zeitzeugnisse hat die Gegenüberstellung des vorangegangenen Kapitels dieser Arbeit auch einige auffällige Unterschiede zutage gefordert. Der wohl gravierendste ist die unterschiedliche Erzahlsituation, und wie so oft zeigt sich hier, welch weitreichende Folgen die erzähltechnische Gestaltung eines literarischen Werkes auf seine Deutung hat. Durch die Einbettung von Hidallas Bericht in einen Erzählrahmen in der Textversion von 1903 vergrößert sich der Abstand zwischen Ich-Erzählerin und Autor. So wird der Leser durch die bei der Zeichnung der Hauptfigur unübersehbare Ironie sowie durch Widersprüche zwischen Vor- bzw. Nachwort und Helene Engels Manuskript an der Gleichsetzung von Figurenperspektive und Textaussage gehindert.

Was Wedekinds Verhältnis zu seinen Figuren anbelangt, so mag man an eine häufig zitierte Passage aus dem Aufsatz Begegnung mit Josef Kainz von 1915 denken, wo es heißt: „Keiner Person in meinen Stücken habe ich jemals meine eigenen Äußerungen in den Mund gelegt. " 165 Was der deutsche Schriftsteller hier in bezug auf seine dramatischen Werke feststellt, läßt sich sicherlich auch als Warnung vor einer vorschnellen Gleichsetzung von Figurenund Autorenperspektive in den literarischen Prosaschriften verstehen. Durch die im Rahmen spürbare ironische Distanz zwischen dem fiktiven Herausgeber und der Ich-Erzählerin verweigert sich Wedekinds Text einer eindeutigen Lesart. Die Behauptung Gittlemans, bei Mine-Haha handle es sich um "Wedekind's personal statement of how to bring up young women", 166 zeugt von einer völligen Mißachtung der erzăhltechnischen Besonderheiten des Fragments.

In erzähltechnischer Hinsicht besteht ein deutlicher Gegensatz zwischen Wedekinds Prosafragment und Arcybasevs Roman, da im Sanin zahlreiche auktoriale Erzählerkommentare den Eindruck erwecken, der Titelheld diene

${ }^{165}$ Wedekind, Bd. 3 (1969), 267. Zitiert z. B. bei J. Schröder-Zebralla, Frank Wedekinds religiöser Sensualismus. „Die Vereinigung won Kirche und Freudenhaus?” (1985), 161.

${ }^{166}$ Gittleman (1969), 130. 
letztendlich in erster Linie als Sprachrohr für die Anschauungen seines Schöpfers Arcybašev. Luker hat insofern Sanin nicht zu Unrecht als "a mouthpiece for the author's views “ ${ }^{167}$ bezeichnet. Neben dem Vorwurf der Pornographie sowie des Amoralismus wurde Arcybašev sowohl von der Literaturkritik als auch von der Literaturwissenschaft deshalb hauptsächlich vorgehalten, daß sein Sanin ein „propagandistischer, um Eindeutigkeit der Aussage (zu) deutlich bemühter Roman“168 sei. Die vergleichsweise grob und unkünstlerisch erscheinende Machart des Sanin steht jedoch durchaus in Einklang mit der Aussage von ArcybaSevs Text: Propagiert wird der radikale Bruch mit der alten Wertehierarchie und der Anbruch einer neuen Zeit - versinnbildlicht durch Sanins Verschmelzen mit dem Sonnenaufgang über der Steppe im letzten Kapitel.

So eindeutig Arcybaševs Roman auch in seiner Ablehnung des Bisherigen ist, so sind die Hinweise darauf, wie genau man sich die neue Zeit vorzustellen habe, dennoch äußerst vage. Auch hierin unterscheiden sich die beiden untersuchten Texte deutlich, denn in Wedekinds Text scheint die neue Zeit, von der Sanin noch träumt, bereits angebrochen. Allerdings versuchte Wedekind durch die Rahmenhandlung in der Ausgabe von 1903, die Utopie wieder in die zeitgenössische Realităt einzubetten. Möglicherweise kann man dies als Ausdruck des Zweifels an der Durchführbarkeit der in Mine-Haha skizzierten Pläne zur Erziehung eines 'neuen Menschen' deuten. Jedenfalls führt die Rahmung von Hidallas subjektiver Erzählung dazu, daß Wedekinds Fragment den Eindruck eines ironischen Oszillierens zwischen Gesellschaftskritik und Affirmation der Gesellschaft erweckt - ein Gestus, der im Sanin mit seinem auktorialen Erzähler gänzlich fehlt. In Arcybaševs Roman findet Gesellschaftskritik in erster Linie in Form einer negativen Zeichnung der staatstragenden gesellschaftlichen Gruppen statt.

${ }^{167}$ Luker (1980), 63. Daß Arcybałev seinem Sanin größtenteils seine eigenen Anschauungen in den Mund gelegt hat, zeigt sich auch in seiner Abhandlung Propoved' $i$ žizn [Die Predigt und das Leben; Übers. d. Verf.]. In dieser berichtet der Schriftsteller davon, wie er einem jungen Mädchen, das sich an ihn mit der Frage wandte, wozu sie leben solle, fast denselben Rat gibt, den Sanin in Kapitel XXXII dem jüdischen Mühlenbesitzer Solovejcik erteilt; vgl. dazu M. P. Arcybašev, Sobranie sočinenij v trech tomach, Bd. 3 (1994), $743 f$.

${ }^{168}$ Nolda (1988), 389. 


\section{DER ‘NEUE MENSCH’ ZWISCHEN KÖRPER UND GEIST}

\subsection{Vorbemerkung}

An der Wende zum zwanzigsten Jahrhundert kam im wilhelminischen Deutschland in weiten Teilen von Kunst und Gesellschaft ein starkes Interesse am menschlichen Körper auf. Nicht umsonst entstand gerade in jenen Jahren eine gesellschaftliche Bewegung, die sich die "Wiederentdeckung des Körpers in einem ganzheitlichen Sinne" ${ }^{\text {(169 }}$ zum Ziel gemacht hatte. Bei der auch unter den Bezeichnungen Nudismus bzw. Naturismus bekanntgewordenen Freikörperkultur-Bewegung handelt es sich ebenso wie bei der bereits erwähnten Siedlungsreformbewegung in erster Linie um eine Reaktion auf die Wohn- und Lebensverhältnisse des modernen Großstadtmenschen. Die Aktivisten der Freikörperkultur traten für eine Befreiung des Menschen von der strengen Kleiderordnung des wilhelminischen Kaiserreichs ein, woran sie die Hoffnung auf eine Wiedergewinnung der verlorengeglaubten Einheit mit der Natur knüpften.

Die Freikörperkulturbewegung entwickelte sich in Deutschland zu Beginn des zwanzigsten Jahrhunderts zu einer verwirrenden Vielfalt unterschiedlicher Strömungen, zumal zahlreiche Vermischungen mit anderen lebensreformerischen und zivilisationskritischen Bewegungen stattfanden - so beispielsweise mit dem Vegetarismus oder der Wandervogelbewegung. Obgleich innerhalb der Freikörperkultur auch sozialistische Ansätze bestanden, handelte es sich bei diesem gesellschaftlichen Phänomen eher um eine rückwärtsgewandte, konservative Erneuenungsbewegung. Bei einigen Vertretern, wie etwa Richard Ungewitter (1868-1958), mündete die Verkultung des schönen und gesunden Körpers bereits in eine völkische Nudistenbewegung mit offen rassistischen Zielsetzungen. Bereits in den ersten Jahren des zwanzigsten Jahrhunderts trat mit dem sogenannten Mittgart-Bund, dessen Anliegen die 'Züchtung' von arischen Rassemenschen war, eine extreme Ausprägung des Körperkults der Jahrhundertwende auf den Plan. ${ }^{170}$

Wie Arthur Kutscher berichtet, praktizierte Frank Wedekind selbst Nacktkultur und Körpergymnastik, ${ }^{171}$ was trotz aller Distanz zu zeitgenössischen Reformbewegungen von einem gewissen Interesse an den Ideen der

${ }^{169}$ U. Linse, Zeithild Jahrhundertwende (1989), 16. In diesem Aufsatz finden sich weitere Informationen zur Entstehung der FKK-Bewegung.

170 Näheres zu diesem von dem sächsischen Fabrikanten und Chemiker Willibald Hentschel gegründeten Verein bei J. Frescot, Die Lebensteformbewegung (1976), 147.

${ }^{i 71} \mathrm{Vgl}$. Kutscher (1927), 130. 
Freikörperkultur zeugt. Auf die Verbindungslinien zwischen Mine-Haha und der Nudistenbewegung der Jahrhundertwende wurde in der Wedekind-Forschung insofern zu Recht hingewiesen. ${ }^{172}$ Kutscher vermutet, daß die 1904 in der Presse lebhaft diskutierten Bestrebungen des Mittgart-Bundes Wedekind als Anregung zu seinem im gleichen Jahr in Buchform erschienenen Drama Hidalla oder Sein und Haben (ab 1911: Karl Hetmann, der Zwerg-Riese) diente. ${ }^{173}$

Aus dem wenigen vorliegenden biographischen Material zu Michail Petrovic Arcybašev geht nicht hervor, daß sich der russische Schriftsteller mit dem Gedankengut der von Deutschland ausgehenden Nudistenbewegung auseinandersetzte. Gleichwohl weist gerade sein skandalträchtiger Roman Sanin mit seiner erkennbaren Faszination des schönen Körpers sowie der immer wieder postulierten Einheit des menschlichen Körpers mit der umgebenden Natur auffallige gedankliche Parallelen zur deutschen Freikorperkultur auf.

Nicht nur die großstadt- und zivilisationsfeindliche Nudistenbewegung zeugt jedoch von einem um die Jahrhundertwende neu erwachenden Interesse am menschlichen Körper. Vielmehr wird dieses auch in der Malerei und Skulptur des sogenannten Jugendstils sichtbar - einer vom Kunstgewerbe vor allem auf die Architektur und bildende Kunst ausstrahlenden Erneuerungsbewegung, die ihre Bezeichnung von der 1896 begründeten Zeitschrift Jugend erhielt. ${ }^{174}$ Gerade die Darstellung des unbekleideten tanzenden Frauenkörpers erfreute sich in Malerei und Graphik des Jugendstils besonderer Beliebtheit, aber auch der männliche Akt spielte bei zahlreichen Künstlem wie etwa dem bekannten Maler und Graphiker Fidus eine gewisse Rolle. ${ }^{175}$ Ebenso entdeckte auch die fest im großstädtischen Milieu verankerte Bühnenkunst jener Jahre den nackten Körper - man denke etwa an den Ausdruckstanz der Amerikanerin Isadora Duncan, die ab 1900 von Paris aus die Bühnen Westeuropas eroberte und bereits 1904 auch in RuBland zum ersten Mal zu Gast war. ${ }^{176}$

${ }^{17}$ Vgl. dazu H. A. Glaser, Arthur Schnitzler und Frank Wedekind. Der doppelköpfige Sexus (1974), 173: „Solch raffinierte Sublimation mit dem Körper rückt die freisinnige Mädchenerziehung in die Nähe der asexuellen Freikörperkultur, die alte Prüderie auf neuem Niveau wiederholt."

${ }^{173} \mathrm{Vgl}$. Kutscher (1964), 215.

${ }^{174}$ Zur Entstehung des Begriffs und zur Entwicklung des Jugendstils in Deutschland vgl. J Mathes (Hrsg.), Theorie des literarischen Jugendstils (1984), 5ff. Vgl. außerdem A. Duncan, Art Nowreau (1994), 27ff. Mathes (18) weist darauf hin, daß zwischen dem Jugendstil und der sich in den zeitgenössischen Künstlerkolonien manifestierenden Zivilisationskritik eine enge Verbindung bestand

${ }^{175}$ Man vergleiche dazu die Abbildungen bei Hamann/ Hermand (2. Aufl. 1975), 201; 470ff.

${ }^{176} \mathrm{Zu}$ Leben und Wirkungsgeschichte Isadora Duncans vgl. G. McVay, Isadora and Esenin. The Story of Isadora Duncan and Sergei Esenin (1980). Eine in Kutschers Biographie veröffentlichte Regieanweisung Wedekinds zu seinem 1912 im Druck erschienenen Drama Franziska zeigt, daß der Dichter Isadora Duncans Tanzstil gut kannte. Vgl. dazu Kutscher, Bd. 3 (1931), 135: „Karaminka [eine Figur in Franziska; Anm. d. Verf.] ist nicht etwa à la 
Wenn also um die Jahrhundertwende die Rede vom 'neuen Menschen' ist, so geht es auch und vor allem um ein neues Verhältnis zum Körper. Insofern ist es naheliegend, die Position des 'neuen Menschen' im Spannungsfeld zwischen Körper und Geist in Frank Wedekinds Mine-Haha und Michail Petrovič Arcybaševs Sanin eingehender zu untersuchen. Dies soll im folgenden Kapitel dieser Arbeit geschehen.

\subsection{Mine-Haha}

\subsubsection{Primat des Körpers gegenüber dem Geist}

Josephine Schröder-Zebralla zufolge stellt der Dualismus von Geist und Körper

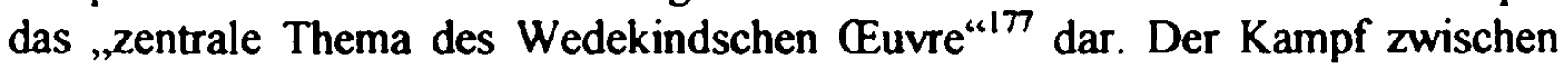
den beiden Polen wird in Frank Wedekinds Romanfragment zunächst eindeutig zugunsten des Körpers entschieden. Wie der Untertitel von Mine-Haha andeutet, steht „die körperliche Erziehung der jungen Mädchen“ im Mittelpunkt des Textes. Die Ausbildung, die die Zöglinge der Erziehungsanstalt genießen, beginnt mit der Einübung des schönen Gangs und der richtigen Haltung und setzt sich dann über Tanz- sowie Musikunterricht bis hin zum Theaterspielen als krönendem Abschluß fort. Die Entwicklung mentaler Fähigkeiten sowie besonders auch die im traditionellen Bildungssystem zentrale Fertigkeit des Lesens und Schreibens werden hingegen völlig vernachlässigt. ${ }^{178}$ So begegnen den Mädchen bei ihrer Entlassung aus dem Park zum ersten Mal in ihrem Leben Schriftzeichen auf den im Bahnhof aufgehängten Plakaten (vgl. 133).

Welche Spuren die starke Betonung des Körperlichen bei den Zöglingen hinterläßt, zeigt sich auch in Hidallas Beschreibungen der übrigen Parkbewohner: Ob sie von ihren Altersgenossen und Altersgenossinnen, von den Erzieherinnen oder den alten Dienerinnen erzählt - stets erwähnt Hidalla in bezug auf die übrigen Menschen in ihrer Umgebung in erster Linie äußere Merkmale wie Figur, Haare, Gang usw. Die Identität eines Menschen ergibt sich somit in Hidallas Erzählung allein aus körperlichen, nicht jedoch aus geistigen oder charakterlichen Besonderheiten, wie in der folgenden Textpassage deutlich wird:

Duncan oder Wiesenthal kostümiert, sondern $\dot{a}$ la Wintergarten, kurzes grellfarbiges Flitterkleid, das die Knie frei läßt, kurze Socken, nackte Beine.“

in Schröder-Zebralla (1985), 8.

${ }^{178} \mathrm{Vgl}$. dazu Moniková (1985), 120 
So erinnere ich mich auch nicht, daß mir all die Mädchen im Park jemals als geistig voneinander verschieden erschienen wären. [...] Nur an den körperlichen Unterschieden kannte man sich gegenseitig auseinander. [...] Von keinem der Mädchen ist mir im Gedächtnis geblieben, wie sie sprach. Ich weiß von jeder nur noch, wie sie ging (113).

Auch bei der Auswahlprozedur im Weißen Haus sind nur körperliche Gesichtspunkte ausschlaggebend. Die Dominanz des Körperlichen im Wertesystem des Parks wird bereits im Ordnen der Mädchen der Größe nach offensichtlich, das am Anfang der Ausbildung steht (vgl. 90). Bezeichnenderweise erscheint dieses Motiv wieder vor der Zusammenfuhrung mit den Knaben in Kapitel IV, so daß die Partnerwahl allein nach phänotypischen Gesichtspunkten stattfindet (vgl. 133). Zwangsläufig drängt sich beim Leser der Gedanke einer biologischen Zuchtwahl auf.

Augenscheinlicher Zweck der Erziehung in der von Hidalla beschriebenen Anstalt ist es, den Geist an den Körper zu binden - ein Motiv, das sich als Konstante durch Wedekinds Werk zieht. ${ }^{179}$ Denken und Verstehen spielen infolgedessen bei der Ausbildung keine Rolle. Das durch die Auswahlprozeduren zum erzieherischen Ideal erhobene $Z$ iel ist vielmehr eine möglichst vollständige Beherrschung des Körpers durch die Perfektionienung von Körperfunktionen.

Medicus hat in seiner Arbeit darauf hingewiesen, daB die Erziehung im Park von Mine-Haha ein „Verrücken des Zentrums vom Kopf in die Beine [und; Erg. d. Verf.] den Unterkörper" ${ }^{\text {"180 }}$ zur Folge hat. Diese Umkehr der traditionellen Hierarchieverhältnisse zwischen Körper und Geist zeigt sich am deutlichsten an folgender hăufig zitierten Stelle des Teils I:

Übrigens merkte ich schon damals, daß alle diese Übungen uns Mädchen viel leichter wurden als den Knaben, die nie über ihre Extremitäten wegkamen. Und wenn einige von uns Mädchen so sehr breite Hüften bekamen, so bin ich fest überzeugt, daß das nur daher rührt, daß wir gewissermaßen mit den Hüften denken lernten (91f.).

Es ist bemerkenswert, daß das 'Denken mit den Hüften' als weibliches Spezifikum angesehen wird. Leider unbeantwortet bleibt infolge des fragmentarischen Charakters von Wedekinds Text die Frage, ob auch die Erziehung der Knaben in dem selben Maße auf eine Unterordnung des Geistes unter den Körper abzielt, oder ob zerebrale Fähigkeiten nur bei Frauen unerwünscht sind. Hidallas abfällige Bemerkung über schreibende Frauen zu Beginn von Teil I scheint diese Schlußfolgenung nahezulegen, denn an

${ }^{179} \mathrm{Vgl}$. dazu Höger (1981), 173.

${ }^{180}$ Medicus (1982), 134. 
schreibenden Männem wie dem Autor von Frühlings Erwachen wird keine Kritik geübt. Allerdings ist zu Wedekinds Verteidigung vor der feministischen Literaturkritik anzumerken, daß die in den Fortsetzungsplänen skizzierten erotischen Kulthandlungen bei Männern wie Frauen gleichermaßen die völlige Unterwerfung des Geistes unter den Körper erfordern.

Angesichts der so starken Betonung des Körperlichen im Erziehungsprogramm des Parks erscheint es nahezu paradox, daß intime körperliche Beziehungen zwischen den Mädchen streng verboten sind. Gleichwohl ist, wie aus Hidallas Bericht deutlich hervorgeht, der Wunsch dazu immer wieder vorhanden. Als Hidalla eines Abends bei einem Spaziergang die ihr besonders nahestehende Hausgenossin Wera fragt, ob sie nicht in der Nacht zu ihr "herüberkommen..." (106) wolle, ist diese außer sich vor Empörung. Als Erklărung verweist Wera auf Margareta, eine der beiden alten Dienerinnen in Hidallas Haus, und erzählt, daß diese in ihrer Kindheit „zu einem andern Mädchen gegangen" (ebd.) sei und nun zur Strafe für immer im Park bleiben müsse. Zweimal noch ist Hidalla später der Versuchung ausgesetzt, eine körperliche Beziehung zu einem anderen Mädchen - ihrer Schutzbefohlenen Arabella - einzugehen. Beide Male jedoch wird sie durch scheinbare Zufalle davon abgehalten - das erste Mal durch ein rätselhaftes Klopfen gegen die Scheiben, das zweite Mal hingegen dadurch, daß das friedlich in seinem Bett schlafende Mädchen plötzlich aufwacht (vgl. 129).

Neben Körper und Geist ist also bei der Entwicklung der Zöglinge ein weiterer Faktor von Bedeutung, nämlich der Komplex der innerhalb des Dualismus von mens und corpus nicht eindeutig einzuordnenden Gefuhle. Wie das oben erwähnte Verbot intimer körperlicher Beziehungen zeigt, sieht das Erziehungsprogramm im Park die Unterdrückung der Gefühle vor. Als Ideal wird der schmerzunempfindliche und seine Empfindungen souverän kontrollierende Mensch propagiert. Darin scheint die Funktion von Gertruds körperlichen Züchtigungen mit der Rute ${ }^{181}$ zu liegen und nicht so sehr darin, die Aufpasserin zur „strafende[n] erotische[n] Stiefelfrau mit der Weidengerte als masochistische Besetzung weiblicher Strafgewalt“182 zu stilisieren, wie Medicus meint.

Die Fähigkeit zur vollständigen Unterdrückung der Gefühle stellt eine wichtige Voraussetzung für die Auswahl für höhere Aufgaben innerhalb der Parkgesellschaft dar. Daß dies nicht den natürlichen Anlagen der Mädchen entspricht, zeigt sich daran, daß Hidalla immer wieder zahlreiche Gefühle erwähnt, die sie und andere mit zunehmendem Alter haben. Neben den rein körperlichen Empfindungen sind das vor allem das Gefühl der Einsamkeit, der $\mathrm{Zu}$ - und Abneigung, der Angst, des Ärgers und der Wut, der Zufriedenheit, des

${ }^{181}$ Hierzu heißt es in Kapitel I: "Gertrud lächelte immer, wenn sie zuschlug. Manchmal schlug sie sich selbst mit der Rute über die gestreckten Beine hinunter, daß es nur so klatschte" (95).

In Medicus (1982), 140. 
Ekels, des Ehrgeizes, des Neids sowie der Eifersucht. Somit wird deutlich, daß sich auch in einer hermetisch von der Außenwelt abgeschlossenen Anstalt die menschliche Entwicklung nicht auf das rein Körperliche beschränken kann.

\subsubsection{Körper- und Schönheitskult}

Wenn man von den musikalischen Fertigkeiten absieht, wird der Wert des Menschen in der Erziehungsanstalt in Mine-Haha ausschließlich nach visuellen Kriterien bemessen. Auch die bei der Ausbildung der Zöglinge angestrebte Geschmeidigkeit der Körper wird als ästhetischer Wert begriffen. Der Gedanke der Beurteilung des Menschen allein nach dem äußeren Erscheinungsbild ist literarisch am deutlichsten in Wedekinds 1897 erschienener kurzer Erzählung Die Liebe auf den ersten Blick entwickelt. ${ }^{183}$

Das Menschenbild, das die Zöglinge auf Grund ihrer Ausbildung im Park entwickeln, ist also in erster Linie am Visuellen orientiert. Nicht umsonst berichtet Hidalla, ihre Hausgenossin Betty habe ,sich in eine ihrer Altersgenossinnen vergaff" (117) - ein Verb, das menschliche Zuneigung in erster Linie als Folge der äußeren Attraktivität des Liebesobjekts begreift.

Wie ihre Hausgenossin läßt sich auch die Ich-Erzählerin bei ihren Gefühlen für andere Menschen in ihrer Umgebung hauptsächlich von deren äußerem Erscheinungsbild leiten. Schöne Menschen wie der Knabe Morni, den sie wăhrend des ersten Abschnitts ihres Aufenthalts im Park kennenlernt (vgl. 92), oder die Erzieherin Gertrud, die Hidalla als „Inbegriff der Schönheit“ (90) gilt, üben auf sie eine starke Faszination aus. Häßliche Menschen hingegen rufen bei ihr Abscheu und Verachtung hervor. So glaubt Hidalla, „vor Ekel vergehen zu müssen" (107) angesichts der Vorstellung, eine der beiden alten Dienerinnen in ihrem Haus ohne Kleider sehen zu müssen. Es läßt sich vermuten, daß auch für Hidallas Abneigung der Musiklehrerin Kairula gegenüber deren wenig ansprechendes Äußeres ausschlaggebend ist (vgl. 105).

Im Erziehungssystem des Parks wird die „Abneigung gegen das Häßliche “ ${ }^{184}$ die im Laufe des Sozialisationsprozesses allen Zöglingen vermittelt

183 Dort heißt es „Der Gang eines Menschen ist nichts Zufäliges. Er ist aufs engste bedingt durch die Art und Weise, wie sein Körper gebaut ist. [...] Man kann in der Tat aus dem Schritt einer Dame eruieren, ob sie eine Stumpfnase oder eine gebogene Nase, ob sie volle oder schmale Lippen hat. Und dann wissen Sie auch schon mit voller Bestimmtheit, ob die Dame, wenn sie Sie kennte, Sie verstehen und lieben würde oder nicht"; zitiert nach Wedekind, Bd. 3 (1969), 53f. Erwähnenswert ist in diesem Zusammenhang auch eine häufig zitierte Bemerkung Wedekinds aus den Notizbüchern, die Kutscher anführt: ,Zeige mir, wie du gehst, und ich sage dir, wer du bist"; Kutscher, Bd. 2 (1927), 122

${ }^{184}$ Kutscher (1964), 203. 
zu werden scheint, planmäßig als Abschreckungsmittel eingesetzt, um regelwidriges Verhalten zu bestrafen. Die Anwesenheit der zwei alten Dienerinnen im Haus dient den Mädchen tagtäglich als augenscheinlicher Beweis dafür, daß Verstöße gegen die von höherer Stelle festgelegte Ordnung des Parks bestraft werden. So berichtet Hidalla, daß in jedem der dreißig Hăuser des Parks zwei alte Dienerinnen wie Margareta und Ima wohnen, die sich während ihrer Ausbildung ein Vergehen zuschulden kommen ließen und die nun mit Häßlichkeit und Unfreiheit für ihr Fehlverhalten büßen müssen (vgl. 107). Die soziale Stigmatisierung von Häßlichkeit ist in der Gesellschaft des Parks so stark, daß keines der Mädchen jemals ein Wort mit den Dienerinnen wechselt und nach Hidallas Vermutung alle auf der Stelle bereit wären, die beiden zu erwürgen, falls sie sich wieder irgend etwas zuschulden kommen ließen. „Die Huldigung der Vollkommenheit des Körpers" ${ }^{\text {"185 }}$ in Hidallas Erzählung trägt also durchaus einen Keim von Gewalttätigkeit in sich und weist damit Züge des Totalitarismus auf, was in einem späteren Kapitel dieser Arbeit noch näher untersucht werden soll.

\subsubsection{Die Ästhetik des Tierischen}

Hidallas Faszination für alles Schöne zeigt sich deutlich in der detaillierten Beschreibung der Kleidung ihrer Lehrerinnen. Besonders auffallig ist dies im Fall von Simba, der Tanzlehrerin im zweiten Erziehungsabschnitt. Die Erzählerin betont, daß sie "derartige Wunderwerke von Schönheit und Sinnenreiz" (101) in ihrem späteren Leben nicht mehr gesehen hat. Ein wesentlicher Bestandteil von Simbas ästhetischer Erscheinung ist die Kleidung. Die exotische Kleidung scheint den Körper der Tanzlehrerin gewissermaßen in Szene zu setzen: Simba trägt ein Mieder, „das aber ihre zarten Brüste vollkommen frei ließ, indem es beide mit großen Ringen einfaßte“ (102). Bei der Tanzlehrerin vereinen sich also Körper, Kleidung und Bewegung zu einem Gesamtbild, wie es das Ideal von Isadora Duncans Ausdruckstanz gewesen war. Insofern beginnt Trockij seinen Wedekind-Aufsatz von 1908 nicht von ungefähr mit einem Verweis auf die skandalumwitterte Tänzerin. ${ }^{186}$

Was aber zeichnet nach Hidallas Auffassung den schönen Menschen vor allen übrigen Personen aus? Hidallas Beschreibung von Simbas Äußerem erlaubt diesbezüglich einige Schlüsse:

Sie hatte lange, schlangenformige Brauen, eine feine Nase und das schmerzlichste und zugleich süßeste Lächeln auf den Lippen, das ich je gesehen habe. Dann

${ }^{185}$ Trotzkij (1968), 373. Im russischen Text steht: „Преклонение пред совершенством тела“; Trockij (1926), 411.

${ }^{186}$ Trotzkij (1968), 363. In der russischen Ausgabe vgl. Trockij (1926), 26. 
erinnere ich mich auch noch ihrer Zungenspitze, die manchmal wie ein Feuersalamander herauszuckte (102).

Wie Medicus zu Recht festgestellt hat, werden Simba in der hier zitierten Textpassage unverkennbar tierische Eigenschaften zugeschrieben, so daß es zu „einer Analogisierung gleicher Organe von Mensch und Tier“187 kommt. Für Hidalla scheinen Simbas „schlangenformige" Brauen sowie ihre einem Feuersalamander gleichende Zungenspitze offensichtlich zur Attraktivităt der Erzieherin beizutragen. Es wird also eine Verbindung hergestellt zwischen dem Tierischen und dem Schönen.

Noch deutlicher wird diese Verknüpfung in der Szene, in der Hidalla auf einem Spaziergang einen Pferdewagen vor dem Weißen Haus stehen sieht und in dem Pferd die Züge ihrer ersten Erzieherin Gertrud zu erkennen glaubt:

Ich sah die Augen und fuhlte, daß ich ein menschliches Wesen vor mir hatte. Mein nächster Gedanke war Gertrud. Diese Stellung der Füße war Gertrud. Dicse stolze Haltung hatte ich nur an Gertrud gesehen. Dieses sprühende Feuer in den Blicken, die Art, den Kopf zu schütteln, alles rief mir Gertrud vor Augen (109).

Auf Grund ihrer pädagogischen Prägung empfinden die Zöglinge der Parkanstalt also Menschen dann als schön, wenn ihr Äußeres ein Höchstmaß an tierischen Eigenschaften aufweist. Entscheidend dabei ist jedoch, daß es sich bei dem oben crwahnten Pferd um cin gebändigtes, um cin dressiertes Tier handelt - dies ist zu einem späteren Zeitpunkt noch näher auszuführen. Schönheit wird insofern als eine aus zwei Komponenten bestehende Eigenschaft begriffen: $\mathrm{Zu}$ dem schönen Körper, mit dem man von der Natur ausgestattet wird, tritt die erworbene Făhigkeit der ästhetischen Haltung und Bewegung hinzu, und erst durch das Zusammenspiel beider Faktoren entsteht der ästhetische Gesamteindruck.

In der kritischen Literatur zu Wedekind wird allenthalben darauf hingewiesen, da $B$ der Autor ein ausgeprägtes Interesse am Zirkus hatte und ihn „ăsthetisch und weltanschaulich bei der Konstruktion seiner Stücke“188 verwandte. So ist die Faszination für das gebändigte Tier ein Motiv, das sich immer wieder in den Werken des deutschen Schriftstellers finden läßt. Das bekannteste Beispiel ist sicherlich der Auftritt des Tierbändigers in dem 1898 zur 10. Auffuhrung entstandenen Prolog des Dramas Erdgeist. Die Hauptdarstellerin Lulu wird hier als „Das wahre Tier, das wilde, schöne Tier“ angekündigt, und die Zuschauer werden aufgefordert, „Die unbeseelte Kreatur zu schauen,/ Gebändigt

${ }^{187}$ Medicus (1982), 144.

${ }^{188}$ V. Klotz, Wedekinds Circus mundi (1975), 23. Auch Adorno hat in einem Vortrag von 1932 auf Wedekinds Faszination für den Zirkus hingewiesen. Hier zitiert nach: Th. W. Adomo, Über den Nachlaß Frank Wedekinds (1974), 631. 
durch das menschliche Genie“. ${ }^{189}$ Zeugnis von der Faszination, die der Zirkus auf Wedekind ausübte, legen auch die Zirkus-Aufsätze des Schriftstellers ab. ${ }^{190}$ Diese wurden von der Wedekind-Forschung immer wieder zur Erläuterung der künstlerischen und weltanschaulichen Positionen des Schriftstellers herangezogen. ${ }^{191}$

\subsection{Sanin}

\subsubsection{Verkultung des schönen Korpers}

Auch in Arcybaševs Text wird der Gegensatz von Körper und Geist immer wieder thematisiert, wenn auch auf eine andere Weise als bei Wedekind. Im Gegensatz zum kollektiven Milieu der Erziehungsanstalt in Mine-Haha mit ihren weitgehend entindividualisierten Figuren treffen im Samin sehr unterschiedliche Charaktere aufeinander. Bei einer näheren Betrachtung der handelnden Personen des Romans fallt auf, daß sich die Beschreibung körperlicher Merkmale bei einigen von ihnen leitmotivisch durch den gesamten Text zieht und auch zur weltanschaulichen Charakterisierung benutzt wird.

Immer wieder erwähnt der Erzähler im Sanin die athletische Figur des Titelhelden, wobei das Schönheitsideal des 'neuen Menschen' durch die beinahe obsessiv wirkende Betonung der körperlichen Stärke Sanins der Ästhetik der deutschen Faschisten auffallend nahekommt. Bereits zu Beginn des Romans ist von Sanins blonden Haaren, seinem hohen Wuchs, seinen muskulösen Armen sowie seinem festen Händedruck die Rede (I, 19ff.; 5ff.). Bei der Beschreibung der Arme und Hände Sanins werden mehrmals Adjektive aus dem Bereich der Metallurgie verwandt, die den heutigen Leser des Romans frappant an die Losungen des Nationalsozialismus erinnern müssen. So heißt es gegen Ende des Kapitels I über Sanin während eines Gesprächs mit seiner Schwester Lida: „Горячая струйка пробежала от его мускулистой, точно железной руки по гибкому и нежному телу Лиды“" (I, 22; Hervorhebung d. Verf.). ${ }^{192}$

\footnotetext{
${ }^{189}$ Wedekind, Bd. 1 (1969), 235.

190 Ende Juni 1887 veröffentlichte Wedekind in der Neuen Zürcher Zeitung unter dem Titel Zirkusgedanken eine Besprechung der Vorstellungen des Zirkus Herzog. Rund ein Jahr später, Anfang August 1888, erschienen in der Neuen Zürcher Zeitung zwei Artikel unter dem Titel Im Zirkus. Die Texte sind abgedruckt in Wedekind, Bd. 3 (1969), 153ff. bzw. $163 \mathrm{ff}$.

${ }^{191}$ Vgl. zuletzt A. Martin, Ein Drahtseilakt. Irank Wedekind und der Erste Weltkrieg (1996)

192 Übersetzung: „Ein heißer Strom rollte von seinem muskulösen, gleichsam eisernen Arm zu dem schmiegsamen, zarten Körper Lidas hinüber" $(I, 9)$.
} 
Wăhrend der Verführungsszene im Boot ist die Rede von Sanins 'stahlharten Muskeln'193 sowie seinen 'stählernen Händen'. 194 Breite Schultern und eine athletische Figur weist neben Sanin auch der Lehrer Ivanov auf, der dem Titelhelden ideologisch von allen Romanfiguren am nächsten steht (vgl. IV, 48; 44).

Auch bei der Zeichnung der beiden zentralen Frauengestalten des Romans, Lida und Karsavina, werden häufig sekundäre Geschlechtsmerkmale wie Brüste und Hüften beschrieben, um den Eindruck körperlicher Attraktivität zu erwecken. $\mathrm{Da} B$ Lida von ihrem Selbstmordversuch abläßt, erscheint im Sinne der Botschaft des Romans geradezu als zwangsläufig, denn in Arcybaševs Roman werden immer wieder Schönheit und Vitalität miteinander in Verbindung gebracht. Demgegenüber wird das Häßliche wiederholt als nicht lebensfähig bzw. als nicht lebenswert dargestellt. Auch hierin mag man eine Parallele zur nationalsozialistischen Rassenideologie sehen.

Besonders deutlich zeigt sich der vitalistische Charakter der Botschaft des Sanin im Schicksal des schwindsüchtigen Studenten Semenov, dessen Tod in den Kapiteln X und XI zunächst aus der Perspektive der Außenstehenden und danach nochmals aus Semenovs eigenem Blickwinkel geschildert wird. Bereits beim ersten Auftreten des Studenten wird durch die Beschreibung körperlicher Mängel eindeutig Semenovs Nähe zum Tod angedeutet:

Семенов был больной чахоткою университетский студент, уже несколько месяцев живший в этом городе на уроки. Он был очень нехрасив, худ и сла6, и на его преждевременно состарившемся лице неуловимо, но жутко лежала тонкая тень близкой смерти $(\mathrm{IV}, 48)^{195}$

In dieselbe Richtung weist auch die Beschreibung der körperlichen Eigenschaften des jüdischen Mühlenbesitzers Solovejčik, bei der sich der heutige Leser des Romans wiederum an die nationalsozialistische Rassenideologie erinnert fühlen muß. Bereits durch die phänotypischen Merkmale sowie das äußere Auftreten wird suggeriert, daß es sich bei Solovejčik um einen lebensunfähigen Menschen

${ }^{193} \mathrm{Vgl}$ XXXVIII, 280: „Карсавина подала руку и ошутила со странной неловкостью и смутным волнением твердые как железо мускулы, передвигавшиеся под тонкой рубахой.“"

194 Vgl. XXXVIII, 286: „Пустите!.. Ради Бога... Что вы! - задыхаюштимя шепотом проговорила она [Карсавина; Erg d. Verf.] после мгновенного жуткого молчания, отрывая его стальные руки“; Übersetzung: "Lassen Sie mich, um Gotteswillen, was tun Sie?' flüsterte sie [Karsavina; Erg. d. Verf.] keuchend nach kurzem, bangem Schweigen, während weichem sie sich aus seinen stählernen Armen reißen wollte" (XXXVIII, 353).

195 Übersetzung: „Letzterer [Semenov; Erg. d. Verf.] war ein schwindsüchtiger Student, der seit einigen Monaten in diesem Städtchen lebte und sich von Privatunterricht ernährte. Er war auffallend häßich, abgezehrt und schwach. Auf seinem vorzeitig gealterten Gesicht lag unerfaßbar und schauerlich der zarte Schatten des nahen Todes" (IV, 44). 
handelt: Neben seinen schlechten Zähnen sind sein fortwährendes unterwürfiges Lächeln sowie seine körperliche Schwäche Elemente, die offensichtlich die Zwangsläufigkeit seines Todes andeuten sollen (vgl. XXV, 182f.; 25f.). Zur negativen Charakterisierung Solovejxiks trägt auch dessen Idiolekt bei - ein nicht hochsprachliches, gewissermaßen als Degenerationsform karikiertes Russisch.

An dieser Stelle muß allerdings angemerkt werden, daß körperliche Attraktivität allein im Sinne der Botschaft des Romans keine Berechtigung zum Leben darstellt. Dies wird am Schicksal des Rittmeisters Zarudin deutlich, dem es, obgleich er über eine körperliche Anziehungskraft auf Frauen verfügt, an der von Sanin propagierten Achtung dem weiblichen Geschlecht gegenüber fehlt. Sanin äußert im Gesprăch mit seiner Schwester folgende Ansichten über Zarudin:

Ты и сама знаешь теперь... да и раньше знала, что это человек, хотя и красивый и для любви подходящий, но дрянной и подлый... Только и было в нем хорошего, что красота, но ею ты уже воспользовалась достаточно! (XIX, 150). ${ }^{106}$

Wie der Selbstmord Zarudins zeigt, führt bloße Schönheit ohne wirkliche charakterliche Stärke ebenso zum Tod wie die Verleugnung des Körpers. Auf der anderen Seite kann eine gesunde Einstellung dem Leben gegenüber nach der Logik des Romans jedoch auch etwaige körperliche Mängel kompensieren. So bezeichnet Sanin die als äußerlich wenig ansprechend charakterisierte Lehrerin Dubova in Gedanken als „prăchtiges Mädchen“ („славная девушка“; XXV, $185 ; 220$ ), weil sie die von dem Studenten Gožienko geleitete politische Versammlung durch ironische Bemerkungen kommentiert.

Trotz aller Begeisterung für den schönen Körper, die in den Personenbeschreibungen des Erzählers spürbar wird, ist also in Arcybaševs Roman körperliche Attraktivität allein nicht ausreichend zur Charakterisierung des 'neuen Menschen'. Der Titelheld verkörpert vielmehr eine naiv anmutende Synthese von Körper und gesunder Einstellung, auf die zu gegebener Zeit noch näher einzugehen ist.

\subsubsection{Jurij Svarožic - Sterilităt des Geistes}

Es fält auf, daß der Leser im Falle der zweiten zentralen Figur des Romans, Sanins Gegenspieler Jurij Svarožič, lediglich sehr spärliche Informationen über

${ }^{19}$ Übersetzung ,Du weißt es ja selbst, und du hast es ja auch früher gewußt, daß er zwar ein ganz hübscher, für die Liebe geeigneter Mensch, aber im Grunde ein gemeiner, niedriger Kerl ist. Seine einzige gute Eigenschaft ist seine Schönheit, und diese hast du wohl ausreichend genossen“ (XIX, 173). 
deren körperliche Merkmale erhält. Dieser Umstand trägt wesentlich zur Charakterisierung Jurij Svarožič als Mensch des Geistes bei, was für die antithetische Argumentationsstruktur des Romans von entscheidender Bedeutung ist. Auf die Gegensätzlichkeit der beiden Hauptfiguren des Sanin wurde in der einschlägigen Sekundärliteratur immer wieder hingewiesen. ${ }^{197}$

Anders als der Titelheld des Romans kann Svarožič seine sexuellen Bedürnisse gegenüber der attraktiven Zinaida Pavlovna Karsavina nicht ausleben, weil ihn seine übermäßige Neigung zu Selbstzweifeln daran hindert. Sowohl wăhrend der gemeinsamen Erkundung der Höhle (vgl. V, 58ff.; 56ff.) als auch beim Treffen mit Karsavina auf dem Abhang in der Nähe des Klosters (vgl. XXXVII) gelingt es Svarožič trotz der sicherlich mit Bedacht gewăhlten, zur Entgrenzung einladenden Schauplätze nicht, sich von der Kontrolle des Körpers durch den Geist zu lösen. Gerade in der letztgenannten Szene wird der Geist als eine Kraft dargestellt, die den Menschen am Ausleben seiner natürlichen Triebe hindert und die mit Kälte und letztendlich auch mit Tod in Verbindung gebracht wird:

И вдруг Юрий с ухасом спросил себя: „Что я делаю?“

Горящего мозга хоснулась ледяная ясность, и все разом опустело, стало бледным и светльм, ках в зимний день, в хотором нет уже ни жизни, ни склы (XXXVII, 268). ${ }^{198}$

Jurij Svarožix wird also als eine Figur gezeichnet, bei der aufgrund der Neigung zur permanenten Reflexion des eigenen Handelns eine ausgeprägte Diskrepanz zwischen Wollen und tatsächlichem Handeln besteht. Daß dies nach der Logik des Sanin zu Sterilität und Verlust der Lebenskraft führt, wird bereits an zwei früheren Stellen des Romans angedeutet: Wie der Leser in Kapitel VIII erfährt, war es Svarožic' ursprünglicher Wunsch, Maler zu werden. Sein politisches Engagement in Moskau hielt ihn jedoch von der Ausfuihrung dieses Vorhabens ab. Als er sich, beflügelt durch Karsavinas körperliche Attraktivität, anschickt, ein Bild mit dem Titel Жизнь ['Das Leben'] zu malen, erweist er sich als unfáhig, unvorhergesehene technische Schwierigkeiten zu überwinden. Statt

${ }^{197}$ Luker bezeichnet Jurij Svarožic als "a foil to the hero"; Luker (1980), 67. Baloueff nennt Svarožic im Gegensatz zur Titelfigur einen 'negativen Helden'. Vgl. dazu Baloueff (1976), 135.

198 Übersetzung: „Und plötzlich fragte sich Jurij entsetzt: 'Was tue ich?' Eisige Klarheit berührte sein brennendes Gehirn, und alles wurde plötzlich leer, wurde blaß und hell, so wie an einem Wintertag, an dem kein Leben und keine Kraft mehr vorhanden sind" [Übers. $d$. Verf.] (vgl. XXXVII, 329). 
dessen bringt er nur ein Gemälde mit dem Titel Cmapocmb ['Das Alter'] zustande (vgl. VIII, 71; 78). ${ }^{199}$

Einige Zeit später unternimmt Jurij Svarožic bereits einen ersten Selbstmordversuch in seinem Zimmer: Da er sich zu höherem berufen fühlt als dazu, einmal eine bürgerliche Ehe mit Karsavina zu führen, versucht er, sich mit einem Revolver das Leben zu nehmen. Allerdings versagt die Waffe im entscheidenden Moment, so daß Jurij auf wundersame Weise noch einmal vor seinem späteren Schicksal bewahrt wird (vgl. XXII, 168; 197). Dennoch sind natürlich sowohl das mißlungene Gemälde als auch der vereitelte Selbstmordversuch als deutliche Signale dafür zu lesen, daß es sich bei Svarožic um einen nicht lebensfahigen Menschen handelt.

\subsubsection{Sanin - gesunder Geist im schönen Korper}

Zeitgenössische Leser des Sanin haben den Gegensatz zwischen den beiden Hauptfiguren in Arcybaševs Roman deutlich erkannt - die Kritikerin E. A. Koltonovskaja beispielsweise schreibt: „В противовес здоровому, уравновешенному Санину, автор выводит в романе неврастеничного, нежизнеспособного студента Юрия. “200 In Anbetracht der Tatsache, daß Arcybaševs ursprünglicher Romantitel „Jurij Svarožic“ lautete, ist sicherlich die Behauptung zutreffender, daß die Person Sanins als Kontrastfigur zu dem Technologiestudenten eingefugt wurde. Im Unterschied zu letzterem wird der Titelheld in Arcybaševs Text als ein Charakter gezeichnet, der keinerlei Neigung zur Reflexion des eigenen Handelns aufweist und bei dem Wollen und Handeln miteinander in Einklang stehen.

In diesem Zusammenhang stellt sich die Frage nach der möglichen Bedeutung des Namens des zentralen Helden, der wiederum eine herausragende Rolle bei der Deutung des gesamten Romans zukommt. Nicht beachtet wurde von der Forschung bisher allem Anschein nach die Tatsache, daß der Arcybaševsche Titelheld möglicherweise in der Hauptfigur des Kurzromans Vešnie vody [deutsche Titel: Frühlingsfluten und Frühlingswogen] (1872) von Ivan Sergeevic Turgenev einen direkten literarischen Vorgänger hat. ${ }^{201}$ Auch in Turgenevs Text spielt die mit Erotik gekoppelte Wassersymbolik eine gewisse Rolle. ${ }^{202}$

199 O'Dell weist auf die deutliche Symbolik des mißlungenen Bildes hin. Vgl. dazu O'Dell (1980), 105.

200 Koltonovskaja (1910), 109; Übersetzung: „Als Gegengewicht zu dem gesunden, ausgeglichenen Sanin entwirt der Autor in seinem Roman die Figur des neurasthenischen, lebensunfähigen Studenten Jurij“ [Übers. d. Verf.]

${ }^{201}$ Diesen Hinweis verdankt der Verfasser Herrn Prof. Dr. Peter Thiergen (Bamberg).

202 Besonders deutlich wird dies im Kapitel XLII; vgl. dazu I. S. Turgenev, Sočinenija, Bd. 8 (2. Aufl. 1981), 373ff. 
Arcybaševs Sanin steht jedoch in deutlichem Kontrast zu Turgenevs Protagonist Dmitrij Pavlovic Sanin, der - mit Ausnahme der kurzen Rahmenhandlung - als charakterlich wenig ausgereifter und wankelmütiger junger Mann gezeichnet wird.

Da wiederum infolge der fehlenden philologischen Aufarbeitung des Arcybaševschen Werks offenbleiben muß, inwieweit der Autor Turgenevs Text kannte, sei hier eher auf verschiedene Versuche verwiesen, Arcybaševs Hauptfigur von der Etymologie ihres Namens her zu charakterisieren. Barchan hat bereits in einer frühen Rezension des Sanin den Namen des Titelhelden mit dem lateinischen Adjektiv sanus ('heil, gesund') in Verbindung gebracht. ${ }^{203}$ Tatsächlich steht in Arcybaševs Roman die Propagierung einer als 'gesund' verstandenen neuen Lebensphilosophie im Vordergrund. Dieser werden die Lebensentwürfe anderer handelnder Personen - Semenov, Zarudin, Solovejcik sowie Jurij Svarožič - gegenübergestellt. Durch Tod bzw. Selbstmord werden die genannten Figuren als nicht lebensfähig charakterisiert.

Insofern erscheint die von Barchan vertretene Deutung von Sanins Namen wesentlich überzeugender als die von Ulrich Steltner vorgeschlagene Lesart: Steltner vertritt die Auffassung, der Name des Titelhelden sei auf altkirchenslavisch sani ('zur Schlange gehörig') bzw. auf satanin zurückzuführen und somit als „ein Kryptogramm auf den Namen des Teufels“204 zu interpretieren. Sanin würde demzufolge zu einer dämonischen Verführerfigur.

In die Richtung von Barchans Deutung weist auch Sanins Vorname Vladimir, der bisher in der einschlägigen Forschungsliteratur kaum beachtet wurde: Der nach wie vor häufig anzutreffende russische Name Vladimir leitet sich von den Morphemen $\{a \imath a \partial-\}$ und $\{$ мup- $\}$ her $^{205}$ und enthält insofern die semantischen Komponenten 'herrschen' und 'Welt'. Somit wird Sanin auch durch seinen Vornamen zum urwüchsigen Kraftmensch stilisiert. Für diese Lesart spricht auch Sanins Patronym Petrovic, das von dem altgriechischen Substantiv petra ('der Fels') abgeleitet ist. ${ }^{206}$ Sanin erscheint demzufolge gewissermaßen als 'Fels in der Brandung', der konsequent seinen eigenen Weg geht, unbeirt von allen zeitgenössischen ideologischen Modeströmungen.

Die drei Bestandteile von Sanins Namen lassen sich also als eine Kombination aus 'Gesundheit', 'Wille' bzw. 'Fähigkeit zur Herrschaft' und 'Standhaftigkeit' interpretieren. Diese Deutung erfährt eine Bestätigung durch das

${ }^{203}$ Barchan (1909), 127. Auch Sally O'Dell vermutet, der Name des Titelhelden in Arcybasevs Roman sei von samus abgeleitet. Vgl. dazu O'Dell (1980), 101

204 Steltner (1988), 238.

$205 \mathrm{Vgl}$. N. A. Petrovskij, Slovar' russkich licmych imen (1995), 97. Lediglich Baloueff verweist in seiner Arbeit kurz auf die Etymologie des Namens Vladimir. Vgl. dazu Baloueff (1976), 169.

206 Vgl. Petrovskij (1995), 237. 
Verhalten des Titelhelden: Anders als Jurij Svarožič erscheint Sanin in Arcybaševs Roman immer wieder als Mensch des Körpers und der Tat. Auch in der Namenswahl für Sanins Antipoden mag man eine Chiffre für den Unterschied zwischen den beiden Hauptfiguren sehen. Baloueff zumindest vertritt diesen Deutungsansatz in seiner Arbeit, indem er Jurijs Familiennamen von Cварог, einem altrussischen Wort für 'Himmel' herleitet. ${ }^{207}$ Im Gegensatz zu dem ganz dem Hier und Jetzt seiner irdischen Existenz zugewandten Titelhelden ließe sich Jurij Svarožič somit als Vertreter des 'alten Menschen' einordnen, der der - nach der Botschaft des Romans - trügerischen Hoffnung auf ein besseres Leben im Jenseits bzw. in der Zukunft anhängt.

Allerdings muß angemerkt werden, daß Sanin seinem eigenen antiintellektualistischen Programm nicht immer treu ist. So hat der Widerspruch zwischen der angeblichen Ablehnung festgefügter philosophischer Wertesysteme und der immer wieder bezeugten Bereitschaft des Titelhelden, seiner Umwelt gegenüber seine Theorien wortreich darzulegen, Rezensenten des Romans bereits früh $\mathrm{zu}$ ironischen Bemerkungen veranlaßt. ${ }^{208}$ Cukovskij weist insofern in seinem vemichtenden Arcybašev-Aufsatz von 1908 unter Verwendung eines Wortspiels zu Recht darauf hin, daß Sanin keineswegs nur ein Mensch des Körpers ist. ${ }^{209}$

\subsection{Zusammenfassung}

Die Tendenz zur übermäßigen Betonung des Körperlichen und der Versuch der Zurückdrängung des Geistigen lassen sich unschwer in beiden hier gegenübergestellten Werken erkennen. Äußere körperliche Merkmale werden zu einem entscheidenden - in Wedekinds Text sogar dem einzigen - Faktor bei der Charakterisierung der handelnden Figuren. Dabei läßt sich sowohl bei Wedekind als auch bei Arcybašev der Versuch der quasi-religiösen Verkultung des schönen

${ }^{207} \mathrm{Vgl}$. Baloueff (1976), 169f. In Sreznevskijs Wörterbuch des Altrussischen wird Coapoz als Name der höchsten Gottheit der Slawen in vorchristlicher Zeit erwähnt. Craposwuy hingegen ist der Name von dessen Sohn. Vgl. dazu I. I. Sreznevskij, Slovar' drevmerusskogo jazyka. Reprintnoe izdanie (1989), 265.

$208 \mathrm{Vgl}$. Barchan (1909), 128: „Gott, was ist das für ein Lebenskünstler, für eine siegreiche Kraftnatur, der seinem Mädel erst eine lange Vorlesung über den 'Körper' und die 'Schönheit' und die 'Begierde' halten muß, bis er sie unterkriegt. [...] Hie raisonnieren, hie agieren ist ein Unding."

209 Cukovskij (1908), 130: „Саннн хочет помыслов о том, что помыслы не нужны. Он логически доказывает, что логика бессильна.“ Cukovskijs Wortspiel ist nur annäherungsweise zu übersetzen als: „Sanin möchte sich darüber Gedanken machen, daß man sich keine Gedanken zu machen braucht. Er beweist logisch, daß die Logik nichts auszurichten vermag“ [Übers. d. Verf.] 
Körpers erkennen. Bei allen Unterschieden zwischen Wedekinds Mine-Haha und Arcybaševs Sanin ist diese Umkehr der bisherigen Wertehierarchie einer der wichtigsten Aspekte, die zum Vergleich der beiden Texte unter dem Gesichtspunkt der Suche nach dem 'neuen Menschen' berechtigen.

In beiden Werken treten jedoch auch deutlich die Grenzen eines auf das rein Körperliche beschränkten Menschenbildes zutage. So macht die sich mit zunehmendem Alter immer weiter ausdifferenzierende Gefühlswelt der Mädchen in Mine-Haha das Leben in der Erziehungsanstalt, deren Funktionieren auf der Ausschaltung der Gefühle basiert, allmählich unmöglich. Im Sanin zeigt die Figur des Rittmeisters Zarudin, daß körperliche Attraktivität allein als Merkmal des propagierten 'neuen Menschen' nicht ausreicht. Körperliche Schönheit erscheint damit in Arcybaševs Roman zwar als Begleiterscheinung einer 'gesunden' inneren Einstellung, nicht jedoch als deren Indikator.

Damit sind bereits wesentliche Differenzen zwischen beiden Texten angesprochen, die ihre Ursache in unterschiedlichen Anschauungen über die Entwicklung des Menschen haben - dies jedoch wird in den folgenden Abschnitten dieser Arbeit eingehender zu untersuchen sein. Festgehalten werden soll an dieser Stelle lediglich, daß Schönheit in Wedekinds Romanfragment auch als eine Folge von Erziehung dargestellt wird, während im Sanin suggeriert wird, daß Schönheit als Attribut des Gesunden und Starken von außen nicht formbar ist. 


\section{DIE GENESE DES 'NEUEN MENSCHEN'}

\section{1 Vorbemerkung}

In einem literarischen Werk, in dem der Entwurf eines neuen Menschentypus im Vordergrund steht, müssen zwangsläufig Fragen der Entwicklung, Bildung und Erziehung thematisiert werden. Ja, es ist ohne die Erörterung pädagogischer und anthropologischer Grundfragen schlichtweg unmöglich, Vorschläge zur Schaffung eines 'neuen Menschen' zu machen. Insofern überrascht es nicht, daß über die Frage nach der Genese des 'neuen Menschen' der Themenkomplex Entwicklung, Bildung und Erziehung in den beiden hier behandelten Texten eine wichtige Rolle spielt. Wird dies im Beispiel Wedekinds bereits am Untertitel des Textes - Über die körperliche Erziehung der jungen Mädchen - deutlich, so zeigt ein Blick auf das Personal in Arcybaševs Roman, daß sich die meisten der Figuren an der Schwelle zum Erwachsensein befinden. Insofern kommt dem Problem der menschlichen Entwicklung auch im Sanin eine besondere Bedeutung zu.

Großen Einfluß auf die Suche nach einem 'neuen Menschen' an der Wende zum 20. Jahrhundert hatten die Theorien des britischen Naturforschers Charles Robert Darwin (1809-1882). In erster Linie zu nennen ist in diesem Zusammenhang Darwins bahnbrechende, 1859 erschienene Abhandlung (On the Origin of Species by means of Natural Selection, or the Preservation of Favoured Races in the Struggle for Life. Das Werk des Briten stieß auch außerhalb des Heimatlandes auf großes Interesse, und bereits funf Jahre nach seinem ersten Erscheinen lagen sowohl eine deutsche als auch eine russische Übersetzung vor. ${ }^{210}$

In Darwins Werk wird die berühmt gewordene These ausgefuihrt, daß sich jeder lebende Organismus in einem Kampf ums Dasein - Darwin verwendet dafür die Begriffe struggle for life sowie struggle for existence ${ }^{21}$ - und damit in Konkurrenz zu anderen lebenden Organismen befindet. Über Erfolg und Mißerfolg in diesem Kampf entscheidet die optimale Anpassung an die gegebenen Bedingungen, so da $\beta$ alles Leben auf der Erde einem ständigen Selektionsprozeß unterworfen ist. Dieser wiederum wird als Grundlage für die Weiterentwicklung aller Organismen begriffen. Darwins Theorie der Evolution

${ }^{210}$ In Deutschland erschien On the Origin of Species by means of Natural Selection erstmals im Jahre 1860 in der Übersetzung von H. G. Bronn. 1864 wurde das Werk vom Verlag der Moskauer Universität in russischer Übersetzung herausgegeben. Vgl. hierzu Ju. $\mathrm{N}$. Emel'janov, Moskovskij universitet $v$ vospominanijach sovrememnikov (I755-19/7) (1989), 11.

$211 \mathrm{Vgl}$. dazu Ch. R. Darwin, The Works of (harles Darwin, Bd. 15 (1988), 45ff. 
bildete die Grundlage für den um die Jahrhundertwende weitverbreiteten Glauben, in den Entwicklungsproze $B$ von Mensch und Natur eingreifen zu können und durch die Schaffung entsprechender Rahmenbedingungen zur Entstehung eines 'neuen Menschen' beitragen zu können.

Sicherlich kann der Einfluß der Darwinschen Abstammungs- und Evolutionslehre auf die Entwicklung der gesamten europäischen Pädagogik nicht unterschätzt werden. Jedenfalls war das ausgehende 19. Jahrhundert trotz aller gesellschaftlichen und kulturellen Unterschiede zwischen den beiden Ländern sowohl in Deutschland als auch in Rußland eine Zeit intensiver Auseinandersetzung mit Fragen der Bildung und Erziehung. Im folgenden soll dieser Diskurs in knapper Form umrissen werden, da er für den geistesgeschichtlichen Hintergrund der beiden in dieser Arbeit untersuchten Werke von Bedeutung ist.

In Deutschland nahm im letzten Drittel des 19. Jahrhunderts vielerorts die Unzufriedenheit mit dem bürgerlichen Bildungssystem zu. Unter den zahlreichen kritischen Stimmen, die sich in der Debatte um die Zukunft der Bildung zu Wort meldeten, war auch die Friedrich Nietzsches. Der Philosoph hielt 1872 funf Vortrăge, denen er spăter den Titel Ueber die Zukunft unserer Bildungsanstalten gab. In ihnen wendet sich Nietzsche gegen jegliches Nützlichkeitsdenken im Bildungswesen sowie gegen das Bestreben, möglichst breiten Bevölkerungsschichten Bildung zukommen zu lassen. ${ }^{212}$

Nietzsches Kritik an Zielen und Inhalten der traditionellen Bildung und Erziehung wurde an der Wende zum zwanzigsten Jahrhundert von den Vertretem der Reformpädagogik wieder aufgegriffen - einer erziehungsreformerischen Bewegung, die in Europa und Nordamerika ab etwa 1890 Verbreitung fand. ${ }^{213}$ Für deren Entstehung war neben Nietzsche vor allem die Pädagogik und Philosophie Jean-Jacques Rousseaus (1712-1778) mit seiner Kritik an dem als verderblich erachteten Einfluß der traditionellen Erziehung auf den Menschen prägend. ${ }^{214}$ In Anlehnung an Rousseaus Theorien heißt es in der zentralen Schrift

${ }^{212}$ Die Vorträge sind abgedruckt in F. Nietzsche, Sämtliche Werke. Kritische Studienausgabe in 15 Einzelbainden, Bd. 1 (2. Aufl 1988), 643ff.

${ }^{213}$ Zur Geschichte und den Zielen der Reformpädagogik vgl. F. März, Personengeschichte der Poidagogik (1998), 565ff.

${ }^{214}$ Rousseau legt seine Ansichten über die Erziehung in seinem berühmten Werk ismile ou De l'échucation von 1762 dar. Der Grundgedanke des Rousseauschen Entwicklungsromans ist bereits in den ersten Worten enthalten: "Tout est bien, sortant des mains de l'auteur des choses: tout dégénére [!] entre les mains de l'homme." Zitiert nach: J.-J. Rousseau, (Fuvres completes, Bd. 4 (1969), 245. Es ist nach dem Kenntnisstand des Verfassers nicht mit Sicherheit zu sagen, inwieweit die beiden für diese Arbeit relevanten Schriftsteller dieses Werk kannten. Im Falle von Arcybasev fehlen diesbezüglich jegliche Angaben. Was Wedekind betriff, so erwähnt Kutscher lediglich die Kenntnis des Rousseauschen Gesellschaftswertrags (1762). Vgl dazu Kutscher (1927), 145. 
der Reformpädagogik, der 1900 verfaßten und 1902 erstmals in deutscher Übersetzung erschienenen Abhandlung Das .Jahrhundert des Kindes der schwedischen Pädagogin Ellen Key (1849-1926): „Ruhig und langsam die Natur sich selbst helfen lassen und nur sehen, daß die umgebenden Verhältnisse die Arbeit der Natur unterstützen, das ist Erziehung. “215

Innerhalb der pädagogischen Emeuerungsbewegung, die zahlreiche unterschiedliche Strömungen in sich vereinigte, wurden von verschiedener Seite Versuche unternommen, die Natur in den Bildungs- und Erziehungsproze $B$ miteinzubeziehen. Die bekanntesten Folgen dieser Bestrebungen waren die bereits in einem früheren Kapitel erwähnte Wandervogelbewegung sowie die Landerziehungsheime Hermann Lietz' (1868-1919) und Gustav Wynekens $(1875-1964) .^{216}$ Somit kam es in der Reformpädagogik zu einem Ineinandergreifen von Zivilisations- bzw. Großstadtkritik und erzieherischer Neuorientierung. Auch die körperliche Erziehung und der Tanz spielten im pädagogischen Programm vieler der um die Jahrhundertwende entstehenden Reformschulen eine wichtige Rolle - ein Trend, der sich unter anderem in der Gründung einer Schule im Berliner Grunewald durch die bereits erwähnte Tảnzerin Isadora Duncan im Jahre 1904 niederschlug. ${ }^{217}$

Die Situation in Rußland unterschied sich von der in Deutschland in erster Linie durch den Umstand, daß das Bildungswesen in dem riesigen Reich zur gleichen Zeit erst im Aufbau begriffen war und von einer entindividualisierenden Massenbildung, wie sie von Nietzsche kritisiert wurde, keinesfalls die Rede sein konnte. ${ }^{218}$ Obwohl unter dem Reformzar Alexander II bereits in den 1860er Jahren ein neues Universitätsstatut (1863) sowie Gesetze über die Volksschulen (1864) und über die höheren Schulen (1865) erlassen worden waren, ${ }^{219}$ ging der Aufbau des Bildungswesens nur dank des Einsatzes zahlreicher Idealisten aus der russischen Intelligenz gegen erhebliche bürokratische Widerstände vonstatten.

Weitaus wichtiger als die Zentralregierung waren für den Aufbau des Schulwesens die örtlichen Selbstverwaltungsorgane der Kreise und Gouvernements, die sogenannten Zemsiva. ${ }^{220}$ Daneben beteiligten sich am Bildungsdiskurs der zweiten Hälfte des 19. Jahrhunderts auch verschiedene

${ }^{215}$ E. Key, Das Jahrhundert des Kindes. Studien. Autorisierte Uebertragung won Francis Maro. Neu herausgegeben mit einem Nachwort von Ulrich Herrmanm (1992), 77.

${ }^{216}$ Auf die Parallele zwischen der Landerziehungsheimbewegung und der Erziehungsanstalt in Mine-Haha wurde bereits hingewiesen; vgl dazu Vivarelli (1981), 58. Zu Wynekens Reformansatz vgl. U. Linse, Die Jugendkulturbewegung (1976), 124ff.

${ }^{217} \mathrm{Vgl}$. dazu McVay (1980), 8f.

${ }^{218}$ Noch 1897 waren 70,67\% der russischsprachigen Bewohner des Russischen Reiches nicht lesefahig. Vgl. dazu Altrichter (1997), 559.

${ }^{219} \mathrm{Vgl}$. dazu Stökl (5. Aufl. 1990), 552ff.

220 Zur Rolle der Zemstrua beim Aufbau des russischen Bildungswesens vgl. V. Davydov (Hrsg.), Rossijskaja pedagogičeskaja énciklopedija v cturuch tomach, Bd. I (1993), 329. 
russische Schriftsteller, allen voran Lev Nikolaevic Tolstoj mit seiner Volksschule auf dem Landgut Jasnaja Poljana. ${ }^{221}$ So stießen die aus Westeuropa und den Vereinigten Staaten kommenden Ideen der Reformpädagogik auch in den Kreisen der russischen Intelligenz auf ein gewisses Interesse. Dies zeigt sich daran, daß Ellen Keys programmatische Schrift bereits drei Jahre nach ihrem Erscheinen in Deutschland 1905 unter dem Titel Vek rebenka auch russischen Lesern zugänglich gemacht wurde. ${ }^{222}$ Beeinflußt von Tolstoj und den ausländischen Reformpädagogen wurden auch in Rußland kurz nach der Jahrhundertwende verschiedene Versuche unternommen, durch veränderte Erziehungsmethoden zu einer Reform der Gesellschaft beizutragen. Eine führende Rolle hierbei übernahm der spätere Mitarbeiter des Volkskommissariats für das Bildungswesen Stanislav Teofilovič Šackij (1878-1934). ${ }^{223}$

Sowohl Wedekind als auch Arcybasev befaßten sich in verschiedenen Texten mit Fragen der Bildung und Erziehung und nahmen dabei einen ausgesprochen kritischen Standpunkt zu den Zielen und Inhalten der traditionellen Bildung ein. Frank Wedekind tat dies in seiner 1891 veroffentlichten 'Kindertragödie' Frühlings Erwachen, und Arcybašev verfaßte bereits 1901 eine Erzăhlung mit dem Namen Paša Tumanov, die auf Grund des Widerstands der Zensurbehörden erst 1906 in seinem ersten Sammelband von Erzählungen erschien. In ihr wird beschrieben, wie ein bei einer Prüfung durchgefallener Schüler aus Verzweiflung den Direktor seines Gymnasiums erschießt. ${ }^{224}$

\subsection{Mine-Haha}

\subsubsection{Erziehung ohne Familie}

Das wohl auffälligste Merkmal des Erziehungsprogramms der in Mine-Haha beschriebenen Erziehungsanstalt besteht in der Trennung des Entwicklungs- und Erziehungsprozesses von seinem traditionellen Träger, der Familie. Bereits

221 Grundgedanke der von Tolstoj entwickelten und auf Jasnaja Poljana angewandten Pädagogik war das Prinzip der Freiheit bei der Erziehung. Ein relativ ausfuhrlicher AbriB über Tolstojs pädagogisches Wirken findet sich in L. Froese, Ideengeschichtliche Triebkräfie der russischen und sowjetischen Poidagogik (2. Aufl. 1963), 78ff.

222 Vgl dazu Davydov, Bd. 1 (1993), 427.

223 Nähere Angaben zu dessen Beitrag zur Entwicklung der russischen und sowjetischen Pädagogik finden sich bei $O$. Anweiler, Geschichte der Schule und Pädagogik in RuBland vom Ende des Zarenreiches bis zum Beginn der Stalin-Ära (1964), 54ff.

${ }^{24}$ Die Erzählung Paša Tumanov ist abgedruckt in Arcybašev (1990), $317 \mathrm{ff}$. 
Trockij hat in seinem Wedekind-Aufsatz auf diese Besonderheit hingewiesen, wenn er in bezug auf Wedekinds Romanfragment von der ,vollständigen Ablehnung der modernen Familie - wenigstens, soweit es sich um die Verbindung zwischen Eltern und Kindern handelt ${ }^{.225}$ - spricht. In dem Versuch, die Familie als Keimzelle der bürgerlichen Gesellschaft durch ein kollektives Erziehungssystem zu ersetzen, nimmt Wedekinds Text ein wesentliches Element der frühsowjetischen Pädagogik vorweg. ${ }^{226}$ Das Interesse sozialistischer Theoretiker wie Trockij an dem Romanfragment ist also nicht völlig zufallig.

Hidallas Erinnerung an ihre Kindheit beginnt zu einem Zeitpunkt, zu dem sie sich bereits in der Erziehungsanstalt im Park befindet. Mit keinem Wort hingegen erwähnt die Ich-Erzählerin ihre Eltern. Vielmehr wächst sie von Anfang an inmitten von anderen Kindern auf, die in zahlenmäßig streng geordneten Verbänden unter der Obhut von an der Schwelle zum Erwachsenenleben stehenden Erzieherinnen leben. $\mathrm{Da}$ Eltern als Bezugspersonen im Erziehungssystem des Parks fehlen, taucht das Motiv einer Eltem-KindBeziehung- für die Zöglinge zum ersten $\mathrm{Mal}$ in der erotischen Pantomime Der Mückenprinz auf, von der Theodor W. Adorno (1903-1969) behauptete, sie enthielte wie die übrigen Ballette den Schlüssel zur Interpretation von Wedekinds Dichtung. ${ }^{227}$ In dem Stück, dessen Inhalt von Hidalla referiert wird, treten ein Zauberer namens Hächi-Bümbüm und seine Tochter Ada auf (vgl. 118ff.).

Der Ausbildung im Park liegt das „Prinzip der Verantwortlichkeit als allgemeiner Erziehungsanspruch“c228 zugrunde, so daß jeweils die älteren Mitglieder einer Gruppe Verantwortung für die jüngeren übernehmen. Diese setzt mit Beginn des fünften Lebensjahres ein und umfaßt zunächst die Pflege der neu in die Anstalt aufgenommenen Säuglinge (vgl. 92). Unklar bleibt in Hidallas Bericht, woher die Säuglinge kommen bzw. wer ihre Eltern sind. Wenn man, wie Medicus, annimmt, daB Wedekinds Romanfragment von vornherein als Teil des später in seinen Notizbüchern skizzierten (iroße-liebe-Projekts geplant war, ${ }^{229}$ so kann man vermuten, daß die Säuglinge in der Erziehungsanstalt das Produkt der Paarungsrituale der Frühlings- und Herbstfeiern sowie der Prostitution sind. ${ }^{230}$

Im Widerspruch zu der auf der Ausschaltung von familiären Bindungen und festen Partnerbeziehungen basierenden Erziehung im Park stehen allerdings einige Umstände aus Hidallas späterem Leben, die die Ich-Erzählerin im Laufe

22s Trotzkij [Trockij] (1968), 375. Die zitierte Stelle steht im russischen Text an folgender Stelle: Trockij (1926), 412

${ }^{226}$ Zur Geschichte der Kollektiverziehung vgl. Chr. Wulf, Wörlerbuch der Frziehung (6. Aufl. 1984), 330ff.

$227 \mathrm{Vgl}$ dazu Adorno (1974), 632.

228 Medicus (1982), 166.

$229 \mathrm{Vgl}$ ebd. 128.

${ }^{230} \mathrm{Vgl}$. Wedekind, NB 39-40, passim. 
ihres Berichts einflicht. Auch wenn sie nirgends eine Ehe erwähnt, so scheint sie dennoch nach ihrem Austritt aus der Erziehungsanstalt in mehreren aufeinanderfolgenden monogamen Gemeinschaften mit Männern gelebt zu haben. Wie sonst sollte man Hidallas Hinweis deuten, daß sie drei Jahre nach ihrem Auftritt im Mückenprinz mit ihrem „damaligen Freund und Beschützer Fabian zum erstenmal als Zuschauerin im Theater war" (122)? Interessant erscheint in diesem Zusammenhang auch der Umstand, daß die Bindung der Ich-Erzählerin an ihren Sohn Edgar offensichtlich stark genug ist, um aus Rücksicht auf ihn von einer sofortigen Veröffentlichung ihrer Lebensgeschichte abzusehen. Derartige Details legen den Schluß nahe, daß außerhalb des Parks durchaus Eltern-KindBeziehungen bestehen.

Wăhrend der gesamten Ausbildung in der Parkanstalt wird versucht, das Entstehen starker zwischenmenschlicher Bindungen unter den Zöglingen zu verhindern. Im Verlauf des in Mine-Haha beschriebenen Erziehungsabschnittes werden die Madchen zweimal aus ihrer gewohnten Umgebung herausgerissen und gewissermaßen in ein völlig neues soziales Umfeld 'verpflanzt'. Sowohl das Verlassen der Kiste zu Beginn der Mădchenjahre (vgl. 96) als auch der Eintritt in die Außenwelt (132f.) tragen infolge des Wechsels von Dunkelheit und Helligkeit deutlich die Züge einer Neugeburt. ${ }^{231}$ Ebenso wie die Erziehung zur Schmerzunempfindlichkeit sowie das Verbot intimer körperlicher Beziehungen zwischen den Zöglingen der Anstalt scheint auch diese zweimalige Entwurzelung der Mädchen das Ziel zu verfolgen, die Gefühle als Steuerungsinstanz des menschlichen Verhaltens auszuschalten.

\subsubsection{Unwissenheit als Erziehungsgrundsatz}

Die Weitergabe von Wissen und Können zwischen den Generationen ist traditionell ein wesentliches Anliegen jeglicher Art von Erziehung. Durch die Entfernung der Eltern aus dem Erziehungssystem in Frank Wedekinds MineHaha wird die Übermittlung von Wissen zwischen Eltern und Kindern gänzlich unterbunden, und die Vermittlung von körperlichen Fertigkeiten findet lediglich innerhalb der eigenen Generation von den Älteren zu den Jüngeren statt. Da sich die Ausbildung der Mädchen ausschließlich auf die körperliche und die rhythmisch-musische Entwicklung beschränkt, spielt die Vermittlung von Wissen ohnehin im Erziehungsprogramm des Parks keine Rolle. Eine Wissensosmose

231 Elizabeth Boa deutet das Einschließen der Kinder in der Kiste, die sie als "coffinlike box" bezeichnet, offensichtlich als symbolischen Tötungsakt. Sie übersieht dabei jedoch, daß für die Zöglinge danach gewissermaßen ein 'neues Leben' beginnt. Vgl. dazu Boa (1987), 190. Vor Boa hatte auch Hans Carossa die Kiste mit einem Sarg verglichen. Vgl. dazu Carossa (1957), 465 . 
zwischen den über ein größeres Wissen verfügenden Erzieherinnen und ihren Schützlingen findet nur an wenigen Punkten der Handlung statt - etwa als Simba Hidalla und ihre Altersgenossinnen über die bevorstehende "Veränderung“ unterrichtet (vgl. 127).

Über weite Strecken hinweg werden die Mädchen jedoch im unklaren darüber gelassen, was mit ihnen geschieht bzw. welchen ultimativen Zweck ihre Erziehung verfolgt - Hidalla spricht zu Beginn des Kapitels III von „der gänzlichen Unwissenheit, in der wir lebten“ (113). So bleiben für die Zöglinge des Parks zahlreiche Fragen offen - so etwa die Frage nach ihrer eigenen Herkunft, nach dem weiteren Schicksal der Auserwählten, nach der Erziehung der Knaben sowie nach dem Leben außerhalb des Parks usw. Unklar bleibt auch, wer hinter der Organisation der Erziehungsanstalt steht bzw. wer über die Aufrechterhaltung der Ordnung wacht. Vom Funktionieren dieser Ordnung zeugen lediglich Ereignisse wie die geheimnisvolle Beseitigung der Leiche des ertrunkenen Mädchens (vgl. 114) sowie die Existenz der Dienerinnen in jedem Haus.

Die bewußte Unterdrückung von Informationen sowie die fehlende Transparenz der Vorgänge im Park - beides Wesensmerkmale totalitärer Gesellschaftssysteme - sind wesentliche Bedingungen für das Funktionieren der Erziehungsanstalt. Das Erziehungskonzept des Parks basiert deshalb auf dem Prinzip der Vermittlung von Erfahrungen anstelle von Verständnis. Besonders deutlich wird dieser Grundsatz in den erotischen Pantomimen, die die Mädchen im Theater auffuihren: Kurz vor dem Erreichen der Geschlechtsreife haben diese Theaterstücke die Funktion einer sexuellen Aufklärung, ohne die Kinder zu einem kognitiven Erfassen ihrer Situation zu führen.

Fechter sah im Motiv der Unwissenheit der Zöglinge in Mine-Haha eine Kritik an „der Sinnlosigkeit unserer bestehenden Mädchenerziehung, die die Kinder, unwissend über alles, was sie angeht, ohne Ahnung von ihren körperlichen Lebensaufgaben und -vorgängen heranwachsen läßt“. ${ }^{232}$ Dem ist jedoch entgegenzuhalten, daß anders als in Frühlings Erwachen das Element der Anprangerung falscher Erziehungsformen in Mine-Haha fehlt. So werden keine tragisch verlaufenden Schicksale von Jugendlichen gezeigt, und das Motiv des Generationenkonflikts - ein wesentlicher Bestandteil von Frühlings Erwachen kommt in Wedekinds Romanfragment überhaupt nicht vor. Vielmehr steht im Mittelpunkt der Handlung eine Erzählerin, deren eigene Haltung zu dem Erziehungsprogramm des Parks erklärtermaßen affirmativ ist.

So wird die Richtigkeit dieses Erziehungsprinzips von der Ich-Erzählerin, wie auch von der Mehrzahl der übrigen Mädchen, zu keinem Zeitpunkt ihres Berichts ernsthaft in Frage gestellt:

${ }^{232}$ Fechter (1920), 154 
Ich weiß, daß ich niemanden mehr gefragt habe, wozu man Olesia und Isabella auserwählt und was mit Wera nächstes Jahr werden würde. Aber ich weiß nicht, ob ich es aus Furcht nicht tat oder ob ich nachgerade wie die anderen fühlen lernte. Blanka war die älteste von uns, sie hatte ihr dreizehntes Jahr zurückgelegt, und sie wußte geradeso wenig wie ich. Das sagte ich mir, wenn mir ein Gedanke kam. Ich erinnere mich auch nicht, in den späteren Jahren noch irgendwie von Neugierde geplagt worden zu sein (110).

Dennoch wird im Laufe von Hidallas Erzählung deutlich, daß der Zustand der Unwissenheit, in dem die Zöglinge der Parkanstalt leben, nicht auf Dauer aufrechterhalten werden kann. So vernimmt Hidalla während einer Aufführung des Mückenprinzen eines Abends eine Stimme aus dem Publikum, die sich mit den Worten „Dir fehlt das Beste“ (126) an sie richtet. Ohne zu wissen, was die anonyme Person meint, ist sich Hidalla dennoch zunehmend der Tatsache bewußt, daß ihre Tage im Park gezählt sind, und sehnt selbst „eine Veränderung herbei“"(131).

\subsubsection{Entwicklung als gelenkter Reifeprozeß}

Wie anhand des Untertitels von Mine-Haha unschwer erkennbar ist, greift Wedekind in seinem Prosafragment auf die in der deutschen Literatur des ausgehenden 18. und des 19. Jahrhunderts weit verbreitete Gattung des Bildungsund Erziehungsromans zurück. Auf diese in der Wedekind-Forschung gelegentlich betonte Traditionslinie verweist beispielsweise Sol Gittleman, indem er Mine-Haha als "novel of education" ${ }^{\text {“233 }}$ bezeichnet. Bei einem Vergleich mit einem der bekanntesten Repräsentanten der Gattung, Goethes 1795/96 erschienenem Roman Wilhelm Meisters lehrjahre, lassen sich in der Tat einige (allerdings nur äußerliche) Anknüpfungspunkte zwischen beiden Texten erkennen.

$\mathrm{Zu}$ erwähnen ist in diesem Zusammenhang zunächst das Motiv der „Wanderung durch die Welt als Gang zu sich selbst ${ }^{\text {‘234 }}$, die in Goethes Roman fester Bestandteil des Bildungsprozesses des Titelhelden ist. In Wedekinds Romanfragment wird das Wandermotiv in Form der Spaziergänge aufgegriffen, die Hidalla - in der Regel gemeinsam mit anderen Mädchen - im Park unternimmt. Analog zu den Helden des klassischen Bildungsromans bringen diese für die Erzählerin stets einen Zuwachs an Erkenntnis mit sich. So erfährt Hidalla von Wera die Vorgeschichte der beiden alten Dienerinnen Irma und Margareta

${ }^{233}$ Gittleman (1969), 130.

${ }^{234}$ F. Loquai, Vom (jehen in der Literatur (1993), 20. 
(106f.), und von Pamela wird ihr das Theater gezeigt (108). Bei einer späteren Gelegenheit sieht sie ein Pferd und fühlt sich an ihre erste Erzieherin Gertrud erinnert (109), und bei zwei weiteren Spaziergängen erblickt sie die Mauern und das Gittertor des Parks (114f.). Verglichen mit dem Werdegang des Helden in Goethes Roman ist das Motiv des Wanderns in Mine-Haha mit seinem hermetisch von der Außenwelt isolierten Naturraum jedoch nur noch rudimentär vorhanden.

Der den Ablauf des Erziehungsprozesses bestimmenden Parkanstalt in Mine-Haha entspricht bei Goethe die mysteriöse Turmgesellschaft, die den Bildungsproze $B$ des Titelhelden ohne dessen Wissen steuert. Im Gegensatz zu Wilhelm Meister wird jedoch Hidalla nach AbschluB der Ausbildung nicht über die Ziele ihrer Erziehung aufgeklärt, und in dieser fehlenden Transparenz wird bereits das in beiden Werken gänzlich unterschiedliche Erziehungs- und Entwicklungskonzept deutlich.

Entscheidend für das Bildungsverständnis in Goethes Roman ist die Tatsache, daß sich Wilhelm Meisters vermeintliche Irrwege letzten Endes als notwendige Bestandteile des Bildungsprozesses des Helden entpuppen. So erfährt die Titelfigur bei ihrer Initiation durch die Turmgesellschaft folgendes vom Abbé:

[...] nicht vor Imtum zu bewahren, ist die Pflicht des Menschenerziehers, sondern den Irrenden zu leiten, ja ihn seinen Irrtum aus vollen Bechern ausschlurfen zu lassen, das ist Weisheit der Lehrer. ${ }^{235}$

Kurz darauf heißt es weiterhin: „Steile Gegenden lassen sich nur durch Umwege erklimmen, auf der Ebene führen gerade Wege von einem Ort zum andern. “236 In der Erziehungsanstalt in Wedekinds Romanfragment hingegen wird jedes Abweichen vom vorgegebenen Weg durch Bestrafung geahndet.

An die Stelle der Anleitung zur individuellen Suche nach Bildung, dem Erklimmen 'steiler Gegenden', auf die die Tätigkeit der Turmgesellschaft abzielt, tritt in Mine-Haha die Erziehung des Menschen zum Kollektivwesen. Das Individuum spielt dabei lediglich eine weitestgehend passive Rolle. Es ist allerdings anzumerken, daß Goethe selbst in der Fortsetzung seines berühmten Romans sein Bildungskonzept aus den lehrjahren in wesentlichen Punkten revidiert hat. In seinem 1821 bzw. 1829 in zwei Fassungen erschienenen Roman Wilhelm Meisters Wanderjahre oder die Entsagenden nämlich gibt der Titelheld seinen Sohn Felix zur Ausbildung in eine Erziehungsanstalt. Diese als 'pädagogische Provinz' bezeichnete Einrichtung, die in ihrer räumlichen Abgeschiedenheit von der Außenwelt die Parkanstalt in Wedekinds Mine-Haha

${ }^{235}$ J. W. Goethe, Sämtliche Werke, Bd. 9 (1. Aufl. 1992), 873

${ }^{236}$ Ebd., 874 
vorwegnimmt, markiert eine behutsame Abkehr vom Prinzip des 'Lernens durch Irrwege'.

Wilhelm Meister gegenüber umreißt der alte Sammler das Erziehungsprogramm der 'pädagogischen Provinz' folgendermaßen:

Weise Männer lassen den Knaben unter der Hand dasjenige finden [!] was ihm gemäß ist, sie verkürzen die Umwege, durch welche der Mensch von seiner Bestimmung, nur allzugefällig, abirren mag. ${ }^{237}$

Anders als in der in Wedekinds Romanfragment beschriebenen Erziehungsanstalt werden in der 'pädagogischen Provinz' der Wanderjahre jedoch trotz des im Vergleich zu den Lehrjahren größeren Ökonomisierungsgrads des Bildungsprozesses keine entindividualisierten Kollektivwesen herangezogen. Nicht zuletzt wird dies an der mannigfaltigen Kleidung der Zöglinge sichtbar.

Was also zeichnet das pädagogische Programm der Parkanstalt in MineHaha aus? Hidalla faßt die Rolle der Zöglinge des Parks im Erziehungsprozeß zu Beginn des Kapitels III mit den folgenden Worten zusammen: „Wir hatten nichts anderes zu tun, als zu wachsen" (113). Sobald mit dem Eintreten der Veränderung - anderswo ist von Reife die Rede (vgl. 114) - ein bestimmtes Stadium der körperlichen Entwicklung erreicht ist, werden die Mädchen aus der Erziehungsanstalt entlassen. Auf den individuellen Zögling abgestimmte pädagogische Ziele werden bei der Erziehung nicht verfolgt. Die Aufgabe der Erziehungsanstalt besteht hierbei in der Schaffung möglichst günstiger Bedingungen für den Reifeproze $B$ der Zöglinge. Deren freies Aufwachsen ist offensichtlich unerwünscht. Högers Behauptung, Wedekinds Frühwerk liege die Prämisse zugrunde, daß es Erziehung nicht brauche, ${ }^{238}$ ist in bezug auf MineHaha zurückzuweisen.

Da nach Hidallas Verständnis Schönheit erst im Zusammenspiel des schönen Körpers und der technisch perfekten Präsentation desselben entstehen kann, wird impliziert, daß sich die menschliche Entwicklung zu einem gewissen Grad von außen beeinflussen läßt. Diese Einflußmöglichkeiten versucht die Anstalt durch die Anleitung der Mädchen zur vollständigen Körperbeherrschung und zur Kontrolle ihrer Gefuihle wahrzunehmen. Dem Erziehungsprogramm der Parkanstalt liegt also die Auffassung zugrunde, daß die menschliche Entwicklung sowohl das Resultat eines körperlichen Reifeprozesses als auch die Folge von Erziehung ist. Gleichzeitig zeigt Hidallas Erzählung jedoch auch deutlich, daB Erziehung die wahre Natur der Zöglinge nicht dauerhaft im Zaum halten kann.

237 Goethe, Bd. 10 (1. Aufl. 1989), 413.

$238 \mathrm{Vgl}$. dazu Höger (1981), 174 


\subsubsection{Bezwingung der Natur als Ziel der menschlichen Entwicklung}

Anstatt auf die geistige Entwicklung der Kinder hinzuarbeiten, zielt die Ausbildung im Park darauf ab, motorische Funktionen des Körpers zur Perfektion zu bringen. Das Erziehungssystem des Parks findet seine Vollendung in Erzieherinnen wie Gertrud und Simba, die in ihrer völligen Beherrschung des Körpers eher einem dressierten Tier als einem Menschen ähneln. Nicht ohne Grund werden beiden tierische Attribute zugeschrieben, auf die in dieser Arbeit bereits hingewiesen wurde. Unübersehbar sind in Mine-Haha auch zahlreiche andere Details in der Beschreibung der Erziehungsanstalt, die den Eindruck einer „Zirkusatmosphärec ${ }^{\text {239 }}$ erwecken - man denke etwa an das Gitter zwischen Bühne und Zuschauerraum im Theater oder an das Aufstellen der Kinder der Größe nach.

Eine in der Forschungsliteratur immer wieder betonte Eigenart des Wedekindschen Erziehungsbegriffs besteht darin, daß der Schriftsteller von der pädagogischen Funktion des Zirkus überzeugt war. ${ }^{240}$ Tatsächlich gleicht die Ausbildung der Mädchen, so wie sie von Hidalla beschrieben wird, eher der Dressur von Tieren in einem Zirkus als der Erziehung von Kindern im herkömmlichen Sinne. Der Begriff Dressur wird in dem von Winfried Böhm herausgegebenen Wörterbuch der Pädagogik als "die Entartung wirklicher Erziehung zum bloßen Einpflanzen herkömmlich-konventioneller Verhaltensweisen und/oder zum Kult technisch-beruflicher Fertigkeiten bei gleichzeitiger Dehumanisienung des menschlichen Lebens ${ }^{\text {“241 }}$ umschrieben. Daß diese Definition auch auf das pädagogische Programm der Erziehungsanstalt in MineHaha zutriff, liegt auf der Hand.

So ist das Ziel der Ausbildung im Park nicht die Herausbildung einer eigenständigen Persönlichkeit durch die Förderung der individuellen Begabungen des Lemenden und die Vermittlung von kulturellem Wissen, sondern die Brechung des eigenen Willens und die Fähigkeit, bis zu einem gewissen Grad gegen die eigene Natur zu handeln. Dies ist der eigentliche Zweck der Geh- und Haltungsübungen zu Beginn der Ausbildung im Park. Auch die Tatsache, daß die Mädchen beim Theaterspielen nacheinander in verschiedenen Rollen auftreten müssen (vgl. 126), macht deutlich, daß die Fähigkeit zur Ausführung eines fremden Willens ein wesentliches Erziehungsziel der Parkanstalt ist. Gefordert wird nicht die tiefgreifende psychologische Interpretation, sondern das mehr oder weniger mechanische Ausführen einer von außen bestimmten Rolle.

\footnotetext{
${ }^{239}$ Moniková (1985), 121

${ }^{240}$ Vgl. R. Kieser, Benjamin Franklin Wedekind. Biographie einer Jugend (1990), 338. Zu Wedekinds Faszination für den Zirkus als 'geistige Bildungsanstalt' vgl. A. Höger, Frank Wedekind. Der Konstruktivismus als schöpferische Methode (1979), $61 \mathrm{ff}$.

${ }^{241}$ W. Böhm, Wörlerhuch der Padagogik (14. Aufl. 1994), 181
} 
Somit treten in der Parkanstalt in Mine-Haha die Bezwingung der eigenen Natur und die Aufgabe des individuellen Willens als übergeordnete Erziehungsziele an die Stelle der aufklärerischen Maxime der Persönlichkeitsentfaltung. Wie bereits gezeigt wurde, erstreckt sich das Gebot der Unterordnung des eigenen Willens unter die von außen auferlegten Verhaltensregeln gerade auch auf den Bereich des Sexuellen. Hans Wageners Behauptung, in Mine-Haha würden ,Schönheit der Bewegung, Betonung des Körperlichen $[\ldots]$ als eine Art natürlicher Erotik proklamiert", ${ }^{242}$ ist insoferm unhaltbar. Zutreffender ist sicherlich das Urteil Elke Austermühls, die in Zusammenhang mit dem Wedekindschen Romanfragment von einem „menschenverachtenden Abrichtungsproze $B$, der entsubjektivierte und entmündigte Automaten hervorbringt" ${ }^{243}$ spricht.

An dieser Stelle ist nochmals auf den Titel des Wedekindschen Textes einzugehen. Angesichts des intertextuellen Verweises auf die nach einem Wasserfall benannte Minnehaha aus Longfellows The Song of Hiawatha sowie angesichts der durch den fiktiven Herausgeber im Nachwort angeführten Übersetzung des Titels als 'Lachendes Wasser' kommt dem Motiv des Wassers in Wedekinds Text eine Schlüsselfunktion bei der Deutung zu. Wie aber hat der Leser das Bild des 'Lachenden Wassers' aufzulösen? Bisher wurden in der Wedekind-Literatur nach dem Wissensstand des Verfassers vier unterschiedliche Deutungsvorschläge gemacht: Paul Fechter interpretiert den Titel Mine-Haha in seiner eher biographisch ausgerichteten Arbeit zu Wedekind im Sinne einer „Mischung von Emst und Spiel, von Spott und Tränen“244, während Thomas Medicus ihn als ambivalenten Verweis auf die Sexualität der Mädchen versteht "lachend als Ausdruck fröhlicher Unschuld oder lachend über ein Wissen, das sich noch verbirgt“. ${ }^{245}$ Walter Schmitz und Uwe Schneider hingegen stellen in ihrem Nachwort zur Insel-Ausgabe des Fragments von 1994 zwei verschiedene Deutungsansätze zur Diskussion - Mine-Haha als ,spöttische Verballhornung des 'Minne'-Konzepts" sowie als Chiffre für den Samenerguß beim Geschlechtsakt. ${ }^{246}$

Es spricht für die literarischen Qualitäten des Wedekindschen Textes, daß sich den bisher erwähnten Interpretationsversuchen des Titels noch eine weitere Lesart hinzufügen läßt. Erinnem wir uns daran, daß der Kontakt mit dem Naturelement Wasser im Erziehungsprogramm des Parks eine wichtige Rolle spielt: Bereits früh werden die Kinder dazu angehalten, während der warmen Jahreszeit einen großen Teil ihrer Freizeit unter freiem Himmel zu verbringen. Im

\footnotetext{
242 Wagener (1979), 55.

${ }^{243}$ Austermühl (1994), 50.

${ }^{244}$ Fechter (1920), 155

245 Medicus (1982), 172

${ }^{246}$ Schmitz/ Schneider (1994), 93f.
} 
Verlauf der ersten Jahre der Erziehung geschieht dies beim gemeinsamen Spielen in einem 'Weiher' mit einer Fontäne (vgl. 91), nach der Trennung von Mädchen und Jungen hingegen beim gemeinsamen Baden im Bach.

Entscheidend jedoch ist in diesem Zusammenhang der bereits in einem früheren Kapitel erwăhnte Umstand, daß die Begegnung der Kinder mit der Natur in einem von Menschenhand geschaffenen Naturraum stattfindet. Infolgedessen erscheint das Wasser in Wedekinds Mine-Haha keinesfalls in Form des wilden, naturbelassenen Wasserlaufs mit einem Wasserfall, sondern es begegnet den Zöglingen der Anstalt als durch Staustufen und Fliesen gezähmte Natur. Im Motiv des Wassers spiegelt sich in Wedekinds Romanfragment also gewissermaßen das auf eine Bezwingung der menschlichen Natur abzielende pädagogische Programm der Parkanstalt wider. Vinçon stellt deshalb zu Recht fest: "Diese wahrhafte Natur ist aber nur eine imaginäre Größe, und der Ort dieser Erziehung ist so künstlich wie die Erziehung selbst. ‘247

Somit läßt sich auch in Wedekinds Mine-Haha ein paradoxer Zug erkennen, der die gesamte von Rousseau inspirierte Naturschwärmerei der Jahrhundertwende prägt: „Erlösung versprach die Natur nicht als Dschungel, sondern als vom Menschen bestellter Garten“. ${ }^{248}$ Möglicherweise handelt es sich bei dieser Sehnsucht nach einer geordneten Natur jedoch um eine Konstante sämtlicher Vorstellungen von einem locus amoenus, denn bemerkenswerterweise läßt sich die Urbedeutung des aus dem Altiranischen stammenden Substantivs Paradies mit 'umwallter oder umzäunter Park oder Garten' paraphrasieren. ${ }^{249}$ Wedekinds Park als Zuchtanstalt des 'neuen Menschen' rekurriert also auf den alten Wunsch, durch die Bezwingung der Natur zu einem erlösten Zustand zu gelangen.

\subsection{Sanin}

\subsubsection{Sanins Entwicklung}

Sanin als 'positiver Held' des Arcybaševschen Romans wird dadurch charakterisiert, daß er als Figur ohne psychologische Tiefe gezeichnet wird.

\footnotetext{
247 Vincon (1987), 169.

${ }^{248}$ Lepp/ Roth/ Vogel (1999), 106.

$249 \mathrm{Vgl}$. dazu K. H. Börner, Auf der Suche nach dem irdischen Paradies. Zur Ikonographie der geographischen Utopie (1984), 17. Gerade im Jugendstil erfreute sich die Vorstellung des hortus conclusus großer Beliebtheit. Vgl. dazu R. Walter, Nietzsche - Jugendstil - H. Mamm. Zur geistigen Situation der Jahrhundertwende (1976), 79.
} 
Anders als sein Gegenspieler Jurij Svarožiž reflektient er nicht über das Für und Wider seines eigenen Verhaltens, sondern er scheint vielmehr stets von der Richtigkeit seines Handelns überzeugt zu sein. Ein Anflug von Selbstkritik des Titelhelden wird nur an wenigen Stellen in der Handlung deutlich, wie etwa als Sanin nach seinem Besuch bei Solovejcik vermutet, daß sich Zarudin erschossen hat:

С минуту он молча глядел в тусклое лицо ночи, и хазалось, между тем загадочным и страшным, что было в ней, и им, высоким, сильным человеком, с твердым взглядом, произошла короткая и страшная, молчаливая борьба (XXXII, 240). ${ }^{250}$

Jedoch dauert Sanins innerer Kampf nicht lange, und wenig später ist er bereits wieder völlig von der Richtigkeit seines Handelns überzeugt: „Не Я в этом виноват, - громко сказал он... - одним больше, одним меньше!..“ (ebd.). ${ }^{251}$

In seiner Stilisierung zum Naturmenschen gleicht Sanin von der Struktur seiner Psyche her eher einem Tier als einem Menschen. Im Gegensatz zu Jurij Svarožic kennt Sanin keine Gefühlsschwankungen. Sofern der Erzähler überhaupt Sanins Empfindungen erwăhnt, sind diese im wesentlichen positiver Art - Freude über die Schönheit der Natur und der Frauen sowie tiefe Zufriedenheit mit seinem Leben. An dem, was in seiner Umgebung vorgeht, nimmt Sanin kaum emotionalen Anteil. Fast durchgangig tritt er seiner Umwelt mit derselben heiteren Gleichgültigkeit gegenüber, und lediglich wenn er wie im Eisenbahnabteil Zeuge 'brutalen' Verhaltens wird, gerät Sanin für kurze Zeit in Wut (vgl. XLVI, 316; 396).

In Sanins Verhalten lassen sich keme Anzeichen entdecken, die Rückschlüsse auf eine geistige oder emotionale Entwicklung im Verlauf der Romanhandlung rechtfertigen. Vielmehr scheint er bei seinem unvermittelten Auftauchen in der Kleinstadt im späten Frühling bereits derselbe Mensch zu sein, als der er sie zu Beginn des Herbstes desselben Jahres wieder verläßt. Nichts in Arcybaševs Text deutet darauf hin, daß die Begegnungen mit den verschiedenen Figuren des Romans sowie auch die intime Beziehung zu Karsavina in Sanins Persönlichkeit irgendwelche Spuren hinterlassen.

Bei der Suche nach einer Entwicklung der Hauptfigur muß man sich also auf die Informationen stützen, die der Erzähler und die Titelfigur selbst zu Sanins Vorgeschichte liefern. Es fällt auf, daß Sanin auf Grund der wenig präzisen

250 Übersetzung: „Einen kurzen Augenblick starte er in das trube Antlitz der Nacht; zwischen jenem Rätselhaften und Unheimlichen, das sich in ihr barg [!] und in dem starken, kräftigen Mann schien ein kurzer, lautloser Kampf zu toben“" (XXXII, 292).

251 Übersetzung: "Nicht ich trage die Schuld daran,' sagte er laut... 'Einer mehr oder weniger!" (ebd.) 
Angaben zu seinem Vorleben nahezu als eine Figur ohne Vergangenheit erscheint: "So scant is the information supplied by Artsybashev about his hero that it is hard to believe in his existence outside the novel. ${ }^{1252}$ Hierin sah die Forschung eine Parallele zwischen Sanin und der zentralen Figur in Turgenevs Roman (Otcy i deti [Väter und Söhne], Evgenij Vasil'evið̌ Bazarov, den Vorovskij in seinem Vergleich der beiden Texte als „человек без прошлого, без 'биографии'“253 bezeichnet.

Was also erfährt der Leser über Sanins Werdegang vor Einsetzen der Romanhandlung? Auf Solovejciks Frage hin, ob er schon immer so gewesen sei, antwortet Sanin, daß auch er Zeiten des Zweifelns und zu Beginn seines Studiums auch eine Phase der Begeisterung für das christliche Gebot der Nächstenliebe erlebt habe (vgl. XXXII, 236; 287). Daß der Titelheld wăhrend seiner mehrere Jahre dauernden Abwesenheit aus der Heimatstadt zu einem anderen Menschen geworden ist, läßt sich an den Reaktionen seiner Mutter und seiner Schwester bei Sanins Rückkehr ins elterliche Haus ablesen. Lida gegenüber erwähnt Sanin einige Details aus seiner Vergangenheit - die Unbeständigkeit seines bisherigen Lebens, Hunger, Entbehrungen, Alkohol, Prauenbeziehungen sowie sein Engagement in illegalen politischen Gruppierungen, dessen er später wieder überdrüssig wurde. Aus den Erfahrungen der Vergangenheit, denen er bei seinem Eintreffen im elterlichen Haus 'völlig gleichgültig' (vgl. I, 20; $)$ gegenübersteht, hat Sanin offensichtlich einige Lehren für sein weiteres Leben gezogen. Seine Entwicklung erscheint jedoch zu Beginn des Romans als abgeschlossen.

Wie, so fragt man sich als Leser des Romans, kam es zu den von Mutter und Schwester zu Beginn des Romans bemerkten Veränderungen, die auf eine Entwicklung Sanins während der Zeit seiner Abwesenheit schließen lassen? Offensichtlich ist die Persönlichkeitsentwicklung des Titelhelden nicht auf den Einfluß traditioneller Bildung zurückzuführen, denn auch wenn Sanin Solovejčik gegenüber ein Studium erwähnt, so erscheint es angesichts der übrigen Details aus Sanins Vergangenheit eher unwahrscheinlich, daß er dieses abgeschlossen hat. Ebensowenig ist Sanins Entwicklung das Produkt traditioneller Erziehung, was der Erzähler bereits zu Beginn des Romans herausstellt:

То, самое важное в жизни, время, когда под влиянием первых столкновений с людьми и природой слагается характер, Владимир Санин прожил вне семъи. Никто не следил за ним, ничъя рука не пнула его, и

252 Luker (1980), 63.

253 V. V. Vorovskij (1923), 77. Übersetzung: „Mensch ohne Vergangenheit, ohne 'Biographie"“ [Übers. d. Verf.]. Eine Verbindung zwischen Bazarov und Sanin sieht auch Nina Malyševa, wobei sie Arcybaševs Held als Versuch der Diskreditienung der Figur in Turgenevs Roman versteht. Vgl. dazu N. Malyseva, Obraz Bazarova v obłcestvenno-politiceskoj polemike 1908-1910gg. (1986), 121. 
душа этого человека сложилась свободно и своеобразно, как дерево в поле $(I, 19){ }^{254}$

Die exponierte Stelle, an der das hier angefuihrte Zitat steht, zeigt, daß diese knappen Angaben zur Entwicklung des Titelhelden höchst signifikant für die Botschaft des Romans sind. Mit Sanin wird ein Menschentyp als positiver Held vorgeführt, dessen Entwicklung die Folge einer individuellen Willensanstrengung ist, der sich gewissermaßen selbst erzogen hat. ${ }^{25 s}$

Sally O'Dell hat in ihrer Arbeit Zweifel an der Angemessenheit des Vergleichs zwischen dem Titelhelden und einem Baum angemeldet, da ein Baum auch auf dem Feld durchaus auf seine Umgebung angewiesen sei. ${ }^{256}$ Tatsächlich muß sich auch Sanin wăhrend bestimmter Phasen seiner Entwicklung unter dem Einfluß anderer befunden haben. Wie sonst hătte er die Kulturtechniken des Lesens und Schreibens erwerben sollen? Offensichtlich beherrscht er diese, obgleich betont wird, daß Sanins Mutter nicht gewohnt ist, ihren Sohn beim Schreiben zu sehen (vgl. XXVIII, 199; 238). Auch die Tatsache, daß die infolge ihrer körperlichen Attraktivităt ausgesprochen positiv gezeichnete Karsavina sich als Lehrerin betătigt, zeigt, daß die Notwendigkeit grundlegender Bildung in Arcybaševs Text nicht in Frage gestellt wird.

In einem negativen Licht erscheint hingegen die höhere Bildung, die durch den Tod des schwindsüchtigen Studenten Semenov und den Selbstmord des aus Moskau verbannten Technologiestudenten Svarožic mit Krankheit bzw. Lebensunfähigkeit in Verbindung gebracht wird. Es gehört zu den Inkonsistenzen der von Sanin propagierten Weltanschauung, daß der Widerspruch zwischen einer offensichtlich als notwendig angesehenen Phase der Beeinflussung von außen und dem Ideal der freien Persönlichkeitsentwicklung nicht aufgelöst wird.

Arcybašev lăßt seinen Titelhelden Kritik an dem Glauben üben, man könne durch das Studium von Büchern zu einer brauchbaren Strategie zur Bewältigung des eigenen Lebens gelangen. „Неужели вы думаете серьезно, что по хаким бы то ни было книгам можно выработать себе какое-то

2s4 Übersetzung: „Jene wichtigste Zeit im Leben, wenn sich unter dem Einiluß der ersten Zusammentreffen mit den Menschen und der Natur der Charakter herausbildet, verlebte Vladimir Sanin außerhalb der Familie. Niemand kümmerte sich um ihn, niemandes Hand beugte ihn, und die Seele dieses Menschen entwickelte sich frei und auf ihre eigene Weise, wie ein Baum auf dem Feld" [Übers. d. Verf.] (vgl. I, 5).

25s Vgl. Vorovskij (1923), 89: „Подобво Базарову Санин не знал никаких воспитательных влияний; ов тоже 'воспитывал сам себя'“. Übersetzung: „Ähnlich wie Bazarov kannte Sanin keinerlei erzieherische Einflüsse; auch er 'erzog sich selbst" [Übers. d. Verf]

${ }^{256}$ Vgl. O’Dell (1980), 102. 
миросозерцание?“" (XXV, 189), ${ }^{257}$ fragt Sanin beim Treffen von Gožienkos Lesezirkel. Bildung durch die Rezeption fremder Ideen widerspricht offensichtlich dem von der Hauptfigur des Romans vertretenen Ideal der sich aus eigener Kraft 'wie ein Baum auf dem Feld' entwickelnden Persönlichkeit. Das Medium des Buches als Mittel der kulturellen Überlieferung erscheint damit im Kontext der Romanhandlung als eine Kraft, die den Menschen vom wirklichen Leben entfernt.

\subsubsection{Aufgeklärte Natürlichkeit als Ziel der menschlichen Entwicklung}

Auch wenn Sanin selbst den Auskünften des Erzählers zufolge während der wichtigsten Phase seiner Entwicklung keinen Einflüssen von außen ausgesetzt war, versucht er seinerseits durchaus, einen erzieherischen Einfluß auf bestimmte Personen in seiner Umwelt auszuüben. Seine Äußerungen während der zahlreichen philosophischen Diskussionen und Gespräche des Romans lassen den Titelhelden gewissermaßen als Prediger eines neuen Menschentypus erscheinen. Dieser Eindruck wird durch den Umstand verstärkt, daß Arcybašev seinem Text ein Epigraph aus dem Prediger Salomo im Alten Testament vorangestellt hat: „Schau, allein das hab ich gefunden: Gott hat den Menschen aufrichtig gemacht; aber sie suchen viele Künste“ (Prediger 7, 29). ${ }^{258}$

Bereits vor Beginn der Romanhandlung wird damit angedeutet, daß der Mensch sich von seiner ursprünglichen Wesensart entfernt habe. ${ }^{259}$ Jedoch ist das Verhältnis des Epigraphs zu Arcybaševs Roman komplizierter, als es zunächst den Anschein macht. Das entsprechende Kapitel des Alten Testaments nämlich, aus dem das Epigraph entnommen ist, ist eine Sammlung von in sich zum Teil widersprüchlichen aphoristischen Spruchweisheiten. Gerade auch der Vers Prediger 7, 29, in dem die Suche nach 'Künsten' als Entfremdung des Menschen von seinem ursprünglichen Wesen charakterisiert wird, steht in Widerspruch zu einem Vers zu Beginn des Kapitels, in dem das Streben des Menschen nach Weisheit als ebenfalls gottgegeben dargestellt wird (vgl. Prediger 1, 13). ${ }^{260}$

Auch innerfiktional wird die Auslegung des Epigraphs dadurch erschwert, daß auf den Prediger Salomo noch an zwei weiteren Stellen im Text rekurriert

257 Übersetzung: „Glauben Sie wirklich ernsthaft, daß man sich aus Büchem eine Weitanschauung aufbauen kann?‘ (XXV, 225).

${ }^{258}$ Im russischen Original des Romans lautet das Epigraph: „Только это нашел я, что Бог создал человека правым, а люди пустились во многие помыслы. 7.29. Екклезиаст“ $(I, 19)$.

${ }^{259} \mathrm{Vgl}$. dazu O'Dell (1980), 101. Vgl. außerdem Luker (1980), 61.

${ }^{260} \mathrm{Zu}$ diesem Widerspruch vgl. M. V. Fox, Qohelet and His Contradictions (1989), 343. 
wird. So schlägt Jurij Svarožič bei dem von dem Studenten Gožienko organisierten Treffen des Lesezirkels als mögliche Lektüren Konfuzius, das Evangelium und den Prediger Salomo (russisch: Eкклезиacm) vor und erntet dafür den Spott des Studenten (vgl. XXV, 188; 224). Kurz vor seinem Selbstmord schließlich liest Jurij Svarožič ein Traktat, das er selbst einige Tage zuvor in Anlehnung an den Prediger Salomo verfaßt hat.

Es ist bemerkenswert, da $B$ das Epigraph hier in abgeänderter Form wieder auftaucht: „Много придумано знаний, но не придумано жизни и счастья, чтобы наполнить их“ (XLI, 300). ${ }^{261}$ Die Erkenntnis des Widerspruchs zwischen dem Wissen, das die Menschheit erworben hat, und der Unfähigkeit, am Lauf der Welt etwas zu ändern, insbesondere das Rätsel des Todes zu lösen, ist das auslösende Moment für Svarožič' Selbstmord. Der Versuch des Technologiestudenten, den Geist des Prediger Salomo nachzuempfinden, scheitert, da es ihm im Gegensatz zum Titelhelden nicht gelingt, den in Prediger 9 formulierten Aufruf zum Lebensgenuß trotz der Erkenntnis der Nichtigkeit allen Seins nachzuvollziehen. Für Sanin hingegen sind sowohl Leben als auch Tod notwendige Bestandteile der menschlichen Existenz, die zu hinterfragen keinen Sinn macht: „Наша жизнь нужна, а следовательно, и смерть нужна...“ $(\mathrm{XII}, 100){ }^{262}$

Sanin predigt allerdings nicht eine bloße Rückkehr des Menschen zu seinen Ursprüngen, zu der das aus seinem Zusammenhang gerissene Zitat aus dem Prediger Salomo aufzurufen scheint, sondern eine Weiterentwicklung. Keinesfalls wird der Ausgangszustand der Menschheit verklärt, wie die folgende Bemerkung Sanins im Gespräch mit Karsavina zeigt:

Было время, когда человек жил узкой и скотской жизнью, не отдавая себе отчета в том, что и почему он делает и чувствует. Потом настала пора жизни сознательной, и первая ступень ее была переоценка всех своих чувств, потребностей и желаний (XXXVIII, 283). ${ }^{263}$

Ein wenig später in der Unterhaltung äußert Sanin noch deutlicher Kritik am ursprünglichen Entwicklungsstand der Menschheit, verbunden mit dem optimistischen Glauben an eine bessere Zukunft:

261 Übersetzung: „Viel Kenntnisse sind erfunden worden, aber man erfand nicht Leben und Glück, um sie zu füllen" (XLI, 373)

262 Übersetzung: „Unser Leben ist notwendig, folglich ist auch unser Tod eine Notwendigkeit.." (XII, /10).

263 Übersetzung: „Es gab eine Zeit, in der der Mensch ein beschränktes und viehisches Leben führte, ohne sich Rechenschaf darüber abzulegen, was er tat und fühlte und warum dies so war. Dann kam die Zeit des bewußten Lebens, und deren erste Stufe war die Neubewertung aller Gefuhle, Bedürfnisse und Wünsche des Menschen" [Übers. d. Verf.] (vgl. XXXVIII, 349). 
Та эпоха, когда люди жили только животом, была варварски грубой и бедной, наша, когда тело подчинено духу и сведено на задний двор, бессмысленно слаба. Но человечество жило не даром: оно выработает новые условия жизни. в которых не будет места ни зверству, ни аскетизму... (XXXVIII, 285) ${ }^{26 t}$

Gerade in diesem unbestimmten Glauben an eine bessere Zukunft widerspricht Sanin allerdings seiner eigenen Maxime, sich in seinem Handeln nur von den eigenen Bedürfnissen des Augenblicks leiten zu lassen.

Sanin unterscheidet drei Stufen der menschlichen Entwicklung, denen sich jeweils verschiedene Personen aus dem Figurenensemble des Romans zuordnen lassen: Auf der ersten - primitiven - Stufe dieser Trias verbleibt der Rittmeister Zarudin, der, wie erwähnt, von Sanins Schwester als скотина ('Mistvieh') bezeichnet wird. Jurij Svarožic hingegen vertritt die zweite logozentrische Stufe eines "profoundly life-denying pessimism that sapped the creative energies of so many members of his generation". ${ }^{265}$ Der Titelheld selbst wird als Vertreter der dritten Stufe vorgeführt, die bezeichnenderweise mit dem Attribut новый ('neu') in Verbindung gebracht wird.

Was jedoch kennzeichnet die menschliche Entwicklungsstufe, auf der sich der Titelheld befindet und die der Botschaft des Romans zufolge das Ziel der menschlichen Entwicklung darstellt? In der Beschreibung der Lebensphilosophie Sanins in Arcybaševs Roman läßt sich der Versuch erkennen, gewissermaßen eine Synthese zwischen der von Zarudin verkörperten primitiven Triebhaftigkeit und Jurij Svarožiz' Bestreben, den Körper dem Geist unterzuordnen, herzustellen. Angestrebt wird ein Zustand, in dem sowohl Brutalität (3версmвo) als auch Askese der Vergangenheit angehören.

Der von Sanin repräsentierte neue Menschentypus zeichnet sich somit dadurch aus, daß er sich seiner natürlichen Bedürfnisse bewußt ist und nicht den Versuch unternimmt, diese als moralisch verwerflich zu unterdrücken. Gerade im Bewußtsein der Macht der Triebe jedoch liegt nach dem Verständnis des Titelhelden der wesentliche Unterschied zwischen dem 'neuen Menschen' und dem Tier: „[...] потребность и понимание наслаждений и есть одна из

260 Übersetzung: „Jene Epoche, als die Menschen nur aus dem Bauch heraus lebten, war auf barbarische Weise grob und armselig, unsere hingegen, in der der Körper dem Geist unterworfen ist und in den Hintergrund gedrängt wurde, ist sinnlos schwach. Aber die Menschheit hat nicht umsonst gelebt: Sie wird neue Lebensbedingungen erarbeiten, unter denen weder Brutalität noch Askese einen Platz haben werden " [Übers. d. Verf.] (vgl. XXXVIII, 35I).

${ }^{265}$ Luker (1980), 68 
немногих черт, которыми естественный человек отличается от животного“ (III, 4I). ${ }^{266}$

$\mathrm{Da} B$ dieses offene Bekenntnis des 'neuen Menschen' zu den Trieben nach der Botschaft des Romans als Ausdruck von Ehrlichkeit und Aufrichtigkeit zu verstehen ist, zeigt sich deutlich in den Attributen, mit denen Zarudin und Sanin beschrieben werden: Während in Zusammenhang mit dem Rittmeister an verschiedenen bereits erwähnten Stellen des Romans immer wieder Wörter aus den Wortfamilien ckom ('Vieh') und зверь ('wildes Tier') verwandt werden, tauchen in Verbindung mit Sanin immer wieder Wörter aus den Wortfamilien естественный ('natürlich'), искренний ('aufrichtig') und правый ('im Recht seiend') auf. ${ }^{267}$ So wie der Erzähler Sanin zum Prediger von Natürlichkeit und Ehrlichkeit stilisiert, verstand Arcybašev selbst seine Dichtung als Ausdruck von Wahrheit. ${ }^{268}$

\subsubsection{Sanin - ein Roman ohne Entwicklung}

In kritischen Arbeiten zu Arcybaševs Sanin wurde immer wieder auf den eindeutig didaktischen Charakter des Romans hingewiesen. ${ }^{269}$ Tatsăchlich legt die in dieser Arbeit bereits untersuchte Antithetik im Figurenschema die Vermutung nahe, dem Leser solle mit dem Titelhelden ein Vertreter eines neuen Menschentypus als positiver I leld vorgefuhrt werden. Paradoxerweise hat jedoch

266 Übersetzang:,$[.$.$] das Bedürninis der Lebensfreude und das Verständnis für den Genuß$ bilden gerade einen jener wenigen Züge, durch die der natürliche Mensch sich von dem Tier unterscheidet" (III, 35).

267 Man vergleiche etwa die folgenden Textstellen: „Я знаю одно, - ответил Санин, - я живу и хочу, чтобы жизнь не была для меня мучением. Для этого надо прежде всего удовлетворять свои естественные желания. Желания - это все: когда в человеке умирают желания, умирает и его жизнь, а вогда он убивает желания убивает себя!“ (XII, 102); „Голос Санина был так искренен и ласков, что ках-то странно было продолхать хрнчать, и Юрий на мкнуту замолчал“ (XXIV, 180); „Aх, Соловейчик, - с легхой досадой сказал Санин, $-[\ldots]$ Нравственная победа не в том, чтобы непременно подставить щеку, а в том, чтобы быть правым перед своею совестью“ (XXXII, 235) [Hervorhebungen d. Verf.]. In Stefania Goldenrings deutscher Übersetzung stehen die angefuhrten Stellen auf den folgenden Seiten: XII, /12; XXIV, 2/3; XXXII, 286

263 In einem 1913 oder in den darauffolgenden Jahren verfaßten Brief des Schriftstellers an Evsej Markovix Aspiz schreibt Arcybašev: .A хочу творить только правду“; М. P. Arcybasev, Pis'ma M. P. Arcybaseva (1991), 363. Übersetzung: „Ich will nur Wahrheit schaffen"

$269 \mathrm{Vgl}$. dazu Barchan (1909), 128: „Es ist [...] ein sehr moralisches Buch“. Vgl. auch Nolda (1983), 389: „Sanin' ist ein propagandistischer, um Eindeutigkeit der Aussage (zu) deutlich bemühter Roman..." 
Sanins Botschaft innerhalb des Textes selbst keine nachhaltige Wirkung, denn als der Titelheld die Kleinstadt am Ende des Romans wieder verläßt, bleibt niemand zurück, der sich seine Lebensauffassung zu eigen gemacht hat. Auch Sanin selbst, so wurde bereits gezeigt, durchläuft in Arcybaševs Text keine Entwicklung: Seine geistige Haltung ist bereits vor dem Einsetzen der Romanhandlung vollständig ausgeprägt, und sie bleibt bis zum letzten Kapitel dieselbe.

O'Dell stellt insofern zu Recht fest, daß in Arcybaševs Text eine deutliche Diskrepanz zwischen einer sich dynamisch entwickelnden äußeren Handlung und dem Fehlen einer inneren Handlung auffallt:

Although the surface action of the novel is very dynamic, the characters do not develop significantly; they do not become anything different from what they are at the beginning of the novel. ${ }^{270}$

Ohne Zweifel treten im Laufe der Romanhandlung zahlreiche Veränderungen ein: Drei der Figuren begehen Selbstmord, wobei zwei der Selbstmorde - der Zarudins und Solovejčiks - unmittelbar mit Sanins Handeln in Zusammenhang stehen, ein Student stirbt eines natürlichen Todes, und zwei junge Frauen verlieren ihre Jungfräulichkeit, werden jedoch vom Titelhelden von ihrer Absicht abgebracht, deswegen Selbstmord zu begehen.

Zumindest die drei Selbstmorde erwecken zunächst den Eindruck, als nehme Sanin durchaus Einfluß auf die Personen in seiner Umwelt. Aber ist dies wirklich der Fall? Der Selbstmord des Rittmeisters wird, wie bereits in einem früheren Kapitel gezeigt wurde, in erster Linie als Folge von dessen Unfähigkeit, sich wie der Titelheld über gesellschaftliche Konventionen hinwegzusetzen, dargestellt. Der Selbstmord des jüdischen Mühlenbesitzers Solovejčik hingegen, so lautet die unterschwellige antisemitische Botschaft des Romans, resultiert aus einer bereits in den Erbanlagen begründeten Lebensunfähigkeit. ${ }^{271}$

Was die Selbstmordabsichten von Sanins Schwester Lida betriff, so zeigt die Beschreibung der entsprechenden Szene am Fluß deutlich, daß die Kräfte des Lebens in Lida auch vor Sanins Eingreifen im Grunde stärker sind als die Kräfte des Todes. Angesichts der üppigen Vegetation am Flußufer erscheint es Lida

\footnotetext{
${ }^{270}$ O'Dell (1980), 146.

271 In diesem Zusammenhang sprechen Sanins Worte Solovejžik gegenüber eine recht eindeutige Sprache: „Это правда, жить никто не научит: искусство жить - это тоже талант. А кто этого таланта не имеет, тот или сам гибнет, или губит свою жизнь, превращая ее в жалкое прозябание без света и радости“ (XXXII, 236); Übersetzung: „Das ist wahr, zu leben kann einen niemand lehren: Die Kunst zu leben ist auch ein Talent. Und wer dieses Talent nicht besitzt, der geht entweder selbst zugrunde, oder er richtet sein Leben zugrunde, indem er es in ein armseliges Dahinvegetieren ohne Licht und Freude verwandelt" [Übers. d. Verf.] (vgl. XXXII, 287).
} 
geradezu als unnatürlich, sich das Leben zu nehmen, ja gewissermaßen versucht die umgebende Natur gewaltsam, Lida vom Selbstmord zurückzuhalten:

[...] широкие лопухи тихо стояли в высокой крапиве, а цепкие репяхн легко цеплялись за широкие кружева Лидиной юбки. Какая-то кудрявая, высокая, как деревцо, трава осыпала ее мелкой, белой пыльцой.

Теперь Лида уже заставляла себя идти туда, куда шла, вопреки могучей внутренней силе, боровшейся с ней $(\mathrm{XIX}, 147) .{ }^{27}$

Auch der Psyche Karsavinas, deren Suizidabsichten zu keinem Zeitpunkt so konkrete Züge annehmen wie die Lidas, ist ein Selbstmord im Grunde wesensfremd, da ihr die übermäBige Neigung zur Selbstreflexion eines Jurij Svarožič fehlt. Durch die ăußerst positive Zeichnung des äußeren Erscheinungsbilds Karsavinas wird zudem suggeriert, daß eine Verbindung zwischen äußerer Schönheit und einer gesunden, lebenszugewandten inneren Einstellung besteht.

Sanins tatsăchlicher erzieherischer Einfluß auf seine Umwelt ist also in Wahrheit minimal. Seine Rolle beschränkt sich im Grunde auf die eines Katalysators, durch den die in den Figuren bereits vorhandenen Veranlagungen zur Geltung gebracht werden. Die Entwicklung der Romanfiguren beschränkt sich damit auf die Realisierung ohnehin vorhandener Potentiale. Somit wird der Glaube an die universale Entwicklungsfähigkeit des Menschen, der sich in Sanins weiter oben angeführtem Zitat über dic stufenweise Weiterentwicklung der Menschheit ausdrückt, durch die Romanhandlung selbst widerlegt. Es ist bezeichnend für die innere Widersprüchlichkeit der Lebenseinstellung Sanins, $\mathrm{da} ß$ der Titelheld an anderer Stelle dem Mühlenbesitzer Solovejčik gegenüber die Überzeugung äußert, ein 'Goldenes Zeitalter' könne es niemals geben. ${ }^{273}$

27n Übersetzung: „Die breiten Blätter der Kletten standen ruhig inmitten der hohen Brennesseln, und klebrige Kletten hefteten sich leicht an die breiten Spitzen von Lidas Rock. Irgendein gekringeltes Gras, so hoch wie ein kleines Bäumchen, bestreute sie mit feinem, weißem Blütenstaub.

Jetzt zwang sich Lida bereits, den eingeschlagenen Weg weiterzugehen, gegen eine mächtige innere Kraft, die mit ihr rang"'Übers. d. Verf.] (vgl. XIX, 170).

${ }^{273} \mathrm{Vgl}$. XXXII, 238: „Золотого века никогда не может быть. Если бы жизнь и люди могли улучшиться мгновенно, это было бы золотое счастье, но этого быть не может!“; Übersetzung: „Ein Goldenes Zeitalter kann es niemals geben. Wenn sich das Leben und die Menschen in einem einzigen Augenblick verbessern könnten, so wäre das das goldene Glück, aber das kann nicht sein!“ [Übers. d. Verf.] (vgl. XXXII, 289). 


\subsection{Zusammenfassung}

Die beiden untersuchten Texte verbindet der Umstand, daß auf der Suche nach dem 'neuen Menschen' eine kritische Haltung zum herkömmlichen Bildungs- und Erziehungsproze $B$ eingenommen wird. Dies ist insofern naheliegend, als die Vorstellung vom 'neuen Menschen' untrennbar mit der Frage nach seiner Genese verbunden ist. Damit jedoch enden bereits die Gemeinsamkeiten zwischen MineHaha und Sanin, denn hinsichtlich der philosophischen, pädagogischen und anthropologischen Grundansichten, die beiden Prosawerken zugrunde liegen, entwerfen Wedekind und Arcybašev zwei völlig gegensätzliche Wege zum 'neuen Menschen'.

In Wedekinds Romanfragment ist die Existenz der Erziehungsanstalt Ausdruck der Überzeugung, man könne die menschliche Entwicklung im Sinne der materialistischen Philosophie durch Einwirkung von außen beeinflussen. Der Einzelne muß sich bei der von Hidalla geschilderten Art von kollektiver Ausbildung dem Willen einer höheren Instanz unterordnen, ohne selbst den Sinn bzw. Unsinn der Erziehung abschätzen zu können. Der Pädagogik kommt im System des Parks die Rolle zu, den körperlichen Reifeprozeß der Zöglinge gewissermaßen zu kanalisieren. Das natürliche Ambiente der Wedekindschen 'pädagogischen Provinz' täuscht insofern, denn Ziel der Ausbildung ist nicht der wilde Wasserfall, sondern der kanalisierte Bach. Damit steht die von Hidalla genossene Erziehung in konträrem Verhältnis zu dem aus Longfellows The Song of Hiawatha entlehnten Titel des Romanfragments.

Auch wenn die Erzählsituation in Mine-Haha voreilige Rückschlüsse von der Figurenperspektive auf die Auffassung des Autors verbietet, so drückt sich zumindest in den bereits erwähnten Kommentaren der Ich-Erzählerin Hidalla im Kapitel IV der Glaube aus, man könne durch die strikte Unterwerfung der Zöglinge unter eine ihrer Natur widersprechende Ordnung zu einer besseren Welt gelangen. Daß Wedekind durch die Hinzufügung der Herausgeberfunktion in der Fassung von 1903 eine zusätzliche erzähltechnische Distanz zwischen sich und seinem Text schuf, kann sicherlich auch als Ausdruck von Unbehagen gegenüber dieser fragwürdigen Legitimation seiner 'pädagogischen Provinz' gedeutet werden.

Trotz der zahlreichen aufdringlich-didaktischen Monologe des Titelhelden läßt die zirkular verlaufende Handlung von Arcybaševs Roman die menschliche Entwicklung als von äußeren erzieherischen Einflüssen weitgehend unabhängig erscheinen. Obwohl die Fabel des Romans reich an äußerer Handlung ist, bewirkt Sanins Auftreten in seiner Heimatstadt keine bleibenden Veränderungen bei den dort nach seinem Weggang zurückbleibenden Personen. Sanin verkörpert das Ideal des 'neuen Menschen', der sich gewissermaßen aus eigener Kraft 
geschaffen hat, denn anders als die Zöglinge der Erziehungsanstalt in Mine-Haha hat sich Sanin bei seiner Entwicklung seine eigenen Regeln gesetzt. Dieser Umstand sowie verschiedene weiter oben angeführte Aussagen des Titelhelden verweisen auf die Auffassung, die Entwicklung des 'neuen Menschen' habe in erster Linie in der Realisation der dem Individuum von Natur aus innewohnenden Potentiale zu bestehen. Hierin steht Arcybaševs Text dem Grundgedanken des klassischen Bildungsromans überraschenderweise näher als Wedekinds Romanfragment. 


\section{1 Vorbemerkung}

Die um die Jahrhundertwende sowohl in Deutschland als auch in Rußland vielerorts zu beobachtende Suche nach Erneuerung in Literatur und Kunst stand zu einem erheblichen Maße unter dem Einfluß der Philosophie Friedrich Nietzsches, der .,im beginnenden Massenzeitalter die Rechte des Individuums vehement verteidigt ${ }^{6274}$ hatte. Von besonderer Bedeutung fur die um die Jahrhundertwende entstehenden Vorstellungen von einem 'neuen Menschen' war Nietzsches in den Jahren 1883 bis 1891 in vier Bänden erschienenes Werk Also sprach Zarathustra, in dem der Philosoph sein Konzept des 'Übermenschen' als Vision eines 'neuen Menschen' vorstellt.

Der Gedanke des 'Übermenschen' entwickelte nicht nur in Deutschland, sondern auch in Rußland, wo die Theorien des deutschen Philosophen ab den frühen 1890er Jahren unter den Angehörigen der Intelligenz kontrovers diskutiert wurden, eine ungeheure Dynamik. Mit dem Erscheinen der ersten russischen Übersetzungen von Nietzsches Zarathustra ab $1898^{275}$ wurde die Idee des 'Übermenschen' einer breiten russischen Leserschaft zugänglich. So konnte sie auch auf Literaturschaffende ohne ausreichende fremdsprachliche Bildung eine starke Faszination ausüben - beispielsweise den jungen Maksim Gor'kij. ${ }^{276}$

Nietzsches Weg zum 'neuen Menschen' sieht eine bewußte Isolation des Individuums von seinen Mitmenschen und dessen Befreiung von allen gesellschaftlichen Bindungen vor. Dabei basiert Nietzsches Idee des 'Übermenschen' auf einem offenen Bekenntnis zum Elitegedanken: Nur in der furchtlosen Gegnerschaft des starken Einzelnen zu der im Zarathustra immer wieder mit pejorativen Ausdrücken wie Fliegen des Marktes oder Heerde ${ }^{27}$ bezeichneten Mehrheit der übrigen Menschen kann der zu diesem Schicksal Auserwăhlte zum 'Übermenschen' werden.

Sowohl im Falle von Wedekind als auch bei Arcybašev kann man von einer Kenntnis der Philosophie Nietzsches zumindest in ihren groben Zügen

\footnotetext{
${ }^{274}$ Mathes (1984), 22.

${ }^{275}$ Eine Chronologie der russischen Übersetzungen sowie der zwischen 1892 und 1919 zu Nietzsches Werken in Rußland erschienenen kritischen Arbeiten findet sich bei R. D. Davies, Nietzsche in Russia, 1892-1919. A Chronological Checklist (1986), 354ff.

${ }^{276} \mathrm{Vgl}$. hierzu: Müller (1998), $79 f$.

277 Vgl. dazu Nietzsche, Bd. 4 (2. Aufl. 1988), 65; 80.
} 
ausgehen. ${ }^{278}$ Gerade für Arcybaševs Roman ist Nietzsches Zarathustra ein wichtiger Prätext, auch wenn zu gegebener Zeit noch zu zeigen ist, daß die Beziehung zwischen Sanins und Zarathustras Philosophie nicht so eindeutig ist, wie es zunächst scheint. Daneben wurden jedoch beide Schriftsteller auch mit den Ideen eines weiteren deutschen Denkers in Verbindung gebracht - dem im Vergleich zu Nietzsche weniger bekannten, aus Bayreuth stammenden Philosophen Max Stirner [eigentlicher Name: Johann Kaspar Schmidt] (18061856). ${ }^{279}$

Stimers Hauptwerk ist eine 1844 erschienene philosophische Abhandlung mit dem Titel Der Einzige und sein Eigentum, in der die Vision einer zukünftigen Gesellschaft von 'Egoisten' entworfen wird. ${ }^{280}$ Egoismus wird in Der Einzige und sein Eigentum als Ausdruck von Aufrichtigkeit des Individuums gegenüber sich selbst bzw. als Akt seiner Selbstbefreiung verstanden. ${ }^{281}$ In Deutschland war Stimers solipsistische Philosophie bereits im Begriff in Vergessenheit zu geraten, als sie im Gefolge der Nietzsche-Rezeption als Vorläufer der Idee des 'Übermenschen' wiederentdeckt wurde. ${ }^{282}$ In Rußland hingegen stießen Stimers Ideen auch lange vor Nietzsche auf großes Interesse. So entdeckte die Forschung unlängst gerade auch in Turgenevs bereits erwähntem Roman Otcy $i$ deti, jenem Vorläufertext zu Arcybaševs Sanin, Spuren der Stimerschen Philosophie. ${ }^{283}$

Entscheidenden Einfluß auf die um die Jahrhundertwende verbreiteten Vorstellungen hinsichtlich des Verhăltnisses zwischen 'neuem Menschen' und 'neuer Gesellschaft' hatte neben Stimer und Nietzsche auch Charles Darwin mit seiner Evolutionstheorie, zumal auch Nietzsche selbst dem Naturforscher

${ }^{278}$ Was Wedekinds Kenntnis der Werke des deutschen Philosophen betriff, so sei auf den Umstand hingewiesen, daß der Schriftsteller während seines Aufenthalts in Paris zwischen 1891 und 1895 intensive Nietzsche-Studien betrieb und sogar einem jungen französischen Philosophen bei der Übersetzung von Werken Nietzsches half. Vgl. hierzu Kieser (1990), 336. $\mathrm{Vgl}$. auch Vincon (1987), 45. Außerdem kann an dieser Stelle auf einen eher oberflächlichen Artikel von Richard Arthur Firda verwiesen werden. Vgl dazu R. A. Firda, Wedekind, Nietzsche and the Dionysian Experience (1972), $720 \mathrm{ff}$.

${ }^{279}$ Vgl. dazu P. Michelsen, Frank Wedekind (2. Aufl. 1969), 51. Vgl außerdem Luker (1980), $63 \mathrm{f}$.

${ }^{200}$ Vgl. hierzu R. W. K. Paterson, The Nihilistic Egoist. Max Stimer (1993), 6lff.

221 Man vergleiche dazu das Kapitel Mein Verkehr in der Zweiten Abteilung, wo es heißt: „Was aber kümmert Mich das Gemeinwohl? Das Gemeinwohl als solches ist nicht mein Wohl, sondern nur die äußerste Spitze der Selbstverleugmung. Das Gemeinwohl kann laut jubeln, während Ich 'kuschen' muß, der Staat glänzen, indes Ich darbe." Zitiert nach: M. Stimer, Der Einzige und sein Eigentum. Mit einem Nachwort herausgegeben von Ahlrich Meyer (1972), 234

$282 \mathrm{Vgl}$. dazu Paterson (1993), $145 \mathrm{ff}$.

${ }^{283} \mathrm{Vgl}$. dazu G. Time, Nemeckaja literaturno-filasofskaja mysl' XVII-XIX vekov v kontekste norरestua I. S. Turgeneva (genetiðeskie i tipologixeskie aspekty) (1997), 76ff. 
wesentliche Anregungen zu seiner Idee des 'Übermenschen' verdankt. ${ }^{284}$ Darwin selbst übertrug seine Theorie vom 'Kampf ums Dasein' nur sehr zögerlich auf den Menschen. Dennoch war es vor allem die Anwendung des Evolutions- und Selektionsgedankens in Soziologie und Geschichte, auf die sich der große und nicht durchweg positive Einfluß des Briten auf die europäische Geistesgeschichte im letzten Drittel des 19. Jahrhunderts gründete. So wurde das eigentlich nicht von Darwin, sondern seinem Landsmann Herbert Spencer (1820-1903) stammende Schlagwort des survival of the fittest ${ }^{285}$ vielfach als Entschuldigung für bestehende soziale Ungerechtigkeiten sowie für nationalen Chauvinismus mißverstanden.

Den Vorstellungen Stimers bzw. Nietzsches zufolge stellt ein rigoroser Individualismus den einzig möglichen Weg zur Erneuerung der Menschheit dar. Nicht vergessen werden darf jedoch an dieser Stelle, daß daneben in den Jahren um die Jahrhundertwende auch gegenteilige Ansätze diskutiert wurden. Einen alternativen Weg zur Schaffung eines 'neuen Menschen' im Kollektiv versuchten sowohl verschiedene sozialistisch bzw. kommunistisch orientierte Gesellschaftsreformer als auch die Anhänger der völkischen Rassenideologie zu gehen. Viele dieser Versuche, eine Gemeinschaft von 'neuen Menschen' aufzubauen, sind eng mit der Suche nach neuen Lebensräumen und neuen Formen des Zusammenlebens verbunden.

Neben der bereits erwähnten gemäßigt-sozialreformerischen Gartenstadtbewegung mag man in diesem Zusammenhang an eine Reihe von heute nahezu vergessenen siedlungsgeschichtlichen Experimenten denken. So wurde beispielsweise ab 1893 in der Nähe von Oranienburg von Anhängern der vegetarischen Bewegung eine genossenschaftlich organisierte Obstbaukolonie mit dem programmatischen Namen Eden gegründet. Eine weitere Siedlung von Vegetariem entstand im Jahre 1900 nach urkommunistischem Modell auf dem in der Nähe des schweizerischen Ascona gelegenen Monte Verità. Trotz ihres wirtschaftlichen Scheiterns wurde sie zum Anziehungspunkt zahlreicher lebensund sozialreformerischer Kräfte. Als historisch und politisch wirkungsvoller haben sich jedoch die Ideen der zionistischen Siedlungsbewegung erwiesen, deren Wurzeln ebenfalls an der Wende zum zwanzigsten Jahrhundert anzusiedeln sind. In dem utopischen Roman Altneuland (1902) des österreichisch-jüdischen

224 $\mathrm{Vgl}$. dazu E. Benz, Das Bild des Übermenschen in der europäischen Geistesgeschichte (1961), 124ff.

23s Dargelegt in dem in den Jahren 1879-93 erschienenen Werk Principles of Ethics. Zum Gedanken des survival of the fittest und seiner Anwendung auf den Menschen vgl. besonders H. Spencer, The Principles of Ethics. Introctuction by Tibor R. Machan, Bd. 1 (1978), 354: "Survival of the fittest insures that the faculties of every species of creature tend to adapt themselves to its mode of life. It must be so with man." 
Schriftstellers, Juristen und Journalisten Theodor Herzl (1860-1904) fand dieser gesellschaftsreformerische Ansatz auch einen literarischen Niederschlag. ${ }^{286}$

Somit stand um die Jahrhundertwende eine breite Palette von Vorschlăgen zur Schaffung eines 'neuen Menschen' zur Diskussion, wobei grundsätzlich zwischen einem individuellen sowie einem kollektiven Ansatz unterschieden werden kann. Im folgenden letzten Kapitel der vorliegenden Untersuchung soll ermittelt werden, welche Position dem 'neuen Menschen' zwischen den Polen Individuum und Gesellschaft von Wedekind bzw. Arcybašev zugewiesen wird, sowie auf welchem Weg - individuell oder kollektiv - seine Erschaffung erfolgen soll.

\subsection{Mine-Haha}

\subsubsection{Der 'neue Mensch' als kollektives Massenwesen}

Wie Hidalla bei der Beschreibung der Badeszenen im Teil II erwăhnt, werden im Park Hunderte von Mädchen in gleicher Weise ausgebildet wie sie (vgl. 98) - dèn Angaben der Erzăhlerin zufolge umfaßt der Park dreiBig Wohn- und Ausbildungshăuser (vgl. 100). Diese Zahlenangaben sowie die strenge Symmetrie, nach der die Zoglinge in Wohn- sowie in Ausbildungsgruppen unterteilt sind, zeigen deutlich, daß die Mădchen trotz der Einbettung der Anstalt in einen Naturraum im Grunde in einer Massengesellschaft leben, in der dem einzelnen Edukanden lediglich ein fester Platz in einem größeren Ganzen zukommt. Elke Austermühl hat darauf hingewiesen, daB der kollektive Charakter der Gesellschaft im Park bereits in der Erzăhlperspektive angedeutet wird:

Das erzăhlende Ich [...] ist nur in der formalen Geste des Erzählens präsent, während es als individuell handelndes Subjekt genausowenig vorkommt wie die im Park kasernierten Mädchen. ${ }^{2 m}$

Auf die passive Rolle, die das Individuum innerhalb des Parks einnimmt, verweist auch der Umstand, daß die innere Struktur der Gesellschaft ohne Beteiligung der Mädchen zustande kommt. Über die Beziehungen zwischen den

${ }^{226}$ Zur Geschichte der Siedlungsreformbewegung und der zionistischen Siedlungsprojekte für Palästina vgl. Lepp/ Roth/Vogel (1999), 148ff. Nähere Informationen zur Geschichte und der kulturgeschichtlichen Wirkung der skurrilen Vegetarierkolonie auf dem Monte Verità finden sich in Ute Druvins Artikel in Gnüg (1982), 236ff.

227 Austermühl (1994), 50. 
einzelnen Zöglingen entscheidet vor allem der externe Faktor des Alters, der die Bildung von Gruppen hinsichtlich des Tags der Unterweisung im Weißen Haus sowie des erlernten Musikinstruments zur Folge hat. Ältere Mädchen müssen jeweils Verantwortung für jüngere übernehmen. Individualität kommt in erster Linie über den Namen, über die Fähigkeit zur Körperbeherrschung und das äußere Erscheinungsbild, nicht jedoch über individuelle Charaktereigenschaften, zustande. Wie auch viele andere Details in Wedekinds Romanfragment bleibt jedoch letztlich offen, wer die Verantwortung für die Verleihung der Namen trägt.

In ihrer Beschreibung der Ausbildung im Park betont Hidalla immer wieder die Tatsache, daß zwischenmenschliche Beziehungen unter den Edukanden der Erziehungsanstalt weitgehend fehlen. Dieser Eindruck gründet sich in erster Linie auf das Motiv der fehlenden Kommunikation, das sich durch Hidallas gesamte Erzählung zieht. In einer sozialen Gemeinschaft, in der sich die Aufgabe des Einzelnen auf das Gehen eines von außen vorgegebenen Weges beschränkt, in der der Austausch von Informationen nur eine untergeordnete Rolle spielt und in der sämtliche Beziehungen zwischen den einzelnen Mitgliedern funktionalisiert sind, ${ }^{288}$ besteht nur wenig Notwendigkeit zur sprachlichen Interaktion. Insofern verwundert es nicht, da $\beta$ in „der Kolonie [...] die sprachliche Verständigung aufs Minimum beschränkt ${ }^{4289}$ ist. Entsprechend lautet eine immer wieder zitierte Passage in Hidallas Erzählung: „Eine dachte und fühlte wie die andere, und wenn eine den Mund auftat, wußten immer alle übrigen schon, was sie sagen wollte. So kam es, daß wir sehr wenig sprachen" (113). Im Hinblick auf die unter den Zöglingen herrschende Beziehungslosigkeit ist die Parkanstalt trotz der scheinbaren Nähe zur Natur ein Spiegelbild der zeitgenössischen Massengesellschaft an der Wende zum zwanzigsten Jahrhundert.

Hidallas Angaben zufolge verlebte sie die gesamten sieben Jahre der Kapitel II und III im Park, „ohne daß ein einziges Mal eine Unterhaltung stattgehabt hätte" (103). Es überrascht deshalb nicht, daß Hidallas Erzählung kaum Passagen in direkter Rede enthält. Hidallas Behauptung zum Trotz berichtet sie dennoch von einigen Unterhaltungen, und an sechs Stellen gibt sie in ihrem Bericht wörtliche Rede wieder. ${ }^{290}$ Es fallt auf, daß zumindest an vier der sechs Stellen die Instabilität der Ordnung in der Erziehungsanstalt bzw. die Unnatürlichkeit des Lebens im Park angedeutet wird. Insofern drăngt sich der Schluß auf, daß die

228 Stärker noch als in Mine-Haha kommt dies in Wedekinds Fortsetzungsplänen zum Ausdruck, wo die einzelnen Figuren in erster Linie mit ihrer rituellen Funktion (jöttermädchen, Opferknabe usw. - bezeichnet werden.

${ }^{289}$ Moniková (1985), 121.

290 Es sind dies in dieser Reihenfolge: Eine Bemerkung Blankas über Hidallas schöne Haare (97); ein kurzer Wortwechsel mit Blanka über das Theater (104); eine Unterhaltung während eines Spaziergangs mit Wera (106); die Stimme aus dem Publikum im Theater (126); eine Ansprache Simbas über die bevorstehende Verändenung (107); eine Unterhaltung mit Selma über die Welt außerhalb der Parkmauem (130). 
kollektive Massengesellschaft des Parks mit ihrer Mißachtung der Rechte des Individuums nur für eine gewisse Zeit auf Grund äußeren Drucks stabil sein kann.

\subsubsection{Unvollstăndige Gesellschaft}

Durch Mauern, schmiedeeiserne Tore und das Gitter zwischen Bühne und Zuschauerraum wird der direkte Kontakt zwischen den Zöglingen der Anstalt und der Außenwelt sorgfaltig vermieden. Der offensichtliche Grund hierfür ist die Annahme, daß die Schaffung einer von unkontrollierbaren äußeren Einflüssen isolierten 'pädagogischen Provinz' bessere Bedingungen für die Entwicklung der Kinder und damit für die Genese eines neuen Menschentypus bietet.

De facto bestehen trotzdem einige wenige Verbindungen zwischen den Edukanden der Anstalt und der Außenwelt, besonders natürlich durch das Theater, das zur Finanzierung der Ausbildung der Mădchen dient (vgl. 122). Dennoch wird der Park durch die fast vollständige Isolation zu einer Art Mikrokosmos innerhalb einer größeren Gesellschaft, ganz gleich, ob man diese als zeitgenössische bürgerliche Gesellschaft auffaßt oder - im Hinblick auf die Fortsetzungsskizzen - als Teil einer umfassenden Utopie begreift.

Dabei darf nicht vergessen werden, daß die Gesellschaft innerhalb der Parkmauem keinesfalls ein Abbild derer außerhalb derselben darstellt. Vielmehr ist die Population des Parks von einer gänzlich unnatürlichen Homogenität: Nach der Geschlechtertrennung im Alter von ungefähr sieben Jahren fehlt den Zoglingen der Anstalt jeder direkte Kontakt zu Personen des anderen Geschlechts. Alle Erwachsenen, mit denen die Mädchen während der Zeit ihrer Ausbildung regulär in Kontakt kommen - die Ausbilderinnen, die Dienerinnen sowie die Mitglieder der Auswahlkommission -, sind ebenfalls weiblichen Geschlechts. Elizabeth Boas in bezug auf Eden und Mine-Haha aufgestellte Behauptung, die Kontrolle über das utopische System liege letztlich in männlicher Hand, entbehrt insofern in Wedekinds Romanfragment jeglicher textlicher Grundlage. $^{291}$

Ebenso unnatürlich wie die Geschlechtsstruktur ist auch die Altersstruktur der Bewohner des Parks. Anders als bei der traditionellen bürgerlichen Erziehung verbringen die Mädchen den größten Teil ihrer Jugendzeit mit anderen Individuen, die sich innerhalb derselben Lebensphase befinden wie sie selbst. Mit den wenigen älteren Personen, mit denen sie regelmäßig in Kontakt kommen den Ausbilderinnen und den alten Dienerinnen -, findet kein wirklicher Austausch statt, da erstere zu hoch in der Hierarchie des Parks stehen, letztere aber zu niedrig. Der Zweck der Segregation der Zogglinge in bezug auf Geschlecht und

${ }^{291} \mathrm{Vgl}$. dazi Boa (1987), 197 
Alter ist offensichtlich die Verhinderung eines unerwünschten Wissens- und Erfahrungstransfers, besonders auch hinsichtlich sexueller Fragen. Auf die Rolle der Unwissenheit im pädagogischen Programm der Anstalt wurde bereits hingewiesen.

Wie am Beispiel der Dienerinnen deutlich wird, setzen die Mädchen auf Grund ihrer sozialen Prägung Alter mit Häßlichkeit gleich. Die Angst davor, ein Leben lang inmitten der jugendlichen Zöglinge der Parkanstalt verbleiben zu müssen, wird innerhalb des Erziehungssystems als wirksames Mittel der Sanktionierung unerwünschten Verhaltens eingesetzt. Durch den Ausschluß der Familie aus dem Erziehungsproze $B$ fehlt den Mädchen weiterhin die Begegnung mit den ebenfalls untrennbar mit dem Leben verbundenen Phänomenen der Krankheit und des Todes. Daß letzterer in der Erziehungsanstalt offensichtlich tabuisiert wird, zeigt die geheimnisvolle Beseitigung der Leiche des ertrunkenen Mädchens am Tag nach dem Vorfall (vgl. 114).

Es ist an dieser Stelle festzuhalten, daß es sich also sowohl in bezug auf die Alters- als auch auf die Geschlechtsstruktur bei der Population des Parks um eine unvollständige Gesellschaft handelt. Damit bestätigt sich der Befund aus einem früheren Kapitel dieser Arbeit, daß die Ausbildung der Mädchen in Mine-Haha nur scheinbar in einem natürlichen Umfeld stattfindet. Vielmehr besteht die Besonderheit des in der Parkanstalt verwirklichten Erziehungsmodells gerade darin, den Edukanden durch die hermetische Isolation von der Außenwelt die Erfahrung einer natürlich gewachsenen Gesellschaft vorzuenthalten. Auch hierin zielt also das pädagogische Programm des Parks auf eine Bezwingung der Natur ab.

\subsubsection{Hierarchisch gegliederte Gesellschaft}

Neben dem Alter ist für die Stellung des Individuums innerhalb der Parkgesellschaft vor allem die körperliche Leistungsfähigkeit von Bedeutung. Dabei verfügen die Mädchen jedoch über keinerlei Wahl- oder Mitbestimmungsrecht. Vielmehr werden sie auf Grund von ihnen weitgehend unbekannten Kriterien von höheren Stellen für eine besondere Laufbahn ausgewählt. Die Bewohnerschaft des Parks weist also eine klare hierarchische Gliederung in eine Elite, die Mittelschicht der Zöglinge sowie die Unterschicht der Dienerinnen auf, und eben diese Struktur ist die Bedingung für das Funktionieren der Anstalt.

Worin aber besteht das pådagogische Ziel der Erziehungsanstalt, dessen Erreichen durch die Auswahl belohnt wird? Betrachtet man die Beschreibung der Auswahlprozedur im Weißen Haus ein wenig genauer, so drängt sich der Eindruck auf, daß das entscheidende Kriterium in der Făhigkeit zur möglichst 
perfekten „Verwandlung des Korpers in den eines Tieres ${ }^{\text {“292 }}$ besteht. So wird Lora, Hidallas Gespielin aus dem Kapitel I, von den beiden Damen offensichtlich deshalb ausgewählt, weil sie die Zähne nach Art einer Raubkatze fletschen und gleichzeitig eine der beiden Prüferinnen ,mit einem flammenden Blick aus ihren tiefblauen Augen" (116) in Verlegenheit bringen kann.

Infolge seines fragmentarischen Charakters läßt Wedekinds Text offen, was für die leistungsfâhigsten und bestaussehenden unter den Zöglingen nach dem Moment der Auswahl im Weißen Haus folgt. Einer Auswahl müssen sich auch die Knaben unterziehen, wie Hidallas Verweis auf das spätere Schicksal des von ihr verehrten Knaben Morni zeigt (vgl. 92f.). Innerfiktional läßt sich vermuten, daß der Selektionsprozeß dazu dient, geeignete Kader für eine Karriere als Ausbilderinnen auszuwählen. Betrachtet man wie Medicus Mine-Haha als von vornherein geplanten Teil des in Wedekinds Notizbüchern skizzierten Romanprojekts Die große Liebe, so dient er dazu, 'Götterknaben' und 'Göttermädchen' für die erotischen Rituale des beschriebenen Staates auszuwählen. ${ }^{293}$

Durch die Ersetzung der Eltern als Träger der Erziehung scheinen alle Kinder über dieselben Voraussetzungen zu verfügen. In Wirklichkeit jedoch sind diese keinesfalls gleich, da, wie bereits erwähnt wurde, das angestrebte Ideal des schönen Körpers zu einem erheblichen Teil als Folge von Veranlagung begriffen wird. Damit ist im Park im Gegensatz zur bürgerlichen Gesellschaft nicht die soziale, sondern die genetische Herkunft ein entscheidendes Kriterium bei der Vergabe gesellschaflicher Positionen - ein gewisser Einfluß von Darwins Evolutionslehre ist unverkennbar. Daneben ist für die Stellung des Individuums innerhalb der sozialen Hierarchie der Erziehungsanstalt seine Loyalităt gegenüber der im Park geltenden Ordnung ausschlaggebend.

\subsubsection{Glück durch Unterordnung}

Das Verhalten der Zöglinge während ihrer Ausbildung im Park ist durch eine Reihe von Verboten geregelt, deren Einhaltung mit Hilfe von Strafen sichergestellt wird: Verboten ist das Quälen von Fischen (91) ebenso wie homosexuelle Kontakte zu anderen Zoglingen oder das vorzeitige Verlassen der Anstalt (106f.). Durch die Anwesenheit der alten Dienerinnen in den Häusern werden die Mädchen permanent daran erinnert, daß Verstöße gegen die Regeln der Erziehungsanstalt tatsächlich bestraft werden.

Nach der Trennung der Knaben und Mädchen am Ende des ersten Erziehungsabschnitts bleibt den Kindern nur wenig Zeit zur eigenen Gestaltung.

292 Medicus (1982), 156.

$293 \mathrm{Vgl}$. ebd. 194. 
Vielmehr ist ihnen der Tagesablauf weitgehend vorgegeben. Der feste Tagesrhythmus, den die neu hinzugekommenen Mädchen von den älteren Gruppenmitgliedern übernehmen, stellt gewissermaßen die einzige Konstante in dem durch ständige Fluktuation und wechselnde zwischenmenschliche Beziehungen geprägten Leben im Park dar. Nur in beschränktem Umfang verbleibt den Mädchen vor und nach dem Abendessen Zeit zur freien Gestaltung, die Hidalla des öfteren für ihre Spaziergänge im Park nutzt.

Auch wenn Hidalla berichtet, daß sie während eines allein unternommenen Spaziergangs „ein tiefer Schmerz überkam, etwas wie Sehnsucht, [...] hinauszukommen, weit fort, in die große Welt hinaus" (109), reicht der Anblick von Mauem und Gittertoren augenscheinlich nicht aus, bei der Erzählerin das Gefühl der Unfreiheit und Unterdrückung hervorzurufen. Zu einer Revolte der Zöglinge gegen die autoritären Erziehungsprinzipien, denen sie unterworfen sind, besteht offensichtlich kein Bedürfnis. So weist nichts in Hidallas Bericht auf Kritik am pådagogischen Programm der Parkanstalt bzw. auf fehlende Identifikation mit demselben hin. Die Erfüllung ihrer Pflicht gegenüber der Anstalt stellt für Hidalla eine Quelle persönlichen Glücksempfindens dar: Als sie die Älteste innerhalb ihrer Wohngruppe wird und ihr die Verantwortung für das jüngste Kind der Gruppe, Arabella, übertragen wird, erlebt sie nach eigenen Angaben den glücklichsten Tag ihrer gesamten Ausbildung im Park (vgl. 128).

Durch ihre Loyalităt der Erziehungsanstalt gegenüber trăgt Hidalla ebenso wie die überwiegende Mehrzahl der übrigen Mădchen zur Perpetuierung des pädagogischen Systems bei. Gelegentlich nimmt diese Loyalität sogar masochistische Züge an, wie etwa das Beispiel Filissas zeigt, des nächstälteren Mädchens aus Hidallas Wohngruppe: Während einer Phase ihrer Ausbildung muß Filissa in einem Theaterstück auftreten, dessen Handlung es erfordert, sich allabendlich von Simba verprügeln zu lassen. Dies jedoch, so Filissa, „mache ihr nichts. Man tanze nachher nur um so besser" (117). Die Unterordnung der eigenen Person unter einen fremden Willen bis hin zur Aufgabe der eigenen körperlichen Empfindung erscheint damit in Mine-Haha als Quelle des persönlichen Glücks. Es ist dies ein Motiv, das bereits in Frühlings Erwachen erschienen war $^{294}$ und das in den Fortsetzungsskizzen mit seinen rituellen Opfenungen der sogenannten Opfermaid in noch weitaus drastischerer Weise entwickelt ist. ${ }^{295}$

294 In zwei Szenen in Frühlings Finwachen (I, 3 und 1, 5) treten Wendla Bergmanns masochistische Neigungen zutage. Vgl dazu Wedekind, Bd. 1 (1969), 105ff; $114 f$.

295 In den Entwürfen zum Romanprojekt Die große liebe wird geschildert, wie ein als Opfermaid auserwähltes Mädchen während der Frühlingsfeier durch einen Wechsel von rituellen Vergewaltigungen und rituellen Auspeitschungen in den Tod getrieben wird. Vgl dazu NB 40/1 ff. 
Die Erziehung zur Unterordnung des Individuums bzw. zur Zügelung der eigenen Natur erscheint in Mine-Haha jedoch nicht nur als ein Schlüssel zum persönlichen Glück. Vielmehr äußert die Ich-Erzählerin gegen Ende ihres Berichts die Überzeugung, daß die von ihr im Park genossene Erziehung zu einer allgemeinen Verbesserung des menschlichen Zusammenlebens beitragen könne:

\begin{abstract}
Vielleicht tut die menschliche Gesellschaft nicht unrecht daran, wenn sie durch ihre Erziehung die praktische Betätigung aller Kräfte in uns zurückhält, um uns dann durch ein tobendes Volksfest in wenigen Tagen zu völlig anderen Geschöpfen umzugestalten; vielleicht begehe ich ein Verbrechen, wenn ich ein Wort zugunsten der uns von Natur aus angeborenen zarteren Empfindungen einzulegen wage. Aber je alter und ruhiger ich werde, um so weniger kann ich mich dem Glauben verschließen, daß die Welt in der Tat weniger brutal eingerichtet sein könnte, als sie es in Wirklichkeit ist (132f.).
\end{abstract}

An dieser Stelle läßt sich auch der Titel des Wedekindschen Romanfragments mit seiner Wassersymbolik wieder ins Spiel bringen: Der Weg zum allgemeinen Glück ist in Mine-Haha nicht der natürliche Wasserfall, nach dem die Figur in Longfellows The Song of Hiawatha benannt ist, sondern vielmehr das von Menschenhand aufgestaute Wasser, das sich ab Erreichen einer bestimmten Stauhöhe den Weg in die Freiheit bahnt.

Der Staustufe am Badeplatz der Kinder entsprechen im pädagogischen System der Parkanstalt die Mauern, Gitter, Regeln und Strafen, die sicherstellen, daß das Leben der Zöglinge nahezu vollständig kontrolliert wird. Angesichts dieses in Hidallas Beschreibung deutlich zutage tretenden Zwangscharakters der Ausbildung im Park muß Wedekinds Text für einen Leser am Ende des zwanzigsten Jahrhunderts unweigerlich wie eine Präfiguration des Totalitarismus erscheinen. Nicht umsonst richteten totalitäre Regime ihr Augenmerk in der Regel kurz nach ihrer Etablierung auf das Erziehungswesen, das als Schlüssel zur Macht begriffen wurde.

Im Hinblick auf Mine-Haha ist also Kritik anzumelden an der vorschnellen Stilisierung Wedekinds zu einem Kämpfer für die Befreiung des Menschen von allen dem Individuum auferlegten Zwängen, wie sie in manchen Arbeiten zu Wedekinds Werk anzutreffen ist. ${ }^{296}$ Verbreitet ist diese Einschätzung des Autors gerade auch in nicht primär literaturwissenschaftlich ausgerichteten Arbeiten, wo

296 Vgl etwa S. Gittleman, Frank Wedekind (1969), 1: "Like his spiritual mentor Friedrich Nietzsche, Wedekind wanted a changed order, a liberated society free from the limitations of a traditional, repressive culture, one uninhibited by taboos." Vgl. auch $\mathrm{H}$. Puknus, Nachwort (1971), 223: , [...] nicht mehr und nicht weniger ist anvisiert als die Befreiung des ganzen Menschen zu seiner vollen natürlichen Schönheit und Genußfahigkeit, eine Gesellschaft der 'großen Liebe', ein paradiesischer Zustand klarer spielerischer Heiterkeit". Von einer „Befreiung des Individuums“ spricht Jürg Mathes in seinem Nachwort in Zusammenhang mit Mine-Haha; vgl. Mathes (1982), 367. 
bisweilen ebenfalls von Wedekinds vermeintlichem Eintreten zugunsten einer „befreiten und entfesselten naturhaften Sexualität ‘297 die Rede ist. Trotz der erwähnten erzähltechnischen Distanz zwischen Autor und Text triff ein solcher Befund für die Darstellung der Sexualität in Mine-Haha und besonders auch in den Fortsetzungsfragmenten sicherlich nicht zu.

Angesichts der in der Parkanstalt praktizierten Erziehung zur bedingungslosen Unterordnung entbehrt vielmehr Monikovás Vergleich mit den Konditionierungslagern für Sportler in den Staaten des ehemaligen Ostblocks nicht einer gewissen Berechtigung. ${ }^{298}$ Moniková geht sogar so weit, den alten Vorwurf der Pornographie wieder aufzugreifen - diesmal allerdings von einem feministischen Standpunkt aus - und Wedekinds Romanfragment wegen seiner Schilderung weiblicher Unterwürfigkeit als ,männliche Wunschprojektion“299 $\mathrm{zu}$ bezeichnen.

Dieser Deutung ist entgegenzuhalten, daß sich trotz der spärlichen Hinweise auf ihr Schicksal auch die Knaben einer auf die absolute Beherrschung des Körpers abzielenden Ausbildung unterziehen müssen. Daneben ist das Verhältnis des Autors Wedekind zu seiner Ich-Erzählerin Hidalla und zu der in Mine-Haha entwickelten Idee der rein körperlichen Erziehung längst nicht so eindeutig, als daß man das Romanfragment in pauschaler Gleichsetzung von Verfasser und Hauptfigur als Wedekinds eigenen erzieherischen Entwurf bezeichnen könnte. Keinesfalls sollte in diesem Zusammenhang die bereits an anderer Stelle ausführlich behandelte erzähltechnische Struktur des Wedekindschen Textes übersehen werden, auf Grund derer sich eine Deutung des Fragments - zumindest in seiner Fassung von 1903 - als Wedekinds ernstgemeinte Vision einer neuen Gesellschaft verbietet.

Es scheint insofern tragfähiger, Mine-Haha als provokanten Beitrag eines durch notorische "Uneindeutigkeit “"300 charakterisierten Schriftstellers in der Diskussion um den 'neuen Menschen' zu deuten. Der fragmentarische Charakter des Textes mit seinen hier und da zutage tretenden Widersprüchen sowie die vergeblichen Bemühungen Wedekinds um eine Fortsetzung lassen darauf schließen, daß Wedekind in erster Linie an der Gestaltung einer Idee und nicht an deren praktischer Durchführbarkeit interessiert war. Möglicherweise bewahrheitet sich auch gerade an Wedekinds Romanfragment Roy Pascals Vermutung, daß den Werken des Schriftstellers letztlich keine eindeutigen Wirkungsabsichten zugrunde liegen. ${ }^{301}$ Zumindest kann an dieser Stelle

${ }^{297}$ T. Nipperdey, Deutsche (jeschichte 1866-1918, Bd. 1 (1990), 788.

${ }^{298} \mathrm{Vgl}$. Moniková (1985), 122.

299 Moniková (1985), 125.

${ }^{300}$ A. Martin, Ein Drahtseilakt. Frank Wedekind und der Erste Weltkrieg (1996), 156.

${ }^{301} \mathrm{Vgl}$. dazu R. Pascal, From Naturalism to Expressionism. (jerman Literature and Society' 1880-1918 (1973), 243: "It seems that Wedekind was not fully aware of what he intended." 
festgehalten werden, daß die Utopie eines 'neuen Menschen' in einer neuen Gesellschaft in Mine-Haha auf einen kleinen Ausschnitt beschränkt bleibt.

\subsection{Sanin}

\subsubsection{Der 'neue Mensch' als Einzelwesen}

Luker hat Sanins Position am Ende des Romans recht treffend mit der Formulierung "unashamedly splendid isolation" ${ }^{\star 302}$ beschrieben. Offensichtlich sind während Sanins rund fünf Monate dauemden Aufenthalts in seiner Heimatstadt keine sozialen Bindungen entstanden, die stark genug sind, den Titelhelden zum Bleiben zu bewegen. Den Volksschullehrer Ivanov, der in verschiedenen philosophischen Diskussionen als Verbündeter Sanins erscheint und der als einziger in der Stadt Sanins Weggang bedauert, ${ }^{303}$ läßt er ebenso zurück wie seine Mutter oder seine Schwester. Letztere, so räsoniert Sanin kurz vor seiner Abreise, hätte sich möglicherweise doch lieber im Fluß ertränken sollen als aus Angst vor sozialer Stigmatisierung wegen ihres unehelichen Kindes eine Beziehung zu dem ungeliebten Novikov einzugehen. ${ }^{304}$ Ohne Zweifel ist dies ein augenscheinlicher Beweis der fehlenden emotionalen Anteilnahme Sanins an seiner Umwelt. Nicht einmal die Erfahrung des sexuellen Abenteuers mit Karsavina ist für Sanin ein Grund zum Bleiben.

Trotz der Vielzahl von Ereignissen, die Sanins Aufenthalt in der Kleinstadt begleitet haben, betont der Titelheld Ivanov gegenüber am Ende des Romans, daß ihn das Leben in der Stadt langweile, und reist ab. Hierin zeigt sich deutlich die Isolation, in der Sanin im Verlauf des gesamten Romans verbleibt. Er scheint der Gemeinschaft mit seinen Mitmenschen keinen besonderen Wert beizumessen, denn bereits an zwei früheren Stellen des Textes - der Beschreibung des von

\footnotetext{
302 Luker (1980), 78.

${ }^{303} \mathrm{Vgl}$ XLV, 314: „- Эх брат! Как я тебя полюбил, как полюбил! - неожиданно закричал Иванов. - Одного настоящего человека только и видел!

- Один ты полюбил! - усмехнулся Санин.“

Übersetzung „Ach, Bruder! Wie lieb ich dich gewonnen habe!' rief Iwanow unerwartet. 'Der einzige Mensch, den ich kennengelemt habe, bist du.'

'Du bist auch der einzige, der mich liebgewonnen hat!' erwiderte Sanin lächelnd" (XIV, 395).

${ }^{304}$ Vgl. XLV, 314: „- Ну Лиде, пожалуй, конец! - подумал он. - Мохет, и лучше сделала бы она, если бы тогда и вправду утопнлась!“, Übersetzung: „Nun, das ist wohl das Ende für Lida!' [Übers. d. Verf.] dachte er, 'sie hätte vielleicht besser getan, wenn sie damals wirklich ins Wasser gegangen wäre!" (XIV, 393).
} 
Gožienko organisierten Lesezirkels (XXV, 191) sowie des Trinkgelages in der Herberge des Klosters (XXXVIII, 277) - verläßt er gelangweilt eine gesellige Runde von Menschen. Als Folge seiner Geringschätzung jeglicher freundschafticher Bindungen zu seinen Mitmenschen ist der Titelheld für seine Umwelt unberechenbar - ein Motiv, das an verschiedenen Stellen in der Romanhandlung auftaucht. ${ }^{305}$ In der selbstgewählten Isolation Sanins besteht eine deutliche Parallele zur Figur des einsamen Philosophen Zarathustra, obgleich Arcybašev, wie noch zu zeigen sein wird, Friedrich Nietzsches philosophisches Werk in seinem Roman nicht gerade in einem positiven Licht erscheinen läßt.

Interessant ist auch die Darstellung der Familie in Arcybaševs Roman. Es fällt auf, daß in Arcybaševs Text keine einzige Ehe näher beschrieben wird. Dies erstaunt angesichts der Tatsache, daß die überwiegende Mehrheit der Romanfiguren im heiratsfähigen Alter ist - Lida Sanina beispielsweise ist 20 Jahre alt, Jurij Svarožic 26 (vgl. II, 33; $2+$ bzw. XLIII, 305; 380) - und daß das Thema der zwischengeschlechtlichen Beziehungen im Roman eine solch herausragende Rolle spielt. Offensichtlich sollen Ehe und Familie als unbedeutend für den Sozialisienungsproze $B$ des 'neuen Menschen' dargestellt werden, denn das Schicksal von Sanins und Lidas Vater verbleibt ebenso im dunkeln, wie auch die Mutter von Jurij und Ljalja Svarožič nicht erwăhnt wird.

Diejenigen Ehen, die sich unter den Vertretern von Sanins Generation andeuten, wie etwa zwischen Jurij Svarožič' Schwester Ljalja und ihrem Verlobten Rjazancev sowie zwischen Lida Sanina und Novikov, sind bereits vor ihrem Abschluß durch Krisen bedroht. Die beiden zentralen männlichen Figuren des Romans, Sanin und Jurij Svarožiz, stehen ungeachtet ihrer unterschiedlichen Anschauungen der Idee der Ehe und der Gründung einer traditionellen Familie eindeutig ablehnend gegenüber. Sanin erwägt in einem seiner ganz seltenen Momente der Schwăche kurzzeitig, Karsavina nach dem nächtlichen Abenteuer die Ehe anzubieten, verwirf diesen Gedanken aber sofort wieder, da dies „kleinlich und jetzt nicht angebracht" sei (XL, 365; 294). Sanins Gegenspieler Jurij Svarožič hingegen lehnt die Vorstellung eines 'bürgerlichen Glücks' mit Ehe und Familie ab, da dies seinen hohen Anlagen widerspreche (vgl. XLI, 298; 370). Es ist somit festzuhalten, daß das Motiv der Ehe und der Familie als gemeinschaftsstiftende, dem Individuum Geborgenheit vermittelnde Instanz im Sanin fast vollständig fehlt, so daß die einzelnen Romanfiguren mehr oder weniger beziehungslos nebeneinander stehen.

${ }^{305} \mathrm{Vgl}$. Luker (1980), 62: "Occasionally the unpredictable nature of Sanin's movements is disconcerting to those around him, especially if it reminds them of their own inadequacies." 


\subsubsection{Triebe als Grundlage des menschlichen Zusammenlebens}

Von Interesse scheinen für Sanin lediglich Beziehungen zu potentiellen Sexualpartnerinnen zu sein. $\mathrm{Zu}$ diesen zählt Sanin offensichtlich auch seine Schwester Lida. Bereits vom ersten Kapitel an ist deutlich, daß zwischen Sanin und Lida eine ausgeprägte erotische Spannung besteht - Nolda spricht von Sanins „fast inzestuösen Wünsche[n] gegenüber seiner Schwester". 306 So beobachtet Sanin seine Schwester eines Nachts vom Garten aus beim Umkleiden und sagt ihr danach unumwunden, daß sie ihm ohne Kleidung wesentlich besser gefalle (vgl. VII). Spăter, als der Titelheld Lida vom Selbstmord abhält, trotzt Sanin seiner Schwester sogar einen leidenschaftlichen Kuß ab (vgl. XIX, 154; 18()). Daß Sanin seiner erotischen Neigung gegenüber seiner Schwester nicht in dem Maße nachgibt wie im Falle Karsavinas, scheint Zufall zu sein. Angst vor den biologischen oder sozialen Folgen einer inzestuösen Beziehung zu seiner Schwester hingegen spielt bei Sanins Handeln offensichtlich keine Rolle.

Nicht nur seiner Schwester, sondern auch anderen Figuren des Romans gegenüber demonstriert Sanin immer wieder seine Ablehnung jeglicher Konventionen. So ruft er die Entrüstung seiner Mutter hervor, indem er sie fragt, ob sie etwa in ihrem ganzen Leben nur einen Mann geliebt habe (vgl. XXVIII, $201 ; 240)$. Rittmeister Zarudins gesellschaftliches Ansehen ruiniert er, indem er ihn zunächst des Hauses verweist, dessen daraufhin vorgebrachte Forderung zum Duell zurückweist und ihm schließlich - allerdings in einem Akt von Notwehr einen demütigenden Faustschlag ins Gesicht versetzt (vgl. XXVIIf.). Kurz vor seiner Abreise aus der Kleinstadt schließlich löst Sanin einen weiteren Skandal aus, indem er am Grab von Jurij Svarožiz die folgenden häufig zitierten Worte über den Verstorbenen ăußert: „Что тут говорить?.. Одним дураком на свете меныше стало, вот и все!“" (XLIV, 309). ${ }^{307}$

Die bisweilen außerst naiv erscheinende Ablehnung jedweder Rücksichtnahme auf gesellschaftliche Konventionen durch den Titelhelden in Arcybaševs Roman hat unverkennbar programmatischen Charakter. Mit Sanin wird dem Leser ein Menschentyp vorgeführt, für den kulturell erworbene Verhaltensmuster keinerlei Bedeutung haben. Bezeichnenderweise preist Sanin wăhrend der Bootspartie in Kapitel VI den Rausch als den Zustand der völligen Befreiung des Individuums von der Einschränkung seines freien Willens durch die Gesellschaft:

${ }^{306}$ Nolda (1983), 395.

307 Übersetzung: „Was ist hier zu reden? Es lebt ein Dummkopf weniger auf der Erde, das ist alles“ (XLIV, 387). 
- Меня всегда удивляло, что люди так ополчаются на вино, - сказал он шутя, - по-моему, только пьяный человек живет как следует [...] пьяный делает только то, что ему хочется... $(\mathrm{VI}, 61) .^{308}$

$\mathrm{Da} B$ Alkoholgenuß bekanntermaßen bei der Ausführung des freien Willens auch hinderlich sein kann, wird nicht reflektiert.

Wegen dieses Bekenntnisses zum Rausch sowie wegen einiger Textstellen, in denen beschrieben wird, wie Sanin Alkohol konsumiert, sahen Teile der zeitgenössischen Kritik im Titelhelden einen Alkoholiker. ${ }^{309}$ Seinem oben angeführten Bekenntnis zum Trotz erscheint Sanin jedoch an keiner Stelle im Roman als Betrunkener. Nach der Episode mit Karsavina, der ein ausgedehntes Trinkgelage mit Ivanov, dessen Onkel Petr Il'ǐ̌ sowie Jurij Svarožič vorausgeht, wird der vollkommen nüchterne Eindruck betont, den Sanin nach dem Alkoholgenuß und dem nächtlichen Erlebnis mit Karsavina auf den Technologiestudent macht (vgl. XLI, 297; 369). Selbst in der Entgrenzung verliert also Sanin nicht die Kontrolle über seinen Körper, so daß die Hierarchieverhältnisse von Körper und Geist durchaus nicht so eindeutig sind, wie man aus Sanins Diskussionsbeiträgen schließen könnte.

An die Stelle von Konventionen und Moralvorstellungen treten in Sanins Weltanschauung die Triebe, vor allem der Selbsterhaltungs- sowie der Geschlechtstrieb, als Grundlage des menschlichen Zusammenlebens. Besonders das freie Bekenntnis zu letzterem ist das Fundament, auf dem Sanins Wertesystem aufbaut. Damit wird im Sanin der Versuch unternommen, „die Dichotymie von Gut und Böse durch den Gegensatz zwischen natürlichem und unnatürlichem Verhalten “310 zu ersetzen. Die Unterdrückung des anthropomorphisierend als 'Wünsche des Körpers' (,желания тела“; XXXVIII, 284) umschriebenen Geschlechtstriebs wird von Sanin als unnatürlich und lebensfeindlich gebrandmarkt. Sanins Ideal ist die sogenannte 'freie Liebe', die, wie er Karsavina gegenüber in dem langen, der Verführungsszene vorangehenden didaktischen Monolog äußert, seiner Auffassung nach die Grundlage einer zukünftigen Gesellschaftsordnung bilden sollte:

Люди должны наслаждаться любовью без страха и запрета, без ограничения... А тогда и самые формы любви расширятся в бесконечную цепь случайностей, неохиданностей и сцеплений (XXXVIII, 285). ${ }^{311}$

308 Übersetzung: "Mich hat es stets verwundert, daß die Menschen so gegen den Wein zu Felde ziehen,' scherzte er, 'meiner Ansicht nach lebt nur der betrunkene Mensch so, wie es sich gehört [...] der Betrunkene tut lediglich das, was er will..." [Übers. d. Verf.] (vgl. VI, 60).

${ }^{309}$ Vgl. z. B. Omel'cenko (1908), 33.

${ }^{310}$ Nolda (1983), 390.

311 Übersetzung: „Die Menschen sollen die Liebe ohne Furcht und Entsetzen [eigentlich: „Verbot“; Anm. d. Verf.] genießen, ganz schrankenlos; dann werden sich die Formen der Liebe 
In dieser hedonistischen Predigt der sogenannten 'freien Liebe', derentwegen der Autor von zahlreichen Kritikern scharf angegriffen wurde, zeigt sich deutlich Sanins Geringschätzung jeglicher fester zwischenmenschlicher Beziehungen: Nicht mehr langfristige Bindungen durch Freundschaften oder die traditionelle monogame Ehe, sondern der Zufall soll das Zusammenleben der Menschen bestimmen.

Die Gefühle möchte Sanin ganz aus den zwischenmenschlichen Beziehungen verbannt wissen, da sie das Individuum an der freien Ausführung seines Willens hindern. Insbesondere richtet sich Sanins Ablehnung gegen die Eifersucht, die er als Ausdruck eines falschen Besitzstrebens in den Beziehungen zwischen den Menschen begreift. Es ist jedoch festzuhalten, daß Sanins Verhalten nicht immer mit der von ihm vertretenen Lebensphilosophie in Einklang steht. So bietet er Karsavina am Morgen nach der nächtlichen Verführungsszene an, jederzeit zu ihren Diensten zu stehen. Die Selbstverpflichtung, die er damit eingeht, hindert ihn jedoch nicht daran, die Heimatstadt wieder zu verlassen, sobald ihm der Sinn danach steht.

\subsubsection{Kein Lebensrecht für Schwache}

In Verbindung mit der wiederholten Betonung der athletischen Figur Sanins wird die vom Titelhelden gepredigte Ablehnung gesellschaftlicher Konventionen als ein Anzeichen von Stärke charakterisiert. Das Festhalten an kulturell erworbenen Verhaltensmustem bzw. die Unfähigkeit, sich wie Sanin über diese hinwegzusetzen, erscheint hingegen im Kontext der Romanhandlung als Indikator von Schwäche. Bezeichnenderweise sagt Sanin über die zeitgenössische Epoche, als deren typischer Vertreter Jurij Svarožił porträtiert wird, daß sie „sinnlos schwach" (XXXVIII, 352; 285) sei. Die bereits zitierten skandalträchtigen Worte Sanins am Grab des Technologiestudenten zeigen deutlich, wie wenig der Titelheld von Menschen wie Svarožic hält.

Als besonderes Anzeichen von Schwäche wird in Arcybaševs Text auch immer wieder die Überzeugung dargestellt, die Bereitschaft zum Leiden für andere sei ein Merkmal von charakterlicher Stärke - Sigrid Nolda spricht in ihrer Arbeit von einem "nietzscheanische[n] Protest gegen die Apotheose des Leidens“. ${ }^{312}$ So heißt es bereits zu Beginn des Romans über den Titelhelden: „Общей идеи в его жизни не было, никого он не ненавидел и ни за кого

in eine endlose Kette von Zufälligkeiten, Uberraschungen und Verbindungen [eigentlich: "Verkettungen“; Anm. d. Verf.] erweitern" (XXXVII, 352).

${ }^{312}$ Nolda (1983), 393 
не страдал“ $(1,21) \cdot{ }^{313}$ Folglich lehnt Sanin Wertesysteme wie das Christentum $a b$, weil sie auf die Unterordnung des Individuums abzielten und nur auf die Zukunft gerichtete Heilsversprechungen machen könnten:

\begin{abstract}
Оно [христианство; Anm. d. Verf.] обмануло сильных, которые могли бы сейчас, сегодня же взять в руки свое счастье, и центр тяжести их жизни перенесло в будущее, в мечту о несуществующем, о том, чего из них не увидит никто... И вся красота жизни исчезла: погибла смелость, погибла свободная страсть, погибла красота, остался только долг и бессмысленная мечта, о грядушем золотом веке... (XXIV, 178)..$^{314}$
\end{abstract}

Wie bereits gezeigt wurde, lehnt Sanin auf die Zukunft gerichtete Heilsversprechungen, wie sie die christliche Religion macht, als 'Tăuschung der starken Menschen' ab. Besonders die Beschreibung des einzigen natürlichen Todes in Arcybaševs Roman, dem Tod des Studenten Semenov, zeigt deutlich, daß die christliche Hoffnung auf ein besseres Leben nach dem Tode zurückgewiesen wird: ${ }^{315}$ Anders als in der berühmten Sterbeszene in Lev Nikolaevið Tolstojs 1886 erschienener Novelle Smert' Ivana Il'iča [deutscher Titel: Der Tod des Ivan Il'ic], in der der Tod der Hauptfigur durch die Worte „Вместо смерти был свет“"316 eindeutig als Erlösung für den Sterbenden dargestellt wird, besteht die letzte Lebensregung des sterbenden Studenten im Sanin darin, den anwesenden Priester als "Lump“ („ракло“) (X, 98; 90) zu beschimpfen. Ebenso wendet sich Sanin gegen den Glauben, der Verzicht auf das Ausleben der individuellen Triebe zugunsten anderer Menschen sei gleichbedeutend mit charakterlicher Stärke. Wie aus Sanins Unterhaltung mit dem jüdischen Mühlenbesitzer Solovejcik deutlich hervorgeht, begreift Sanin Triebverzicht vielmehr als Leiden, wobei der Hang zum Leiden durch die Freitode Solovejxiks und Svarožičs mit Lebensunfăhigkeit gleichgesetzt wird.

Sanins Weltanschauung zufolge ist der Versuch, die 'natürlichen' Triebe zu unterdrücken, jedoch nicht nur ein Indikator für Schwăche, sondern vielmehr gleichbedeutend mit Tod: „Желание - это все: когда в человеке умирают

${ }^{313}$ Übersetzung: „Irgendeine Idee lag seinem Leben nicht zugrunde; er haßte niemanden und litt um keines Menschen willen" (I, 7$)$.

314 Übersetzung: „Es [das Christentum; Anm. d. Verf.] täuschte die Starken, die ihr Glück sofort in demselben Augenblick in ihre Hände nehmen konnten und trug den Schwerpunkt ihres Lebens in die Zukunft, in den Traum an etwas, das nicht existierte, das keiner von ihnen je erblicken würde... und alle Schönheit des Lebens verschwand: Der Stolz [eigentlich: „die Kühnheit"], die freie Leidenschaft, die Schönheit... Es blieb nur das Licht [im Original steht. "die Pflicht"!; Anm. d. Verf.] und der törichte Traum an das kommende, goldene Zeitalter..." (XXIV, 2II).

${ }^{315} \mathrm{Vgl}$. dazu Ostrogorskij (1908), 10

${ }^{316}$ L. N. Tolstoj, Sobranie soxinenij v dwadcati tomach, Bd. 12 (1964), 115; Übersetzung. „Anstelle des Todes war Licht“ [Übers. d. Verf.] 
желания, умирает и его жизнь, а когда он убивает желания - убивает себя!“ (XII, 102). ${ }^{317}$ Bereits vor dessen Selbstmord spricht deshalb Sanin seinem Gegenspieler Jurij Svarožič gewissermaßen das Lebensrecht ab: „У него нет жизни, как таковой“ (XXXVIII, 283). ${ }^{318}$

In eine ähnliche Richtung weisen auch einige Bemerkungen, die Sanin Solovejcik gegenüber macht: Als dieser nach Zarudins Demütigung im Stadtpark von tiefen Zweifeln über die Berechtigung von Gewaltanwendung sowie den Sinn des Lebens gepeinigt wird, erzählt Sanin ihm die Lebensgeschichte seines Studienkollegen Ivan Lande. Mit der Figur des christusähnlichen Studenten Ivan Lande, der die Tolstojsche Maxime des Gewaltverzichts verkörpert, beschäftigte sich Arcybašev auch in der im Jahre 1904 erschienenen längeren Erzăhlung Smerr ' Lande [deutscher Titel: Der Tod des Ivan Lande]. ${ }^{319}$ Lande, so Sanin, sei „ein Christ nicht aus Prinzip, sondern der Natur nach" (XXXII, 287; 236) gewesen und habe sein Leben für den kranken Studenten Semenov hingegeben, indem er sich zu Fuß auf den langen Weg zu ihm auf die Krim gemacht habe.

Sanin macht deutlich, daß er das durch den Studenten Ivan Lande verkörperte Ideal der Bereitschaft zum Leiden für andere für sich ablehnt:

Нет смысла страдатъ, а жить вечно все равно никто не будет. Жить надо только тому, вто в самой жизни видит уже приятное. А страдаюшим лучше умереть (XXXII, 239). ${ }^{320}$

Der Titelheld macht keinen Hehl aus seiner Auffassung, daß auch sein Gesprächspartner Solovejxik zu jenen nicht lebensfähigen Menschen gehört, die das Leiden für andere zur Tugend erhoben haben: „Вы мертвый человек, [...] и, пожалуй, мертвецу самое лучшее и вправду - могила...“ (ebd.). ${ }^{321}$ Gerade bei der Figur Solovejciks wird deutlich, daß Arcybaševs im Sanin literarisch gestaltetes Programm des 'neuen Menschen' den Tod alles Schwachen und Kranken als Bedingung für die Emeuenung der Menschheit voraussetzt. Damit ist eine gewisse geistige Năhe zum Euthanasie-Gedanken gegeben, obgleich der Text keine Apologie für die aktive Tötung 'lebensunwerten Lebens'

${ }^{317}$ Übersetzung: „Der Wunsch ist alles. Sterben im Menschen die Begierden, so stirbt auch sein Leben, und tötet er seine Begierden, so tötet er auch sich!" (XXII, 112).

318 Übersetzung: „Er hat kein Leben im eigentlichen Sinne des Wortes“ [Übers. d. Verf.] (vgl. XXXVIII, 350).

319 Abgedruckt in Arcybasev, Sobranie soximenij, Bd. 1 (1994), 588ff.

320 Übersetzung: „Es hat keinen Sinn zu leiden, und ohnehin wird niemand ewig leben. $\mathrm{Zu}$ leben braucht nur derjenige, der im Leben selbst bereits etwas Angenehmes sieht. Diejenigen jedoch, die leiden, täten besser daran zu sterben" [Übers. d. Verf.] (vgl. XXXII, 29I).

${ }^{321}$ Übersetzung: „Sie sind ein toter Mensch, [...] Und für einen Toten ist wohl das Grab das Beste“" (XXXII, 29I). 
enthält. ${ }^{322}$ Wie weit verbreitet im Gefolge des Einflusses vitalistischer Philosophien die Gedanken von Euthanasie und Eugenik gerade auch bei den fortschrittlichsten Köpfen der Zeit um die Jahrhundertwende waren, zeigt auch eine of übersehene Passage in Ellen Keys bereits erwähnter Programmschrift der Reformpädagogik, Das Jahrhunderı des Kindes. ${ }^{32.3}$

Wie Nolda richtig festgestellt hat, kann aus Sanins negativen Äußerungen über das Christentum als 'Religion der Schwachen' nicht der Schluß gezogen werden, Arcybaševs Titelfigur vertrete eine atheistische Weltanschauung. ${ }^{324}$ Aufschluß bietet diesbezüglich ein Gespräch mit Ivanov, Petr Il'ỉ und Jurij Svarožič nach der symbolträchtigen Sterbeszene des Studenten Semenov. Dort sagt Sanin von sich selbst, daß er an Gott glaube und keine Veranlassung sehe, diesen in ihm seit der Kindheit verwurzelten Glauben zu zerstören (vgl. XII, 101; 111). Da nicht näher erläutert wird, was 'an Gott glauben' konkret für den Titelhelden bedeutet, ist Sanins Haltung zur Religion wohl in erster Linie als Ausdruck seiner antirationalistischen Lebensphilosophie zu verstehen. Nicht alle Geheimnisse des Lebens ergründen zu können widerspricht für Sanin offensichtlich nicht der Maxime, keine Instanzen oberhalb des eigenen Willens anzuerkennen.

Es ist nicht das Leiden für andere an sich, das Sanin als Anzeichen charakterlicher Schwäche ablehnt, sondern vielmehr der Glaube, durch die Nachahmung großer Leidensfiguren zu moralischer Stärke gelangen zu können, obwohl die eigene Natur dem widerspricht: „Ланде надо родиться. Христос был прекрасен, христиане - ничтожны“ (XXXII, 239). ${ }^{325}$ In dieser Aussage zeigt sich ein wesentliches Element von Sanins Philosophie - die kultische Überhöhung des starken Einzelnen, dem die als Schwächlinge und Imitatoren abgetanen Kollektivmenschen gegenübergestellt werden.

\footnotetext{
${ }^{322}$ Deutlichere Anklänge an den Euthanasie-Gedanken finden sich in Arcybasevs publizistischem Werk, wie eine Lektüre der 1914 im Rahmen der Zapiski Pisatelja [Notizen eines Schriftstellers; Übers. d. Verf.] erschienenen Abhandlung Propoved' $i$ Zizn' [Die Predigt und das Leben; Übers. d. Verf.] zeigt. Hier heißt еs: „Прежде никто не удивлялся, что родившихся слабых и калев безжалостно истребляли, теперь строят приюты для самых безнадежных идиотов и дорожат важдой каплей хизни до того, что преследуют уничтожение даже еще не появившегося на свет плода." Hier zitiert nach: Arcybašev, Sobranie sočinenij, Bd. 3 (1994), 738. Übersetzung: „Früher wunderte sich niemand darüber, daß man die auf die Welt gekommenen Schwächlinge und Krüppel erbarmungslos vernichtete, jet $\pi$ baut man Heime für die hoffnungslosesten Idioten und mißt jedem Tropfen Leben einen derartig hohen Wert bei, daß man sogar die Tötung der noch nicht auf die Welt gekommenen Leibesfrucht strafrechtlich verfolgt" [Übers. d. Verf.]

${ }^{323} \mathrm{Vgl}$. dazu Key (1992), 30.

${ }^{324} \mathrm{Vgl}$. Nolda (1983), 393

325 Übersetzung: „Man muß so [eigentlich: als Lande; Anm. d. Verf.] geboren werden. Jesus Christus war herrlich, die Christen armselig" (XXXII, 290).
} 
In der Verkultung des Starken, in der Gleichsetzung von körperlicher Schwäche mit Lebensunfähigkeit sowie in den antisemitischen Untertönen in Arcybaševs Roman sind Anklănge an die spătere Ideologie der deutschen Faschisten unverkennbar. Zu Arcybaševs Verteidigung muB jedoch angemerkt werden, daß seine philosophischen Äußerungen im Samin wie auch sein späteres publizistisches Werk eher gegen eine Lesart des Sanin als präfaschistischer Text sprechen. Viel zu stark werden im Sanin die Rechte des Einzelnen - allerdings auf Kosten der Gesellschaft - betont, als daß sich die Botschaft des Romans mit der ideologischen Gängelung des Individuums durch jedwelche kollektive Weltanschauungen vereinbaren ließe.

ArcybaSevs Verkultung des Starken ist in weiten Teilen der Darwinschen Überzeugung verpflichtet, daß das Leben ein Kampf sei, in dem nur das Starke bestehen kann, das Schwache hingegen unweigerlich zugrunde gehen muß. Diese geistige Affinität wird in einer Passage aus den Zapiski pisatelja von 1914 besonders deutlich. In einer dort unter dem Titel $O$ Tolstom [Über Tolstoj; Übers. d. Verf.] erschienenen Abhandlung schreibt Arcybašev: „Мир основан на взаимоистреблении всего живущего, и единственный захон вечен и общ - закон борьбы за существование...“326

Wenn sich auch Arcybałev an dieser Stelle offensichtlich der Darwinschen Terminologie bedient, so scheint der Schriftsteller mit seinem Sanin doch der Spencerschen Vorstellung des survival of the fittest näher zu sein als den Ansichten Darwins. Dieser hatte nämlich in seinem Werk On the Origin of Species versucht, den eigenen Theorien gewissermaßen ihre Schärfe zu nehmen, indem er feststellte:

When we reflect on this struggle, we may console ourselves with the full belief, that the war of nature is not incessant, that death is generally prompt, and that the vigorous, the healthy, and the happy survive and multiply. ${ }^{327}$

Zudem betont Darwin in seiner Schrift wiederholt den Aspekt der gegenseitigen Abhăngigkeit aller Lebewesen, gerade auch im Hinblick auf die Arterhaltung als überindividuelles Ziel - ein Gedanke, der im Sanin völlig fehlt.

326 Arcybašev, Sobranie soxinenij, Bd. 3 (1994), 691; Übersetzung: „Die Welt hat die gegenseitige Vernichtung alles Lebenden zur Grundlage, und ein einziges Gesetz ist ewig und allgemein gültig - das Gesetz des Kampfes ums Dasein... " [Übers. d. Verf.].

${ }^{327}$ Darwin, Bd. 15 (1988), 58. 


\subsubsection{Glück durch Überordnung}

Im Gegensatz zu Jurij Svarožič erkennt Sanin keinerlei übergeordnete Instanzen oberhalb seines eigenen Willen an. Bezeichnend für diese Haltung ist eine Stelle gegen Ende des Romans: Als Ivanov den Titelhelden fragt, warum er aus der Kleinstadt abreisen wolle, antwortet dieser: „Друг, не задавай глупых вопросов! Хочется, только и всего“ (XLV, 312) ${ }^{328}$ Stärke, so wie sie in Arcybaševs Text dargestellt wird, ist damit nicht nur körperliche Stärke, sondern auch und vor allem Willensstärke. Entscheidend für Sanins Anschauung ist jedoch, daß der Wille nicht als eine über dem Körper stehende Instanz begriffen wird, sondern daß vielmehr eine Einheit von geistigem Streben und körperlichem Trieb angestrebt wird. Nach Sanins Verständnis des Begriffes ist der Wille die Bereitschaft des Individuums, der eigenen Natur entsprechend $\mathrm{zu}$ handeln und sich von dem Korrektiv der kulturell erworbenen Konventionen und moralischen Wertesysteme zu befreien.

Auch wenn er im Gespräch mit Karsavina seinen Traum von einer besseren Zukunft erwähnt, ist Sanins Lebensphilosophie in erster Linie am Hier und Jetzt orientiert. Nirgends zeigt sich dies deutlicher als in Sanins Rechtfertigung Karsavina gegenüber nach der Verführungsszene:

Что я должен был сделать? Был такой момент, когда я почувствовал, что между нами что-то исчезло, и что если я пропушу, этот момент в моей жизни никогда не повторится... вы пройдете мимо, и никогда $я$ не переживу того наслаждения и счастъя, которое могу пережить... (XI, 293). ${ }^{329}$

Sanin erhebt hier den Grundsatz des carpe diem, der sich auch in dem von seinem Gegenspieler Jurij Svarožix ohne Erfolg nachgeahmten Bibeltext findet (vgl. Prediger 9, 7ff.), zur Richtschnur seines Handelns. Das oberste Ziel des Lebens ist in den in Arcybaševs Text immer wieder nebeneinander gebrauchten Begriffen 'Genuß' (наслаждение) und 'Glück' (счастье) zu suchen. Letzteres, so lautet Sanins Botschaft, kann nur durch die radikale Überordnung des Individuums über gesellschaftliche und moralische Beschränkungen erreicht werden.

Angesichts der sich in Sanins Worten ausdrückenden Maxime der rücksichtslosen Überordnung der Interessen des Individuums über die der

${ }^{328}$ Ubersetzung: „Lieber Freund, stelle nicht so dumme Fragen. Ich habe Lust, das genügt!" (XIV, 39I).

329 Ubersetzung: „Was sollte ich tun? Es gab einen Augenblick, da ich fühlte, daß zwischen uns etwas entschwunden war, und daß, wenn ich diesen Augenblick vergehen ließe, er sich in meinem Leben nie mehr wiederholen würde... Sie würden an mir vorbeigehen, und ich würde niemals den Genuß und das Glück erleben, das ich erleben konnte“ (XI, 363f.). 
Gesellschaft erscheint es wenig verwunderlich, daß Arcybaševs Titelheld immer wieder mit der Philosophie Friedrich Nietzsches in Verbindung gebracht wurde. ${ }^{330}$ Besonders von dessen in Also sprach Zarathustra vorgestelltem Konzept des 'Übermenschen' scheinen zahlreiche Verbindungslinien zu Sanin zu führen: Wie Zarathustra tritt auch Arcybaševs Held mit dem Gestus des einsamen, seiner Zeit vorweggreifenden Predigers auf. Mit Nietzsches Zarathustra verbindet ArcybaSevs Text weiterhin die unverkennbare Tendenz zur Verkultung des großen und starken Einzelnen, auf die in dieser Arbeit bereits eingegangen wurde. Dessen Großße besteht gerade auch darin, sich über die als Gängelung des starken Menschen empfundenen Grundsätze der christlichen Religion hinwegzusetzen, insbesondere über das Gebot der Nächstenliebe bzw. der selbstlosen Aufopferung für den Nächsten. ${ }^{331}$

Das Verhältnis von Sanin zur Philosophie Friedrich Nietzsches ist jedoch nicht so eindeutig, wie es zunächst scheinen mag. Luker hat zu Recht bedauert, daß der Titelheld von Arcybaševs Text nur allzu oft vorschnell mit Nietzsches 'Übermensch' gleichgesetzt wird. Arcybašev selbst hingegen bekannte sich eher zu den Ideen des bereits erwähnten Max Stimer. ${ }^{332}$ Wenn man den Selbstaussagen des Autors Glauben schenken darf, so las Arcybašev sogar keines von Nietzsches Werken zu Ende. ${ }^{333} \mathrm{DaB}$ ihm Nietzsches Philosophie dennoch in den Grundzügen bekannt war, zeigt die bereits an früherer Stelle erwähnte abfallige Charakterisierung Ivanovs als сверхчеловек ('Übermensch'), die der Autor Jurij Svarožič in den Mund legt (vgl. XXXVIII, 272; 334).

Dennoch kann Nietzsches Vorstellung vom 'Übermenschen' keineswegs mit Sanins Ideal des 'neuen Menschen' gleichgesetzt werden, was sich darin äußert, daß der Nietzsche-Anhănger Ivanov am Ende des Romans als inerter Trinker ohne den Willen zur wirklichen Veränderung in der Kleinstadt zurückbleibt. Im Gegensatz zu Sanin fehlt ihm der Mut zur Befreiung von allen gesellschaftichen Bindungen. Ebensowenig wagt Lida, in deren Zimmer Sanin eine Ausgabe von Also sprach Zarathustra findet (vgl. III, 43), diesen Schritt. Sanin legt das Buch bereits nach wenigen Seiten verärgert zur Seite. Wer wie Edith Clowes Arcybašev vorwirf, er habe mit seinem Sanin zur Diskreditierung von Nietzsches

${ }^{330}$ Vgl. 2. B. Barchan (1909), 124; Pachmus (1966), 78; E. W. Clowes, Literary Receptıon as Vulgarization. Nietzsche 's Idea of the Superman in Neo-Realist Fiction (1986), 323ff.

${ }^{331}$ Hierzu heißt es in Abschnitt 11 des Kapitels Vom höheren Menschen im vierten Teil von Also sprach Zarathustra: „Ihr Schaffenden, ihr höheren Menschen! Man ist nur fur das eigene Kind schwanger. [...] Das 'für den Nächsten' ist die Tugend nur der kleinen Leute: da heisst es 'gleich und gleich' und 'Hand wäscht Hand': - sie haben nicht Recht noch Kraft zu eurem Eigennutz!“; Nietzsche, Bd. 4 (2. Aufl. 1988), 362.

${ }^{332} \mathrm{Vgl}$. Artzibashef (1969), 9.

${ }^{333} \mathrm{Vgl}$. ebd 
Philosophie beigetragen, ${ }^{334}$ verkennt den Umstand, daß im Roman bewußt eine kritische Position zu Nietzsches Philosophie eingenommen wird.

Was Sanins Weltanschauung offensichtlich von Nietzsches Philosophie unterscheidet, ist zum einen der bereits erlăuterte Umstand, daß Arcybaševs Held die Religion längst nicht so grundlegend und umfassend kritisiert, wie es der deutsche Philosoph mit seiner bekannten These vom Tod Gottes tat. ${ }^{335}$ Daneben fehlt Sanin das elitäre Bewußtsein, das den Prediger Zarathustra auszeichnet. Sanin selbst sieht sich erklärtermaßen als 'natürlichen' und damit als gewöhnlichen Menschen, nicht als einen zu einem besonderen Schicksal Auserwählten in der Art eines Christus oder Ivan Lande, auch wenn Sanins Haltung bei seinem Abschied von Ivanov Anklänge an die Gestalt des einsamen Predigers Zarathustra aufweist. Ein weiterer wichtiger Unterschied zur Philosophie des letzteren besteht auch darin, daß Sanin das nietzscheanische Konzept des 'Willens zur Macht' - im Zarathustra als Gemeinsamkeit aller Lebewesen verstanden ${ }^{336}$ - fremd ist: Trotz aller Betonung der Interessen des Individuums gegenüber der Gesellschaft impliziert Sanins Ideal des 'neuen Menschen' nicht die Dominanz einzelner über die Masse.

Besonders deutlich zeigt sich dies bei den für Sanins Weltanschauung so wichtigen zwischengeschlechtlichen Beziehungen. Wie O'Dell in ihrer Arbeit festgestellt hat, steht Zarudins Verhalten Lida gegenüber in einem auffalligen Gegensatz dazu, wie sich Sanin Karsavina gegenüber verhält: Zarudin wird in der Szene, in der Sanins Schwester ihm von ihrer Schwangerschaft erzählt, als äußerst gefuihlskalt dargestellt (vgl. XVII). Sanin hingegen, so wird betont, bringt Karsavina auch nach dem Vollzug des Geschlechtsverkehrs noch Achtung entgegen. ${ }^{337}$ Während der Rittmeister Zarudin, der nicht ohne Grund wiederholt mit tierischen Attributen in Verbindung gebracht wird, in seinen Beziehungen zum anderen Geschlecht den Besitz von Frauen anstrebt, predigt Sanin die Maxime des gegenseitigen Lustgewinns durch die 'freie Liebe'. Insofern ist Noldas Einschătzung, daß in Arcybaševs Roman „das rücksichtslose Ausleben des Sexualtriebs“338 im Mittelpunkt stehe, zu korrigieren.

\footnotetext{
$334 \mathrm{Vgl}$. Clowes (1986), 326: "Both Andreev and Artsybashev created interesting and in some ways sympathetic heroes, using as thematic material some widespread misinterpretations of Nietzsche's superman. [...] In my view, they helped to discredit the German philosopher."

${ }^{335}$ In dem Der tolle Mensch betitelten $§ 125$ von Nietzsches Die Fröhliche Wissenschafi aus dem Jahre 1882 tritt ein Wahnsinniger auf, der seiner Umwelt verkündet: „Gott ist todt! Gott bleibt todt! Und wir haben ihn getötet!“‘; Nietzsche, Bd. 3 (2. Aufl. 1988), 481.

${ }^{336}$ Hierzu heißt es im Kapitel Von der Selbst-Übenwinctung im zweiten Teil von Also sprach Zarathustra: „Wo ich Lebendiges fand, da fand ich Willen zur Macht; und noch im Willen des Dienenden fand ich den Willen, Herr zu sein“; Nietzsche, Bd. 4 (2. Aufl. 1988), $147 f$.

${ }^{337} \mathrm{Vgl}$. O'Dell (1980), 108.

338 Nolda (1983), 388.
} 
Weitgehend ausgeklammert wird in Arcybaševs Roman allerdings das Problem der Folgen der 'freien Liebe' für die Frauen. $\mathrm{DaB}$ in dieser Hinsicht die von Sanin so vehement abgelehnten sozialen Konventionen durchaus einen Sinn haben, indem sie in den zwischenmenschlichen Beziehungen für Berechenbarkeit und Zuverlässigkeit sorgen, wird im Sanin nicht reflektiert. Da Sanins Lebensphilosophie in erster Linie am Hier und Jetzt orientiert ist, lehnt der Titelheld die Übernahme von langfristiger Verantwortung für das eigene Handeln ab. Seiner Schwester rät er deshalb unmißverständlich, ihr Kind von Zarudin abzutreiben (vgl. XIX, 151; 175) - ein in seiner Offenheit für die damalige Zeit natürlich skandalöser Vorschlag. Er demonstriert jedoch wiederum deutlich Sanins Grundauffassung, daß das Leiden für andere Verrat an der Natur der Starken und Schönen sei.

Zum Schluß ist auf einen auffalligen Widerspruch in Sanins Weltanschauung hinzuweisen, denn trotz der Behauptung, die Lebensphilosophie des Titelhelden führe zu allgemeinem Glück für alle körperlich Starken und Schönen, wird das weibliche Geschlecht ganz offensichtlich benachteiligt. So ist die von Sanin gepredigte Maxime der Überordnung der eigenen Interessen über die der Gesellschaft allem Anschein nach nur die männliche Variante des Wegs zum Glück. Das Glück der Frauen besteht hingegen der Botschaft des Romans zufolge in der Unterordnung unter einen ,fremden männlichen Willen und eine männliche Kraft“ („чужой мужской воле и силе“) [Übers. d. Verf.] (XXXVIII, 286; vgl. 353).

\subsection{Zusammenfassung}

Das Verhältnis des 'neuen Menschen' zur Gesellschaft ist sicherlich der Aspekt, hinsichtlich dessen die Unterschiede zwischen den beiden hier verglichenen Texten am augenscheinlichsten zutage treten. Zwar läßt sich sowohl in MineHaha als auch im Sanin der Versuch erkennen, durch den Entwurf eines 'neuen Menschen' zu einer besseren Gesellschaft zu gelangen. Hinsichtlich der Frage jedoch, wie jenes in beiden Fällen lediglich äußerst vage definierte Ziel - Hidalla spricht von einer "weniger brutal" (132) eingerichteten Welt, Sanin von einer 'glücklichen Zeit' (,счастливое время“; XXXVIII, 284; 35I)-erreicht werden soll, werden in beiden Texten gänzlich unterschiedliche Vorschläge gemacht.

Hidallas Weg zum Glück besteht in der bedingungslosen Unterordnung ihrer eigenen Person unter die Zwänge eines kollektiven Erziehungsprogramms, dessen Sinn ihr erst im nachhinein einsichtig werden kann. Auch wenn in Wedekinds Romanfragment keine konkreten Aussagen über die Organisation des Parks getroffen werden, impliziert die Beschreibung der Erziehungsanstalt ohne Zweifel die Existenz einer übergeordneten Instanz, die die Geschicke des Individuums 
lenkt. Daß deren Weisungen unbedingt Folge zu leisten ist, wird den Zöglingen tagtäglich durch die Anwesenheit der alten Dienerinnen vor Augen geführt.

Demgegenüber predigt Sanin die Auffassung, daß nur die Befreiung des Individuums von dem Zwang, aus Rücksichtnahme auf seine Mitmenschen auf die Erfüllung des individuellen Willens zu verzichten, zum Glück führen kann. Aus diesem Grund lehnt der Titelheld in Arcybaševs Roman Wertesysteme ab, die wie das Christentum das stellvertretende Leiden als Zeichen moralischer Stärke begreifen. Sanins Ablehnung richtet sich jedoch gleichermaßen gegen alle religiösen und philosophischen Entwürfe, die Anspruch auf die Führung des Individuums erheben. Insofern erscheint auch Nietzsches Philosophie in Arcybaševs Text nicht in einem sonderlich positiven Licht, obgleich von ihr, wie gezeigt wurde, zahlreiche Verbindungslinien zu Sanins Porträt des 'neuen Menschen' führen. Dessen oberste Maxime besteht im offenen Bekenntnis zu den dem Individuum von der Natur mitgegebenen Anlagen. Damit tritt im Sanin der Gegensatz von natürlichem und unnatürlichem Verhalten an die Stelle der traditionellen Dichotymie von moralischem und unmoralischem Handeln.

Gemeinsam ist den beiden hier untersuchten Texten, daß die in ihnen vorgestellten Gesellschaftsentwürfe zahlreiche innere Widersprüche aufweisen. So zeigt Wedekinds Romanfragment nur einen kleinen Ausschnitt der Gesellschaft, und infolge des fragmentarischen Charakters des Textes bleibt letztlich offen, wie der in Mine-Haha aufgezeigte Weg zur Züchtung des 'neuen Menschen' auf die Gesellschaft in ihrer Gesamtheit übertragen werden soll. Was aus Hidallas Erzählung jedoch deutlich hervorgeht, ist der Umstand, daß die Ordnung und die unnatürliche Homogenität innerhalb der Parkanstalt nur mit Hilfe von äußerem Zwang aufrechterhalten werden kann. Mit fortschreitender Handlung zeigt sich zunehmend, daß die Unterdrückung der ,praktische[n] Betătigung aller Kräfte" (132) des Individuums durch die Gesellschaft nur für eine gewisse Zeit möglich ist: Früher oder später 'meldet sich die Reife' und, um das für den Text zentrale Bild des Wassers noch einmal aufzugreifen, die aufgestaute Natur bahnt sich ihren Weg ins Freie.

Arcybašev präsentiert dem Leser in seinem Text einen Helden, der einen bereits an Solipsismus grenzenden Individualismus predigt. Sanin stellt seinen eigenen Willen über die Belange aller anderen Menschen, ohne allerdings die Frage zu lösen, wie das Individuum mit der Verantwortung für die gesellschaftlichen Folgen seines Handelns umgehen soll. Nirgends zeigt sich die Widersprüchlichkeit in Sanins Lebensphilosophie deutlicher als bei dem für die Programmatik des Romans so wichtigen Thema der 'freien Liebe': Während der Titelheld einerseits das freie Ausleben der natürlichen Triebe propagiert, wird andererseits gerade durch den Kontrast zwischen Sanin und dem Rittmeister Zarudin deutlich gemacht, daß der 'neue Mensch' seinem Partner auch nach Vollzug des Geschlechtsakts noch Achtung entgegenbringen soll. Sanins 
Maxime, daß für den 'neuen Menschen' einzig und allein das offene Bekenntnis zur eigenen Natur die Richtschnur seines sozialen Verhaltens bilden solle, wird damit gewissermaßen unterlaufen. Allerdings muß auch darauf hingewiesen werden, daß Sanin es beim bloßen Bekunden seiner Dankbarkeit Karsavina gegenüber beläßt: Durch den Gedanken an deren weiteres Schicksal läßt er sich nicht vom Verlassen seiner Heimatstadt abhalten.

Sanins Auffassung zufolge stellt die traditionelle Ehe als einziger gesellschaftlich sanktionierter Ort der Sexualität einen Atavismus dar. Insofern lehnt er - wie im übrigen auch sein Gegenspieler Jurij Svarožič - die Familie als Weg zum individuellen Glück ab. Unbeantwortet bleibt dabei jedoch die Frage, wie ohne die Familie in einer Gesellschaft der 'neuen Menschen' der Fortbestand der Menschheit gesichert werden soll. Seiner eigenen Schwester rät der Titelheld bezeichnenderweise davon ab, das Resultat ihrer Affäre mit Zarudin auszutragen und empfiehlt ihr, sich "dieses Kindes, das kein Mensch auf der Welt braucht", zu entledigen („избавиться от этого ребенка, никому на свете не нужного“) [Übers. d. Verf.] (vgl. XIX, 151; 175). Hierin offenbart sich eine weitere Inkonsistenz in Sanins Lebensentwurf - der Widerspruch zwischen dem Traum von einer 'glücklichen' Zukunft und der hedonistischen Fixierung auf die Gegenwart, aus der heraus der Titelheld die Übernahme von Verantwortung für zukünftige Generationen ablehnt.

Im Gegensatz zu Mine-Haha spielt in Arcybaševs Roman die Frage, wie eine Kindheit ohne Familie aussehen soll, keine Rolle. Der Text läßt offen, welche Institutionen anstelle der Familie die Schutz- und Fürsorgefunktion während der biologisch bedingten Phase der Abhängigkeit des 'neuen Menschen' von seiner Umwelt übernehmen sollen. Die Tatsache, daß Sanins Kindheit - wie überhaupt das Thema Kindheit - in Arcybaševs Roman fast völlig ausgeblendet wird, zeigt deutlich, daß es sich bei dem Lebensentwurf des Titelhelden nicht um ein gesamtgesellschaftlich tragfähiges Konzept handelt.

,Jeder Mensch und jede Gesellschaft stehen in der Spannung zwischen [...] Individualismus und Kollektivismus", 339 schreibt Alfons Gallati in seiner Untersuchung zu Individuum und Gesellschaft im Werk Wedekinds. Bei Frank Wedekinds Mine-Haha und Michail Petrovic Arcybaševs Sanin handelt es sich um Entwürfe eines 'neuen Menschen', die im Verhältnis zwischen den beiden Polen zwei einander entgegengesetzte Extreme markieren: Während Wedekinds Fragment den Versuch beschreibt, den 'neuen Menschen' gewissermaßen 'von oben' zu erschaffen, propagiert der Titelheld in Arcybaševs Roman dessen Entstehung 'von unten' durch die natürliche Auslese des Starken und Schönen. Der in Hidallas Erzählung aufgezeigte kollektive Weg zum 'neuen Menschen' basiert auf der Unterordnung des Individuums unter einen fremden Willen und auf

${ }^{339}$ A. Gallati, Individuum und Gesellschaft in Frank Wedekinds Drama. Drei Interpretationen (1981), 3. 
der Bereitschaft zum Leiden im Dienste eines höheren Ziels. Gerade dies lehnt die Hauptfigur in Arcybaševs Text als 'Betrug an den Starken' strikt ab.

Die Untersuchung der vorangegangenen Kapitel hat jedoch erkennen lassen, daß sowohl Hidallas kollektiver als auch Sanins individualistischer Weg zum 'neuen Menschen' letzten Endes an ihrer Kompromißlosigkeit scheitern. So wird am Ende von Hidallas Erzählung offensichtlich, daß sich die individuelle Natur des Menschen nicht dauerhaft zugunsten eines kollektiven Ideals unterdrücken läßt. In Arcybałevs Text hingegen zeigt sich gerade in Zusammenhang mit der von Sanin so vehement gepredigten 'freien Liebe' deutlich, daß der Weg des 'neuen Menschen' zum Glück nicht in der völligen Beschränkung auf sich selbst bestehen kann. 


\section{SCHLUSSWORT UND AUSBLICK}

In der vorliegenden Arbeit wurden zwei literarische Texte der Jahrhundertwende miteinander verglichen, die in der bisherigen literaturwissenschaflichen Forschung allem Anschein nach nicht miteinander in Verbindung gebracht wurden. Dies mag daran liegen, daß die beiden Einzelwerke nicht zu den bekanntesten ihrer Zeit zählen und zudem zum Teil immer noch mit dem Makel der Trivialităt bzw. der fehlenden Seriosităt behaftet sind. Indem der Vergleich unter den übergeordneten Aspekt der Suche nach dem 'neuen Menschen' gestellt wurde, wurde eine neue Lesart erprobt, die auf Wedekinds Mine-Haha bisher noch nicht angewendet wurde. Auch zu Arcybaševs Sanin liegt diesbezüglich noch keine umfassende Untersuchung vor, wenngleich der Titelheld von Literaturwissenschaft und -kritik hier und da mit dem Topos des 'neuen Menschen' in Verbindung gebracht wurde.

Wenn in einer komparatistischen Untersuchung wie der vorliegenden Beziehungen zwischen zwei Texten auf der Grundlage typologischer Analogien postuliert werden, ist selbstverständlich die kritische Frage nach der Vergleichbarkeit der Untersuchungsgegenstände zu stellen. Dies ist hier um so dringender geboten, als die Formulierung 'neuer Mensch' nicht von den Autoren selbst, sondern vom Verfasser dieser Arbeit stammt. Das Schlagwort vom 'neuen Menschen' hat sich jedoch als äußerst nützlich erwiesen, um wichtige Eigenheiten der miteinander verglichenen Texte herauszustellen und dabei einen Großteil der Ergebnisse der bisherigen Wedekind- bzw. Arcybašev-Forschung miteinzubeziehen. Sicherlich wăre ein Vergleich der beiden Werke auch unter einem anderen thematischen Schwerpunkt möglich gewesen - angeboten hätten sich etwa der in der Sekundärliteratur zu Mine-Haha und Sanin immer wieder betonte Aspekt der Erotik oder die Frage nach den Geschlechterrollen. In der vorliegenden Arbeit wurde das tertium comparationis bewußt etwas weiter gefaßt, so daß auch weitere Gesichtspunkte wie der Gegensatz von Natur und Zivilisation, Grundfragen der menschlichen Entwicklung sowie das Verhăltnis von Individuum und Gesellschaft behandelt werden konnten.

Als Gemeinsamkeit der beiden Texte hat sich der Umstand herausgestellt, daß sowohl in Wedekinds Prosafragment als auch in Arcybaševs Roman das Streben nach einer umfassenden Erneuerung des Einzelmenschen und der Gesellschaft durch ein neues Verhältnis zur Natur sowie zur Körperlichkeit zu erkennen ist. Was die Beziehung des 'neuen Menschen' zur Natur betriff, so wurde gezeigt, daß es sich bei dem Park in Mine-Haha nur um einen scheinbaren Naturraum handelt. Vielmehr ist hier allenthalben der gestalterische Einfluß des Menschen spürbar. Hierin spiegelt sich der pädagogische Grundgedanke der Erziehungsanstalt wider, daß bei der Schaffung des 'neuen Menschen' nichts dem freien Spiel der Natur und damit dem Zufall überlassen bleiben sollte. Dies ist das 
genaue Gegenteil einer 'die Arbeit der Natur' unterstützenden Erziehung, wie sie von Reformpädagogen wie Ellen Key gefordert wurde.

Arcybaševs Text steht hinsichtlich der Positionen, die zu Fragen der Bildung, Erziehung und Entwicklung eingenommen werden, einigen Strömungen der Reformpädagogik überraschenderweise wesentlich näher als der von Wedekind. Mit dem Titelhelden nämlich wird im Sanin das Ideal eines sich frei 'wie ein Baum auf dem Felde' aus sich selbst heraus entwickelnden 'neuen Menschen' entworfen. Im deutlichen Kontrast zu Sanin zeigt der Roman eine Reihe von Vertretern des 'alten Menschen' - Jurij Svarožič, Semenov, Zarudin, Solovejzik. Ein gewisser Brutalismus ist dabei unübersehbar, denn der Logik des Sanin entsprechend muß derjenige, der wie die genannten Personen den Keim des 'neuen Menschen' nicht in sich trägt, unweigerlich zugrunde gehen.

Der auffalligste Unterschied zwischen den beiden verglichenen Werken liegt jedoch im Verhältnis von Individuum und Gesellschaft, das mit den gegensätzlichen Formeln 'Glück durch Unterordnung' im Falle von Mine-Haha und 'Glück durch Überordnung' in bezug auf Arcybaševs Sanin umrissen wurde: Während Hidallas Erzählung das kollektive Ideal einer Unterwerfung des Einzelnen unter die Interessen der Gesellschaft als Weg zu einer besseren Welt erscheinen läßt, propagiert Sanin einen bewußten Egoismus Stirnerscher Prägung als Weg zum Glück, wobei er seiner eigenen Maxime jedoch bisweilen widerspricht. Gerade mit Blick auf die spätere historische Entwicklung scheint es bemerkenswert, daß ArcybaŠevs Text trotz der ostentativen Gegnerschaft zur Philosophie Nietzsches der westlichen Denktradition mit ihrer Betonung des Individuums nahesteht. Die Beschreibung des Parks in Wedekinds Romanfragment hingegen läßt Anklänge an den Kollektivismus der frühsowjetischen Pädagogik erkennen. Insofern stellen beide Werke gewissermaßen Fremdkörper in ihrem jeweiligen geistesgeschichtlichen Kontext dar, was eine Beschäftigung mit ihnen jedoch nur um so reizvoller macht.

Es wurde gezeigt, daß die Lebensphilosophie Sanins nicht als Aufruf zu Brutalität und Rücksichtslosigkeit den Mitmenschen gegenüber zu deuten ist, sondern daß Egoismus im Sanin im Sinne Stimers als positiver Wert, als Befreiung des Einzelnen, begriffen wird. Was Wedekinds Romanfragment anbelangt, so ist an dieser Stelle nochmals auf die distanzierende Erzählsituation hinzuweisen. Diese und gewisse Widersprüche zwischen Rahmenhandlung und Binnenerzählung sowie die erwähnten ironischen Anspielungen in Namen und Biographie Helene Engels verhindern eine Gleichsetzung von Autoren- und Figurenperspektive. Hinzu kommt die ungelöste Frage nach den Gründen für den Selbstmord der Lehrerin. Insofern ist eine Deutung des Fragments als Apologie des Totalitarismus, wie sie von Moníková vertreten wurde, zurückzuweisen.

Jedes der beiden untersuchten Werke zeigt deutlich, daß die Idee vom 'neuen Menschen' lediglich als Denkfigur wirksam sein kann. Dabei liegt den 
hier miteinander verglichenen Texten die durchaus ehrenwerte Hoffnung auf eine bessere Zeit als die gegenwärtige zugnunde. Beide Versuche der literarischen Umsetzung der Idee müssen jedoch zahlreiche Fragen offenlassen, da sie jeweils Extrempositionen darstellen und da ein Ausgleich zwischen den Interessen des Einzelnen und denen der Gesellschaft fehlt. „Es gibt keinen absoluten Individualismus und keinen allein herrschenden Kollektivismus", ${ }^{440}$ schrieb der deutsche Soziologe Leopold von Wiese (1876-1969), und genau mit diesem Grundsatz sind die beiden in dieser Arbeit betrachteten literarischen Entwürfe eines 'neuen Menschen' nicht vereinbar.

So läßt das, was von Wedekinds Romanprojekt veröffentlicht wurde, letztlich die Frage offen, wie lange ein Erziehungs- bzw. Gesellschaftssystem bestehen kann, das auf der gewaltsamen Unterdrückung der Natur und der Rechte des Individuums basiert und das dem Einzelnen keinerlei Freirăume läßt. In Arcybaševs Text hingegen bleibt am Ende unklar, wie es zu der von Sanin beschworenen 'glücklichen Zeit' kommen soll angesichts der programmatischen Fixierung des Titelhelden auf den Augenblick. Auf Grund der Maxime des carpe diem schließt Sanins Lebensphilosophie gerade auch die Ablehnung der Übernahme von Verantwortung für nachfolgende Generationen ein.

Da eine biographische und philologische Aufarbeitung des Arcybaševschen Gesamtwerks bisher fehlt, kann eine genetische Beziehung zwischen den beiden untersuchten Texten hier weder behauptet noch vollig ausgeschlossen werden. Möglicherweise lassen sich diesbezüglich in der Zukunft präzisere Aussagen treffen. Für die in der vorliegenden Arbeit behandelte Themenstellung waren jedoch ohnehin die typologischen Analogien zwischen beiden Texten ausschlaggebend. Gleichwohl wurde gezeigt, daß sich die Berechtigung für die Gegenüberstellung von Mine-Haha und Sanin auch aus den zum Teil gleichen philosophischen Grundlagen herleiten läßt. So wurde auf den Kontakt beider Autoren mit den philosophischen Theorien Stimers und Nietzsches hingewiesen. Im Falle der Philosophie Rousseaus sind infolge des Fehlens entsprechender Untersuchungen in bezug auf Arcybašev keine Aussagen möglich.

Damit ist bereits das Problem der Forschungslücken angesprochen, die bei der Bearbeitung des Themas offenkundig wurden. Es hat sich gezeigt, daß über das Zusammenspiel von Kunst, Gesellschaft, Kultur und Wissenschaft der Jahrhundertwende in Rußland weniger verläßliche Untersuchungen vorliegen als zum selben Zeitraum in Deutschland, der bereits seit den 1970er Jahren Gegenstand zahlreicher wissenschaftlicher Arbeiten ist. Insbesondere betriff dies die Geschichte der für den Vergleich von Mine-Haha und Sanin so interessanten lebensreformerischen Bewegungen der Jahrhundertwende. Insofern ergibt sich in den Vorbemerkungen bisweilen zwangsläufig ein gewisses Übergewicht der

${ }^{340}$ L. v. Wiese, Das Ich und das Kollektiv (1967), 62. 
deutschen Sozial- und Geistesgeschichte. Es ist zu hoffen, daß die russischen Gesellschafts-, Geschichts- und Kulturwissenschaften die nächsten Jahre dazu nutzen, nach dem Wegfall der ideologischen Gängelung von Forschung und Lehre jener so überaus interessanten Epoche in der russischen Geschichte verstärkt ihr Augenmerk zu widmen.

Die vorliegende Untersuchung hat sich auf zwei einzelne Prosatexte beschränkt, in denen das Streben nach Erneuerung ein zentraler Bestandteil ist und deren Vorschläge zur Schaffung eines 'neuen Menschen' gegensätzlich genug sind, um einen Vergleich reizvoll zu machen. Eine Untersuchung zur Idee des 'neuen Menschen' im Werk von Wedekind und Arcybašev könnte jedoch durchaus auch weitere, nicht zwangslăufig nur erzählerische Texte der genannten Autoren miteinbeziehen - zu denken wäre etwa an Frühlings Erwachen, die Lulu-Dramen, den Marquis von Keith oder Hidalla bzw. an Arcybaševs Smert ${ }^{\circ}$ lande oder die dramatischen Werke des russischen Schriftstellers.

Ebenso interessant dürfte eine Ausweitung des Vergleichs durch die Betrachtung weiterer Autoren der Jahrhundertwende - etwa Stanislaw Przybyszewskis mit seiner Trilogie Homo Sapiens (1895-1896) und seinem Roman Satans Kinder (1897) - oder die Kontrastierung mit Vorstellungen vom 'neuen Menschen' aus anderen geistesgeschichtlichen Epochen sein. Sehr lohnend für zukünftige Untersuchungen der beiden Texte scheint auch eine Kontrastierung mit anderen literarischen Werken der Jahrhundertwende in bezug auf die Bildungs-, Entwicklungs- und Erziehungsthematik zu sein beispielsweise mit Robert Musils 1906 erschienenem Roman Die Verwirrungen des Zoglings Torleß. Schließlich bleibt abzuwarten, was die Zukunft an literarischen Entwürfen eines 'neuen Menschen' bringen wird und insbesondere, ob man dereinst vergleichbare Vorstellungen auch in der Literatur der Wende zum dritten Jahrtausend wird erkennen können. 


\section{АННОТАЦИЯ}

Поиски „нового человека“ в немецкой и русской литературе на переломе столетий. „Мине-Гага“ Франка Ведекинда и „Санин“ Михаила Петровича Арцыбашева

Настоящая работа представляет собой сравнительное исследование двух литературных произведений, написанных на рубеже XIX-XX вв. и известных на сегодняшний день лишь узкому кругу читателейспециалистов. Предметом исследования являются фрагментарная повесть „Мине-Гага“ немецкого писателя $Ф$. Ведекинда, опубликованная в 1901 и (в переработанной форме) в 1903гт., а также роман „Санин“ русского писателя М. П. Арцыбашева, вышедший в свет в 1907г. Несомненно, „Мине-Гага“ и „Санин“ были написаны в совершенно разных социально-культурных условиях, и по имеющимся на сетодняшний день скупым сведениям о жизни и творчестве Арцыбашева пока что ничего не указывает на то, что роман „Санин“ писался под каким-либо влиянием вышеупомянутого произведения Ведекинда. Тем не менее оба произведения связывает общая идея, увлекавшая многих мыслителей и писателей конца XIX начала XX вв. - интерес $\mathrm{k}$ „новому человеку“.

По поставленной задаче настоящее исследование выходит за традиционные рамки германской и русской филологии, т. к. сравниваются повесть и роман, которые были написаны на разных языках - немецком и русском соответственно. Следует заметить, что изучаемые здесь произведения раньше вообще не сравнивались. Кроме того, словосочетание „новый человек“, довольно часто применяемое по отношению $\mathrm{k}$ литературе немецкого экспрессионизма и $\mathbf{K}$ литературе раннего советского периода, до настоящего времени почти не встречается в научно-исследователских трудах, посвященных немецкой и русской литературе 1900-х годов. Однако в данной работе показано, что стремление к обновлению человечества на рубеже XIX-XX вв. охватывало широкие круги общественности как в Германии, так и в России. В этой дискуссии принимали участие и Ведекинд, и Арцыбашев.

В повести „Мине-Гага“, с точки зрения героини по имени Гидалла (Hidalla), описываются детство и юность, проведенные в детской воспитательной колонии. В этом заведении, расположенном в большом парке и герметически отгороженном от внешнего мира, дети вырастают без какого-либо участия родителей и семьи в условиях, напоминающих тоталитарную систему. Главная цель воспитания заключается в приучении питомцев $K$ строгой 
дисциплине, красоте движений и совершенству тела. Умственное развитие не играет никакой роли в воспитательном процессе.

В своем романе „Санин“ М. П. Арцыбашев выводит тип „нового человека“, совершенно свободного от всяких моральных и социальных ограничений. Этому образу автор противопоставляет ряд других персонажей, с которыми герой сталкивается во время своего летнего пребывания в родном городе. От этих представителей „ветхого человека“ Санин отличается тем, что он не готов отказываться от достижения своего собственното счастья ради других. Такое поведение изображено в романе как „естественное“.

Автор данного исследования придерживается „интегрированного" подхода, В рамках которого повесть Ведекинда и роман Арцыбашева рассматриваются параллельно и с разных тематических точек зрения. Так, во вступительной главе коротко реферируется история идеи о „новом человеке“, после чего дается краткое изложение сюжета рассматриваемых литературных произведений. Приводятся также некоторые подробности их публикации и восприятия читателями. В следующих главах речь идет об отношении „нового человека“ к своему времени, о протовопоставлении тела и духа, о вопросах воспитания, а также о том, какой может быть позиция „нового человека“ в обществе.

Несмотря на то, что „Мине-Гага“ и „Санина“ связывает общая идея, не следует забывать и о главной разнице между этими двумя литературными произведениями: повесть Ведекинда описывает коллективный путь к счастью, в то время как герой Арщыбашева проповедует крайний индивидуализм как единственный ключ к счастью. Из этого можно сделать вывод, что „Мине-Гага“ и „Санин“ представляют собой в некотором смысле чужеродные тела в соотвествующих социально-культурных контекстах. Сравнение, проведенное в данной работе, показывает, что интерес к „новому человеку" почти одновременно нашел отражение в творчестве немецкого и русского писателей. В то же время именно транскультурное сравнение дает возможность раскрыть и особенности индивидуальной трактовки этой идеи. 


\section{LITERATURVERZEICHNIS}

\section{Primärliteratur}

\section{Werke von Arcybašev und Wedekind}

Arzzibashef, Michael Petrovich [Michail Petrovix Arcybasev]: Introduction. In: Michael Petrovich Artzibashef, The Millionaire. Translated by Percy Pinkerton. New York 1969, 5-10

Arcybasev, Michail Petrovix: Sanin. Letchworth 1969 (= Rarity Reprints 10).

Arcybašev, Michail Petrovix: Teni utra. Roman, povesti, rasskazy. Moskau 1990.

Arcybasev, Michail Petrovix: Pis'ma M. P. Arcybaseva. In: Voprosy literatury 11-12 (1991), 359-371.

ArcybaSev, Michail Petrovic: Sobranie soxinenij v trech tomach. Moskau 1994.

Artzibaschew, M. [Michail Petrovið Arcybašev]: Ssanin. Aus dem Russischen übersetzt von Stefania Goldenring. Berlin o. J.

Wedekind. Frank: Die Fürstin Russalka. München 1897.

Wedekind, Frank: Mine-Haha In: Die Insel 2/3 (1901), 27-36; 93-111; 234-255.

Wedekind, Frank: Gesammelte Briefe. Herausgegeben von Fritz Strich. 2 Bde. München 1924

Wedekind, Frank: Werke in drei Bänden Herausgegeben und eingeleitet von Manfred Hahn. 1. Aufl. Berlin/ Weimar 1969

Wedekind, Frank: Die Tagebücher. Ein erotisches Leben, hrsg. von Gerhard Hay. Frankfurt a. M. 1986.

Wedekind, Frank: Werke. Kritische Studienausgabe. Bde. IIV1 u. IIL/2. Darmstadt 1996.

Wedekind, Frank: Notizbücher 38-42 [maschinengeschriebene Transkription von Wedekinds Notizbüchern, aufbewahr unter der Signatur L 3491 im Literaturarchiv der Münchner Stadtbibliothek Monacensia].

\section{Weitere Primärliteratur}

Blok, Aleksandr Aleksandroviz: Sobranie soxinenij v vos'mi tomach Bd. S: Prosa 1903-1917. Moskaw/ Leningrad 1962. 
Darwin, Charles: The Works of Charles Darwin. Edited by Paul H. Barrett \& R. B. Freeman. Bd. 15. On the Origin of Species. 1859. London 1988

Goethe, Johann Wolfgang von: Sämtliche Werke. Bde. 9, 10. 1. Aufl. Frankfurt a. M. 1992 , 1989 (= Bibliothek deutscher Klassiker 82, 50).

Longfellow, Henry Wadsworth: The Poems. New York 1944

Macpherson, James: The Poems of Ossian and related works. Edited by Howard Gaskill. Edinburgh 1996.

Nietzsche, Friedrich: Sämtliche Werke. Kritische Studienausgabe in 15 Einzelbänden Bde. 1, 3, 4. 2. Aufl. München 1988.

Przybyszewski, Stanisław: Studienausgabe. Werke, Aufzeichnungen und ausgewählte Briefe in acht Bänden und einem Kommentarband. Bd. 1. Paderborn 1990.

Rousseau, Jean-Jaques: OEuvres complètes. Bd. 4. Dijon 1969 (= Bibliothèque de la Pléiade 208).

Rotermund, Erwin (Hrsg.): Gegengesänge. Lyrische Parodien vom Mittelalter bis zur Gegenwart München 1964.

Spencer, Herbert: The Principles of Ethics. Introduction by Tibor R. Machan. 2 Bde. Indianapolis 1978.

Stirner, Max: Der Einzige und sein Eigentum. Mit einem Nachwort herausgegeben von Ahlrich Meyer. Stuttgart 1972 (= Universal-Bibliothek 3057).

Tolstoj, Lev Nikolaevic: Sobranie soxinenij v dvadcati tomach. Bd. 12. Moskau 1964.

Turgenev, Ivan Sergeevix: Polnoe sobranie socinenij i pisem v tridcati tomach. Bd. 8. 2. Aufl. Moskau 1981.

\section{Sekundärliteratur}

\section{Frank Wedekind}

Adorno, Theodor W.: Uber den Nachlaß Frank Wedekinds. In: Theodor W. Adorno, Gesammelte Schriften. Bd. 11: Noten zur Literatur. Frankfurt a. M. 1974, 627-633.

Austermühl, Elke: Frank Wedekind. In: Deutsche Dichter des 20. Jahrhunderts, hrsg. von Hartmut Steinecke. Berlin 1994, 43-58.

Best, Alan: Frank Wedekind. London 1975 (= Modern German Authors 4). 
Best, Otto F.: Zwei mal Schule der Körperbeherrschung und drei Schriftsteller. In: Modem Language Notes 85 (1970), 727-741.

Boa, Elizabeth: The Sexual Circus. Wedekind's Theatre of Subversion. Oxford 1987.

Bohnen, Klaus: Frank Wedekind und Georg Brandes. Unveröffentlichte Briefe. In: Euphorion 72 (1978), 106-119.

Carossa, Hans: Mine-Haha. In: Hans Carossa, Geschichte einer Jugend. Wiesbaden 1957, 465469.

Dehnow, Fritz: Frank Wedekind. Leipzig 1922.

Fechter, Paul: Frank Wedekind. Der Mensch und das Werk. Jena 1920.

Firda, Richard Arthur: Wedekind, Nietzsche and the Dionysian Experience. In: Modern Language Notes 87 (1972), 720-731.

Gallati, Alfons von Näfels GL: Individuum und Gesellschaft in Frank Wedekinds Drama. Drei Interpretationen. Zürich 1981.

Gittleman, Sol: Frank Wedekind. New York 1969 (= Twayne's World Authors Series 55).

Glaser, Horst Albert: Arthur Schnitzler und Frank Wedekind - Der doppelköpfige Sexus. In. Wollüstige Phantasie. Sexualästhetik der Literatur, hrsg. von Horst Albert Glaser. München 1974 (= Reihe Hanser 147), 148-184.

Gutjahr, Ortrud: Erziehung zur Schamlosigkeit. Frank Wedekinds Mine-Haha oxder Iber die körperliche Erziehung der jungen Moudchen und der intertextuelle Bezug zu Frihlings Enwachen. In: Frank Wedekind, hrsg. von Ortrud Gutjahr. Würzburg 2001 (= Freiburger Literaturpsychologische Gespräche. Jahrbuch für Literatur und Psychoanalyse 20), 93-124.

Gutjahr, Ortrud: Mit den Hüften denken lemen? Körperrituale und Kulturordnung in Frank Wedekinds Mine-Haha oder Über die körperliche Erziehung der jungen Moidchen. In: Kontinuităt - Diskontinuităt. Diskurse zu Frank Wedekinds literarischer Produktion (19031918). Ein Symposium der Editions- und Forschungsstelle Frank Wedekind an der Fachhochschule Darmstadt, hrsg. von Sigrid Dreiseitel u. Hartmut Vinçon. Würzburg 2001 [voraussichtlich] (= Wedekind-Lektüren 2) [Typoskript mit vorläufiger Paginierung].

Hahn, Manfred: Frank Wedekind. Leben und Werk. In: Frank Wedekind, Werke in drei Banden. 1. Aufl. Berlin/Weimar 1969, 7-93.

Heuß, Theodor [Theodor Heuss]: Frank Wedekind. In: Der Kunstwart 22 (1909), 262-269.

Heuss, Theodor: Frank Wedekind. In: Theodor Heuss, Vor der Bücherwand. Skizzen zu Dichtern und Dichtung, hrsg. von Friedrich Kaufmann u. Hermann Leins. Tübingen 1961, 253-258. 
Hoger, Alfons: Frank Wedekind. Der Konstruktivismus als schöpferische Methode. Konigstein i. Ts. 1979 (= Theorie - Kritik - Geschichte 21).

Hoger, Alfons. Hetärismus und bürgerliche Gesellschaft im Fühwerk Frank Wedekinds. Kopenhagen/ München 1981 (= Text \& Kontext 12)

Höger, Alfons: Das Parkleben Darstellung und Analyse von Frank Wedekinds Fragment Das Sommenspektrum In: Text \& Kontext 11/1 (1983), 35-55

Jones, Rober A./ Leroy R. Shaw (Hrsg.): Frank Wedekind. A Bibliographic Handbook. 2 Bde München u. a. 1996

Kapp, Julius: Frank Wedekind. Seine Eigenart und seine Werke. Berlin 1909.

Kieser, Rolf: Benjamin Franklin Wedekind. Biographie einer Jugend. Zürich 1990.

Kieser, Rolf: Amerikanische Motive im Werk Benjamin Franklin Wedekinds. In: The German Quarterly 65 (1992), 369-377.

Klotz, Volker: Wedekinds Circus mundi. In: Viermal Wedekind. Methoden der Literaturanalyse am Beispiel von Frank Wedekinds Schauspiel „Hidalla“. Vier Vorträge von Helmut Amtzen, Emst Nef, Volker Klotz und Wolfdietrich Rasch, hrsg. von Karl Pestalozzi. Stuttgant 1975, 22-47.

Kutscher, Artur: Frank Wedekind. Sein Leben und seine Werke. 3 Bde. München 1922, 1927, 1931.

Kutscher, Artur: Wedekind. Leben und Werk. Zum hundertsten Geburtstag des Dichters bearbeitet und neu herausgegeben von Karl Ude. München 1964.

Martin, Ariane: Ein Drahtseilakt. Frank Wedekind und der Erste Weltkrieg. In: Text + Kritik $131 / 132$ (1996), 147-159.

Medicus, Thomas: „Die große Liebe“. Ökonomie und Konstruktion der Körper im Werk von Frank Wedekind. Marburg a. d. Lahn 1982 (= Reihe Métro 11).

Meyer, Michael: Theaterzensur in München 1908 - 1918. Geschichte und Entwicklung der polizeilichen Zensur und des Zensurbeirates unter besonderer Berücksichtigung Frank Wedekinds. München 1982 (= Miscellanea Bavarica Monacensia 111).

Michelsen, Peter: Frank Wedekind. In: Deutsche Dichter der Moderne, hrsg. von Benno von Wiese. 2. Aufl. Berlin 1969, 13-28.

Monikovà, Libuše: Das totalitäre Glück. Frank Wedekind. In: Neue Rundschau 96 (1985), 118-125.

Muschg, Adolf: Frank Wedekind: 'Mine Haha'. In: Adolf Muschg, Besprechungen. 19611979. Stuttgart 1980 (= Poly 10), 43-45. 
Muylaer, Marc: L'image de la femme dans l'oeuvre [!] de Frank Wedekind Stuttgart 1985 (= Stuttgarter Arbeiten zur Germanistik 159).

Proost, Karel F.: Frank Wedekind. Zijn leven en werken. Zeist 1928.

Puknus, Heinz: Nachwort. In: Frank Wedekind, Die Liebe auf den ersten Blick und andere Erzählungen. München/Wien 1971, 219-223.

Rath, Willy: [Rezension zur erweiterten Version von Mine-Haha]. In: Das literarische Echo 5 (1902/03), 1290-1292.

Rothe, Friedrich: Frank Wedekinds Dramen. Jugendstil und Lebensphilosophie. Stuttgart 1968 (= Germanistische Abhandlungen 23).

Schmitz, Walter/ Uwe Schneider: Editorische Nachbemerkung. In: Frank Wedekind. MineHaha oder Über die körpertiche Erziehung der jungen Mädchen. Mit "Nu au miroir" von Balthus. Frankfurt a. M./ Leipzig 1994, 92-96.

Schneider, Uwe: Das Projekt sinnlicher Erziehung im Frühwerk Frank Wedekinds Untersuchungen zu Mine-Haha und den nachgeordneten Nachlaßteilen. Magisterarbeit. München 1992.

Schröder-Zebralla, Josephine: Frank Wedekinds religiöser Sensualismus. „Die Vereinigung von Kirche und Freudenhaus?". Frankfurt a. M. u. a. 1985 (= Europäische Hochschulschriften V 840).

Seehaus, Günter: Frank Wedekind. Mit Selbstzeugnissen und Bilddokumenten. 6. Aufl. Reinbek 1993 (= rowohlts monographien 213).

Simplicissimus 8 (1903), Nr. 3, 2. Beiblatt [Rezension zu Mine-Haha]

Trockij, Lev: Frank Vedekind. In: Lev Trockij, Socinenija. Bd. 20. Moskau/ Leningrad 1926, 401-420.

Trotzkij, Leo [Lev Trockij]: Frank Wedekind. In: Leo Trotzkij, Literatur und Revolution. Berlin 1968, 363-383.

Vieth, Adolf R : Die Stellung der Frau in den Werken von Frank Wedekind. Diss. Wien 1939.

Vingon, Hartmut. Frank Wedekind. Stuttgart 1987 (= Sammlung Metzler 230).

Vinçon, Hartmut: Anmerkungen zu einer neuen Leseausgabe von Frank Wedekinds Werken In: Wirkendes Wort 41 (1991), 316-321.

Vinçon, Hartmut: Prolegomenon zur Kritischen Studienausgabe der Werke Frank Wedekinds In: Text + Kritik 131/ 132 (1996), 160-175. 
Vivarelli, Vivetta: Mine-Haha e l'utopia autoritaria di Frank Wedekind. In: Studi Tedeschi 24 (1981), 57-83.

Volevic, I. V.. Vedekind. In: Istorija nemeckoj literatury, hrsg von N. 1. Balachova u. a. Bd. 4: 1848-1918 Moskau 1968, 524-535.

Wagener, Hans: Frank Wedekind. Berlin 1979 (= Köpfe des XX. Jahrhunderts 90).

Willeke, Audrone Barunas: Frank Wedekind's Narrative Prose. Diss. Stanford University 1972.

\section{Michail Petrovič Arcybašev}

Agafonov, E.: Vospominanija o M. P. Arcybaseve. In: Michail Petrovið Arcybałev, Sobranie soxinenij v trech tomach. Bd. 1. Moskau 1994, 761-779.

Aspiz, Evsej Markovic: Vospominanija o M. P. Arcybałeve. In: Voprosy literatury 11-12 (1991), 354-359.

Barchan, Paul: Sanin und die erotische Bewegung. In: Die Neue Rundschau 20/1 (1909), 123128.

Cukovskij, Kornej Ivanovið: M. Arcybǎ̌ev. In: Komej Ivanovið Cukovskij, Ot Cechova do nasich dnej. Literaturnye portrety. Charakteristiki. 3. Aufl. Sankt Petersburg 1912, 119-134.

Koltonovskaja, E. A : Problema pola v molodoj literature. (Wedekind i Arcybasev). In: E. A. Koltonovskaja, Novaja Žizn. Kritiðeskie stat'i. Sankt Petersburg 1910, 86-117.

Luker, Nicholas: Artsybashev's Samin. A Reappraisal. In: Renaissance \& Modern Studies 24 (1980), 58-78.

Luker, Nicholas: In Defence of a Reputation. Essays on the Early Prose of Mikhail Artsybashev. Nottingham 1990.

Luker, Nicholas (Hrsg.): The Short Story in Russia 1900 - 1917. Nottingham 1991.

Luker, Nicholas/ O'Dell Sally Margarte: Mikhail Artsybashev. A Comprehensive Bibliography. Nottingham 1983 (= Astra Soviet and East European Bibliographies 2).

L'vov-Rogačevskij, V.: M. Arcybałev. In: Sovremennyj mir 11 (1909), 26-48.

Müller, Georg: Der "Sanin“ und seine Schicksale in Deutschland. In: M. Artzibaschew [Michail Petrovið Arcybašev], Ssanin. Übertragen von André Villard und S. Bugow. München/ Leipzig 1909, VII-LXX.

Nikonenko, S. S.: Michail Arcybasev. In: Michail Petrovix Arcybasev, Teni utra. Roman, povesti, rasskazy. Moskau 1990, 3-18. 
Nolda, Sigrid: M. P. Arcybałevs Roman „Sanin“. Zur Aktualität eines vergessenen Skandals Zeitschrift für slavische Philologie 43 (1983), 287-399.

O'Dell, Sally Margaret: Mikhail Petrovich Artsybashev (1878-1927). A Centennial Presentation and Assessment. Diss. Vancouver 1980.

Omel'cenko, A. P.: Geroj nezdorovogo tvoř̌estva. „Sanin“, roman Arcybałeva. Sankt Petersburg 1908.

Ostrogorskij, A. N.: Pedagogiðeskie èkskursii v oblast' literatury. „Sanin“ Arcybałeva. K voprosu o besedach o polovomu voprosu. In: Russkaja škola 3 (1908), 1-22.

Pachmus, Temira: Michail Artsybashev in the Criticism of Zinaida Gippius In: The Slavonic and East European Review 44 (1966), 76-87.

Pil'skij, Petr: M. Arcybašev. In: Michail Petrovix Arcybǎ̌ev, Sobranie sox̌inenij $v$ trech tomach. Bd. I. Moskau 1994, 768-772.

Poritzky, J. E.: Dämonische Dichter. Probleme und Porträts. München 1921

Prokopov, Timofej: Žizni i smerti Michaila Arcybaševa. In: Michail Petrovic Arcybałev, Sobranie soxinenij $v$ trech tomach. Bd. 1. Moskau 1994, 5-31

Revjakina, A. A: Arcybał̌ev Michail Petrovix. In: Pisateli russkogo zarubežja (1918-1940). hrsg. von der Rossijskaja Akademija Nauk. Institut naučnoj informacii po obšcestvennym naukam. Moskau 1993, 57-62.

Revjakina, A. A.: Arcybašev Michail Petrovic. In: Literatumaja ènciklopedija russkogo zarubež'ja (1918-1940), hrsg. von A. N. Nikoljukin. Moskau 1997, 43-45

Rudnev, A.: „Ja Čelovek žizni, i tol'ko žizni, zemnoj, celovečeskoj...". In: Voprosy literatury 11-12 (1991), 352-354.

Sielicki, Franciszek: Michal Arcybaszew w Polsce. In: Przegląd Humanistyczny 18/6 (1974), 131-137.

Steltner, Ulrich: Symbolismus und Symbolik in M. P. Arcybaševs Roman "Sanin“. In: Zeitschrift für slavische Philologie 49 (1988), 228-240.

Trockij, Lev: O smerti i ob èrose. In. Lev Trockij, Soxinenija. Bd. 20. Moskaw/ Leningrad 1926, 275-285.

Villard, Andre: Vorwort. In: M. Artzibaschew [Michail Petrovic Arcybasev], Ssanin. Übertragen von André Villard und S. Bugow. München/ Leipzig 1909, LXXI-LXXVIIl.

Vjazmitinova, L. G.: Sanin. In: Énciklopedija literaturnych geroev, hrsg. von S. V. Stachorskij. Moskau 1997, 362-363. 
Vorovskij. Vaclav Vaclavovic: Bazarov i Sanin Dva nigilizma. In Vaclav Vaclavovic Vorovskij, Literaturnye oxerki. Moskau 1923, 71-98.

\section{Zu Literatur, Kunst und Gesellschaft der Jahrhundertwende}

Baloueff, John J Reflection of the Young Intelligentsia in Russian Fiction 1905-1914. Diss. Nashville 1976

Benz, Ernst: Das Bild des Übermenschen in der europäischen Geistesgeschichte. In: Der Ubermensch, hrsg. von Ernst Benz. Zürich/ Stuttgart 1961, 19-161.

Borisova, Elena A./ Grigorij Ju. Sternin: Russkij modern Moskau 1994.

Clowes, Edith W.: Literary Reception as Vulgarization. Nietzsche's Idea of the Superman in Neo-Realist Fiction. In: Nietzsche in Russia, hrsg. von Bernice Glatzer Rosenthal. Princeton 1986, 315-329.

Clowes, Edith: The Revolution of Moral Consciousness Nietzsche in Russian Literature, 1890-1914. DeKalb 1988.

Davies, Richard D.: Nietzsche in Russia, 1892-1919. A Chronological Checklist. In: Nietzsche in Russia, hrsg. von Bernice Glatzer Rosenthal. Princeton 1986, 355-392.

De Rentiis, Christoph: Zum historischen Konzept Helleraus (Werkstätten, Gartenstadt und Bildungsanstalt) und den Möglichkeiten seiner ökologisch-industriell orientierten Entwicklung. In: Die Zukunft der Stadt. Spurensuche in Dresden-Hellerau, hrsg. von Werner Fricke. Bonn 1995 (= Forum Zukunft der Arbeit 4), 25-41

Duncan, Alastair: Art Nouveau. London 1994.

Engelstein, Laura: The Keys to Happiness. Sex and the Search for Modernity in Fin-de-Siècle Russia. Ithaca/ London 1992.

Feudel, Elfriede: Rhythmische Erziehung Berlin 1939

Feudel, Elfriede: Die Geschichte der Bildungsanstalt Hellerau (1910-14). In: Rhythmische Erziehung 3/4 (1956), 3-13.

Frescot, Janos: Die Lebensreformbewegung. In: Das wilhelminische Bildungsbürgertum. Zur Sozialgeschichte seiner Ideen, hrsg. von Klaus Vondung. Göttingen 1976 (= Kleine Vandenhoeck-Reihe 1420), 138-152.

Hamann, Richard/ Jost Hermand: Stilkunst um 1900. 2. Aufl. München 1975 (= Epochen deutscher Kunst von 1870 bis zur Gegenwart 4). 
Hartmann, Kristiana: Deutsche Gartenstadtbewegung. Kulturpolitik und Gesellschaftsreform München 1976.

Hermand, Jost: Der Schein des schönen Lebens. Studien zur Jahrhundertwende. Frankfurt a M. 1972.

Howard, Ebenezer: Garden Cities of To-Morrow. Edited with a preface by F. J. Osborn Essay by Lewis Mumford. Cambridge, Mass./London 1965.

Jost, Dominik: Literarischer Jugendstil. Stuttgart 1969 (= Sammlung Metzler 81).

Kafitz, Dieter (Hrsg.): Dekadenz in Deutschland. Beiträge zur Erforschung der Romanliteratur um die Jahrhundertwende. Frankfurt a. M. U. a. 1987 (= Studien zur Deutschen Literatur des 19. und 20. Jahrhunderts 1).

Key, Ellen: Das Jahrhundert des Kindes. Studien. Autorisierte Uebertragung von Francis Maro. Neu herausgegeben mit einem Nachwort von Ulrich Herrmann. Weinheim/ Basel 1992 (= Pädagogische Bibliothek Beltz 7).

Krabbe, Wolfgang R.: Gesellschaftsveranderung durch Lebensreform. Strukturmerkmale einer sozialreformerischen Bewegung im Deutschland der Industrialisienungsperiode. Göttingen 1974 (= Studien zum Wandel von Gesellschaft und Bildung im Neunzehnten Jahrhundert 9).

Linse, Ulrich: Die Jugendkulturbewegung. In: Das wilhelminische Bildungsbürgertum. Zur Sozialgeschichte seiner Ideen, hrsg. von Klaus Vondung. Göttingen 1976 (= Kleine Vandenhoeck-Reihe 1420), 119-137.

Linse, Ulrich (Hrsg.): Zurück, o Mensch, zur Mutter Erde. Landkommunen in Deutschland 1890-1933. München 1983 (= dtv 2934).

Linse, Ulrich: Zeitbild Jahrhundertwende. In. 'Wir sind nackt und nennen uns Du'. Von Lichtfreunden und Sonnenkämpfern. Eine Geschichte der Freikörperkultur, hrsg. von Michael Andritzky u. Thomas Rautenberg. Giessen 1989, 10-49.

Magistrat der Stadt Darmstadt Denkmalschutz - Kulturamt (Hrsg.): Die Darmstädter Mathildenhöhe. Architektur im Aufbruch zur Moderne. Zwei Spaziergänge zu den Bauten der Jahrhundertwende. Darmstadt 1998 (= Beiträge zum Denkmalschutz in Darmstadt 7).

Malyševa, Nina: Obraz Bazarova v obšcestvenno-politixeskoj polemike 19c8-1910gg. In. ceskoslovenskà rusistika 31 (1986), 118-122.

Mathes, Jürg: Nachwort. In: Prosa des Jugendstils, hrsg. von Jürg Mathes. Stuttgart 1982 (=Universal-Bibliothek 7820), 321-377.

Mathes, Jürg (Hrsg): Theorie des literarischen Jugendstils. Stuttgart 1984 (= UniversalBibliothek 8036) 
Pascal, Roy: From Naturalism to Expressionism. German Literature and Society 1880-1918. London 1973.

Sarfer, Hans-Jürgen: Hellerau Die Gartenstadt und Künstlerkolonie. 3. Auf Dresden 1995 (= Kleine Sächsische Bibliothek 3).

Völpel, Christiane: Hermann Hesse und die deutsche Jugendbewegung Eine Untersuchung über die Beziehungen zwischen dem Wandervogel und Hermann Hesses Frühwerk. Bonn 1977 (= Studien zur Literatur der Moderne 4).

Walter, Rudolf: Nietzsche - Jugendstil - H. Mann. Zur geistigen Situation der Jahrhundertwende. München 1976 (= Münchner Germanistische Beiträge 17).

Wintzigerode-Knorr, Karl-Wilhelm Freiherr von: Hanns v. Gumppenbergs künstlerisches Werk. Ein Beitrag zur Geschichte der deutschen Literatur der Wende vom 19. zum 20. Jahrhundert. Bamberg 1958.

Zil'berštejn, I. S./ N. I. Dikušina (Hrsg.): Gor'kij i russkaja Łurnalistika načala XX veka. Neizdannaja perepiska. Moskau 1988 (= Literaturnoe nasledstvo 95).

Žmegą̌, Viktor (Hrsg.): Deutsche Literatur der Jahrhundertwende. Königstein, Ts. 1981 (= Neue wissenschaftliche Bibliothek 113).

Zorkaja, Neja Markovna: Na rubeže stoletij. U istokov massovogo iskusstva v Rossii 19001910 godov. Moskau 1976.

\section{Weitere zitierte Literatur}

Altrichter, Helmut Rußland 1917. Ein Land auf der Suche nach sich selbst. Paderborn u. a. 1997.

Anweiler, Oskar: Geschichte der Schule und Pädagogik in Rußland vom Ende des Zarenreichs bis zum Beginn der Stalin-Ära. Berlin 1964 (= Osteuropa-Institut an der Freien Universităt Berlin. Erziehungswissenschaftliche Veröffentlichungen 1).

Bagrij, A. V.: Russkaja literatura XIX-go - pervoj cetverti XX-go V.V. Posobie k lekcijam. Baku 1926.

Die Bibel oder die ganze Heilige Schrift des Alten und Neuen Testaments nach der Übersetzung Martin Luthers. Revidierter Text 1975. Stuttgart 1978.

Böhm, Winfried: Wörterbuch der Pädagogik 14. Aufl. Stuttgart 1994 (= Kröners Taschenausgabe 94).

Börner, Klaus H.: Auf der Suche nach dem irdischen Paradies. Zur Ikonographie der geographischen Utopie. Frankfurt a. M. 1984. 
Davydov, Vasilij V. (Hrsg.): Rossijskaja pedagogiceskaja ènciklopedija $v$ dvuch tomach 2 Bde. Moskau 1993.

Ďurišin, Dionýz: Die wichtigsten Typen literarischer Beziehungen und Zusammenhange. In. Vergleichende Literaturforschung in den sozialistischen Ländern, hrsg. von Gerhard R. Kaiser. Stuttgart 1980 (= Studien zur allgemeinen und vergleichenden Literaturwissenschaft 21), 91102.

Durišin, Dionýz: Theory of Literary Comparatistics. Bratislava 1984.

Emel'janov, Ju. N. (Hrsg.): Moskovskij universitet $v$ vospominanijach sovremennikov (17551917). Moskau 1989.

Flaker, Aleksandar: Avant-garde et érotisme. In: Amour et érotisme dans la littérature russe du XXe siècle. Actes du colloque de juin 1989 oranisé par l'Université de Lausanne, avec le concours de la Fondation du 450ème anniversaire, hrsg. von Leonid Heller. Bern u. a. 1992 (= Slavica Helvetica 41), 91-100.

Fox, Michael V.: Qohelet and His Contradictions. Sheffield 1989 (= Bible and Literature Series 18)

Froese, Leonhard: Ideengeschichtliche Triebkräfte der russischen und sowjetischen Pädagogik 2. Aufl. Heidelberg 1963.

Gnüg, Hiltrud (Hrsg.): Literarische Utopie-Entwürfe. Frankfurt a. M. 1982 (= suhrkamp taschenbuch 2012).

Günther, Katharina: Literarische Gruppenbildung im Berliner Naturalismus. Bonn 1972 (= Abhandlungen zur Kunst-, Musik- und Literaturwissenschaft 120).

Kaiser, Gerhard R.: Einfuihrung in die vergleichende Literaturwissenschaft. Forschungsstand Kritik - Aufgaben. Darmstadt 1980

Kellner, Douglas: Expressionist Literature and the Dream of the "New Man". In: Passion and Rebellion. The Expressionist Heritage, hrsg. von Stephen Eric Bronner u. Douglas Kellner. South Hadley/ London 1983, 166-200.

Konstantinovic, Zoran: Vergleichende Literaturwissenschaft. Bestandsaufnahme und Ausblicke. Bern u. a. 1988 (= Germanistische Lehrbuchsammlung 81).

Küenzlen, Gottfried Der Neue Mensch. Eine Untersuchung zur säkularen Religionsgeschichte der Moderne. München 1994.

Lepp, Nicola/ Martin Roth/ Klaus Vogel (Hrsg.): Der Neue Mensch. Obsessionen des 20. Jahrhunderts. Katalog zur Ausstellung im Deutschen Hygiene-Museum Dresden vom 22. April bis 8. August 1999. Ostfildern-Ruit 1999.

Loquai, Franz: Vom Gehen in der Literatur. Eggingen 1993 (= Parerga 11). 
März, Fritz: Personengeschichte der Pädagogik Ideen - Initiativen - Illusionen. Bad Heilbrunn i. Obb. 1998

McVay, Gordon. Isadora and Esenin. The Story of Isadora Duncan and Sergei Esenin. London u. a. 1980.

Müller, Derek: Der Topos des Neuen Menschen in der russischen und sowjetrussischen Geistesgeschichte. Bern u. a. 1998 (= Geist und Werk der Zeiten 90).

Nipperdey, Thomas: Deutsche Geschichte 1866-1918. Bd I: Arbeitswelt und Bürgergeist. München 1990

Paterson, R. W. K : The Nihilistic Egoist. Max Stimer. Oxford 1993

Petrovskij. N. A.: Slovar' russkich lixnych imen Moskau 1995.

Pietrow-Ennker, Bianka: Rußlands 'neue Menschen' Die Entwicklung der Frauenbewegung von den Anfangen bis zur Oktoberrevolution. Frankfurt a M./ New York 1999 (= Reihe „Geschichte und Geschlechter" 27).

Riedel, Walter: Der neue Mensch. Mythos und Wirklichkeit. Bonn 1970 (= Studien zur Germanistik, Anglistik und Komparatistik 6).

Ritter, Joachim/ Karlfried Gründer (Hrsg.): Historisches Wörterbuch der Philosophie. Völlig neubearbeitete Ausgabe des 'Wörterbuches der philosophischen Begriffe' von Rudolf Eisler. Bisher 9 Bde. Basel Stuttgart $1971 \mathrm{ff}$.

Rundt, Arthur: Der Mensch wird umgebaut. Ein Rußlandbuch. Berlin 1932.

Schenk, Gunter: Vergleich. In: Europäische Enzyklopädie zu Philosophie und Wissenschaften, hrsg. von Hans Jörg Sandkühler. Bd. 4. Hamburg 1990, 698-701.

Sieferle, Rolf Peter: Fortschrittsfeinde? Opposition gegen Technik und Industrie von der Romantik bis zur Gegenwart. München 1984 (= Die Sozialverträglichkeit von Energiesystemen 5).

Sinjawskij, Andrej [Andrej Sinjavskij]: Der Traum vom neuen Menschen oder Die Sowjetzivilisation. Aus dem Russischen von Swetlana Geier. Frankfurt a. M. 1989

Sreznevskij, I. I.: Slovar’ drevnerusskogo jazyka. Reprintnoe izdanie. Bd. 3. Moskau 1989.

Stökl, Gunther: Russische Geschichte. Von den Anfängen bis zur Gegenwart. 5. Aufl Stuttgart 1990 (= Kröners Taschenausgabe 244).

Thiergen, Peter: Wilhelm Heinrich Riehl in Rußland (1856-1886). Studien zur russischen Publizistik und Geistesgeschichte der zweiten Hälfte des 19. Jahrhunderts. Gießen 1978 (= Bausteine zur Geschichte der Literatur bei den Slaven 11). 
Time, Galina A.: Nemeckaja literatumo-filosofskaja mysl' XVIII-XIX vekov $v$ kontekste tvoř̌estva I. S. Turgeneva (genetið̌eskie i tipologiðeskie aspekty). München 1997 (= Vorträge und Abhandlungen zur Slavistik 31).

Upham, Warren: Minnesota Geographic Names. Their Origin and Historic Significance. With an Introduction by James Taylor Dunn. Saint Paul 1969.

Voitolovskij, L.: Oxerki istorii russkoj literatury XIX i XX vekov. Bd. 2. The Hague/ Paris 1969 (= Slavistic Printings and Reprintings 183).

Westwood, J. N.: Endurance and Endeavour. Russian History 1812-1986. 3. Aufl. Oxford 1987.

Wiese, Leopold von: Das Ich und das Kollektiv. Berlin 1967 (= Erfahnung und Denken 21).

Wietek, Gerhard (Hrsg.): Deutsche Künstlerkolonien und Kunstlerorte München 1976.

Wulf, Christoph (Hrsg.): Wörterbuch der Erziehung. 6. Aufl. München Zürich 1984. 


\section{PERSONENREGISTER}

Adorno, Th. W. 72, 85

Agafonov, E. 57

Alexander II, Zar v. Rußland 83

Altrichter, H. 44, 83

Anweiler, 0.84

Andt, M. 12

Aspiz, E. M. 60,100

Austermühl, E. 28., 92, 108

Bagrij, A. V. 38

Baloueff, J. J. 32, 39, 61f., 76, 78f.

Barchan, P. 37, 78f., 100, 126

Beardsley, A. 26

Benz. E. 107

Best, A. 22

Best, O. F. 26

Bierbaum, J. O. 20

Blok, A. A. 29, 36

Boa, E. 27f., 47, 86, 110

Bogdanovic, A. 32

Bohnen, K. 21

Böhm, W. 91

Borisova, E. A. 44

Bömer, K. H. 93

Böttger, A. 48

Brandes, G. 13, 21

Bronn, H. G. 81

Bronštejn, L. D. [siehe Trockij, L.]

Bugov, S. 33

Bulgakov, M. A. 14

Carossa, H. 26, 86

Cernyševskij, N. G. 13f.

Christus [siehe Jesus Christus]

Clowes, E. W. 39, $126 f$.

Cukovskij, K. I. [Kornejcukov, N. V.] 35$37,39,79$

Dalkes, J. [siehe Jaques-Dalcroze, $\dot{E}$.]

Darwin, Ch. 81f., 106f., 112, 124

Davies, R. D. 105

Davydov, V. V. $83 f$.

Dehnow, F. 45

De Rentiis, Ch. $42 \mathrm{f}$.

Dikusina, N. I. 32

Dirse, U. 12

Dostoevskij, F. M. 13, 34, 60

Druvin, U. 108

Duncan, A. 66

Duncan, I. 66f., 71, 83
Ďurišin, D. 16

Džgašvili, J. V. [siehe Stalin, J. V.]

Emel'janov, Ju. N. 81

Engelstein, L. 37, 40f.

Emst Ludwig. Großherzog v. Hessen u. bei Rhein 43

Esenin, S. A. 66

Fechter, P. 27, 48, 87, 92

Feher, F. 37

Feudel, E. 26f.

Fidus [Höppener, H.] 55, 66

Firda, R. A. 106

Flaker, A. 35

Fox, M. V. 97

Frescot, J. 65

Friedenthal, J. 48

Fritsch, Th. 42

Froese, L. 84

Gallati, A. v. N. GL 130

Ganghofer, L. 34

Gippius, Z. N. 38

Gittleman, S. 27f., 63, 88, 114

Glaser, H. A. 66

Gnüg, H. 45, 108

Goethe, J. W. v. 88-90

Gogol', N. V. 34

Goldenring, S. 18, 54, 57, 100

Goncarov, 1. A. 34

Gorbacev, M. S. 33

Gor'kij, M. [Peškov, A. M.] 15, 32, 105

Gründer, K. 12

Gruzenberg, O. O. 32

Gumppenberg, H. Freiherr v. $25 f$.

Günther, K. 42

Gutjahr, O. 28, 47

Jaques-Dalcroze, É. [Dalkes, J.] 26f., 43

Jesus Christus 12, 62, 95, 121-123, $126 f$. 129

Jones, R. A. 28

Jost, D. 43

Hahn, M. 17, 20, 45, 48

Hamann, R. 12, 66

Hartmann, K. 43

Hentschel, W. 65

Hermand, J. 12, 55, 66

Herrmann, U. 83aniel Schümann - 9783954794133 $\begin{array}{ll}\text { Herzl, Th. } 108 & \text { via free access }\end{array}$ 
Hesse, H. 40

Heuss, Th. 25

Heymel, A. W. 20

Hoget, A. 21f., 52, 68, $90 f$.

Höppener, $H$. [siehe Fidus]

Howard, E. 42f.

Kafitz, D. 15

Kainz, J. 63

Kaiser, G. 11

Kant, I. 12

Kapp, J. 27, 46f., 52

Kellner, D. 13

Key, E. 83f., 123, 133

Kieser, R. 48, 91, 106

Klotz, V. 72

Koltonovskaja, E. A. 29, 36, 77

Komissarževskaja, V. F. 29

Konstantinovic, Z. $16 f$.

Kornejčkov, N. V. [siehe Cukovskij, K. I.]

Krabbe, W. R. 42

Küenzlen, G 14

Kuprin, A. I. 32

Kuprina-Jordanskaja, M. K. 32

Kutscher, A. 17, 20-24, 26f., 51, 65f., 70. 82

Lange, H. 52

Langen, A. 20

Lenin [Ul'janov], V. I. 14

Lepp, N. 15, 93, 108

Lietz, H. 83

Linse, U. 65, 83

Longfellow, H. W. 48f., 92, 103, 114

Loquai, F. 88

Luker, N. 31-36, 39, 53, 56f., 59, 61, 64, $76,95,97,99,106,116 f ., 126$

L'vov-Rogacevskij, V. 32, 53

Machan, Tibor R. 107

Macpherson, J. 22

Malyšseva, N. 13, 95

Mamontov, S. I. 44

Mann, H. 93

Maro, F. 83

Marx, K. 14, 35

Martin, A. 73, 115

März, F. 82

Mathes, J. 28, 52, 66, 105, 114

McVay, G. 66, 83

Medicus, Th 23, 27f., 45, 47, 49f., 68f., $72,85,92,112$
Meyer, A. 106

Meyer, M. 33

Michelsen, P. 106

Monet, C. 52

Moniková, L. 27f., 45, 67, 91, 109, 115, 133

Müller, D. 14f., 105

Müller, G. 33f.

Muschg, A. 26

Musil, R. 135

Muylaen, M. 27f., 52

Newolin, B. 37

Nietzsche, F. 12f., 39, 61, 82f., 93, 105$107,114,120,126 f ., 129,133 \mathrm{f}$.

Nikolaj II, Zar v. Rußland 62

Nikonenko, S. S. 17, $32 \mathrm{f}$.

Nipperdey, Th. 115

Nolda, S. 39, 64, 100, 118-120, 123, 127

O’Dell, S. M. 31, 38f., 77f., 96f., 101, 127

Olbrich, J. M. 43

Ostrogorskij, A. N. 36, 60, 121

Omel'čenko, A. P. 36, 119

Pachmus, T. 38, 126

Pascal, R. 115

Paterson, R W K. 106

Peškov, A. M. [siehe Gor'kij, M.]

Petrovskij, N. A. 78

Pietrow-Ennker, B. 13

Pil'skij, P. 35

Poritzky, J. E. 37, 53

Prokopov, T. 32

Proost, K. F. 27

Przybyszewski, S. 54f., 135

Puknus, H. 114

Rath, W 24

Revjakina, A. A. 34, 37

Riedel, W. 13

Riehl, W. H. 44

Rilke, R. M. 42

Ritter, J. 12

Rotermund, E. 26

Roth. M. 15, 93, 108

Rothe, F. 23

Rousseau, J.-J. 42, 82, 93, 134

Rudnev, A. 37

Rundt, A. 36

Šackij, S. T. 84

Sandkühler, H. J. 11

Sarfert, H.-J. 43aniel Schümann - 9783954794133

Schende, G. I PubFactory at 01/10/2019 02:35:37AM 
Schmidt. J. K. [siehe Stimer, $M$ ] ]

Schmitz, W. 20, 22, 28, 92

Schneider, U. 20, 22, 27f., 92

Schroder, A. 20

Schröder-Zebralla, J. 63, 67

Seehaus. G. 42

Shaw, L. R 28

Sieferle, R. P. 41

Sielicki, F. 35, 37f.

Sinjavskij, A. 15

Spencer, H. 107, 124

Sreznevskij, 1. 1. 79

Stalin [Džugašvili], J. V. 15, 84

Steltner, U. 35, 39, 54, 78

Sternin, G. Ju. 44

Stimer, M. [Schmidt, J. K.] 106f., 126, $133 \mathrm{f}$.

Stökl, G. 62,83

Strich, F. 26

TeniSeva, M. K. 44

Thiergen, P. 44, 77

Time, G. A. 106

Tolstoj, L. N. 44, 62, 84, 121f., 124

Trefilov, S. 37

Trockij, L. [Bronštejn, L. D.] 24f., 27f., 36, 71,85

Turgenev, I. S. 13, 34, 77f., 95, 106

Ul'janov, V. I. [siehe Lenin, V. I.]

Ungewitter, R. 65

Upham, W. 49

Valloton, F. 20
Vasnecov, V. M. 61

Verbickaja, A. A. 40

Vieth, A. 27, 47

Villard, A. 33, 35f.

Vinçon, H. 21f., 24, 27f., 42, 48, 93, 106

Vivarelli. V. 27f., 45, 83

Vjazmitinova, L. G. 33

Vogel, K. 15, 93, 108

Vogeler, H. 42

Voitolovskij, L. 37f.

Volevic, I. V. 29

Völpel, Ch. 41

Vorovskij, V. V. 13, 35, 37f., 95f.

Wagener, H. 27f., 50, 53, 92

Walter, R. 93

Wedekind. Tilly 27

Weidl, E. 17

Westwood. J. N. 62

Wiese, L. v. 134

Wietek, G. 42

Wilhelm Il, Kaiser u. König v. Preußen 41, 50,65

Willeke, A. B. $26 f$.

Wintzigerode-Knorr, K.-W. F. v. 26

Wulf, Ch. 85

Wyneken, G. 83

Zamjatin, E. 1. 14

Zil'berstejn, 1. S. 33

Žmegax, V. 12, 16

Zorkaja, N. M. 38 


\section{VORTRÄGE UND ABHANDLUNGEN ZUR SLA VISTIK}

- herausgegeben von Peter Thiergen (Bamberg) -

Verzeichnis der bislang erschienenen Bände

(W. Schmitz Verlag, Gießen)

Band 1: Peter Thiergen

Turgenevs "Rudin" und Schillers "Philosophische Briefe".

(Turgenev Studien III)

1980, 66 S., broschiert, DM 19,80

Band 2: Bärbel Miemietz

Kontrastive Linguistik. Deutsch-Polnisch 1965-1980.

1981, 132 S., broschiert, DM 25,-

Band 3: Dietrich Gerhardt

Ein Pferdename. Einzelsprachliche Pointen und die Möglichkeiten ihrer Übersetzung am Beispiel von A. P. Čechovs "Lošadinaja familija".

1982, 69 S., broschiert, DM 20,-

Band 4: Jerzy Kasprzyk

Zeitschriften der polnischen Aufklärung und die deutsche Literatur. 1982, 93 S., broschiert, DM 20,-

Band 5: Heinrich A. Stammler

Vasilij Vasil'evič Rozanov als Philosoph.

1984, 90 S., broschiert, DM 20,-

Band 6: Gerhard Giesemann

Das Parodieverständnis in sowjetischer Zeit. Zum Wandel einer literarischen Gattung.

1983, 54 S., broschiert, DM 19,-

Band 7: Annelore Engel-Braunschmidt

Hebbel in Rußland 1840-1978. Gefeierter Dichter und verkannter Dramatiker.

1985, 64 S., broschiert, DM 20,-

Band 8: Suzanne L. Auer

Borisav Stankovićs Drama "Koštana". Übersetzung und Interpretation.

1986, 106 S., broschiert, DM 25,- 
(Otto Sagner Verlag, München)

Band 9: Peter Thiergen (Hrsg.)

Rudolf Bächtold zum 70. Geburtstag.

1987, 107 S., broschiert, DM 22,-

Band 10: A. S. Griboedov

Bitternis durch Geist.

Vers-Komödie in vier Aufzügen. Deutsch von Rudolf Bächtold.

1988, 101 S., broschiert, DM 20,- (vergriffen)

Band 11: Paul Hacker

Studien zum Realismus I.S. Turgenevs.

1988, 79 S., broschiert, DM 20,- (vergriffen)

Band 12: Suzanne L. Auer

Ladislav Mñacko. Eine Bibliographie.

1989, 55 S., broschiert, DM 16,-

Band 13: Peter Thiergen

Lavreckij als "potenzierter Bauer". Zu Ideologie und Bildsprache in I. S. Turgenevs Roman "Das Adelsnest".

1989, $40 \mathrm{~S}$. Text plus $50 \mathrm{~S}$. Anhang, broschiert, DM 18,-(vergriffen)

Band 14: Aschot R. Isaakjan

Glossar und Kommentare zu V. Astafjews "Der traurige Detektiv". 1989, 52 S., broschiert, DM 10,-

Band 15: Nicholas G. Žekulin

The Story of an Operetta: Le Dernier Sorcier by Pauline Viardot and Ivan Turgenev.

1989, 155 S., broschiert, DM 18,-

Band 16: Edmund Heier

Literary Portraits in the Novels of F.M. Dostoevskij.

1989, 135 S., broschiert, DM 18,-

Band 17: Josef Hejnic (u. Mitarbeiter)

Bohemikale Drucke des 16.-18. Jahrhunderts.

1990, 65 S., broschiert, DM 8,-

Band 18: Roland Marti

Probleme europäischer Kleinsprachen: Sorbisch und Bündnerromanisch.

1990, 94 S., broschiert, DM 17,- 
Band 19: Annette Huwyler-Van der Haegen

Gončarovs drei Romane - eine Trilogie?

1991, 100 S., broschiert, DM 20,-

Band 20: Christiane Schulz

Aspekte der Schillerschen Kunsttheorie im Literaturkonzept Dostoevskijs.

1992, 258 S., broschiert, DM 40,-

Band 21: Markus Hubenschmid

Genus und Kasus der russischen Substantive: Zur Definition und Identifikation grammatischer Kategorien.

1993, 134 S., broschiert, DM 20,-

Band 22: France Bernik

Slowenische Literatur im europäischen Kontext. Drei Abhandlungen. 1993, 75 S., broschiert, DM 16,-

Band 23: Werner Lehfeldt

Einführung in die morphologische Konzeption der slavischen Akzentologie.

1993, 141 S., broschiert, DM 30,-

Band 24: Juhani Nuorluoto

Die Bezeichnung der konsonantischen Palatalität im Altkirchenslavischen. Eine graphematisch-phonologische Untersuchung zur Rekonstruktion und handschriftlichen Überlieferung.

1994, 138 S., broschiert, DM 25,-

Band 25: Peter Thiergen (Hrsg.)

Ivo Andric 1892-1992. Beiträge des Zentenarsymposions an der OttoFriedrich-Universität Bamberg.

1995, 161 S., broschiert, DM 25,-

Band 26: Sebastian Kempgen

Russische Sprachstatistik. Systematischer Überblick und Bibliographie.

1995, 137 S., broschiert, DM 25,-

Band 27: Peter Thiergen (Hrsg.)

Ivan S. Turgenev - Leben, Werk und Wirkung. Beiträge der Internationalen Fachkonferenz aus Anlaß des 175. Geburtstages an der Otto-Friedrich-Universität Bamberg, 15.-18. September 1993.

1995, 282 S., broschiert, DM 44,- 
Band 28: A. A. Donskov (Hrsg.)

L. N. Tolstoj i M. P. Novikov. Perepiska.

1996, 120 S., broschiert, DM 20,-

Band 29: A. A. Donskov (Hrsg.)

L. N. Tolstoj i T. M. Bondarev. Perepiska.

1996, 142 S., broschiert, DM 25,-

Band 30: V. Setschkareff

Die philosophischen Aspekte von Mark Aldanovs Werk.

1996, 80 S., broschiert, DM 18,-

Band 31: Galina A. Time

Nemeckaja literaturno-filosofskaja mysl' XVIII-XIX vekov v kontekste tvorčestva I. S. Turgeneva (Genetičeskie i tipologičeskie aspekty).

1997, 140 S., broschiert, DM 30,-

Band 32: L. D. Gromova-Opul'skaja/Z. N. Ivanova (sost.)

Novye materialy L. N. Tolstogo io Tolstom. Iz archiva N. N. Guseva. Redaktion: A. A. Donskov.

1997, 267 S., broschiert, DM 40,-

Band 33: Martin Schneider

Postmeister und Stationsaufseher. Eine Studie zur deutschen PuškinRezeption.

1997, 177 S., broschiert, DM 30,-

Band 34: Leonore Scheffler

"Roman-punktir". - Indirektes Erzählen durch Leerstellen in Jurij Trifonovs Roman "Zeit und Ort".

1998, 104 S., broschiert, DM 20,-

Band 35: Anna Rothkoegel

Russischer Faust und Hamlet. Zur Subjektivismuskritik und Intertextualität bei l. S. Turgenev.

1998, 162 S., broschiert, DM 30,-

Band 36: István Lơkös

Erlebnisse und Rezeption. Krležas Kerempuh-Balladen aus ungarischer Sicht.

1999, 118 S., broschiert, DM 20,- 
Band 37: Martin Erdmann

Heraldische Funeralpanegyrik des ukrainischen Barock. Am Beispiel des „Stolp Cnot Syl'vestra Kossova“.

1999, 261 S., broschiert, DM 60,-

Band 38: Janusz Siatkowski

Slawismen in den schlesischen Romanen von Horst Bienek. Übersetzt von Tadeusz Kachlak. Unter der Redaktion von Karl Gutschmidt. 2000, 124 S., broschiert, DM 20,-

Band 39: Edmund Heier

Comparative Literary Studies: Lermontov, Turgenev, Goncharov, Tolstoj, Blok - Lavater, Lessing, Schiller, Grillparzer.

2000, 201 S., broschiert, DM 36,- 